\title{
WestVirginiaUniversity
}

THE RESEARCH REPOSITORY @ WVU

Graduate Theses, Dissertations, and Problem Reports

2007

\section{Mechanical evaluation and FE modeling of composite sandwich panels}

\author{
Ashish S. Bambal \\ West Virginia University
}

Follow this and additional works at: https://researchrepository.wvu.edu/etd

\section{Recommended Citation}

Bambal, Ashish S., "Mechanical evaluation and FE modeling of composite sandwich panels" (2007). Graduate Theses, Dissertations, and Problem Reports. 1818.

https://researchrepository.wvu.edu/etd/1818

This Thesis is protected by copyright and/or related rights. It has been brought to you by the The Research Repository @ WVU with permission from the rights-holder(s). You are free to use this Thesis in any way that is permitted by the copyright and related rights legislation that applies to your use. For other uses you must obtain permission from the rights-holder(s) directly, unless additional rights are indicated by a Creative Commons license in the record and/ or on the work itself. This Thesis has been accepted for inclusion in WVU Graduate Theses, Dissertations, and Problem Reports collection by an authorized administrator of The Research Repository @ WVU. For more information, please contact researchrepository@mail.wvu.edu. 


\title{
MECHANICAL EVALUATION AND FE MOIDELING OF COMPOSITE SANIDWICH PANELS
}

\section{Ashish S Bambal}

\author{
Thesis submitted to the \\ College of Engineering and Mineral Resources at \\ West Virginia University in \\ partial fulfillment of the requirements \\ for the degree of
}

\section{Master of Science \\ in \\ Chemical Engineering}

\author{
Ruifeng Liang, Ph.D., Chair \\ Hota V. S. GangaRao, Ph.D., Co-chair \\ Rakesh K. Gupta, Ph.D.
}

\section{Department of Chemical Engineering}

\author{
Morgantown, West Virginia \\ 2007
}

Keywords: bending, compression molding, CFRP, FEA, pultrusion, tension, resin infusion, sandwich, SEM 


\title{
ABSTRACT
}

\section{Mechanical Evaluation and FE Modeling of FRP Sandwich Panels}

\begin{abstract}
Ashish Bambal
Most sandwich structures are defined using a three-layer type of construction, two thin layers and a thick core layer. Typically, the thickness ratio of core to face sheet is in the range of 10 to 15 . For this study, end grain balsa was used as a core material (thickness $\sim 3$ in.) and Fiber Reinforced Polymer Composite (FRP thickness $\sim 0.25$ in.) was used as face sheet material.

The objective of this research was to develop a modeling approach to predict response of composite sandwich panels under static bending conditions. Different model including 2D and 3D solid with isotropic and orthotropic material properties were attempted in advanced Finite Element (FE) software MSC.NASTRAN. Comparison of FE model predictions with experimental data on sandwich panel mechanical properties helped in establishing appropriate modeling approach. FEA has been carried out both the bench and full scale panel levels. The effects of different material properties and panel profiles (with caps and w/o caps) were investigated. Finally, the FEA was further extended to predict response of jointed FRP sandwich panels. Proposed modeling has been proved to give reasonably accurate prediction for composite sandwich panels under the mentioned scenarios.

Another objective of this study was to evaluate mechanical and physical properties of Carbon FRP composites including both laminates and sandwich panels. CFRP sandwich panels of 0.25 " thick face sheets sandwiching balsa core were produced by BRP Inc., while additional laminates were manufactured either by compression molding (CFCWVU lab) or Resin Infusion process (Fiber-Tech.) with varying resin system, fabric architecture and 3D stitched fabric. Mechanical property evaluation of composite material was carried out on both the coupon and panel levels under bending, tension etc. Effect of different process parameters, material structure and resin on composite properties was discussed. Microstructure study of composite specimens was carried out in order to analyze fiber-matrix adhesion and void content which in turn affect the strength of FRP composites.
\end{abstract}




\section{ACKNOWLEDGEMENTS}

I would like to express my sincere gratitude and appreciation to the Department of Chemical Engineering, West Virginia University for allowing me this fantastic opportunity to pursue M.S. degree in the department.

I would like to gratefully acknowledge the enthusiastic supervision of Dr. Ruifeng Liang during this work. With his enthusiasm, his inspiration, and his great efforts to explain things clearly and simply, he helped to make this work, a great experience for me. Throughout my research, he provided encouragement, sound advice, good teaching, good company, and lots of sensible ideas. The work would be impossible without the always involved Dr. Hota. His unrelenting pursuit to see the work through and guide all of his students beyond graduation is very evident and much appreciated. I would also like to acknowledge Dr. Rakesh Gupta for his willingness to serve as a member of my examining committee.

Beyond the educational and technical guidance, my deepest thanks must go to my mother Sandhya and father Suresh who made my undergraduate and graduate education possible. Their love, belief, and guidance will never go unappreciated. I am forever indebted to my brother Manish for his understanding, endless patience and encouragement when it was most required throughout the life. Finally, I am also grateful to uncle Ramesh and aunt Vijaya for their support and guidance. 


\section{TABLE OF CONTENTS}

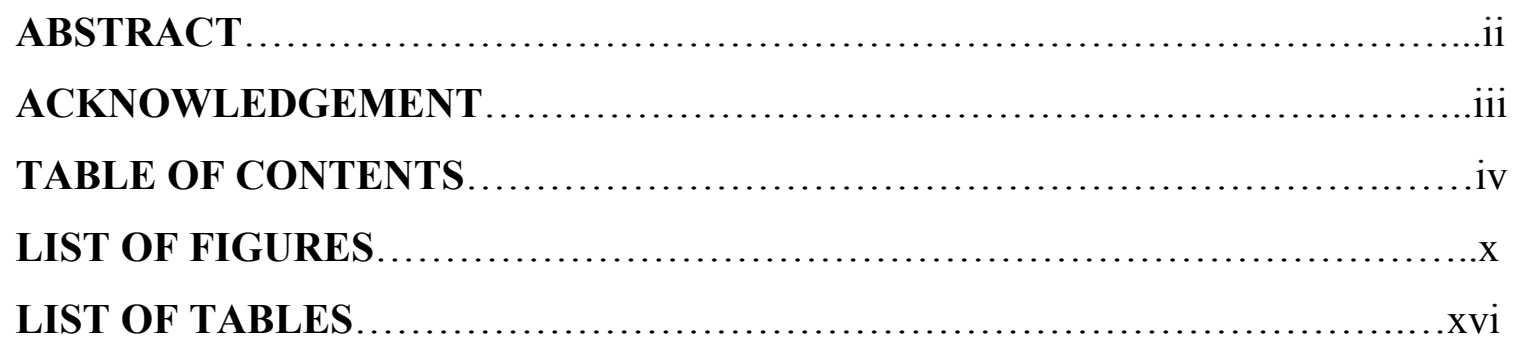

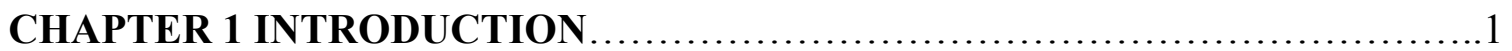

1.1 Background ........................................................

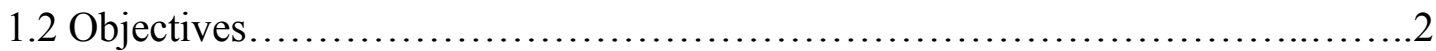

1.2.1 Mechanical Characterization FRP composites......................2

1.2.2 Finite Element Modeling of FRP sandwich panels.....................2

1.3 Organization of Thesis.......................................................

CHAPTER 2 LITERATURE REVIEW .....................................

2.1 Introduction to composites...........................................

2.2 Carbon Fiber Reinforced Polymer (CFRP) Composites........................5

2.2.1 Introduction........................................................

2.2.2 Resin for CFRP Composites.........................................5

2.2.3 Literature Data.................................................6

2.2.4 CFC-WVU Past Work ..........................................

2.3 Application of CFRP Composites....................................... 10

2.3.1 Naval Vessels................................................... 10

2.3.2 Other Applications.............................................11

\section{CHAPTER 3 MATERIALS AND MANUFACTURING OF TEST SPECIMENS..14}

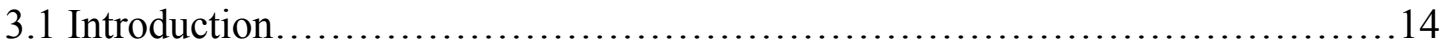

3.2 Fiber Composites.................................................. 14

3.2.1 Introduction.................................................... 14

3.2.2 Design of Fiber Reinforced Composites............................. 14

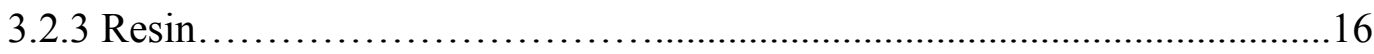


3.2.4 Conventional Thermosetting Resin..................................17

3.2.4.1 Epoxy-Resin System.........................................17

3.2.4.2 Vinyl Ester Resin.......................................... 18

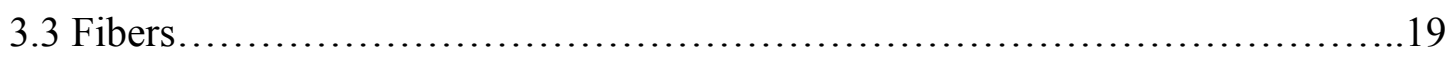

3.3.1 Introduction to Carbon Fibers.........................................19

3.3.2 Fiber Properties.................................................. 20

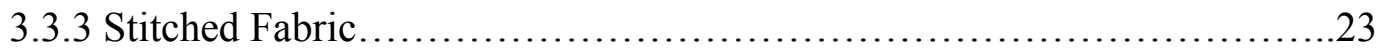

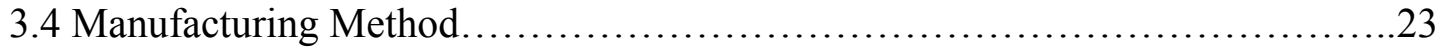

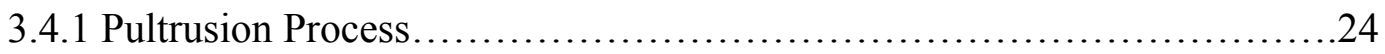

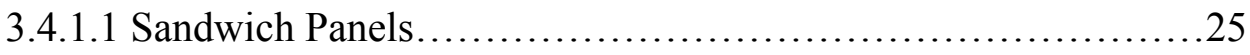

3.4.1.2 Core Material Balsa Wood.....................................26

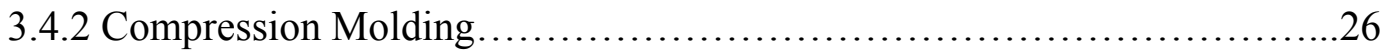

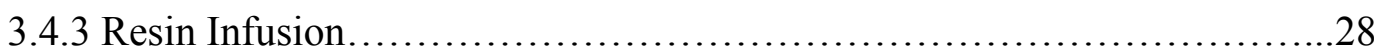

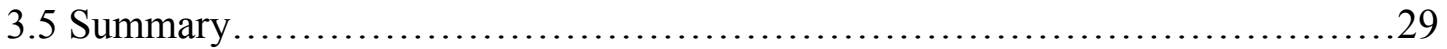

CHAPTER 4 EXPERIMENTATION ...............................................

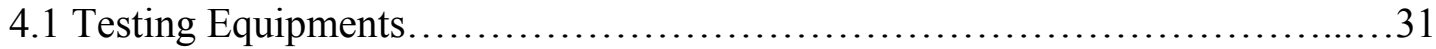

4.1.1 Baldwin Universal Testing Machine ................................... 31

4.1.2 Instron Model 8501 Servo-Hydraulic Material Testing System..............32

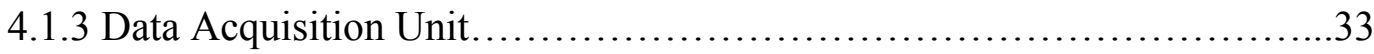

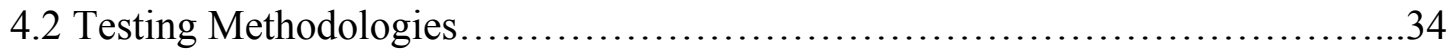

4.2.1 Tension Test...................................................... 34

4.2.1.1 Stepwise Procedure for Tension Test.............................35

4.2.1.2 Tension Test Calculations.......................................

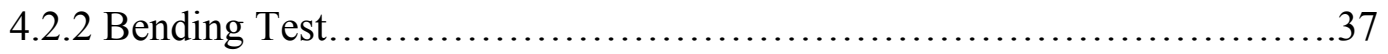

4.2.2.1 Four Point Bending Test..................................... 37

4.2.2.2 Stepwise Procedure for Bending Test ............................38

4.2.2.3 Three Point Bending Tests....................................40

4.2.3.4 Stepwise Procedure for Bending Test ............................43

4.2.3.5 Comparison between three point and four point bending test......45

4.3 Theoretical Strength Prediction by Classical Laminate Theory...................45 


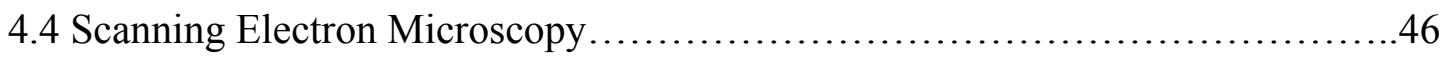

4.5 Physical and Morphological Properties.......................................48

4.5.1 Fiber Content ..................................................... 48

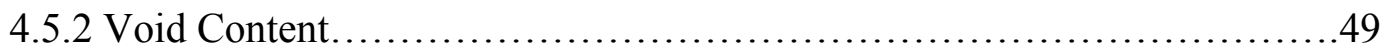

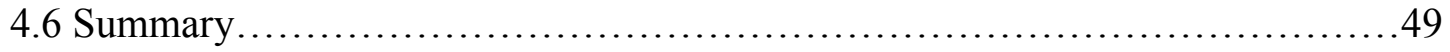

CHAPTER 5 DATA ANALYSIS AND RESULTS ............................51

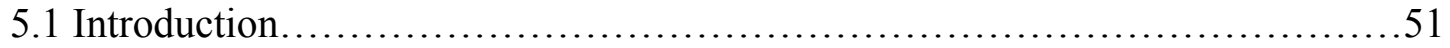

5.2 Coupon Level Testing .................................................... 51

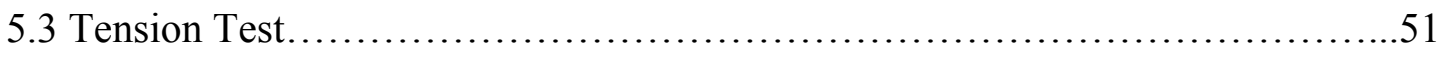

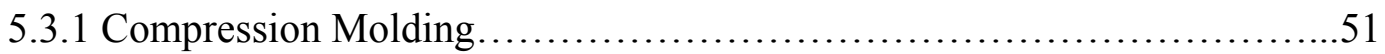

5.3.1.1 Symmetric Fiber Architecture with 510A VE Cured at 190F......52

5.3.1.2 Symmetric Fiber Architecture with 510A VE Cured at RT........52

5.3.1.3 Symmetric Fiber Architecture with CSM and 510A VE Cured at

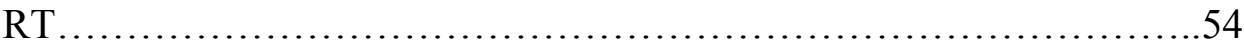

5.3.1.4 Symmetric Fiber Architecture with Epoxy Cured at 190F........55

5.3.1.5 Symmetric Fiber Architecture with Stitched Layers and Epoxy

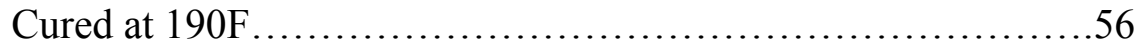

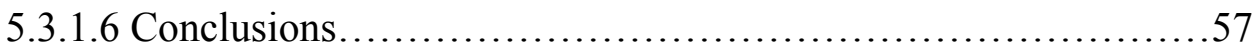

5.3.2 Pultrusion Process........................................................60

5.3.2.1 Non-symmetrical Fiber Architecture with 510A VE: Long. Direction (Run1) .......................................60

5.3.2.2 Symmetrical Fiber Architecture with CSM and 510A VE: Long. direction (Run2) .......................................60

5.3.2.3 Symmetrical Fiber Architecture with CSM and 510A VE: Trans.

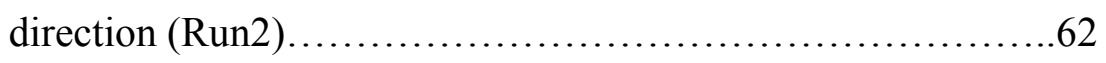

5.3.2.4 Symmetrical Fiber Architecture after Removing CSM and 510A VE: Long. direction (Run2)................................64

5.3.2.5 Symmetrical Fiber Architecture after Removing CSM and 510A VE: Trans. direction (Run2) ..............................65

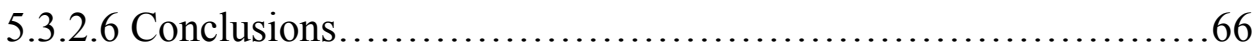


5.3.3 Resin Infusion.

5.3.3.1 Symmetric Fiber Architecture with Epoxy cured at $140 \mathrm{~F}$ for 105 $\min$ .69

5.3.3.2 Symmetric Fiber Architecture with Epoxy Cured at $140 \mathrm{~F}$ for 145 $\min$. .70

5.3.3.3 Symmetric Fiber Architecture with 510A VE Cured at RT.......71

5.3.3.4 Conclusions........................................... 72

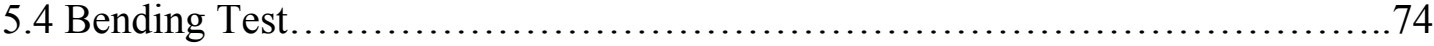

5.4.1 Compression Molding.................................................... 75

5.4.1.1 Symmetric Fiber Architecture with 510A VE Cured at 190F .....75

5.4.1.2 Symmetric Fiber Architecture with 510A VE Cured at RT ......76

5.4.1.3 Symmetric Fiber Architecture with CSM and 510A VE Cured at

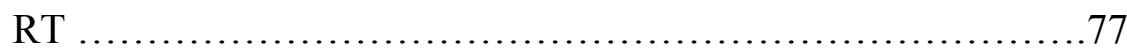

5.4.1.4 Symmetric Fiber Architecture with Epoxy Cured at 190F ........78

5.4.1.5 Symmetric Fiber Architecture with Stitched Layers and Epoxy

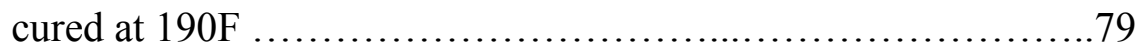

5.4.1.6 Conclusions.............................................. 81

5.4.2 Pultrusion Process................................................... 83

5.4.2.1 Non-symmetrical Fiber Architecture with 510A VE: Long. Direction (Run1).................................... 84

5.4.2.2 Non-symmetrical Fiber Architecture with 510A VE: Trans.

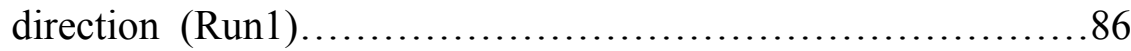

5.4.2.3 Symmetrical Fiber Architecture with CSM and 510A VE: Long.

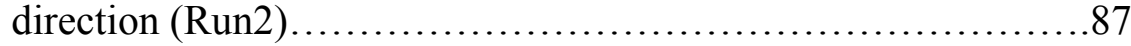

5.4.2.4 Symmetrical Fiber Architecture with CSM and 510A VE: Trans.

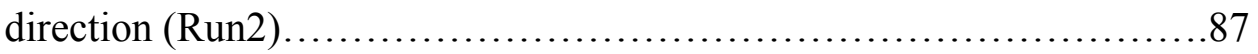

5.4.2.5 Symmetrical Fiber Architecture after Removing CSM and 510A VE: Long. direction (Run2) ...........................90

5.4.2.6 Symmetrical Fiber Architecture after Removing CSM and 510A VE: Trans. direction (Run2) .......................... 91

5.4.2.7 Conclusions .93 
5.4.3 Resin Infusion.

5.4.3.1 Symmetric Fiber Architecture with Epoxy Cured at 140 F for 105 $\min$

5.4.3.2 Symmetric Fiber Architecture with Epoxy Cured at $140 \mathrm{~F}$ for 145 $\min$ .94

5.4.3.3 Symmetric Fiber Architecture with 510A VE Cured at RT.......95

5.4.3.4 Conclusions.............................................97

5.5 Sandwich Panel Testing.................................................... 99

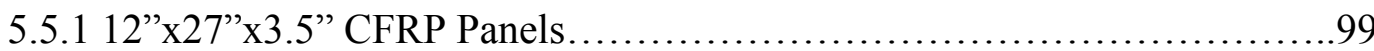

5.5.2 12"x80"x3.5" CFRP Panels........................................ 100

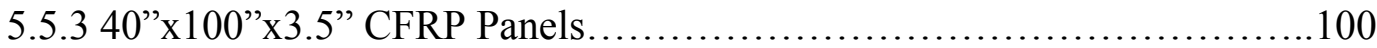

5.6 Physical Characterization................................................... 104

5.6.1 Void Analysis of FRP Composites by Scanning Electron Microscopy)...104

5.6 .2 Conclusions................................................. 107

CHAPTER 6 MODELING OF FRP SANDWICH PANELS .................... 108

6.1 Objectives...................................................... 108

6.2 Finite Element Analysis Software - MSC.Nastran...........................108

6.3 Experimental Set-up and Loading Conditions..............................109

6.4 Evaluation of FE Models for Sandwich Panels................................109

6.4.1 Sandwich Beam Model........................................................................... 110

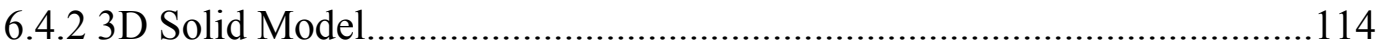

6.4.3 Orthotropic Beam Model...........................................116

6.4.4 3D Orthotropic Solid Model.........................................117

6.4.4.1 Deflection and strain....................................118

6.4.4.2 Bending stress........................................... 120

6.4.4.3 Shear stress.........................................121

6.4.5 Conclusion....................................................... 123

6.5 Prediction of CFRP Sandwich Panel Response................................ 123

6.5.1 End Caps of Pultruded Sandwich Panels........................... 125

6.5.2 Deflection: Effect of End Caps on Mechanical Response.................127

6.5.3 Bending Stress: Effect of End Caps on Mechanical Response ............128 
6.5.4 Shear Stress: Effect of End Caps on Mechanical Response ...............130

6.5.4 Conclusions....................................................... 130

6.6 Joint Analysis of Composite Sandwich Analysis.............................130

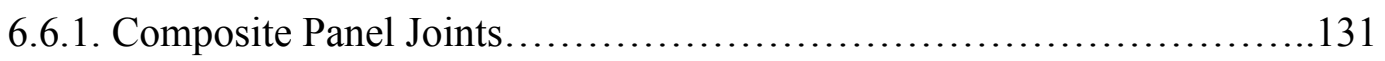

6.6.2 FE Analysis of Joined Sandwich Panels ................................135

6.6 .3 Conclusion.................................................. 136

CHPATER 7 CONCLUSIONS AND RECOMMENDATIONS ...........................136

7.1 Mechanical Testing of CFRP Composites.............................. 136

7.1.1 Compression Laminates.........................................136

7.1.2 Pultrusion Laminates ............................................ 136

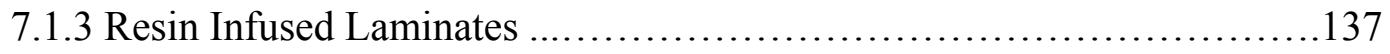

7.2 Sandwich Panel Test................................................ 137

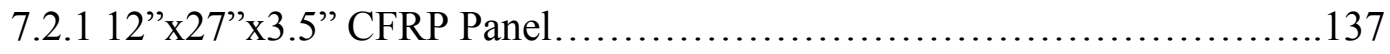

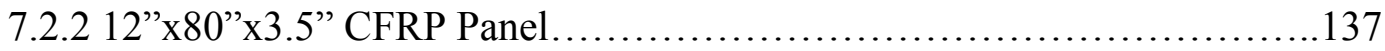

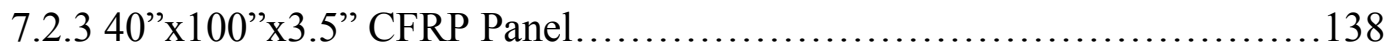

7.3 Finite Element Modeling of FRP Sandwich Panel........................... 138

7.4 Recommendations................................................ 138

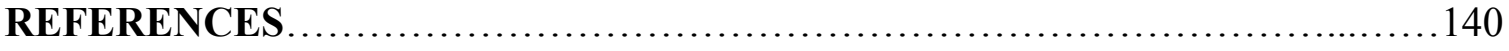




\section{LIST DF FIGURES}

Figure 3.1 Quad-axial Toray T700SC/12K/FOE carbon fabric.....................20

Figure 3.2 Generalized orientations of multiaxial fibers............................22

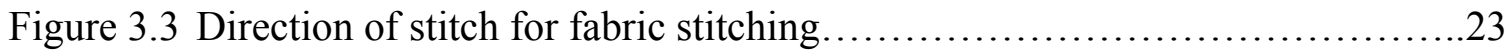

Figure 3.4 Stitching Machines..................................................

Figure 3.5 Manufacturing line for typical pultrusion process $\ldots \ldots \ldots \ldots \ldots \ldots \ldots \ldots \ldots \ldots . .25$

Figure 3.6 Experimental set for compression molding...........................27

Figure 4.1 Baldwin Universal Testing Machine.................................. 32

Figure 4.2 Instron Model 8501 Servo-hydraulic Material Testing System..............33

Figure 4.3 Data Acquisition Unit.................................................. 34

Figure 4.4 Schematic of tension test sample along with the cross sectional view AA....35

Figure 4.5 Tension test specimens............................................ 35

Figure 4.6 Typical Plot of Stress vs. Strain for Pultruded Sample under Tension Test...37

Figure 4.7 Schematic of 4pt. bending test set up with stress and moment distribution in

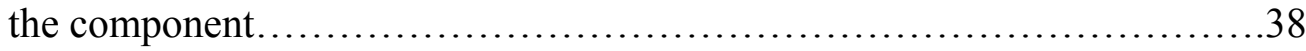

Figure 4.8 Typical Lab Set-up for 4pt Bending Test.............................. 39

Figure 4.9 Three different dimensions of sandwich panels tested by $4 p t$ bending test....41

Figure 4.10 Typical plot of load vs. strain for sandwich panel.......................42

Figure 4.11 Schematic of 3pt. bending (midspan type) test set up with stress and moment distribution in the component......................................42

Figure 4.12 Typical plot of load vs. deflection for pultrusion sample.................44

Figure 4.13 Typical bending test specimens....................................44

Figure 4.14 Hitachi S-4700 field emission scanning electron microscope (FE-SEM)....46

Figure 4.15 SEM images of pultruded composites..............................49

Figure 5.1 Stress-strain behavior of carbon/VE composites cured at high temperature..53

Figure 5.2 Stress-strain behavior of room temperature cured carbon/VE composites....53

Figure 5.3 Stress-strain behavior of room temperature cured carbon/VE composites with

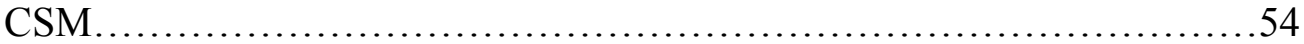

Figure 5.4 Stress-strain behavior of room temperature cured carbon/VE composites with CSM. 
Figure 5.5 Stress-strain behavior of room temperature cured one way stitched carbon/Epoxy composites......................................57

Figure 5.6 Stress-strain behavior of room temperature cured two way stitched carbon/Epoxy composites.......................................57

Figure 5.7 Chart comparison of maximum stress for carbon/VE/epoxy composites by compression molding 59

Figure 5.8 Chart comparison of tensile modulus for carbon/VE/epoxy composites by compression molding

Figure 5.9 Stress-strain behavior of pultruded carbon/VE composites in longitudinal direction.

Figure 5.10 Stress-strain behavior of pultruded carbon/VE composites in longitudinal direction (with CSM)

Figure 5.11 Stress-strain behavior of pultruded carbon/VE composites in transverse direction (with CSM) .63

Figure 5.12 Stress-strain behavior of pultruded carbon/VE composites in longitudinal direction (w/o CSM) 64

Figure 5.13 Stress-strain behavior of pultruded carbon/VE composites in transverse direction (w/o CSM) .........................................65

Figure 5.14 Chart comparison of maximum stress for carbon/VE composites by

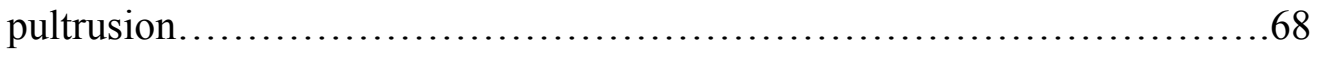

Figure 5.15 Chart comparison of tensile modulus for carbon/VE composites by pultrusion.

Figure 5.16 Stress-strain behavior of carbon/epoxy composites by resin infusion........70

Figure 5.17 Stress-strain behavior of carbon/epoxy composites by resin infusion........71

Figure 5.18 Stress-strain behavior of carbon/VE composites by resin infusion..........73

Figure 5.19 Stress-strain behavior of carbon/VE composites by resin infusion...........73

Figure 5.20 Chart comparison of maximum stress for carbon/VE/epoxy composites by resin infusion. 74

Figure 5.21 Chart comparison of tensile modulus for carbon/VE/epoxy composites by resin infusion. 
Figure 5.22 Load-deflection behavior of carbon/epoxy composites by compression molding........................................................ 76

Figure 5.23 Load-deflection behavior of carbon/epoxy composites by compression

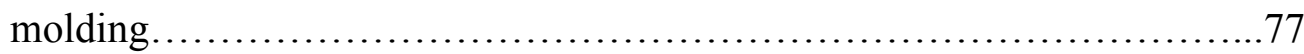

Figure 5.24 Load-deflection behavior of carbon (stitched 1/2 fabric)/epoxy composites by compression molding.......................................... 78

Figure 5.25 Load-deflection behavior of carbon (stitched-1 fabric)/epoxy composites by compression molding..... .79

Figure 5.26 Load-deflection behavior of carbon (stitched-2 fabric)/epoxy composites by compression molding

Figure 5.27 Load-deflection behavior of carbon/VE (190F) composites by compression molding.... .81

Figure 5.28 Load-deflection behavior of carbon/VE (RT) composites by compression molding.... 83

Figure 5.29 Load-deflection behavior of carbon/VE composites by compression molding (with CSM) .83

Figure 5.30 Chart comparison of bending stress for compression molding.............85

Figure 5.31 Chart comparison of $\mathrm{E}_{\mathrm{b}}$ for compression molding......................85

Figure 5.32 Load-deflection behavior of carbon/VE composites by pultrusion (longitudinal)

Figure 5.33 Load-deflection behavior of carbon/VE composites by pultrusion (transverse)

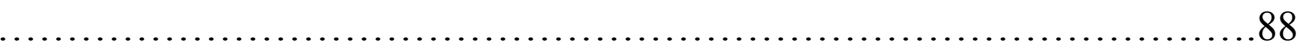

Figure 5.34 Load-deflection behavior of carbon/VE composites by pultrusion (CSM+Longitudinal)

Figure 5.35 Load-deflection behavior of carbon/VE composites by pultrusion (CSM+Transverse) .90

Figure 5.36 Chart comparison of bending stress for carbon/VE composites by pultrusion.

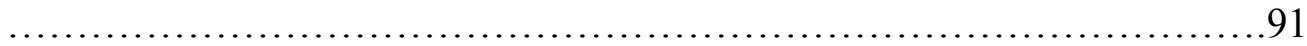

Figure 5.37 Chart comparison of elasticity modulus for carbon/VE composites by pultrusion................................................... 92

Figure 5.38 Load-deflection behavior of carbon/epoxy composites by resin infusion.....94 
Figure 5.39 Load-deflection behavior of carbon/epoxy composites by resin infusion

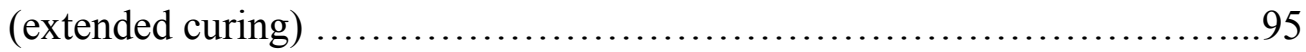

Figure 5.40 Load-deflection behavior of carbon/VE composites by resin infusion.......97

Figure 5.41 Load-deflection behavior of carbon/VE composites by resin infusion.......97

Figure 5.42 Chart comparison of bending stress for carbon/VE/epoxy composites by resin infusion.

Figure 5.43 Chart comparison of $\mathrm{E}_{\mathrm{b}}$ for carbon/VE/epoxy composites by resin infusion.98 Figure 5.44 Pultrusion sample confirming different fiber orientation. .104

Figure 5.45 Pultrusion sample showing good fiber-matrix adhesions. ... 105

Figure 5.46 Pultrusion sample showing high void content surface....................105

Figure 5.47 Pultrusion sample with regions of high/low void density................106

Figure 5.48 Resin infusion showing improper wet out............................ 106

Figure 5.49 Resin infusion showing improper wet out.......................... 107

Figure 5.50 Compression molding sample showing better wet out.................. 107

Figure 6.1 Predicted deflection contours by sandwich beam model for 40"x100" panel.

Figure 6.2 Predicted and experimental deflection data across the span under failure load for 40"x 100" panel.

Figure 6.3 Predicted and experimental deflection as a function of loads for 40"x100" panel.

Figure 6.4 Predicted and experimental bending stress across the span under failure load for 40"x100' panel.

Figure 6.5 Predicted and experimental deflection data across the span under failure load for 12"x96" panel.

Figure 6.6 Predicted and experimental bending stress across the span under failure load for $12 " x$ 96" panel. .114

Figure 6.7 Construction of 3D Orthotropic Solid Model A.........................117

Figure 6.8 Construction of 3D Orthotropic Solid Model B........................117

Figure 6.9 Predicted deflection contours by 3D orthotropic model B for 12"x 96" panel. 
Figure 6.10 Predicted and experimental deflection data across the span under failure load for 12 " x 96" panel.

Figure 6.11 Predicted and experimental deflection data as a function of loads for 12"x96" panel.

Figure 6.12 Predicted and experimental strain data as a function of loads for 12"x96" panel.

Figure 6.13 Predicted bending stress contours by 3D orthotropic model B for 12"x 96" panel. 120

Figure 6.14 Predicted and experimental bending stress data across the span under failure load for $12 "$ x 96 " panel. 121

Figure 6.15 Predicted bending stress across the thickness under failure load for 12"x96" panel. 121

Figure 6.16 Predicted shear stress contours by 3D orthotropic model B for 12"x 96" panel.

Figure 6.17 Predicted shear stress across the span under failure load for 12" x 96" panel.

Figure 6.18 Predicted shear stress across the thickness under failure load for 12"x96" panel........................................................ 123

Figure 6.19 Cross sectional view of sandwich panel showing end caps...............125

Figure 6.20 Predicted deflection contours by 3D orthotropic model for 40"x100" panel. .126

Figure 6.21 Predicted deflection data across the span under failure load for 40"x100"

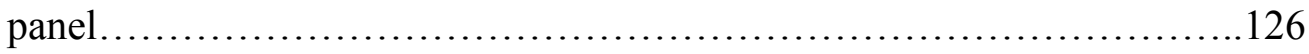

Figure 6.22 Predicted bending stress contours for 40"x100" panel...................126

Figure 6.23 Predicted bending stress data across the span under failure load for 40"x100"

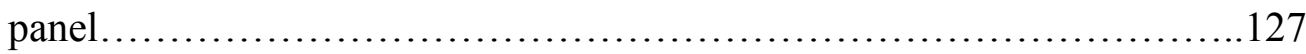

Figure 6.24 Predicted bending stress across the thickness under failure load for 40"x100" panel. 127

Figure 6.25 Predicted shear stress contours for model w/o end caps for 40"x100" panel. .128 
Figure 6.26 Predicted shear stress contours for model with end caps for 40"x100"

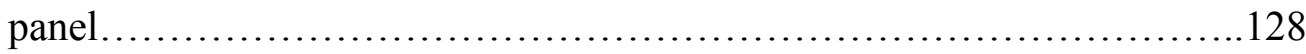

Figure 6.27 Predicted shear stress profile across the thickness under failure load for 40"x100" panel.

Figure 6.28 Schematic joining of two 4' wide sandwich panels by a double sided lap joint.

Figure 6.29 Predicted deflection contours for model with 11.5"x80" joint panel with 24", 18 "and 12 " wide layers. 130

Figure 6.30 Predicted bending stress contours for model with 11.5"x80" joint panel with 24", 18" and 12" wide layers. 133

Figure 6.31 Predicted shear stress contours for model with 11.5"x80" joint panel with 24", 18" and 12" wide layers. .134

Figure 6.32 Predicted deflection contours for model with 11.5"x80" joint GFRP panel with 24", 18"and 12" wide layers. .134

Figure 6.33 Predicted bending stress contours for model with 11.5"x80" joint GFRP panel with 24", 18"and 12" wide layers. 134

Figure 6.34 Predicted shear stress contours for model with 11.5"x80" joint GFRP panel with 24", 18"and 12" wide layers 135 


\section{LIST OF TABLES}

Table 2.1 Properties of some thermoplasts for carbon fiber polymer-matrix composites

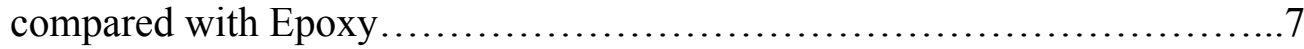

Table 2.2 Effect of various surface treatments on properties oh high-modulus carbon fibers and their epoxy-matrix composites............................8

Table 2.3 Mechanical properties of unidirectional carbon fiber (62 vol\% AS-4) epoxy matrix composites................................................. 9

Table 2.4 Room temperature mechanical properties of carbon fiber epoxy-matrix composites with P-75 fibers and 934 epoxy........................... 9

Table 2.5 Sandwich panel 40"x100"x3.5" bending properties, 4 pt. bending test........10

Table 3.1 Data sheet for Vinyl Ester resin...................................... 19

Table 3.2 Data sheet for carbon fiber composite................................21

Table 3.3 Fiber orientation and share in each direction.............................

Table 3.4 Fiber lay up for symmetric and non-symmetric architecture.................22

Table 3.5 Details of production runs for CFRP sandwich panels.....................25

Table 3.6 Data sheet for balsa wood............................................ 26

Table 3.7 Summary of different conFigureuration of fiber orientation, resin system and manufacturing methods used for CFRP fabrication...................... 30

Table 4.1 Range of fiber content for different manufacturing processes...............48

Table 4.2 Range of laminate thickness for different manufacturing processes..........48

Table 4.3 Summary of specimen tested for mechanical testing.......................50

Table 5.1 Tension test results for carbon/VE composites cured at high temperature.....52

Table 5.2 Tension test results for carbon/VE composites cured at room temperature...53

Table 5.3 Tension test results for carbon/VE composites cured at room temperature with CSM layer.........................................................

Table 5.4 Tension test results for carbon/epoxy composites cured at $190 \mathrm{~F} \ldots \ldots \ldots \ldots . . .55$

Table 5.5 Tension test results for stitched carbon/epoxy composites cured at 190F.....56

Table 5.6 Tension test results for carbon/VE composites in longitudinal direction......61

Table 5.7 Tension test results for pultruded carbon/VE composites in longitudinal direction (with CSM) 
Table 5.8 Tension test results for pultruded carbon/VE composites in transverse direction (with CSM) .......................................63

Table 5.9 Tension test results for pultruded carbon/VE composites in longitudinal direction (w/o CSM) ..........................................64

Table 5.10 Tension test results for pultruded carbon/VE composites in transverse direction (w/o CSM) ........................................65

Table 5.11 Tension test results for carbon/epoxy composite by resin infusion...........70

Table 5.12 Tension test results for carbon/epoxy composite by resin infusion...........71

Table 5.13 Tension test results for carbon/VE composite by resin infusion.............72

Table 5.14 Tension test results for carbon/VE composite by resin infusion..............72

Table 5.15 Bending test results for carbon/epoxy composite by compression molding...75

Table 5.16 Bending test results for carbon (stitched fabric)/epoxy composite by compression molding.......................................... 76

Table 5.17 Bending test results for carbon /VE composite by compression molding.....77

Table 5.18 Bending test results for carbon /VE (RT) composite by compression

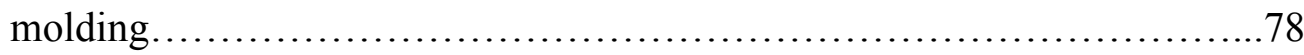

Table 5.19 Bending test results for carbon /VE composite by compression molding (with

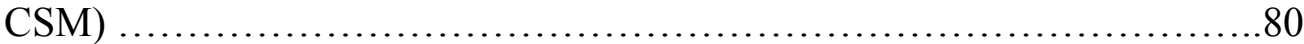

Table 5.20 Bending test results for carbon /VE composite by pultrusion (longitudinal)..84

Table 5.21 Bending test results for carbon /VE composite by pultrusion (transverse)....85

Table 5.22 Bending test results for carbon /VE composite by pultrusion (CSM+Longitudinal) ........................................ 86

Table 5.23 Bending test results for carbon /VE composite by pultrusion

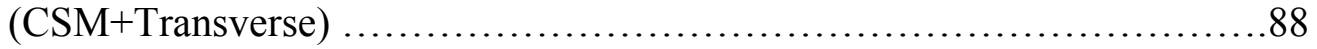

Table 5.24 Bending test results for carbon /VE composite by pultrusion (No CSM+Longitudinal) ......................................... 89

Table 5.25 Bending test results for carbon /VE composite by pultrusion (No

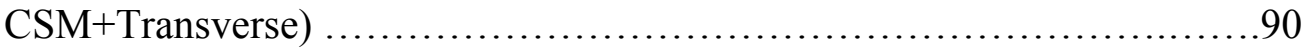

Table 5.26 Bending test results for carbon /epoxy composite by resin infusion..........94

Table 5.27 Bending test results for carbon /epoxy composite by resin infusion (extended curing) 
Table 5.28 Bending test results for carbon /VE composite by resin infusion............96

Table 5.29 Bending test results for carbon /VE composite by resin infusion.............96

Table 5.30 12"x27" Sandwich Panels Bending Properties...........................101

Table 5.31 12"x80" Sandwich Panels Bending Properties............................ 102

Table 5.32 40"x100" Sandwich Panels Bending Properties..........................103

Table 6.1 Load/BC and material properties for sandwich beam model...............111

Table 6.2 Sandwich beam model predictions in comparison with experimental values for

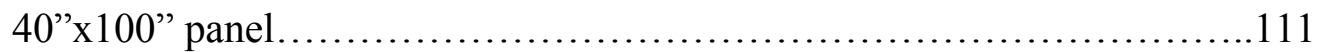

Table 6.3 Load, BC and material properties for isotropic 3D solid model............115

Table 6.4 Model predictions in comparison with experimental values for 12"x96" panel @ failure load 17062 lbs.............................................115

Table 6.5 Load/BC and material properties for orthotropic beam model..............116

Table 6.6 Material properties for 3D Orthotropic Solid Model A and B..............118

Table 6.7 Model predictions in comparison with experimental values for 12"x96" panel............................................................ 118

Table 6.8 Material properties for CFRP sandwich panels..........................124

Table 6.9 Model prediction in comparison with experimental values for 12 "x 80 " and

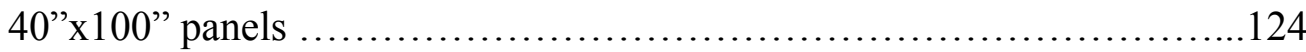

Table 6.10 Material properties for GFRP sandwich panels with joints.................131

Table 6.11 Model prediction in comparison with experimental values for 11.5"x80"

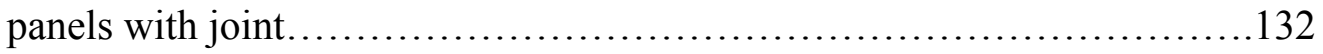




\section{INTROIDUCTION}

\subsection{Background}

A composite material is composed of reinforcement (fibers, particles, flakes, and/or fillers) embedded in a cured resin also known as a matrix (polymers, metals, or ceramics). The matrix holds the reinforcement together to form the desired shape while the reinforcement improves the overall mechanical properties of the matrix. When designed properly, the new combined material exhibits improved strength compared with each individual material. A fiber-reinforced composite is a material system made primarily of varying amounts of fiber reinforcement embedded in a protective material called a matrix, with a coupling agent applied to the fiber to improve the adhesion of the fiber to the matrix material. FRP composites unlike steel or aluminum are anisotropic (properties are different in different direction) whereas steel or aluminum is isotropic (uniform properties in all directions, independent of applied load). Therefore, FRP composite properties are directional, meaning that the best mechanical properties are in the direction of the fiber placement. The field of application for such composites depends on their physical and mechanical properties. These properties can be evaluated from standard ASTM procedures.

In field of material world, FRP composites find wide application due to their excellent properties especially in marine industries. Navy ships have historically been made of steel, an ideal material for ship construction, being both durable and cost effective. Steel being corrosive, requires constant maintenance. Today there is significant emphasis on eliminating such costs. The U.S. Navy is considering carbon fiber composites in lieu of E-glass composites for next generation topside ship structures such as destroyers, aircraft carriers, littoral combat ships and other high speed vehicles to satisfy their weight and performance requirement. The advance $\mathrm{DD}(\mathrm{X})$ of Navy fleet is expected to have a composite mast and deckhouse, consuming about 500,000 lb to 1 million $\mathrm{lb}$ of carbon/vinyl ester composites per ship. Objective is to improve mechanical properties of 
these composites through accurate estimation for structural properties of these composites is needed.

\subsection{Objectives}

Objectives of this research are listed below,

\subsubsection{Mechanical Characterization FRP composites}

One of the objectives of this study is to characterize the mechanical properties of CFRP composites under bending and tension. Mechanical characterization was carried out on coupon specimen and sandwich panels. In addition, comparison of performance is made based on parameters like manufacturing methods, fiber architecture, resin etc.

1. Manufacturing CFRP plates using hand lay-up in conjunction to compression molding.

2. Preparing coupon specimen from plates manufactured by compression molding, pultrusion process and Resin Infusion.

3. Conducting bending and tension tests on coupon specimens to find mechanical properties as per ASTM standard.

4. Comparing stress-strain behavior of different fiber architecture, effect of 3D stitching, resin system etc.

\subsubsection{Finite Element Modeling of FRP sandwich panels}

Another objective of this study is to focus on Finite Element Analysis of FRP sandwich panels with MSC.Nastran and comparison with experimental results. Number of tasks performed in this analysis includes,

1. Developing and evaluating different modeling approach to predict FRP sandwich panel response.

2. Comparing experimental data with FEA data for sandwich panels.

3. Verifying it for different panel dimensions and material properties after validating the approach as stated in item 2.

4. Analyzing jointed sandwich panel response and studying effect of layers of external reinforcements 


\subsection{Organization of Thesis}

Chapter 2: highlights literature data available on CFRP composites and their various field applications especially for marine industry.

Chapter 3: Summary of constituent materials and manufacturing methods used for fabrication of composites. Constituent materials include fiber and resin matrix with their detailed datasheets. Further, brief information about each manufacturing method used is provided. Steps involved in coupon specimens preparation are listed in the end.

Chapter 4: describes the various experiments conducted for mechanical characterization at coupon level and panel level. In addition, step wise procedure of each test method is listed followed by equations and plots required for property determinations.

Chapter 5: It contains comprehensive summary of results and data analysis for various test methods. Stress-strain and load-deflection behaviors are thoroughly studied for comparisons. Effect of various parameters and manufacturing conditions are discussed.

Chapter 6 Different FEA modeling approach including 2D and 3D is discussed. Model predictions are then compared with experimental data for validation of modeling approach.

Chapter 7 Conclusions and recommendations for future work are presented. 


\section{LITERATURE REVIEW}

This chapter gives a brief literature overview available on different FRP composites and their properties. In addition, the work carried out at CFC-WVU in recent years is described. The various applications of FRP sandwich structures are overviewed in last section.

\subsection{Introduction to Composites}

The evolution of composite material has replaced most of the conventional material of construction in automobile, aviation industry etc. Fiber reinforced composites have been widely successful in hundreds of applications where there was a need for high strength materials. There are thousands of custom formulations which offer FRPs a wide variety of tensile and flexural strengths. When compared with traditional materials such as metals, the combination of high strength and lower weight has made FRP an extremely popular choice for improving a product's design and performance (Chung et. al., 1994). Some of the features of these materials are listed below.

Part Consolidation: A well designed composite part can easily eliminate the assembly of many metal parts by allowing one to mold them as one complete piece. In addition, inserts can be molded into the SMC material to aid in the assembly process. The result is a finished unit with fewer components which reduces the time and money spent on additional assembly.

Design Flexibility: Parts molded with polyester or vinyl ester composite materials can reproduce almost any shape desired. The molding process allows for a more aesthetically pleasing part to be designed than is often possible when the part was fabricated in metal, thermoformed, or made from another material or process.

Dimensional Stability: Products made from composite materials offer a greater degree of dimensional stability when compared to thermoplastics, wood, and some metals. Composites can maintain their shapes even under intense mechanical and environmental stresses. 
Light Weight: Composite parts offer more strength per unit of weight than any unreinforced plastic and most metals. For some parts, the reduction can be significant. This can reduce shipping costs, reduce the labor needed to install parts, and reduce injuries from installing large, heavy components.

High Strength: Composite parts can be designed to provide a wide range of impact, tensile and flexural strength properties, depending on the specific requirements of the application. Each compound is custom made to meet user requirements for strength as well as other properties.

Corrosion Resistance: Composites do not rust or corrode, and offer various levels of chemical and environmental resistance, depending on the resin system chosen for the application.

Low Electrical and Thermal Conductivity: Composites can offer a wide range of insulating properties to meet specific requirements for electrical and thermal resistance.

\subsection{Carbon Fiber Reinforced Polymer (CFRP) Composites}

\subsubsection{Introduction}

A carbon fiber composite refers to a composite in which at least one of the fillers is carbon fibers, short or continuous, unidirectional or multidirectional, woven or nonwoven. The matrix is usually a polymer, a metal, a carbon, a ceramic, or a combination of different materials. The matrix is three-dimensionally continuous, whereas the filler can be three-dimensionally discontinuous or continuous. Carbon fiber fillers are usually three-dimensionally discontinuous, unless the fibers are three-dimensionally interconnected by weaving or by the use of a binder such as carbon.

\subsubsection{Resin for CFRP Composites}

The physical properties of carbon fiber reinforced polymer (CFRP) composite material depends considerably on the nature of matrix, the fiber alignment, the volume fraction of the fiber and matrix, and on the molding conditions. Therefore by choosing suitable parameters, it is possible to make composite suited to a particular need. Several types of matrix material such as polymers, glass and ceramics and metals have been used as 
matrices for reinforcement by carbon fibers. However from the point of view of mechanical properties, density and fiber matrix cohesion, epoxy resins are frequently the best choice. Carbon fibers are considered excellent reinforcement for polymers because

1. They are strong, stiff and lightweight

2. Their high modulus makes the reinforced structure stiff and

3. Many polymers have good adhesion characteristics towards carbon fibers and can make sound structures.

Based on theoretical and experimental work on fiber-resin system, a number of following requirements must be fulfilled in order to realize the maximum benefits from fiber reinforcement (Chung et. al., 1994):

1. The fiber content should be as high as possible since the fibers are the source of strength. In practice, up to $70 \%$ by volume of fiber can be achieved with care.

2. The alignment and directions of the fibers is of paramount importance. The property of fibers in any direction determines the properties of composite in that direction. Twist in the reinforcement, even though it may involve only a small percentage of fibers, is detrimental as twisted fibers do not contribute fully, but do give uneven resin distribution.

3. Fibers should be wetted out fully by the resin to ensure good contact and bonding at the interface so that the load may be transferred from one fiber to another throughout the composite.

4. Good bond strength at the resin-fiber interface is essential for load transfer in the composite. The matrix should be compatible with the fiber and should not debond or crack when the fiber undergoes maximum strain at full load.

5. Fiber quality is important. Kinks and twists in the fibers, produce stress concentrations.

\subsubsection{Literature Data}

Polymer-matrix composites are much easier to fabricate than metal-matrix, carbonmatrix, and ceramic-matrix composites, whether the polymer is a thermoset or a thermoplastics. Thermosets (especially epoxy) have long been used as polymer matrices 
for carbon fiber composites. The properties of several thermoplastic resin with carbon fiber are listed in Table 2.1 in comparison with epoxy. In contrast, epoxies have tensile strengths of 30-100 MPa, moduli of elasticity of 2.8-3.4 GPa, ductilities of 0-6\% and a density of $1.25 \mathrm{~g} / \mathrm{cm}^{3}$. Thus, epoxies are much more brittle than most of the thermoplastics.

Table 2.1 Properties of some thermoplasts for carbon fiber polymer-matrix composites compared with Epoxy (Chung et. al., 1994)

\begin{tabular}{|c|c|c|c|c|c|c|}
\hline & 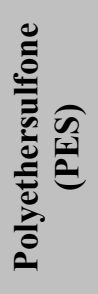 & 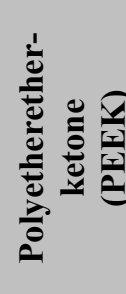 & 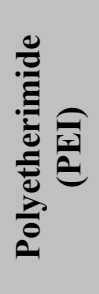 & 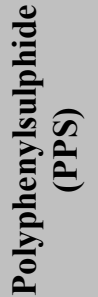 & 兽 & 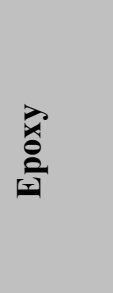 \\
\hline Glass transition Temperature $\mathrm{T}_{\mathrm{g}}\left({ }^{0} \mathrm{C}\right)$ & 230 & 170 & 225 & 86 & 256 & \\
\hline Decomposition Temperature $\left({ }^{\circ} \mathrm{C}\right)$ & 550 & 590 & 555 & 527 & 550 & \\
\hline Processing Temperature $\left({ }^{0} \mathrm{C}\right)$ & 350 & 380 & 350 & 316 & 304 & $<200$ \\
\hline Tensile Strength $(\mathrm{MPa})$ & 84 & 70 & 105 & 66 & 138 & $30-100$ \\
\hline Modulus of Elasticity (GPa) & 2.4 & 3.8 & 3.0 & 3.3 & 3.4 & $2.8-3.4$ \\
\hline Ductility (\% elongation) & $30-80$ & $50-150$ & $50-65$ & 2 & 5 & $0-6$ \\
\hline Izod Impact (ft lb/in.) & 1.6 & 1.6 & 1 & $<0.5$ & 1.5 & - \\
\hline Density $\left(\mathrm{g} / \mathrm{cm}^{3}\right)$ & 1.37 & 1.31 & 1.27 & 1.3 & 1.37 & 1.25 \\
\hline
\end{tabular}

In general, the ductility of semi-crystalline thermoplastics decreases with increasing crystallinity. For example, the ductility of PPS can range from 2 to $20 \%$, depending on the crystallinity ${ }^{2}$. Another major difference between thermoplasts and epoxies lies in the higher processing temperatures of thermoplasts $\left(300-400^{\circ} \mathrm{C}\right)$. Much work has been done to improve epoxies for controlling the fiber-matrix interface ${ }^{5,6}$, increasing the toughness ${ }^{7,8}$, and reducing the moisture sensitivity. Other than epoxies, thermosets used for carbon fibers include polyimide and bismaleimide. Polyimides can be thermoplasts or thermosets.

The addition of fibers increases the creep resistance because it impedes the molecular mobility. The effect is greater with amorphous thermoplasts than with semi-crystalline thermoplasts, as crystalline polymers themselves inhibit creep ${ }^{2}$. Water absorbed by a polymer acts as a plasticizer and decreases strength and stiffness, but increases toughness. As fibers absorb much less water than polymers, addition of fibers decreases the amount 
of water absorption. It also increases the dimensional stability when the temperature is changed, because fibers have much lower thermal expansion coefficients than polymers. The use of fibers produces higher melt viscosities at a given shear rate, so higher processing temperatures and/or higher injection pressures are necessary. On the other hand, the addition of fibers reduces shrinkage during processing. Surface treatments of carbon fibers are essential for improving the bonding between the fibers and the polymer matrix. They involve oxidation treatments and the use of coupling agents, wetting agents, and/or sizings (coatings). Table 2.2 shows the effect of oxidation treatments on the mechanical properties of high-modulus carbon fibers and their epoxy-matrix composites. The treatments degrade the fiber properties but improve the composite properties to some extent.

Table 2.2 Effect of various surface treatments on properties oh high-modulus carbon fibers and their epoxy-matrix composites (Chung et. al., 1994)

\begin{tabular}{|c|c|c|c|c|}
\hline \multirow[b]{2}{*}{ Fiber Treatment } & \multicolumn{2}{|c|}{ Fiber Properties } & \multicolumn{2}{|c|}{ Composite Properties } \\
\hline & $\begin{array}{c}\text { Wt. loss } \\
(\%)\end{array}$ & $\begin{array}{c}\text { Tensile } \\
\text { Strength } \\
\text { loss }(\%)\end{array}$ & $\begin{array}{l}\text { Flexural } \\
\text { Strength } \\
\text { loss }(\%)\end{array}$ & $\begin{array}{c}\text { ILSS gain } \\
(\%)\end{array}$ \\
\hline $\begin{array}{c}400^{\circ} \mathrm{C} \text { in air } \\
(30 \mathrm{~min})\end{array}$ & 0 & 0 & 0 & 18 \\
\hline $\begin{array}{c}500^{\circ} \mathrm{C} \text { in air } \\
(30 \mathrm{~min})\end{array}$ & 0.4 & 6 & 12 & 50 \\
\hline $\begin{array}{c}600^{\circ} \mathrm{C} \text { in air } \\
(30 \mathrm{~min})\end{array}$ & 4.5 & 50 & - & - \\
\hline $\begin{array}{c}60 \% \mathrm{HNO}_{3} \\
(15 \text { min.) }\end{array}$ & 0.2 & 0 & 8 & 11 \\
\hline $\begin{array}{c}5.25 \% \mathrm{NaoCl} \\
\text { (30min.) }\end{array}$ & 0.4 & 1.5 & 5 & 30 \\
\hline $\begin{array}{c}15 \% \mathrm{HclO}_{4} \\
(15 \mathrm{~min} .)\end{array}$ & 0.2 & 0 & 12 & 0 \\
\hline
\end{tabular}

Table 2.3 below shows typical properties of unidirectional carbon-epoxy composites. In addition, room temperature properties of typical P-75 fibers and 934 epoxy composites are listed in Table 2.4 . 
Table 2.3 Mechanical properties of unidirectional carbon fiber (62 vol\% AS-4) epoxy matrix composites. (Chung et. al., 1994)

\begin{tabular}{ll}
\hline Tensile Strength & $2353 \mathrm{MPa}$ \\
Tensile Modulus & $145 \mathrm{GPa}$ \\
Flexural Strength & $1794 \mathrm{MPa}$ \\
Flexural Modulus & $131 \mathrm{GPa}$ \\
Short-Beam Shear Strength & $124 \mathrm{MPa}$ \\
\hline
\end{tabular}

Table 2.4 Room temperature mechanical properties of carbon fiber epoxy-matrix composites with P-75 fibers and 934 epoxy (Chung et. al., 1994)

\begin{tabular}{|c|c|c|c|c|}
\hline \multicolumn{2}{|c|}{ Properties/Test Method } & Unit & Unidirectional & Quasi-isotropic \\
\hline \multirow{3}{*}{$0^{0}$ Tension } & Modulus & GPa (Msi) & $310(45)$ & $103(14.9)$ \\
\hline & Strength & $\mathrm{MPa}(\mathrm{ksi})$ & $999(145)$ & $246(35.8)$ \\
\hline & Ult. Strain & $\%$ & 0.31 & 24 \\
\hline \multirow{3}{*}{$90^{0}$ Tension } & Modulus & GPa (Msi) & $7.7(1.1)$ & $108(15.7)$ \\
\hline & Strength & $\mathrm{MPa}(\mathrm{ksi})$ & $21.3(3.1)$ & $351(51.0)$ \\
\hline & Ult. Strain & $\%$ & 0.3 & 0.33 \\
\hline \multirow{3}{*}{$0^{0}$ Compression } & Modulus & GPa (Msi) & $229(33.3)$ & $66(9.6)$ \\
\hline & Strength & $\mathrm{MPa}(\mathrm{ksi})$ & $421(61.2)$ & $183(26.7)$ \\
\hline & Ult. Strain & $\%$ & 0.32 & 0.5 \\
\hline \multirow{3}{*}{$90^{\circ}$ Compression } & Modulus & $\mathrm{GPa}(\mathrm{Msi})$ & $7.6(1.1)$ & $76(11.1)$ \\
\hline & Strength & $\mathrm{MPa}(\mathrm{ksi})$ & $129(61.2)$ & $186(27)$ \\
\hline & Ult. Strain & $\%$ & - & 0.55 \\
\hline
\end{tabular}

The high thermal conductivity of carbon fibers, especially the high modulus pitch-based fibers (Amoco's Thornel P-100 and P-120, with fiber thermal conductivity at $300 \mathrm{~K}$ of 300 and $520 \mathrm{~W} / \mathrm{m} / \mathrm{K}$, respectively) and the vapor grown carbon fibers (with fiber thermal conductivity at $300 \mathrm{~K}$ of $1380 \mathrm{~W} / \mathrm{m} / \mathrm{K}$ ), makes these fibers highly effective for increasing the thermal conductivity of polymers. The highest thermal conductivity at $245 \mathrm{~W} / \mathrm{m} / \mathrm{K}$ is associated with the P-120 fibers. This conductivity value is higher than that of aluminum; though lower than that of copper.

\subsubsection{CFC-WVU Past Work}

Composite Sandwich panels with E-glass/vinyl ester polymer (GFRP) as face sheets and end grain balsa as a core, were manufactured by pultrusion process. The mechanical 
properties were evaluated by bending and tension tests on coupon level and panel level samples. Same approach has been used in this study to evaluate Carbon/VE sandwich panels with same core material (GangaRao Hota et. al., 2005, 2006).

The E-glass/vinyl ester system through a vacuum-assisted resin transfer molding (VARTM) process has emerged as the base-line composite panel manufacturing for Navy applications (Beach et. al., 2002). An effort is being made to demonstrate feasibility of an automated pultrusion process which can produce a equally good or better quality composite panels on bulk level at low cost. In past three years, mass production and characterization of E-glasss/Derakane 510A vinyl ester resin based pultruded composite panels have been characterized for their mechanical properties. This has been further extended to characterize carbon/vinyl ester system produced by same process. Some of the mechanical properties for GFRP sandwich panels produced by pultrusion and VARTM process are listed in Table 2.5.

Table 2.5 Sandwich panel 40"x100"x3.5" bending properties, 4 pt. bending test (GangaRao Hota et. al., 2005, 2006)

\begin{tabular}{|l|c|c|}
\hline & Pultruded GFRP & VARTM GFRP \\
\hline Failure load per unit width, lb/in. & 1331 & 1120 \\
\hline Failure Strain, microstrain & 5944 & 6020 \\
\hline Balsa Stress at failure, $p$ si & 204.7 & 172.2 \\
\hline FRP stress at failure, $k$ si & 22.05 & 17.63 \\
\hline Modulus from load/strain slope, $m s i$ & 4.06 & 2.96 \\
\hline Modulus from load/deflection, $m s i$ & 4.27 & 3.06 \\
\hline
\end{tabular}

\subsection{Applications of CFRP Composites}

\subsubsection{Naval Vessels}

In Defense world, marine composites offer various advantages due to their properties as mentioned earlier. Navy ships have historically been made of steel, an ideal material for ship construction, being both durable and cost effective. Steel being corrosive, requires constant maintenance. Today there is significant emphasis on eliminating such costs. Further, the loss of ship availability, due to this type of maintenance, is considered a major cost penalty, because other ships must be added to the fleet to assure availability. 
The heavy weight of steel ships also places limits on their speed and increases fuel consumption. This has resulted into the use of composite materials in naval application.

The U.S. Navy is considering carbon fiber composites in lieu of E-glass composites for next generation topside ship structures such as destroyers, aircraft carriers, littoral combat ships and other high speed vehicles to satisfy their weight and performance requirement. The advance $\mathrm{DD}(\mathrm{X})$ of Navy fleet is expected to have a composite mast and deckhouse, consuming about 500,000 lb to 1 million $\mathrm{lb}$ of carbon/vinyl ester composites per ship. In the past, pultrusion process has been used to produce E-glass (GFRP) sandwich panels for such purpose. Similar approach is used in here for production of CFRP sandwich panels.

\subsubsection{Other Application}

Carbon fiber polymer-matrix composites are predominantly used for the aerospace industry, but the decreasing price of carbon fibers is widening the applications of these composites to include the automobile, marine, sports, biomedical, construction, and other industries (Mallick, 1997).

One area of aerospace applications is space vehicles. The United States Space Shuttle uses carbon fiber epoxy-matrix composites for its payload bay door and remote manipulator arm; its solid rocket motor cases also use epoxy-matrix composites; its booster tail and fins use polyimide-matrix composites. Satellite structures and solar panels also use carbon fiber polymer-matrix composites. Most space applications utilize standard aerospace grade carbon fibers (tensile strength $3550 \mathrm{MPa}$, tensile modulus 235 GPa) combined with a $177^{\circ} \mathrm{C}$ cure multifunctional epoxy resin matrix. Filament wound rocket motor cases employ a $121^{\circ} \mathrm{C}$ cure, modified bis-A-epoxy as the resin matrix. Stiffness requirements of some satellite applications dictate the use of high-modulus carbon fibers (350 GPa). Thermoplast matrices such as PEEK and PES are gaining attention for space applications. A second area is military aircraft. Examples include Gripen, EFA, French Rafale, and U.S. B-2, which use the $177^{\circ} \mathrm{C}$ cure toughened thermoset matrix resins along with intermediate-modulus (295 GPa), or high-strength (5 
$590 \mathrm{MPa}$ ), intermediate-modulus carbon fibers. Outer and front sections of the engine are subjected to lower temperatures and can utilize an epoxy matrix. For example, the front fan ducts on Rolls-Royce engines and the blocker doors and transcowls on General Electric's CF6-8OC2 engines use $177^{\circ} \mathrm{C}$ cure epoxy. Engine rear section components operate at higher temperatures; this necessitates polyimide matrices such as PMR-15, which is used for thrust reversers and bypass ducts. Thermoplasts such as PEEK are being considered for engine applications. Aluminum is a lightweight metal that competes with carbon fiber polymer-matrix composites for aerospace applications. In addition to their much higher strength and modulus, the carbon fiber composites are produced using much less energy and costly pollution control compared to aluminum.

Carbon fiber polymer-matrix composites have started to be used in automobiles mainly for saving weight for fuel economy. The so-called graphite car employs carbon fiber epoxy-matrix composites for body panels, structural members, bumpers, wheels, drive shaft, engine components, and suspension systems. This car is $1250 \mathrm{lb}$. (570 kg) lighter than an equivalent vehicle made of steel. It weighs only $2750 \mathrm{lb}$ instead of the conventional $4000 \mathrm{lb}$ for the average American car. Thermoplastic composites with PEEK and polycarbonate (PC) matrices are finding use as spring elements for car suspension systems.

The electrically conductive characteristic of carbon fiber polymer-matrix composites makes them suitable for static dissipation (which requires an electrical resistivity of 104$106 \Omega . \mathrm{cm}$ ), functional elements in high-impedance circuits (which require a resistivity of 102-103 $\Omega . \mathrm{cm}$ ), and shielding from radio frequency interference (which requires a resistivity of 10-102 $\Omega . \mathrm{cm}$ ). From loadings as low as $10 \mathrm{wt} \%$, a polymer is made staticdissipating, protecting electronic circuits or avoiding spark generation. In addition, carbon fiber polymer-matrix composites are used for RF components. The protection of aircraft from lightning damage is a related application. The electrically conductive characteristic also makes carbon fiber polymer-matrix composites useful as electrodes. 
The high thermal conductivity and low thermal expansion of continuous carbon fiber polymer-matrix composites make them suitable for heat sinks in electronics. Since a heat sink is in contact with a ceramic chip carrier or a printed circuit board, a low thermal expansion is preferred. The low density of the composites (compared to copper) makes them even more attractive for aerospace electronics. The X-ray transparency of carbon fibers makes carbon fiber polymer matrix composites useful for passing small-impulse electric currents to monitor a patient's vital signs while he is being X-rayed. Thermoplasts filled with short or continuous carbon fibers are useful as bone plates for fracture fixation. Metal bone plates suffer from metallic ion leaching, which may cause adverse local tissue reactions and even local tumor formation, and from stress protection atrophy. Polylactic acid (PLA) is an absorbable thermoplastic used for this application, but its mechanical properties are not sufficient for long bone fixation, so continuous carbon fibers are added to produce a semi-absorbable composite. Polymers, such as PEEK, which are not absorbable, are also used for this application. Due to the concern about the loss of bone around stiff metallic femoral stems, more flexible carbon fiber polymermatrix composites are being considered for use in hip replacement prostheses.

Continuous carbon fiber polymer-matrix composites are replacing steel for reinforcing concrete structures, because the composites are lightweight, available in continuous and long lengths, and do not rust. The lightweight characteristic makes them convenient to install. Continuous carbon fiber polymer-matrix composites are used as acoustic diaphragms in speakers and microphones because of their low weight, high elasticity, fast sound transmission velocity, and excellent rigidity. These diaphragms exhibit less deformation due to an external force, a small sound distortion, wide sound reproduction range, distinct sound quality, and are suitable for digital audio applications. Short carbon fibers, together with graphite powder, in a polyimide matrix provide an abrasion-resistant material that is useful for bearings. Short carbon fibers in a polyurethane resin or its precursor provide a sealing compound with a high tensile strength for use in filling and sealing a gap between two parts. 


\section{CHAPTER 3}

\section{MATERIALS AND MANUFACTURING DF TEST SPECIMENS}

\subsection{Introduction}

This chapter gives brief overview on different types of polymer matrix, fiber configuration, mechanical properties of these materials and their contribution in composites manufactured from them. A brief insight is provided on different fabrication methods such as compression molding, pultrusion etc. used in this study for composite manufacturing. Additionally, coupon sample preparation is described for tension test, bending test etc.

\subsection{Fiber Composites}

\subsubsection{Introduction}

Composite materials refer to materials containing more than one phase such that the different phases are artificially blended together. A carbon fiber composite refers to a composite in which at least one of the fillers is carbon fibers, short or continuous, unidirectional or multidirectional, woven or non-woven. The matrix is usually a polymer, a metal, a carbon, a ceramic, or a combination of different materials. The high strength and modulus of carbon fibers makes them useful as reinforcement for polymers, metals, carbons, and ceramics, even though they are brittle. In composites, matrix acts binding agent and protects the fiber while transferring any applied load.

\subsubsection{Design of Fiber Reinforced Polymer Composites}

The mechanical properties of composite is constituted by the individual properties of its constituents such as fibers, resin etc. Effective reinforcement requires good bonding between the fibers and the matrix. For a unidirectional composite, the longitudinal tensile strength is quite independent of the fiber-matrix bonding, but the transverse tensile strength and the flexural strength (for bending in longitudinal or transverse directions) increases with increasing fiber-matrix bonding. On the other hand, excessive fiber-matrix 
bonding can cause a composite with a brittle matrix (e.g., carbon and ceramics) to become more brittle, as the strong fiber-matrix bonding causes cracks to propagate straightly, in the direction perpendicular to the fiber-matrix interface without being deflected to propagate along this interface. In the case of a composite with a ductile matrix (e.g., metals and polymers), a crack initiating in the brittle fiber tends to be blunted when it reaches the ductile matrix, even when the fiber-matrix bonding is strong. Therefore, an optimum degree of fiber-matrix bonding is needed for brittle-matrix composites, whereas a high degree of fiber-matrix bonding is preferred for ductile-matrix composites. In conclusion, it is utmost important that in a given composite fiber and matrix shows a good compability.

The mechanisms of fiber-matrix interaction include chemical bonding, van der Waals bonding, and mechanical interlocking. Chemical bonding gives the largest bonding force, provided that the density of chemical bonds across the fiber-matrix interface is sufficiently high. This density can be increased by chemical treatments of the fibers or by sizing on the fibers. Mechanical interlocking between the fibers and the matrix is an important contribution to the bonding if the fibers form a three-dimensional network. Otherwise, the fibers should have a rough surface in order to form a small degree of mechanical interlocking. Both chemical bonding and van der Waals bonding require the fibers to be in intimate contact with the matrix. For intimate contact to take place, the matrix or matrix precursor must be able to wet the surfaces of the carbon fibers during infiltration of the matrix or matrix precursor into the carbon fiber preform. Chemical treatments and coatings can be applied to the fibers to enhance wetting. The choice of treatment or coating depends on the matrix. Another way to enhance wetting is the use of a high pressure during infiltration. A third method is to add a wetting agent to the matrix or matrix precursor before infiltration. As the wettability may vary with temperature, the infiltration temperature can be chosen to enhance wetting. The occurrence of a reaction between the fibers and the matrix helps the wetting and bonding between the fibers and the matrix. However, an excessive reaction degrades the fibers, and the reaction products may be undesirable for the mechanical, thermal, or moisture resistance properties of the composite. Therefore, an optimum amount of reaction is preferred. Carbon fibers are 
electrically and thermally conductive, in contrast to the non-conducting nature of polymer and ceramic matrices. Therefore, carbon fibers can serve not only as reinforcement, but also as an additive for enhancing the electrical or thermal conductivity. Furthermore, carbon fibers have nearly zero coefficient of thermal expansion, so they can also serve as an additive for lowering the thermal expansion. The combination of high thermal conductivity and low thermal expansion makes carbon fiber composites useful for heat sinks in electronics and for space structures that require dimensional stability. As the thermal conductivity of carbon fibers increases with the degree of graphitization, applications requiring a high thermal conductivity should use the graphitic fibers, such as the high-modulus pitch-based fibers and the vapor grown carbon fibers. Carbon fibers are more cathodic than practically any metal, so in a metal matrix, a galvanic couple is formed with the metal as the anode. This causes corrosion of the metal. The corrosion product tends to be unstable in moisture and causes pitting, which aggravates corrosion. To alleviate this problem, carbon fiber metal-matrix composites are often coated.

\subsubsection{Resin}

For fiber composites, large numbers of resins are available commercially. The selection of suitable one depends on compability with the fibers and enhancement in the properties. Different resin system can be broadly divided into a number of groups according to their chemical formulations, but for use in composite manufacture it is propose to divide them into following categories:

1. Conventional thermosetting resins which can operate in the temperature range $125-200^{\circ} \mathrm{C}$. Thermosetting resin includes phenolics, Alkyds, Amino compounds, polyesters etc.

2. High-temperature thermosetting resins which can operate at temperature over $250^{\circ} \mathrm{C}$, extending up to $350^{\circ} \mathrm{C}$. High Temperature Thermosetting resin includes Aromatic polyamides, Polyamide-Imides and polyester-Imides, polyimide, polybenzothiazoles etc.

3. Thermoplastic resins which by definition are limited to temperature near ambient. Thermoplastic Resin includes Acrylonitrile-butadiene-styrene (ABS), Acrylics, Acetal Copolymers, Acetal Homopolymers etc. 


\subsubsection{Conventional Thermosetting Resin}

Thermosets have long been used as polymer matrices for carbon fiber composites. During curing, usually performed in the presence of heat and pressure, a thermoset resin hardens gradually due to the completion of polymerization and the cross linking of the polymer molecules.

\subsubsection{Epoxy-Resin System}

Epoxy resins can be described as being highly versatile, as having a broad capacity for blending with different hardeners, catalysts etc. Epoxy formulation can be soft, flexible or hard, as they are available in form of solids or liquids. Epoxies are resistant to many environmental conditions and can be used up to $135^{\circ} \mathrm{C}$ on a continuous basis. A notable characteristic is their excellent degree of adhesion which coupled with relative ease of application, high strength and good reproducibility. Moreover the low molecular weight of uncured epoxide resins in the liquid state results in exceptionally high molecular mobility during processing. This characteristic behavior has led to their widespread use with carbon fiber.

Epoxy resins are characterized by having two or more epoxides group per molecule. The chemical structure of an epoxide group is

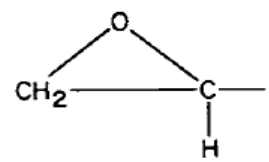

The general chemical structure for most commercial epoxy is shown below

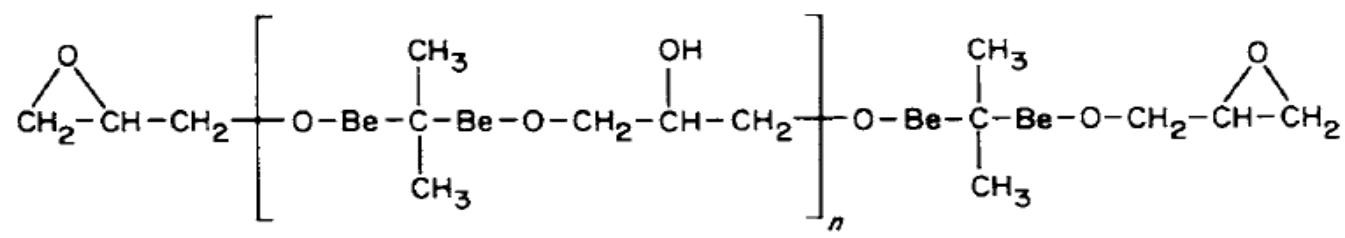

Where $\mathrm{Be}=$ benzene ring. For liquids, $\boldsymbol{n}$ is usually less than $\mathbf{1}$; for solid resins, $\boldsymbol{n}$ is 2 or greater.

The curing of an epoxy resin requires a cross-linking agent and/or a catalyst. The epoxy and hydroxyl groups (-OH) are the reaction sites for cross linking. Cross linking agent 
includes amine, anhydrides and aldehyde condensation products. In the curing reaction, the epoxide ring is opened (called ring scission) and a donor hydrogen from converter hydroxyl group bonds with the oxygen atom of the epoxide group. As no by-product is given off during curing, shrinkage is low.

Given below is the detail of epoxy resin used for composites in this study supplied by Dow Chemical Co. Halogen (BR) free toughened epoxy (Part A) was procured along with its converter (Part B). The mixing ratio of $5 \mathrm{~A}: 1 \mathrm{~B}$ was used for all the sample preparations. Curing was done at $160-180 \mathrm{~F}$ for about $30 \mathrm{~min}$.

\subsubsection{Vinyl Ester Resin}

Vinyl ester resins are stronger than polyester resins and cheaper than epoxy resins. Vinyl ester resins utilize a polyester resin type of cross-linking molecules in the bonding process. Vinyl ester is a hybrid form of polyester resin which has been toughened with epoxy molecules within the main molecular structure. Vinyl ester resins offer better resistance to moisture absorption than polyester resins but its downside is its sensitivity to atmospheric moisture and temperature. Sometimes it would not cure if the atmospheric conditions are not right. It also has difficulty in bonding dissimilar and already-cured materials. As vinyl ester resin ages, it becomes a different resin (due to its continual curing as it ages) so new vinyl ester resin sometimes resists bonding to older canoe, or will bond and then later peel off at a bad time. It is also known that vinyl ester resins bond very well to fiberglass, but offer a poor bond to Kevlar and carbon fibers due to the nature of those two more exotic fibers.

Commercially available DERAKANE 510A-40 Vinyl ester resin was used to make composite sandwich panels by pultrusion and laminates by compression molding and resin infusion. DERAKANE 510A-40 (Epoxy) Vinyl Ester Resin is a brominated bisphenol-A based vinyl ester designed to offer the maximum degree of fire retardance combined with enhanced chemical resistance and toughness. It offers the highest bromine content of any DERAKANE Resin. Typical properties of the same are listed below in Table 3.1. 
MEKP (Methyl Ethyl Ketone Peroxide) is principally used as an initiator or "catalyst" for the room temperature cure of unsaturated polyester and vinyl ester resins. It is also needed with all gel coats. It is typically used between $1.25 \%$ and $1.75 \%$ of resin weight.

Table 3.1 Data sheet for Vinyl Ester resin 510A (Dow Chemical Co.)

Typical Properties for VE Resin

\begin{tabular}{|l|c|}
\hline Dynamic Viscosity @ $25^{\circ} \mathrm{C}\left(77^{\circ} \mathrm{F}\right), \mathrm{mPa} . \mathrm{s}$ & 400 \\
\hline Styrene Content, \% & 38 \\
\hline Density @ $25^{\circ} \mathrm{C}\left(77^{\circ} \mathrm{F}\right), \mathrm{g} / \mathrm{ml}$ & 1.23 \\
\hline Commercial Warranty, dark, @ $25^{\circ} \mathrm{C}\left(77^{\circ} \mathrm{F}\right)$, months & 4 \\
\hline
\end{tabular}

Typical Room-Temperature Properties of Clear Castings Made with DERAKANE 510A-40 Resin ${ }^{(1)}$

\begin{tabular}{|l|c|}
\hline Tensile Strength, $\mathrm{MPa} /$ psi & $85 / 12,300$ \\
\hline Tensile Modulus, GPa/unit $10^{5}$ psi & $3.4 / 5.0$ \\
\hline Tensile Elongation, $\%$ & 5 \\
\hline Flexural Strength, MPa/psi & $150 / 21700$ \\
\hline Flexural Modulus, GPa/unit $10^{5}$ psi & $3.6 / 5.2$ \\
\hline Specific Gravity & 1.34 \\
\hline $\begin{array}{l}\text { Heat Distortion Temperature, }{ }^{\circ} \mathrm{C}\left(\mathrm{F}^{\circ}\right) \\
\text { at } 1.82 \mathrm{Mpa}(264 \text { psi) applied stress }\end{array}$ & $110 / 230$ \\
\hline Barcol Hardness & 40 \\
\hline
\end{tabular}

\subsection{Fibers}

\subsubsection{Introduction to Carbon Fibers}

Carbon, E-glass and aramid fibers are most widely used for fiber reinforced composites. For this study carbon fibers in form of stitched fabric are used for fabrication purpose. The properties of carbon fibers vary widely depending on the structure of the fibers. In general, attractive properties of carbon fibers include the following:

Low density, high tensile modulus and strength

Low thermal expansion coefficient

Excellent creep resistance

Chemical stability, particularly in strong acids

Biocompatibility

High thermal conductivity, low electrical resistivity

Availability in a continuous form

Decreasing cost with advanced production technology 
Disadvantages of carbon fibers include the following:

Anisotropy (in the axial versus transverse directions)

Low strain to failure, compressive strength is low compared to tensile strength

Oxidation of carbon fibers is catalyzed by an alkaline environment

\subsubsection{Fiber Properties}

Military grade Toray T700SC/12K/FOE carbon fiber was used for the composite fabrication purpose. It is a grade of carbon fiber of highest strength (711 ksi) and standard modulus $(33.4 \mathrm{msi})$. The selected code $(\mathrm{T} 700 \mathrm{SC} / 12 \mathrm{~K} / \mathrm{FOE})$ represents a never twisted carbon fiber of 12000 filaments per tow, with a sizing type designated for vinyl ester and surface treated at a sizing amount $0.7 \%$. Total fiber density was $168 \mathrm{oz}$ per sq yd and directional share as described in next section. The carbon fiber used here was procured from Saertex USA, LLC. Figure 3.1 shows the longitudinal and transverse view of the same fiber.
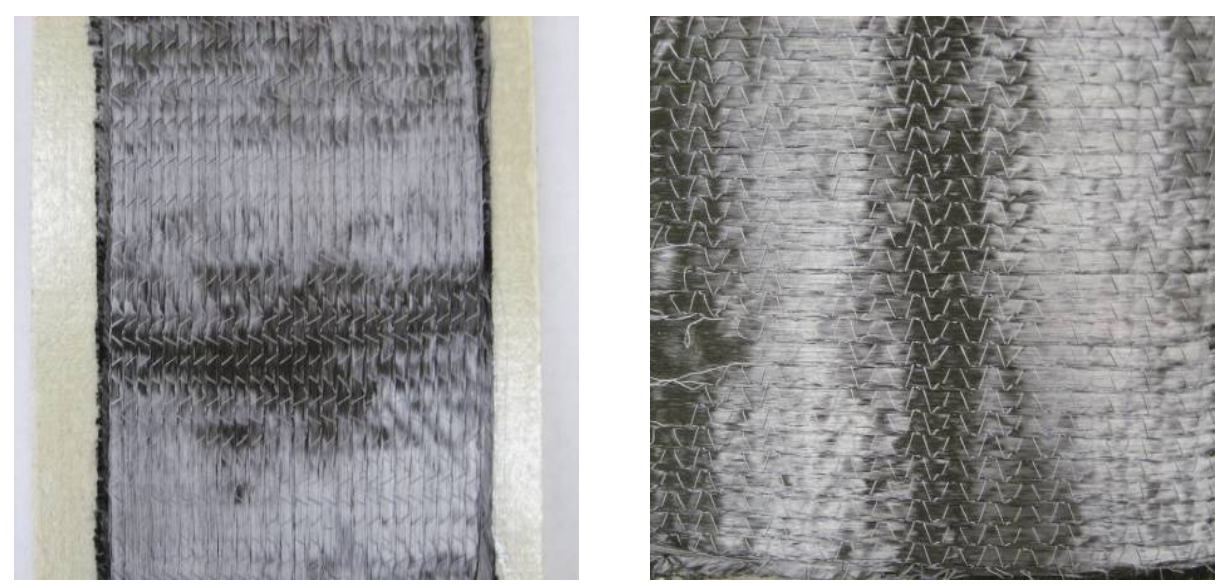

Figure 3.1 Quad-axial Toray T700SC/12K/FOE carbon fabric

Table 3.2 gives detail description about T700SC/12K/FOE, as supplied by manufacturer. For entire set of samples (coupon and panel level) six layers of identical carbon fabric was used. Different types of fiber orientation were used in order to study the effect of share of fiber in given direction. This was categorized into symmetric and non-symmetric orientation for the convenience. Table 3.4 below shows the fabric arrangement for each layer in six layers for two different arrangements. Fiber orientation for each fabric layer and its share is shown below in Table 3.3 and Figure 3.2. 
Table 3.2 Data sheet for carbon fiber composite (Toray Carbon Fibers America, Inc.)

\begin{tabular}{|c|c|}
\hline \multicolumn{2}{|c|}{ Typical Fiber Properties } \\
\hline Tensile strength $k s i$ & 711 \\
\hline Tensile Modulus $M s i$ & 33.4 \\
\hline Strain & $2.1 \%$ \\
\hline Density $l b s / i n 3$ & 0.065 \\
\hline Filament Diameter in. & $2.8 \times 10^{-04}$ \\
\hline \multicolumn{2}{|l|}{ Yield $f t / l b s$} \\
\hline $6 \mathrm{~K}$ & 3.724 \\
\hline $12 \mathrm{~K}$ & 1.862 \\
\hline $24 \mathrm{~K}$ & 903 \\
\hline \multicolumn{2}{|l|}{ Sizing type and amount } \\
\hline $50 \mathrm{C}$ & $1.0 \%$ \\
\hline $60 \mathrm{E}$ & $0.3 \%$ \\
\hline FOE & $0.7 \%$ \\
\hline Twist & Never twisted \\
\hline Specific heat $\mathrm{Cal} / \mathrm{g} .{ }^{0} \mathrm{C}$ & 0.18 \\
\hline Thermal Conductivity $\mathrm{cal} / \mathrm{cm} . \mathrm{s} .{ }^{0} \mathrm{C}$ & 0.0224 \\
\hline Electric resistivity $\Omega . \mathrm{cm}$ & $1.6 \times 10^{-3}$ \\
\hline \multicolumn{2}{|l|}{ Chemical Composition } \\
\hline Carbon & $93 \%$ \\
\hline $\mathrm{Na}+\mathrm{K}$ & $<50 \mathrm{ppm}$ \\
\hline \multicolumn{2}{|c|}{ (Toray 250F Epoxy Resin, Normalized to $60 \%$ fiber volume) } \\
\hline Tensile Strength $k s i$ & 370 \\
\hline Tensile Modulus $M s i$ & 20.0 \\
\hline Tensile Strain & 1.7 \\
\hline Compressive Strength ksi & 215 \\
\hline Flexural Strength $k s i$ & 245 \\
\hline Flexural modulus $M s i$ & 17.5 \\
\hline ILSS ksi & 13 \\
\hline $90^{0}$ Tensile Strength $k s i$ & 10.0 \\
\hline
\end{tabular}

Table 3.3 Fiber orientation and share in each direction (Toray Carbon Fibers America, Inc.)

\begin{tabular}{|c|c|c|}
\hline Fiber & Orientation & Share \\
\hline $0^{0}$ & $36 \mathrm{oz}$ & $21.45 \%$ \\
\hline$-45^{0}$ & $48 \mathrm{oz}$ & $28.6 \%$ \\
\hline $90^{0}$ & $36 \mathrm{oz}$ & $21.4 \%$ \\
\hline $45^{0}$ & $48 \mathrm{oz}$ & $28.6 \%$ \\
\hline Total & \multicolumn{2}{|c|}{$\mathbf{1 6 8} \mathrm{oz} / \mathbf{y d}^{2}$} \\
\hline
\end{tabular}




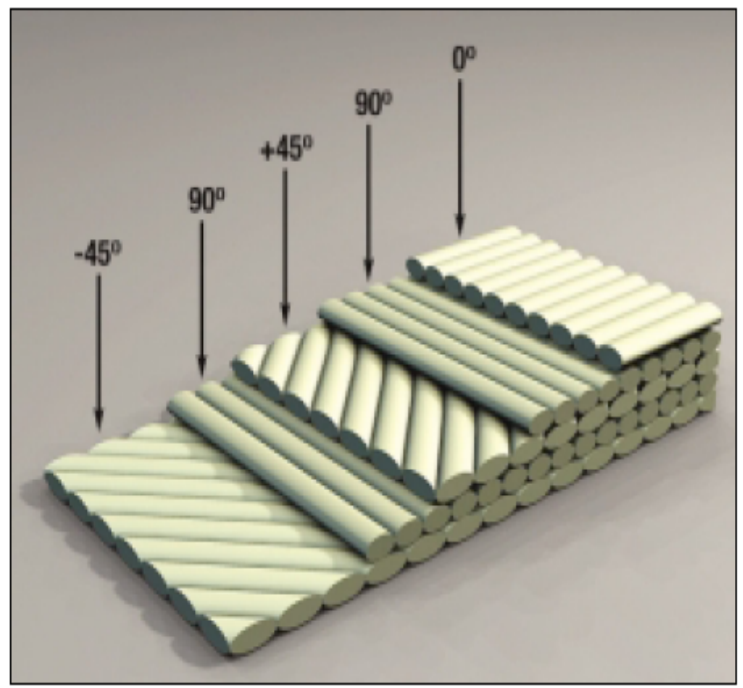

Figure 3.2 Generalized orientations of multiaxial fibers

Table 3.4 Fiber lay up for symmetric and non-symmetric architecture

\begin{tabular}{|c|c|c|}
\hline \multicolumn{3}{|c|}{ SYMMETRIC } \\
\hline Layers & Orientation & OZ/SQ YD \\
\hline \multirow{4}{*}{1} & $0^{0}$ & 6 \\
\hline & $-45^{0}$ & 8 \\
\hline & $90^{0}$ & 6 \\
\hline & $+45^{0}$ & 8 \\
\hline \multirow{4}{*}{2} & $+45^{0}$ & 8 \\
\hline & $90^{0}$ & 6 \\
\hline & $-45^{0}$ & 8 \\
\hline & $0^{0}$ & 6 \\
\hline \multirow{4}{*}{3} & $0^{0}$ & 6 \\
\hline & $-45^{0}$ & 8 \\
\hline & $90^{\circ}$ & 6 \\
\hline & $+45^{0}$ & 8 \\
\hline \multirow{4}{*}{4} & $+45^{0}$ & 8 \\
\hline & $90^{0}$ & 6 \\
\hline & $-45^{0}$ & 8 \\
\hline & $0^{0}$ & 6 \\
\hline \multirow{4}{*}{5} & $0^{0}$ & 6 \\
\hline & $-45^{0}$ & 8 \\
\hline & $90^{0}$ & 6 \\
\hline & $+45^{0}$ & 8 \\
\hline \multirow{4}{*}{6} & $+45^{0}$ & 8 \\
\hline & $90^{0}$ & 6 \\
\hline & $-45^{0}$ & 8 \\
\hline & $0^{0}$ & 6 \\
\hline
\end{tabular}

\begin{tabular}{|c|c|c|}
\hline \multicolumn{3}{|c|}{ NON-SYMMETRIC } \\
\hline Layers & Orientation & OZ/SQ YD \\
\hline \multirow{4}{*}{1} & $0^{0}$ & 6 \\
\hline & $-45^{0}$ & 8 \\
\hline & $90^{0}$ & 6 \\
\hline & $+45^{0}$ & 8 \\
\hline \multirow{4}{*}{2} & $0^{0}$ & 6 \\
\hline & $-45^{0}$ & 8 \\
\hline & $90^{0}$ & 6 \\
\hline & $+45^{0}$ & 8 \\
\hline \multirow{4}{*}{3} & $0^{0}$ & 6 \\
\hline & $-45^{0}$ & 8 \\
\hline & $90^{0}$ & 6 \\
\hline & $+45^{0}$ & 8 \\
\hline \multirow{4}{*}{4} & $0^{0}$ & 6 \\
\hline & $-45^{0}$ & 8 \\
\hline & $90^{0}$ & 6 \\
\hline & $+45^{0}$ & 8 \\
\hline \multirow{4}{*}{5} & $0^{0}$ & 6 \\
\hline & $-45^{0}$ & 8 \\
\hline & $90^{0}$ & 6 \\
\hline & $+45^{0}$ & 8 \\
\hline \multirow{4}{*}{6} & $+45^{0}$ & 8 \\
\hline & $90^{0}$ & 6 \\
\hline & $-45^{0}$ & 8 \\
\hline & $0^{0}$ & 6 \\
\hline
\end{tabular}




\subsubsection{Stitched Fabric}

In order to improve the stiffness in depth direction, layers of carbon fabric were stitched in one direction and two directions as shown below in Figure 3.3.

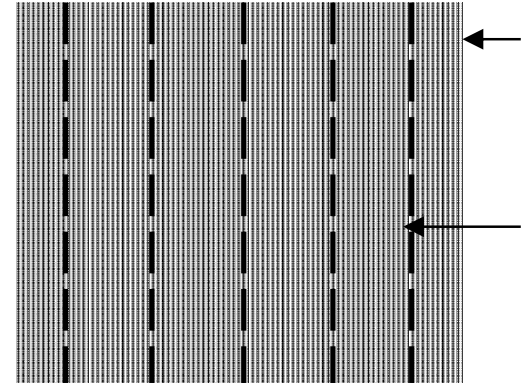

One-way stitched

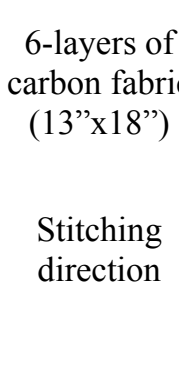

(13"x

$(13 ” x 18 ”)$

Stitching

Figure 3.3 Direction of stitch for fabric stitching

Multiaxial carbon fiber helps to provide good strength in the longitudinal and transverse direction. Some reinforcement in depth by stitched material could help in achieving better properties in the depth axis. The composite laminates were prepared by compression molding and were cut into coupon sample dimensions. These samples were tested for mechanical properties under bending test and tension test. For stitching purpose, two stitching machines used are shown below in Figure 3.4.
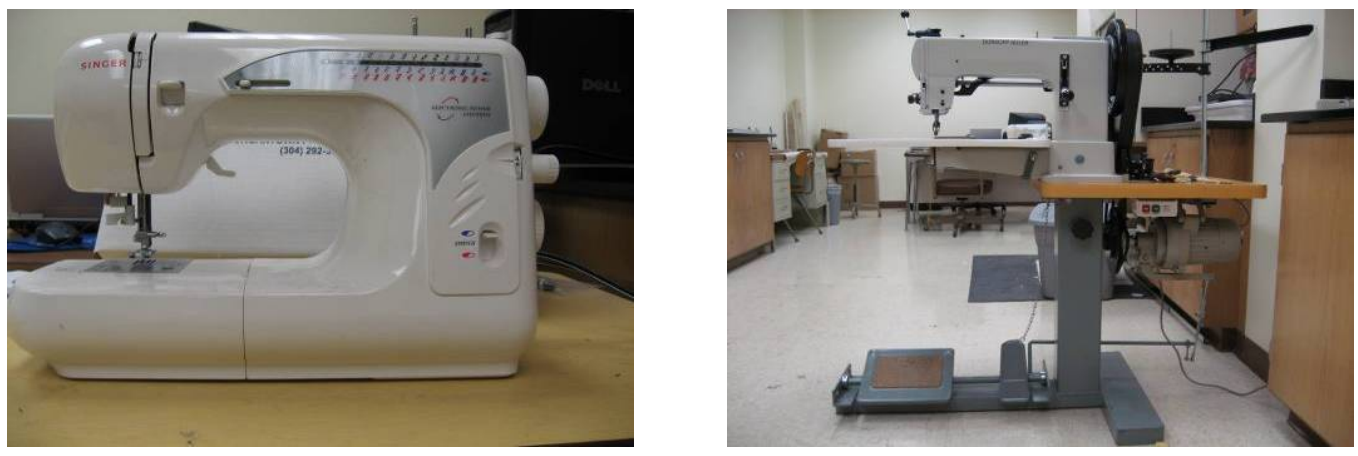

Figure 3.4 Stitching Machines

\subsection{Manufacturing Method}

Three different manufacturing methods were used for production of CFRP composites namely Pultrusion process, Hand lay-up in conjunction with Compression Molding and Resin Infusion. Pultrusion process was used for production of sandwich panels. Sandwich panels were tested under bending as a whole and composite laminates were cut from face sheets and tested under bending and tension. Compression Molding and Resin Infusion 
sample were used to fabricate coupon laminates of CFRP composites. These manufacturing methods are discussed below in details

\subsubsection{Pultrusion Process}

The 'pultrusion' process has been deployed for use with glass fiber and is specially related to the production of beams, sandwich panels, tubes and channel section. Basically, it consists of drawing carbon/glass-fibers through a resin bath, followed by passage through a bush of the required shape to remove the excess resin and any entrapped air. The pulled material is then passed continuously through an oven to harden the resin. In the extrusion process, material is typically pushed through a forming die. In the Pultrusion process, material is physically pulled through the die.

The pultrusion process as a whole is simple in theory, but yet somewhat complex in the actual process. In case of sandwich panel, balsa wood which is a core material was fed just before the resin bath between layers of fabric. As the glass passes through the wet out bath and through the injection manifolds, it is completely saturated with a thermoset resin that includes the fillers, catalyst, pigments, etc. As the glass enters the back of the die, it is under extreme pressure, forcing out any air and excess resin from the reinforcement as shown in Figure 3.5. Once inside the controlled heated die, the part passes through various stages of heat, which initiates several catalyst systems to react within the laminate allowing the layers of reinforcements to be mechanically fixed to each other resulting in a solidified laminate exiting the die. Upon exit of the die, the profile continues its journey towards the puller. The temperature at the entrance of the die was about $320^{\circ}-350^{\circ} \mathrm{F}$ and at the exit it was maintained at about $220^{\circ}-250^{\circ} \mathrm{F}$. The puller is typically made up of a caterpillar design that sandwiches the profile between a series of pads that is connected to a drive mechanism that keeps the laminate moving. Therefore resulting in what is also referred to as Continuous Laminating Process. Upon exiting the puller, the laminate passes through the final stage of a cut off saw where it is cut to its final length. The schematic of pultrusion process is shown below in Figure 3.5. For this study, pultrusion was carried out by Bedford Reinforced Plastics Inc. facility at Bedford, PA. Two runs of 
sandwich panels were successfully carried out. For both production run, vinyl ester resin system was used. These production runs are described in Table 3.5.
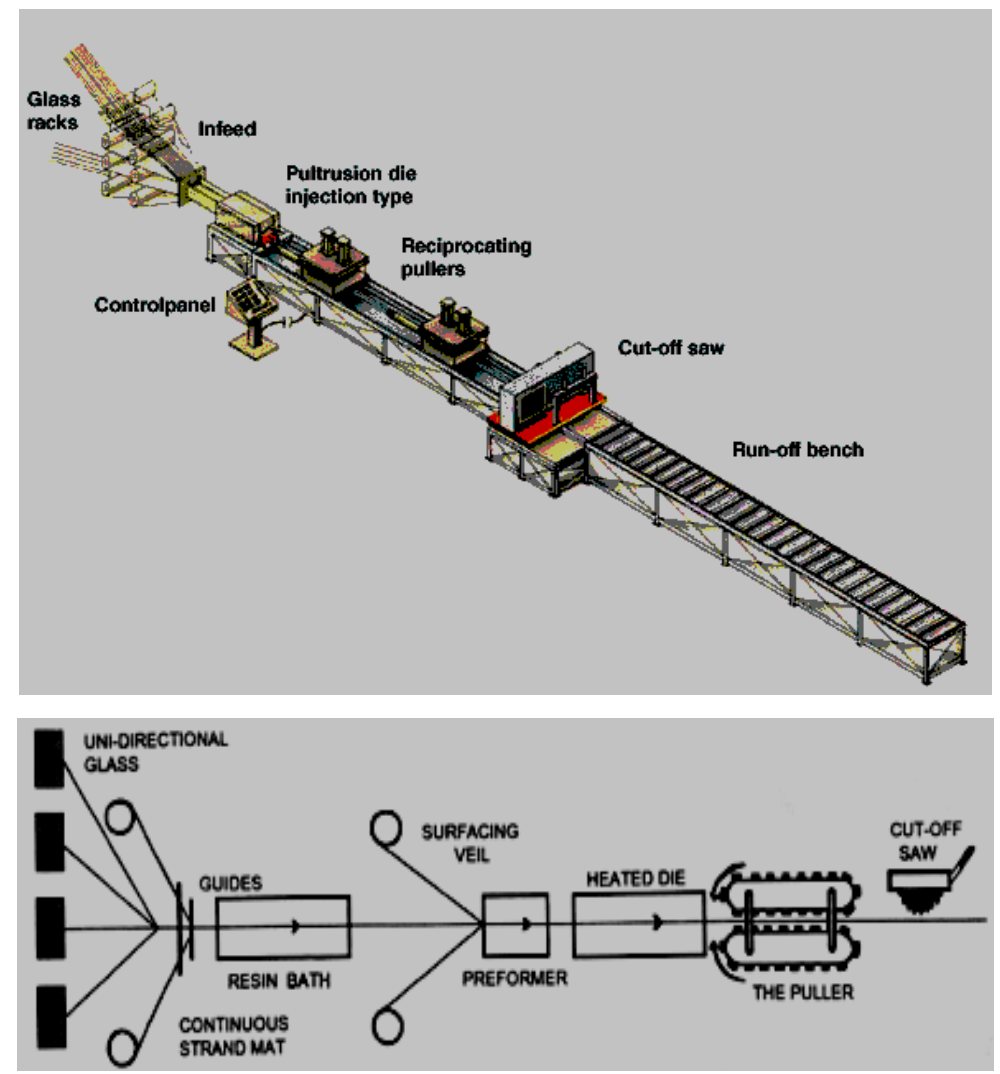

Figure 3.5 Manufacturing line for typical pultrusion process

\subsubsection{Sandwich Panels}

Sandwich panels produced by this process were tested by standard four point bending tests. Face sheets of these panels were cut from sandwich panels and were further tested by bending and tension test in longitudinal as well as transverse direction.

Table 3.5 Details of production runs for CFRP sandwich panels

\begin{tabular}{|l|c|c|c|c|c|c|c|}
\hline & $\begin{array}{c}\text { Sandwich } \\
\text { Panel } \\
\text { Dimension }\end{array}$ & $\begin{array}{c}\text { Fabric } \\
\text { Orientati } \\
\text { on }\end{array}$ & Resin & $\begin{array}{c}\text { No. of } \\
\text { panels } \\
\text { produced }\end{array}$ & $\begin{array}{c}\text { Curing } \\
\text { Temp. }\end{array}$ & $\begin{array}{c}\text { Pulling } \\
\text { Rate }\end{array}$ & CSM \\
\hline Run 1 & 12 "x80"x3.5" & $\begin{array}{c}\text { Non- } \\
\text { symmetric }\end{array}$ & VE & 8 & $180 \mathrm{~F}$ & $\begin{array}{c}2 "-24 " \\
\text { per min. }\end{array}$ & $\times$ \\
\hline Run 2 & $40 " x 100 " x 3.5 "$ & Symmetric & VE & 6 & $180 \mathrm{~F}$ & $\begin{array}{c}2 \text { "-24" } \\
\text { per min. }\end{array}$ & $\checkmark$ \\
\hline
\end{tabular}




\subsubsection{Core Material Balsa Wood}

A core material produced from certified kiln-dried balsa wood in the 'end-grain' configuration was used. The properties of balsa make it ideal as a core for sandwich construction. It has extremely high strength and stiffness to weight ratios, and achieves an excellent bond with all types of resins and adhesives. It is compatible with a variety of manufacturing processes and is resistant to temperature changes, or exposure to fire, or chemicals such as styrene. It is an ideal core material for an extensive range of applications. Typical properties for the balsa wood used in this study are listed in Table 3.6.

Table 3.6 Data sheet for balsa wood (Baltek Corporation)

\begin{tabular}{|l|c|}
\hline \multicolumn{2}{|c|}{ Typical End Grain Balsa Properties } \\
\hline Nominal Density $l b / f t^{3}$ & 9.4 \\
\hline $\begin{array}{l}\text { Compressive Strength } p s i \\
\text { (perpendicular to plane) }\end{array}$ & 1837 \\
\hline Compressive Modulus $p s i$ & 568661 \\
\hline Tensile Strength $p s i$ & 1886 \\
\hline Tensile Modulus $p s i$ & 510176 \\
\hline Ultimate Shear Strength $p s i$ & 427 \\
\hline Shear Modulus $p s i$ & 22829 \\
\hline Thermal Conductivity (BTU.in.) $/\left(f t^{2} . h r .{ }^{0} F\right)$ & 0.453 \\
\hline Maximum Operating Temperature ${ }^{0} F$ & 325 \\
\hline
\end{tabular}

\subsubsection{Compression Molding}

Compression molding primarily uses thermoplastic composite resin systems, which uses heat to form and permanently set the shape of a part. Once the resin is cured, the part cannot be reformed, making the process irreversible. The two halves of the mold, which are mounted in a hydraulic molding ram, are closed after the charge. The combination of heat and pressure caused the thermoset material to cure in the mold. Molding cycles will range from well under 1 minute to over 40 minutes, depending on the size and cross sectional thickness of the part. The mold is then opened, and the part is removed. CFRP laminates of dimensions 12 " $\mathrm{x} 18$ " $\mathrm{x} 0.2$ " were prepared by compression molding for this study.

All the specimens prepared by this method consisted 6 layers of carbon fibers (Toray T700SC/12K/FOE). Such quad axially stitched fabric has specific density of $28 \mathrm{oz} / \mathrm{sq}$ yd. 
Fiber orientation and share in the given direction is specified in the earlier section. Carbon fabrics were cut into dimensions of 12"x18", decided by the dimensions of mold. A PHI molding equipment (Model SO-230H) with a maximum force limit of 50 tons and heating capacity upto $600^{\circ} \mathrm{F}$ was available at CFC-WVU as shown in Figure 3.6. The molding machine consists of two hot platens (top and bottom) that apply pressure to the mold placed in between. Surface temperature of pressure plates was set to desired condition by electric preheating.
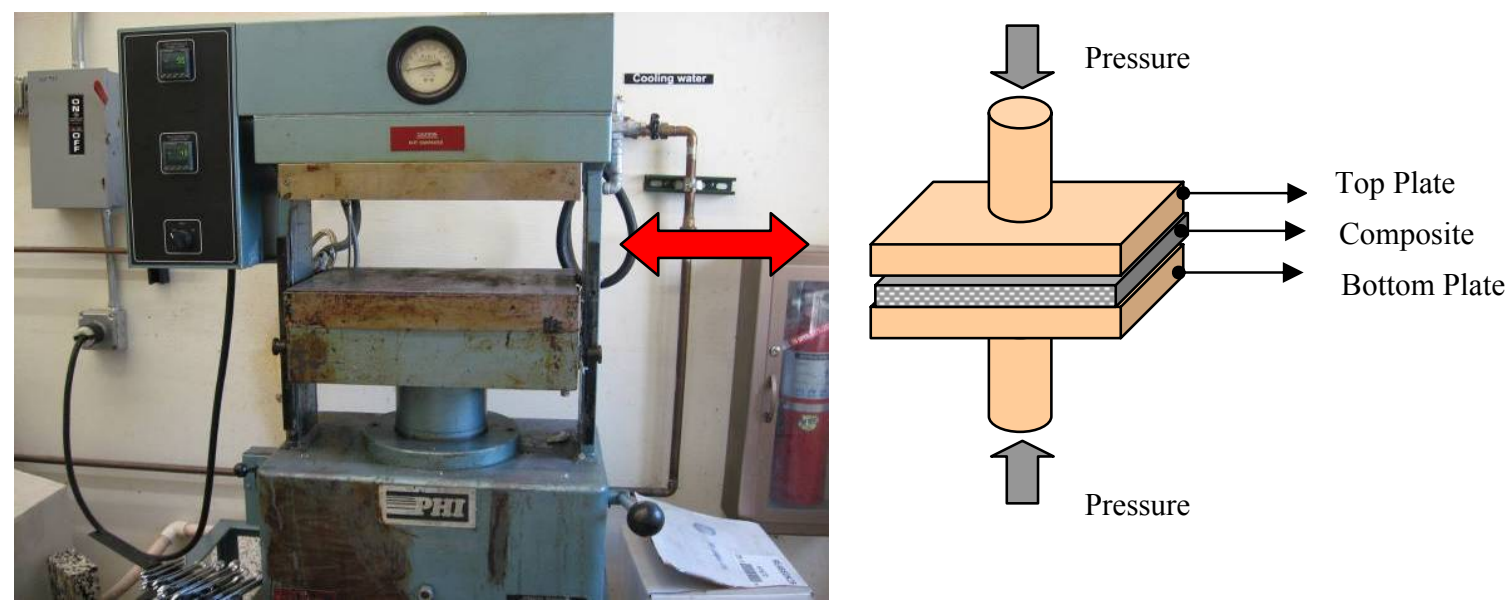

Figure 3.6 Experimental setup for compression molding

Step wise procedure for compression molding is given below.

Temperature Setting: Plate temperature was accurately set to desired temperature. For Epoxy resin, the curing temperature was $190 \mathrm{~F}$ and for VE it was at room temperature conditions as specified by the supplier.

Mold Preparation: All the heat transfer surfaces were wrapped with aluminum foil, in order to prevent the contact of resin. It was made sure that this surface wrapping did not make any interference in heat transfer. Additionally, the aluminum molding were also wrapped with the aluminum foil. These plates served the purpose of providing heat transfer and good surface finishing. Degreaser was then sprayed on the wrapped surfaces, facilitating the removal of sample.

Resin Preparation: Two types of resin were used for the lab scale composite manufacturing namely Epoxy and Vinyl Ester. Epoxy and Vinyl ester resin with the specification mentioned earlier, were mixed with their corresponding catalyst or converter, in appropriate proportion. Total weight of resin taken was approximately equal 
to weight of the six layers of fabric. After weighing the resin and catalyst/converter, they were thoroughly mixed for uniform mixture.

Resin Spreading: A well mixed resin was then uniformly spread over both side of each layer of carbon fabric, with the help of a brush. Thereafter, all the six layers were stacked together in accordance with the fiber orientation required for the sample. These resin rich layers were then kept in between two wrapped plates. This assembly was then transferred between heating surfaces of compression molding machine.

Pressure Molding: The desire pressure was applied during compression by manually operating hydraulic pressure jack. For all the composite samples here, pressure was maintained constant in the range of 10-15tons. Application of pressure agitates the reaction components and increase impregnation. It also helps the impregnation of the matrix through the reinforcement by compression. During the process of pressure application, resin squeezes out of the gaps. The proper wrapping along all the surfaces of equipment, helped in preventing any resin from sticking to the surface. The compression cycle were run under constant pressure and temperature, for about 35 to 45 min depending on cycle time.

Removal of Mold: Once the resin was properly cured, heating was switched off and heating plates were cooled by cold water circulation. After that, system was depressurized with the lever and sample was removed. Use of degreaser helped in removing part of aluminum foil glued to composite surface. All the surfaces of the machines were neatly cleaned by use of Acetone.

Sample Cutting: After fabricating the laminates using the compression molding machine, a dry or wet saw was used to cut the composite plate into sample dimensions specified by ASTM for mechanical characterization by bending test and tension test. For tensile test, testing specimen with dimensions 1 'W $\mathrm{W} 18$ "L $\mathrm{x} 1 / 4$ ”T were prepared. Testing specimens were bonded with FRP end tabs of length 4" as per ASTM D3039.

\subsubsection{Resin Infusion}

In this method, vacuum is applied to saturate or infuse a dry lay-up of fibers with resin. Resin infusion is a specialized advanced laminating technique that greatly improves the quality and strength of fiberglass parts versus conventional hand lay up. Applying 
laminate engineering and resin infusion technology simultaneously allows for optimization of a composite part in terms of strength and weight. Next in the infusion process the outer skin of fiber reinforcement fabrics are carefully fitted into the mold over top of the skin coat. Next, in the case of a cored part, the structural core materials are cut and fitted, and adhered into place. Then the inner skin of reinforcement fabrics is carefully fitted over the core to form a sandwich. Next the resin distribution hoses and vacuum lines are laid out atop the fiberglass and the entire inside of the mold is covered with a large sheet of loosely fitting plastic sheeting and sealed onto the mold's perimeter. With a vacuum pump all the air in this "vacuum bag" is evacuated which compresses or de-bulks the dry stack of reinforcement fabrics. Through the series of feed hoses sealed into the bag, catalyzed resin is then sucked via the vacuum from large mixing containers. The vacuum is kept on until the resin has cured several hours later. The vacuum bag and feed hoses are removed, and the part's lamination is complete. This process can leave air voids within the bond layer and in the many "contour slits" in the core. With resin infusion numerous benefits and significant strength gains are intrinsic due to the method of consolidating the materials within a vacuum all at once. The tremendous clamping pressure of the vacuum (approximately 1 ton / sq.ft.) helps fuse the materials together with any air voids being replaced by resin. Due to the reliability of high quality results with this process, and the elimination of potential errors by the skill of the laminator, the engineer can afford to specify less material in the structure. This along with the vacuums compressing the fiberglass reducing the amount of resin absorption, results in a weight saving of over $30 \%$ over traditional cored fiberglass laminate while improving its strength.

\subsection{Summary}

In summary, Table 3.7 below summarizes the test specimens prepared with different fiber orientation, resin system, and types of testing carried out for three different manufacturing approaches. In addition to mechanical testing, composite specimens were also tested for their physical and morphological properties. 
Table 3.7 Summary of different configuration of fiber orientation, resin system and manufacturing methods used for CFRP fabrication

\begin{tabular}{|c|c|c|c|c|c|c|c|c|c|c|c|}
\hline \multirow{3}{*}{$\begin{array}{c}\text { Manufacturing } \\
\text { Method }\end{array}$} & \multicolumn{2}{|c|}{$\begin{array}{c}\text { Sample } \\
\text { Size }\end{array}$} & \multicolumn{4}{|c|}{$\begin{array}{c}\text { Fiber } \\
\text { Configuration }\end{array}$} & \multicolumn{2}{|c|}{ Resin } & \multicolumn{3}{|c|}{$\begin{array}{c}\text { Mechanical } \\
\text { Testing }\end{array}$} \\
\hline & \multirow[b]{2}{*}{ 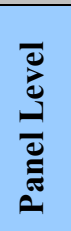 } & \multirow[b]{2}{*}{ ن̃ } & \multirow[b]{2}{*}{ 裳 } & \multirow[b]{2}{*}{ 莺 } & \multicolumn{2}{|c|}{ Stitched } & \multirow[b]{2}{*}{ 产 } & \multirow[b]{2}{*}{$\frac{51}{>}$} & \multirow[b]{2}{*}{ 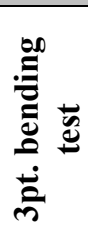 } & \multirow[b]{2}{*}{ 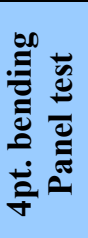 } & \multirow[b]{2}{*}{ 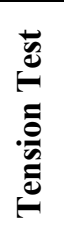 } \\
\hline & & & & & $\begin{array}{c}\overrightarrow{2} \\
i \\
i\end{array}$ & i & & & & & \\
\hline Pultrusion & $\checkmark$ & $\checkmark$ & $\checkmark$ & $\checkmark$ & $x$ & $x$ & $x$ & $\checkmark$ & $\checkmark$ & $\checkmark$ & $\checkmark$ \\
\hline $\mathrm{CM}$ & $x$ & $\checkmark$ & $\checkmark$ & $\checkmark$ & $\checkmark$ & $\checkmark$ & $\checkmark$ & $\checkmark$ & $\checkmark$ & $x$ & $\checkmark$ \\
\hline Resin Infusion & $x$ & $\checkmark$ & $\checkmark$ & $x$ & $x$ & $x$ & $\checkmark$ & $\checkmark$ & $\checkmark$ & $x$ & $\checkmark$ \\
\hline
\end{tabular}




\section{EXPERIMENTATION}

This chapter gives a brief introduction on different types of experimentation used for mechanical property and physical characterization of the composite samples. The mechanical testing mainly includes tension and bending tests. Tension test was performed on coupon level samples, whereas bending test was used for both coupon level and sandwich panels. Further, experimental set up, testing equipments used and procedure for data analysis are briefly discussed. Additionally, physical property characterization such as fiber content and void content was tested.

\subsection{Testing Equipments}

This section deals with different equipments used for mechanical testing of composites. Important parts of these equipments and their working principles are discussed. The major equipments used for testing include:

1. Baldwin Universal Testing Machine

2. Instron 8501 Machine

3. Data Acquisition System for recording strain, and load data.

\subsubsection{Baldwin Universal Testing Machine}

Baldwin Machine with a 200,000 lbs maximum load capacity as shown in Figure 4.1 is usually used to test for tension, compression, and bending or flexure strength. The load applied during experiments is measured by means of dial indicator which is connected to the pressure gage. The applied load rate was maintained manually nearly constant in all experiments. Different jigs and grips are available for tensile, compression, and bending tests. Two sets of shims were used on top and bottom, in order to hold the samples properly. However, same shim sizes on each side should be placed in order to align grips in the center. For this study, Baldwin machine was used only for tension testing. Strain gages were mounted on specimens tested for tension in longitudinal direction. Data acquisition system is used to record load versus strain data. Data were analyzed for 
determining tensile modulus of the samples. Sample dimensions for the tension test were $18 " x 1 " x 0.25 "$.
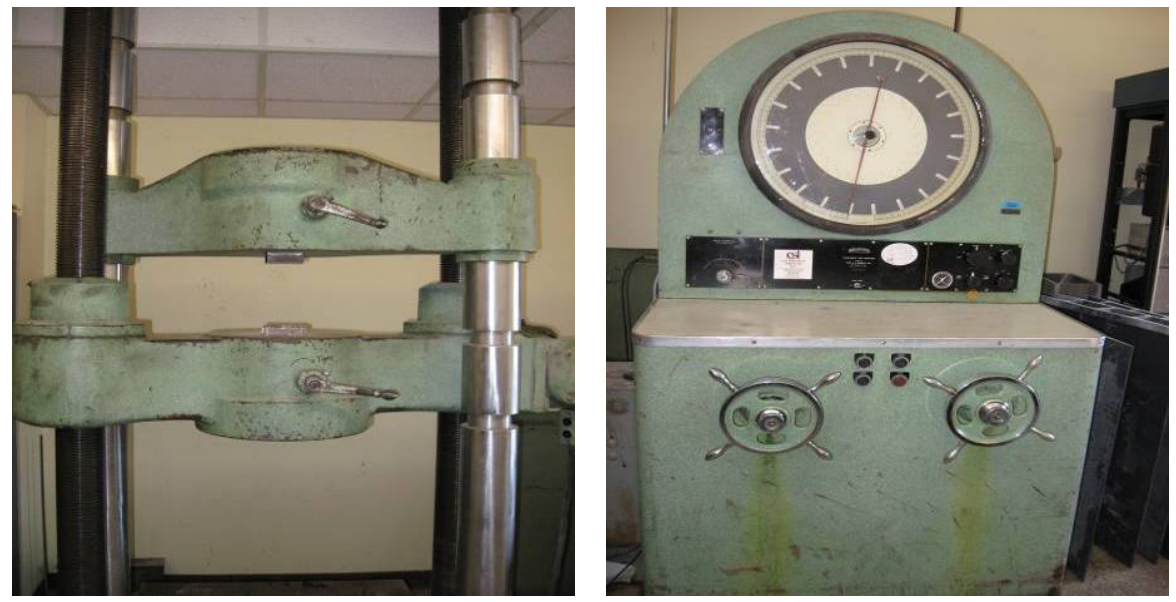

Figure 4.1 Baldwin Universal Testing Machine

\subsubsection{Instron Model 8501 Servo-Hydraulic Material Testing System}

Instron-8501 has a maximum load capacity of $100-\mathrm{kN}$ (22 kip) and is used to conduct broad range of testing such as compression, tension, bending, shear, and fatigue. The applied load rate is uniformly maintained by electronic control panel. Typical equipment setup is shown in Figure 4.2. Some of the important components of Instron System are listed below.

- Strength-Testing Machine

- Hydraulic System

- Control Tower

- Control Console

- Computer and Dedicated Data Recording Unit

This equipment was used to carry out bending tests on coupon sample. For all bending test samples, dimensions were approximately kept constant. The samples used were of the average dimensions 5 " $(\mathrm{L}) \mathrm{x} 0.5$ "(W)x 0.25 "(t). During bending test, position control mode is used by controlling the travel of hydraulic piston. Load and deformation data were collected.

The unit consists of a two-column load frame with a movable crosshead. Auxiliary hydraulic lift cylinders regulate the position of the crosshead. Hydraulic column clamps 
fix the crosshead in the desired position. A load cell is mounted on the crosshead. The force applied to the specimen is sensed by in-built strain gage type load cell placed on the stationary top cross-head, wherein the analog signals from the load cell are amplified and converted into a digital signal. The machine is operated by the control module of the computer, where the readings are displayed and are transmitted to the data acquisition computer for data collection using WaveMaker ${ }^{\circledR}$ software. The displacement is determined from grip position. The data were evaluated for mechanical properties.

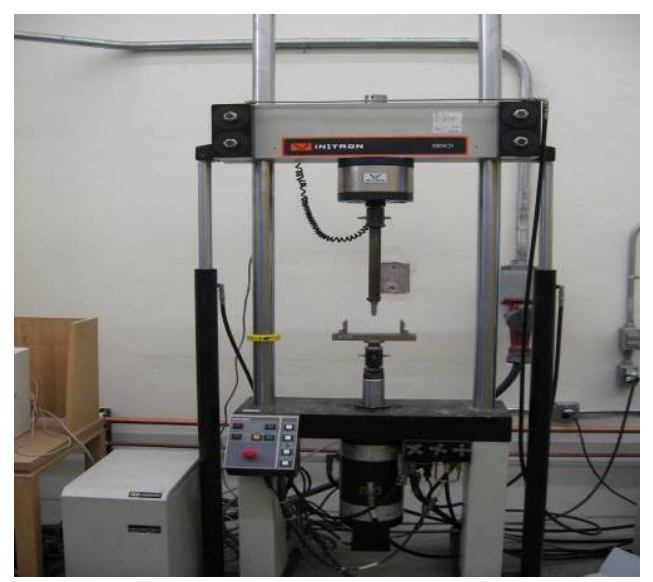

Figure 4.2 Instron Model 8501 Servo-hydraulic Material Testing System

\subsubsection{Data Acquisition Unit}

Data Acquisition Unit is an independent unit consisting of a computer system and a Model 5000 scanner (Vishay) as shown in Figure 4.3. It can be externally connected to any testing equipment for data recording. It collects and stores instantaneous data such as strain, load, deflection, etc. Strain gage and load cell lead wires were connected to the Model 5000 scanner, which was further connected to the computer unit. The loading was generated through testing machine with a programmable controller and the corresponding values for strains were recorded using the data acquisition system. For panel level testing manually operated hydraulic pump was used to generate loads. The recorded data was then reduced to MS Excel sheet and further data analysis was carried out. 


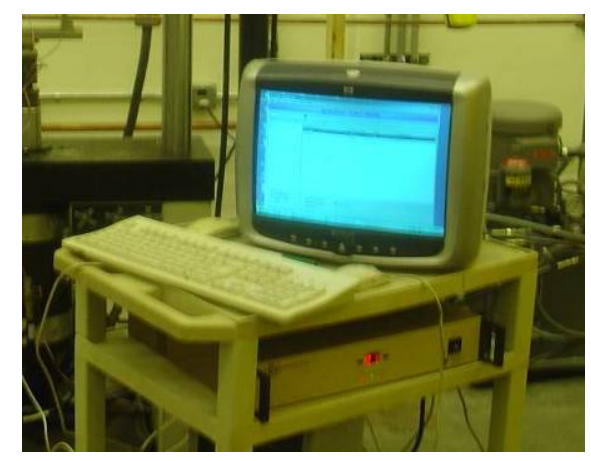

Figure 4.3 Data Acquisition Unit

\subsection{Testing Methodologies}

CFRP laminate coupon specimens were subjected to tension and bending loads, to determine the mechanical properties. A comprehensive summary of standard testing methodologies, results and data analysis for each of the above is listed below.

\subsubsection{Tension Test}

Axial tension tests were conducted on CFRP laminates manufactured by compression molding, pultrusion method and resin infusion. This test determines tensile strength and modulus. All the tests were carried out as per ASTM D3039 standard. The specimens subjected to tension test were of the size 18 "x1". Thickness of test specimen varied from 0.15 " to 0.30 ", depending on manufacturing method. Schematic diagram of tension test specimen is shown in Figure 4.4. Test specimens were bonded with composite tabs of 4" in length on both the ends. The tabs distribute gripping stresses and prevent specimen failure caused by grip jaws. Commercially available bonding adhesive called Pliogrip ${ }^{\mathrm{TM}}$ and Epoxy type adhesive were used for this purpose. A minimum of 24 hours curing time was allowed for the bonding agent to fully cure before testing the samples. Strain gages were mounted axially along the length of specimen. All the tension test specimens were tested with Baldwin Machine by maintaining loading rate nearly constant. Data of load versus strain were recorded. These data were then reduced for stress versus strain curve. The slope of linear portion of stress versus strain plot is referred to as modulus of elasticity, a measure of stiffness of a material. Results and comparison for different sets of sample are summarized in Chapter 5. 

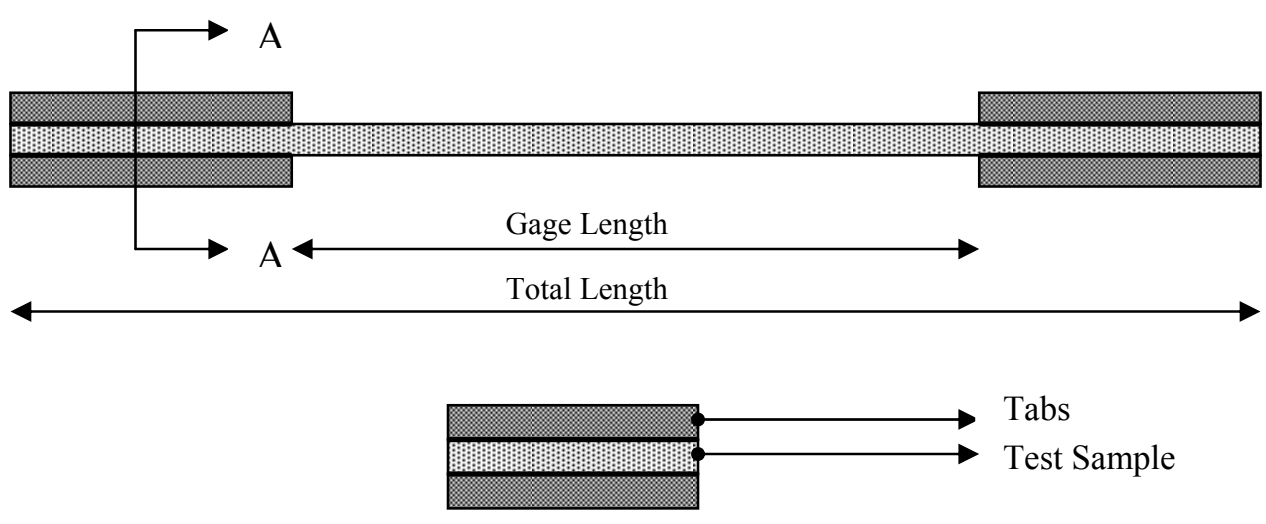

Cross Sectional View A-A

Figure 4.4 Schematic of tension test sample along with the cross sectional view AA

Coupon specimens with different fiber orientation (symmetric and non-symmetric), manufacturing method (compression molding, pultrusion etc.), resin matrix (epoxy and vinyl ester) were tested in longitudinal and transverse direction. Standard procedure listed by ASTM D3039, was followed for all the samples. All tension specimens were tested in Baldwin machine.
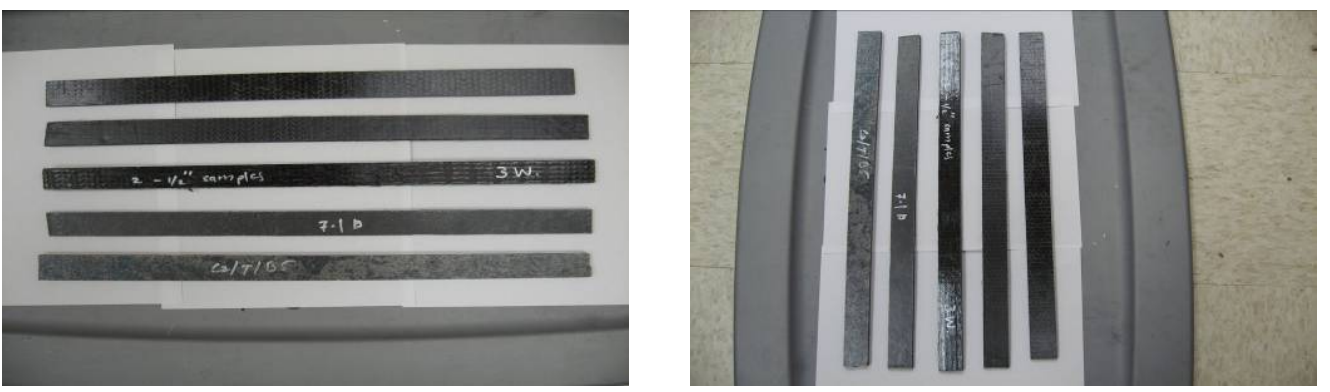

Figure 4.5 Tension test specimens

\subsubsection{Step wise Procedure for Tension Tests}

I. Width and thickness of test samples were measured at three different locations. Cross sectional area was calculated from average width and thickness.

II. The end surfaces of test samples were grinded to facilitate good bond between tabs and sample surface. Tabs of 4" length were bonded on end surfaces. A commercially available bonding agent, Pliogrip, was used for this purpose. End surface of the tab was made flat after grinding the excess glue stick on it, so that holding of test samples inside the jaws gets to be more uniform.

III. Next step of sample preparation includes mounting strain gages in axial direction at mid-span. 
IV. Tension specimens were centrally aligned between the jaws ensuring uniform force distribution. Strain gages were connected to data acquisition unit with connecting wires. Load cell of Baldwin machine was connected to the input port of data acquisition unit. During the test, loading rate was manually maintained constant. All the samples were tested till failure.

V. Data were recorded for load versus strain variation during the test. Experimental values of tensile strength and stiffness were calculated.

Data analysis and results are discussed in detail in Chapter 5. Typical plot of stress vs. strain for pultruded sample under tension test is shown in Figure 4.6.

\subsubsection{Tension Test Calculations}

Tensile strength

$$
\sigma_{u l t}=\frac{P_{u l t}}{w t}
$$

Tensile modulus

$$
E_{s s}=\frac{\sigma}{\varepsilon}
$$

where,

P - Applied load on the specimen (lbs)

w - Average width of specimen (in)

$\mathrm{t}$ - Thickness of specimen (in)

$\mathrm{A}=\mathrm{W} \times \mathrm{T}=$ Cross-sectional area of the specimen $\left(\mathrm{in}^{2}\right)$

$E_{s s}-$ Calculated from slope of elastic zone of Stress Vs. Strain curve 


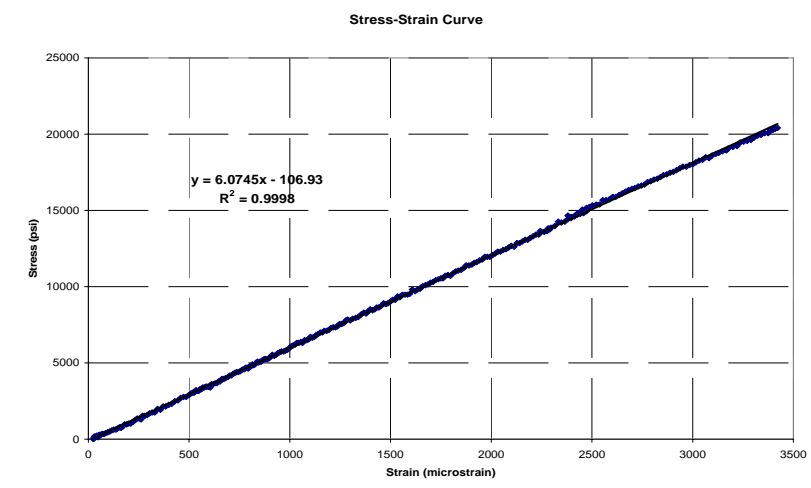

Figure 4.6 Typical plot of stress vs. strain for pultruded sample under tension test

\subsubsection{Bending Test}

This type of testing method is used to determine flexural properties of composite material under three point or four point bending. In this study, four point bending scheme was chosen for panel level testing whereas three point bending scheme was selected for coupon level testing.

\subsubsection{Four Point Bending Test}

In a four point bending test, a simply supported bar is loaded with a concentrated load $\mathrm{P} / 2$ at two positions of span where $\mathrm{P}$ is total applied load. It is also known as quarter point loading. A schematic representation of test, as per ASTM test standard D6272 (2005), and D790 (2005), is shown in Figure 4.7. This method of testing was used only for panel level testing.

Sandwich panels tested using this method were of the size 12"x80"x3.5", 40"x100"x3.5" and 12"x27"x3.5". All the panels were manufactured by pultrusion process with CFRP as a face sheet and balsa as a core material. Figure 4.8 shows the schematic set up available for testing. Panels were simply supported on steel rollers during test. Rollers were supported on concrete beams. Two concentrated loads were applied via a steel beam supported by steel rollers and bearing plates at a certain distance from supports. Load was measured by $100 \mathrm{kN}$ load cell attached on a hydraulic ram. Deflections were measure with LVDT at mid span. Strains were measured in both the longitudinal and transverse directions at mid span with electric strain gages attached on top and bottom surface of 
panels. The data from the tests were used to obtain the flexural modulus and flexural strength. All the panels were tested till failure.

\subsubsection{Step-wise Procedure for Bending Tests}

I. Width and thickness of test panel were measured at three different locations. Cross sectional area was calculated from average width and thickness.

II. Strain gages were mounted at mid-span for longitudinal and transverse strain.

III. Test panel was placed on the concrete support and was centrally aligned.

IV. Strain gages and load cell were connected to data acquisition system. Load was applied manually with hydraulic pump. Data for load versus strain and deflection were recorded.

This procedure was repeated for each panel. Typical test setup for three different panel dimensions is shown in Figure 4.8. Experimental values of stiffness, bending strength, and bending strain for each panel were calculated and tabulated
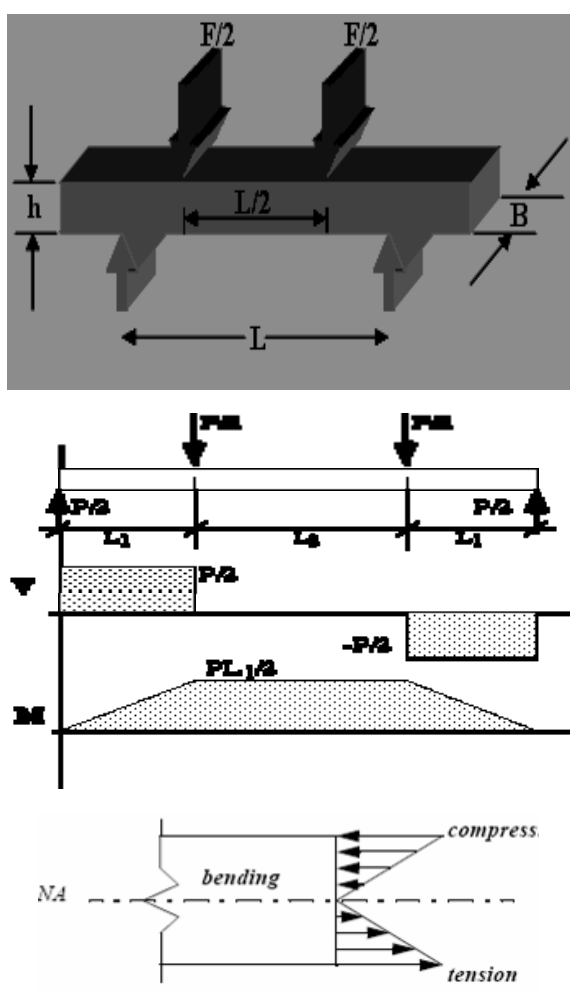

Figure 4.7 Schematic of $4 p t$. bending test set up with shear force, stress and moment distribution in the component 


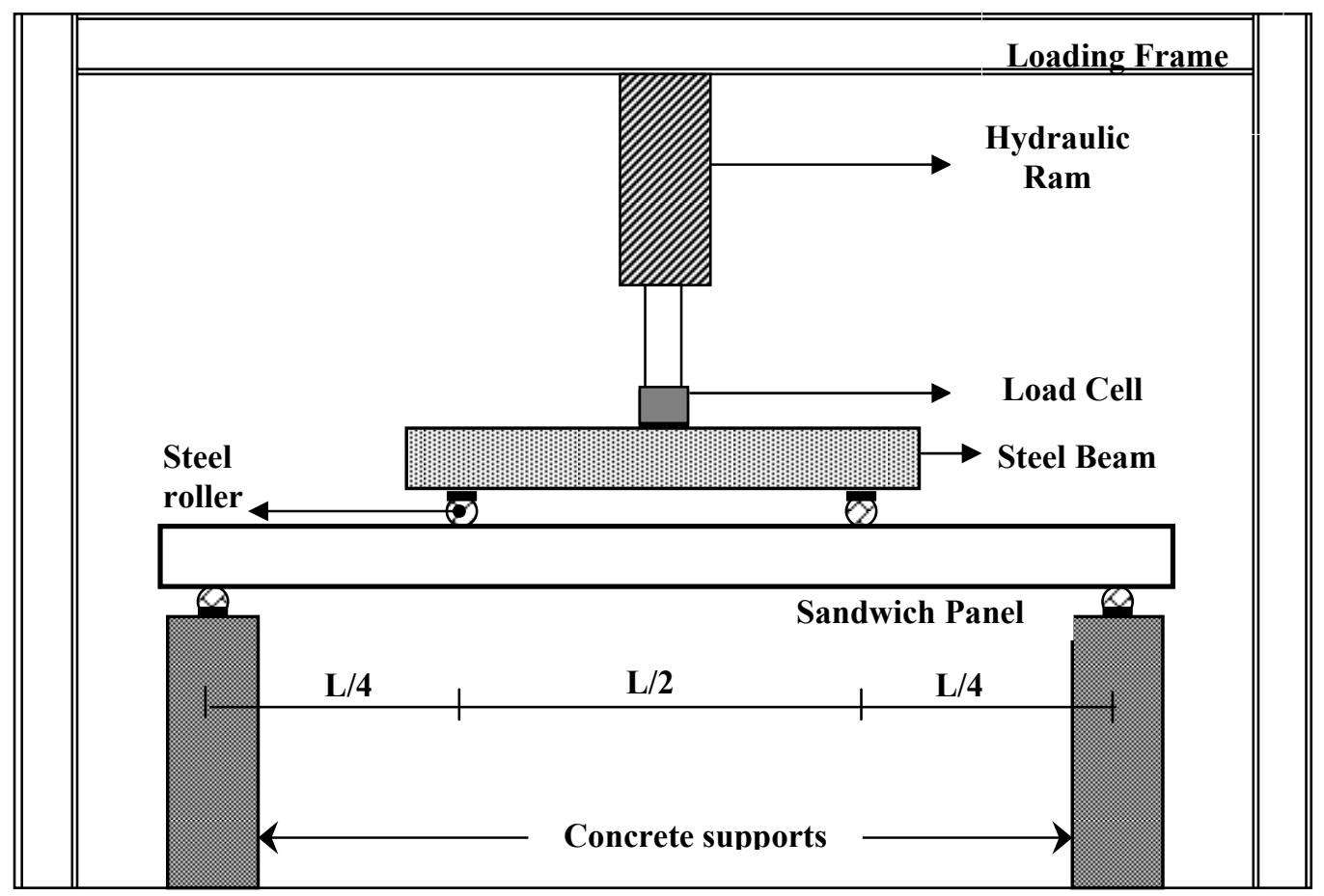

Figure 4.8 Typical Test set-up for four point bending test

Figure 4.9 shows the experimental set-up for three different panel dimensions subjected to four point bending. Typical stress-strain curve for composite sandwich panel is shown in Figure 4.10. The formula for computing flexural modulus as per ASTM Test D790 is based on the equation, which implicitly assumes that all deformation is contributed by bending, and any shear deflection is ignored.

Bending modulus (from stress-strain curve)

$$
E_{x}^{B}=\left(\frac{P}{\varepsilon}\right) \frac{L \times t}{16 I}
$$

The flexural strength

$$
\sigma_{u l t}=\frac{P \times L \times t}{16 I}
$$

Moment of Inertia

$$
\begin{aligned}
& I=\frac{w \times t_{f} \times h^{2}}{2} \\
& h=\frac{d+c}{2}=3.25
\end{aligned}
$$




\section{Other formulae for theoretical calculations}

\section{Maximum deflection}

$$
\Delta=\frac{P a}{24 E I}\left(3 l^{2}-4 a^{2}\right)
$$

Where,

$\mathrm{P}$ applied load

a length between load and support point

1 length of the span

E modulus of elasticity of face sheet

I moment of inertia of sandwich beam

\section{Maximum core shear stress}

$$
S S=\frac{P}{2 b h}
$$

where,

$\mathrm{P}$ is the maximum load (lbs)

w - width of specimen (in)

$\mathrm{t}$ - thickness of the specimen (in)

$\mathrm{t}_{\mathrm{f}}-$ face sheet thickness (in) 

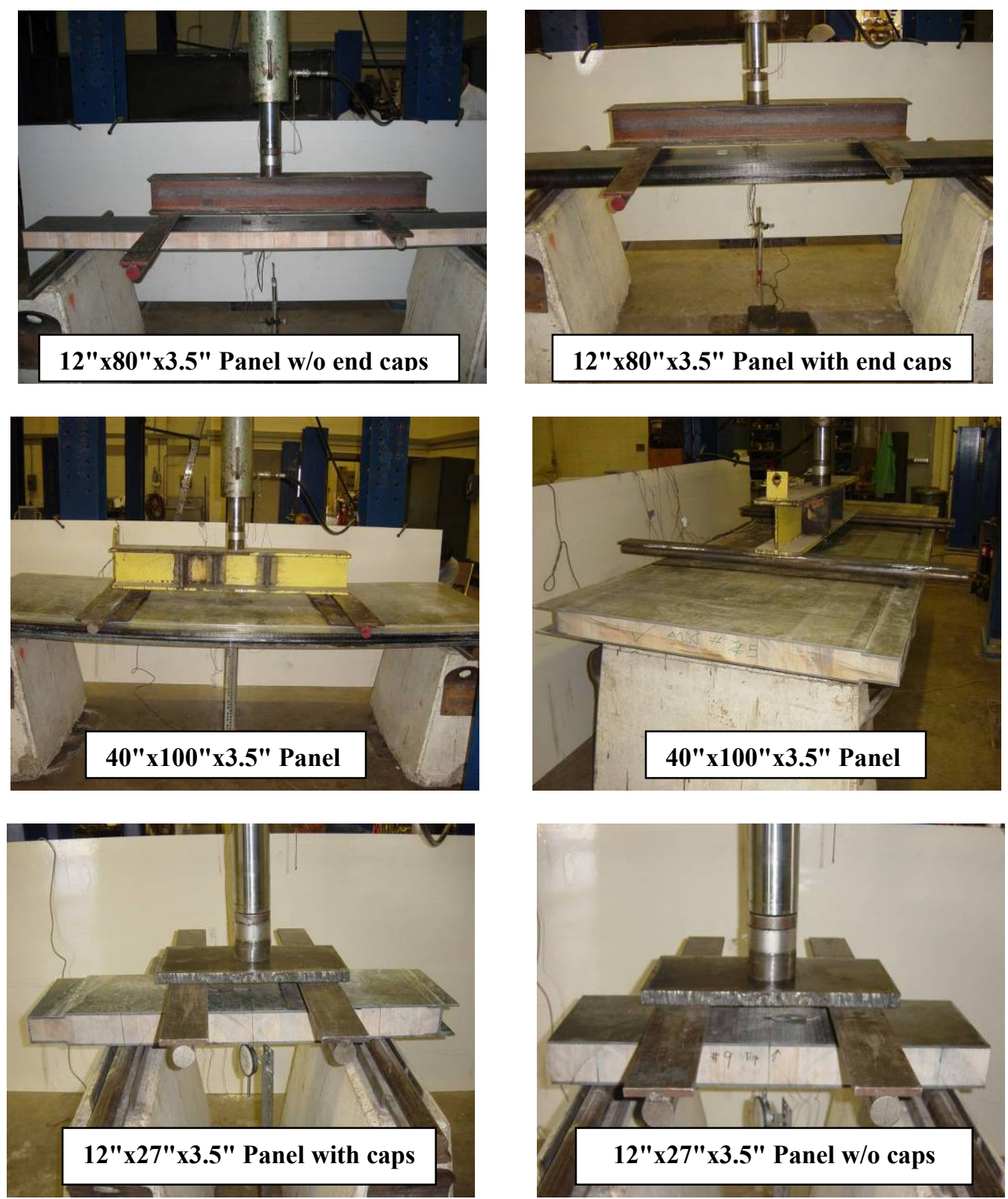

Figure 4.9 Three different sizes of sandwich panels tested by $4 \mathrm{pt}$ bending test 


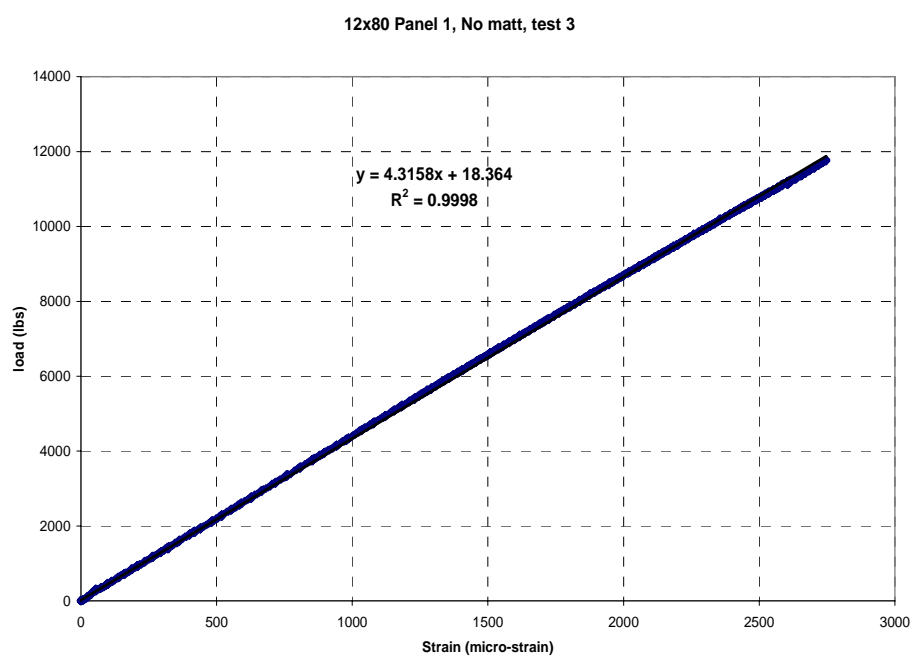

Figure 4.10 Typical load vs. strain curve for sandwich panel

\subsubsection{Three Point Bending Tests}

In case of three point bending, concentrated load $\mathrm{P}$ is applied at mid-span. A schematic representation of test set up is shown in Figure 4.11. This test method was used for coupon level specimens manufactured through compression molding, pultrusion and resin infusion process. Tests were carried on Instron-8501.
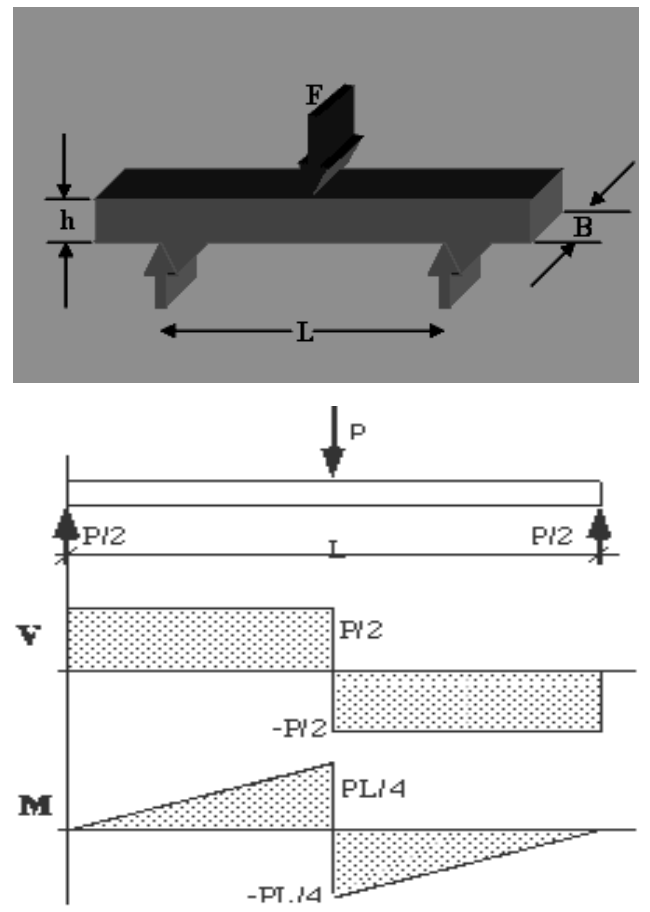

Figure 4.11 Schematic of three point bending (midspan type) test set up with shear force and moment distribution in the component 
All coupon specimens were tested under bending in both the transverse and longitudinal directions to determine their flexural properties. Tests were carried out as per ASTM D790 (2005) and ASTM D6272 (2005) specifications. An over hang of 1" on either side was provided to prevent the specimen from slipping through the supports. All tests were displacement controlled at an actuator rate of $0.1 \mathrm{in} / \mathrm{min}$ using a 22kip servo hydraulic test machine (Instron model 8501). The data from the tests were used to obtain the flexural modulus and strength.

\subsubsection{Step-wise Procedure for Bending Tests}

I. Width and thickness of sample were measured at three different locations.

II. The sample was placed on test fixtures and centrally aligned with 4" span.

III. The Instron machine was calibrated for zero load. The loading rate of $0.1 \mathrm{in} / \mathrm{min}$ was used for all the tests. Specimens were tested to failure.

IV. This procedure was repeated for each specimen. Experimental values of stiffness, bending strength, and bending strain for each specimen were calculated and tabulated. Specimen deflection was measured. A typical load-deflection curve for composite coupon specimens is shown in Figure 4.12.

The formula for computing flexural modulus as per ASTM D790 and D6272 is based on the equation, which implicitly assumes that all deformation is contributed by bending and any shear deflection is ignored. Figure 4.13 below shows typical test specimens tested by three point bending.

Bending modulus (from load-deflection curve)

$$
E_{x}^{B}=\left(\frac{P}{\delta}\right) \frac{L^{3}}{4 \times w \times t^{3}} \quad \mathrm{msi}
$$

The flexural strength

$$
\sigma_{u l t}=\frac{3 P L}{2 w t^{2}} \quad \text { psi }
$$

Where,

P - maximum load (lbs)

w - width of specimen (in) 
$\mathrm{t}$ - thickness of the specimen (in)

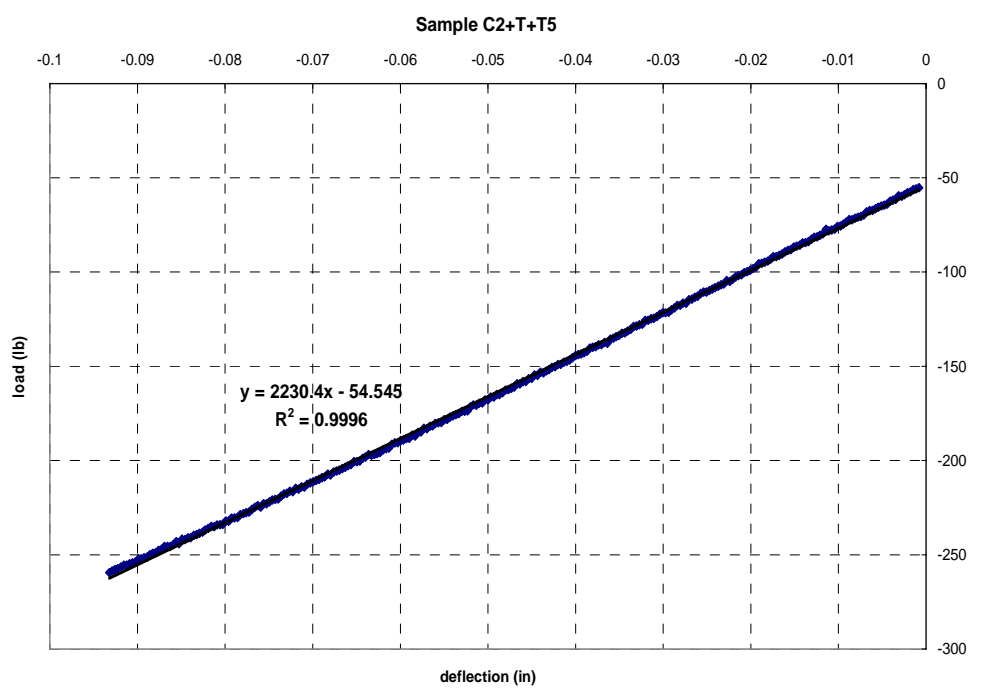

Figure 4.12 Typical plot of load vs. deflection for pultrusion sample
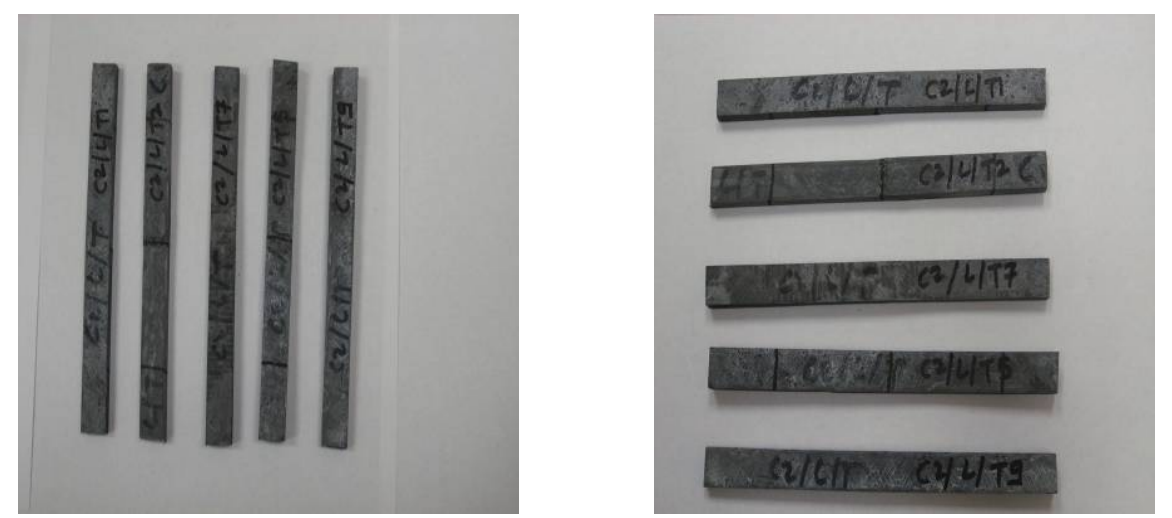

Figure 4.13 Typical bending test specimens

\subsubsection{Comparison between Three Point and Four Point Bending}

The four point bending test gives rise to a maximum bending that is constant in the region between the top two loading points. Results from the test are insensitive to translational misalignment of the sample resulting in small errors due to misalignment rupture. Especially, it provides pure bending between inner supports with no shear component. Since, uniform stress and strain field exists along the surface of test specimen during test, no stress concentration near point of loading is observed. 
As compared to four point bending, three point bending set up is easy to achieve. In contrast to four point bending, shear deformation here can be quite significant due to presence of both normal and shear stresses throughout the surface. Moreover, maximum stress may not always occur at outer surface of specimen due to observed stress concentration region near loading point. In case of, three point bending results are more reproducible. In addition, four point bending gives higher modulus as compared to three point bending. As mentioned in literature, mean variance of the results are higher for four point bending as compared to three point bending.

For this study, four point bending was selected for sandwich panel evaluation in order to achieve true bending properties. On the other hand, coupon composite specimens were evaluated by three point bending to accurately evaluate the strength.

\subsection{Theoretical Strength Prediction by Classical Laminate Theory}

Micromechanics can be used to predict stiffness and strength of FRP composites. In this work, theoretical approach was used to predict the stress and modulus to compare with experimental results. Most of the equations needed for above prediction are programmed into the software to eliminate tedious computation. The software, titled Computer Aided Design Environment for Composites (CADEC; copyrights Ever Barbero 1998) is a window application with an intuitive, Web-browser-like graphical user interface. Readers are requested to refer Chapter 3,4 and 5 of the textbook for theoretical details (Barbero, 1998).

Laminates were built based on the properties of a lamina. Building of a ply or lamina is a necessary step before studying the mechanics of a laminate. Inputs needed for lamina study includes material properties of fibers and matrix, and fiber volume fraction. Such laminas are then arranged in desired order to build to laminates. This step requires knowledge of fiber orientation, applied load and thickness of lamina. Load was applied in the direction of $0^{0}$ fibers similar to set up of tension tests. From this laminate analysis under tension, bending strength and modulus was predicted based on the laminate theory (Barbero, 1998). 
Tensile and flexural modulus are correlated by A,B D matrix. A complete set of formulas are listed in Chapter 6 (Barbero, 1998). In addition, literature has mentioned a statistical approach by two parameter Weibull theory for the above dependency (Whitney et. al, 1980 and Wisnom 1992)

\subsection{Scanning Electron Microscopy}

The behavior and performance of polymer composite cannot be understood solely on the basis of the specific properties of its principal components (the fibers and the matrix). The interface that exists between fibers and matrix is an essential element of the composite. Adequate adhesion between the fibers and matrix is a precondition for an optimized stress transfer in fiber reinforced polymer. Some of the observations cited in literature show,

- Surface treatment improves the fiber-matrix adhesion by modifying the structure and the chemical composition of the fiber surface,

- When sizing is used, stress transfer from the matrix to the fibers depends both on the fiber-resin adhesion and the quality of the sizing-matrix junction.

Electron microscopy Figure 4.14, in a high resolution mode is necessary to obtain useful information about the fine structure of the fiber-matrix interface. For the microstructure study by SEM, small sample dimension of cubical shape of size 0.25 " was selected.

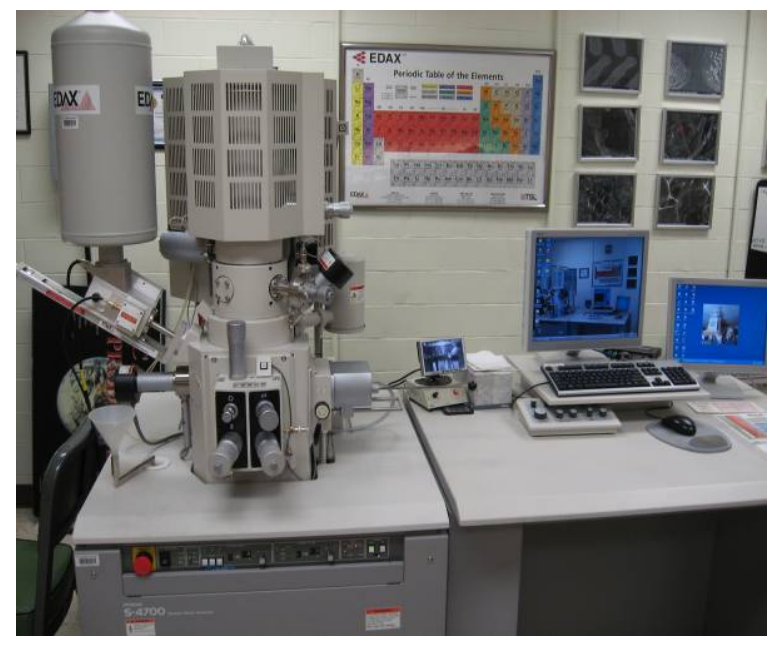

Figure 4.14 Hitachi S-4700 field emission scanning electron microscope (FE-SEM)

A Cold Field Emission Gun Scanning Electron Microscope (FEGSEM) of "below-thelens" design is capable of (manufacturer's claims) $1.5 \mathrm{~nm}$ resolution at $15 \mathrm{kV}, 12 \mathrm{~mm}$ 
W.D.; and $2.5 \mathrm{~nm}$ resolution at $1 \mathrm{k}, 2.5 \mathrm{~mm}$ W.D. Magnification ranges from $30 \mathrm{X}$ to $500,000 \mathrm{X}$. Specimen tilt is possible at $12 \mathrm{~mm}$ W.D up to 45 degrees. Electron source is a cold FE gun producing high brightness $\left(\sim 2 \mathrm{X} 10^{9} \mathrm{~A} / \mathrm{cm}^{2} / \mathrm{sr}\right)$ with little energy spread $(0.2-0.3 \mathrm{eV})$. The "below-the-lens" design and large sample chamber port permits samples as large as $100 \mathrm{~mm}$ diameter X $17 \mathrm{~mm}$ thick. Oil-free vacuum systems pump column and sample exchange. Available image modes include secondary and backscattered electron images. There are two secondary electron detectors; one above the objective lens, the other below. Digital images may be acquired in BMP, TIFF, or JPEG file formats at 640 X 480, 1280 X 960, or 1560 X 1920 pixels.

Steps involved in sample preparation for SEM images are discussed below

I. The dimension of sample for SEM study is decided by the Microscopy Unit. Cubical shape sample of size 0.25 " was cut from the composite plate.

II. This sample was molded in cylindrical rubber mold with epoxy. Ratio of epoxy to converter was 5:1. Approximately 12-15gms of epoxy was used for each sample. Composite sample was placed in cylindrical mold and epoxy was poured on it. Care should be taken to remove air bubbles below the sample surface, in order to avoid any sample damage during grinding step. Mold was allowed to cure for $24 \mathrm{hrs}$.

III. These cylinders were fixed on rotating circular disc for grinding purpose. These discs are connected to rotating shaft with motor. Out of two rotating discs top one has arrangement to hold cylindrical epoxy sample. The bottom disc has surface which allows mounting of different sand paper on it. Different types of sand paper were used in steps in order to achieve fine surface on sample. Sand papers with grid number of 180, 240, 320, 400 and 600 were used. Higher the grit number, smoother is the surface of sand paper. Each step of grinding was carried out for about 30 minutes.

IV. Final surface finishing includes grinding the sample surface on a white cloth by replacing sand papers. Silica solution was continuously sprayed on the white cloth mounted on bottom disc. Silica solution with different particle size $1 \mu \mathrm{m}, 0.3 \mu \mathrm{m}$ and $0.05 \mu \mathrm{m}$, was used for this purpose. 
V. Sample was then cleaned with water and epoxy cover was removed by crushing in jaws. It must be ensured that during crushing step, sample is kept away from any damage.

VI. This sample was then put under SEM machine for viewing.

\subsection{Physical and Morphological Properties}

\subsubsection{Fiber Content}

Strength of a composite is typically in direct proportion with fiber content. Hence, quantitative measure of fiber fraction in a given composite is essential. There are many standard methods to determine FVF for FRP composites specified by ASTM such as ASTM D3171. Due to presence of combustible fiber material, these methods can not be applied for CFRP. In order to determine fiber content in the composite sample, a layer of fabric was weighed. The six layers of carbon fabric were also weighed independently. The average dimensions of sample were measured with help of vernier caliper. With these quantities, fiber content was calculated. Table 4.1 shows range of fiber content for different fabrication processes.

Table 4.1 Range of fiber content for different manufacturing processes

\begin{tabular}{|c|c|}
\hline Process & $\begin{array}{c}\text { Range of Fiber Content } \\
\text { (wt\%) }\end{array}$ \\
\hline Pultrusion & $55-65 \%$ \\
\hline Compression Molding & $60-70 \%$ \\
\hline Resin Infusion & $50-65 \%$ \\
\hline
\end{tabular}

Thickness of sample was averaged over three different locations in order to find average thickness. Average thickness, for all the samples prepared by pultrusion, compression molding and resin infusion, was between $0.15^{\prime}-0.30$ '.

Table 4.2 Range of laminate thickness for different manufacturing processes

\begin{tabular}{|c|c|}
\hline Process & Thickness \\
\hline Pultrusion & 0.22 '-0.27" \\
\hline Compression Molding & 0.16 '-0.19" \\
\hline Resin Infusion & $0.25 "-0.30 "$ \\
\hline
\end{tabular}




\subsubsection{Void Content}

In order to achieve superior properties of FRP composites, it is required to have good physical bond between fibers and matrix. Also, during resin curing air entrapment resulting into small voids should be kept minimum. Microstructure of composite such as fiber-matrix bond, void content can be studied by Scanning Electron Microscope (SEM) method. A small piece of sample (0.25") was cut from composite plate in order to process SEM images. This sample after going through few sample preparation stages was tested for SEM images. Figure 4.15 shows some of the SEM images of CFRP samples.
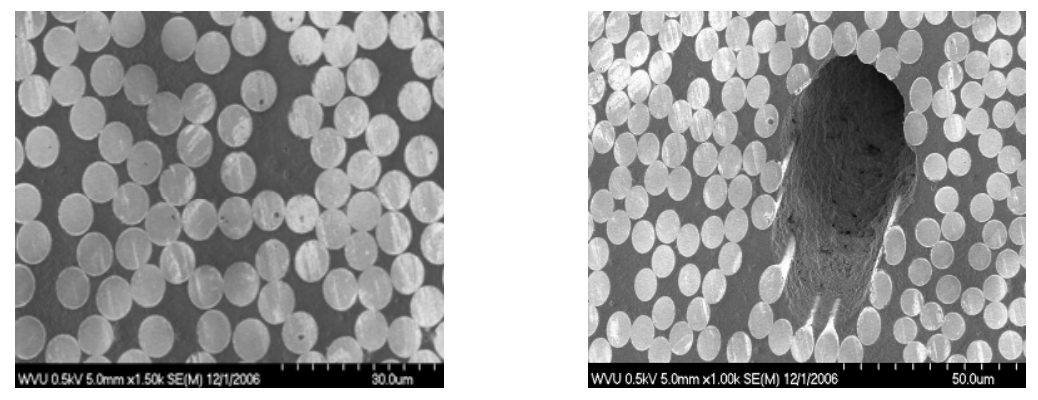

Figure 4.15 SEM images of pultruded composites

\subsection{Summary}

In summary, Table 4.3 summarizes the different manufacturing processes, fiber architecture, resin etc used for composite manufacturing. In addition, total number of specimen tested in each of the case is listed. Furthermore, it must be noted that sandwich panels were manufactured only by pultrusion process. Different parameters considered for evaluation of mechanical response includes symmetric or non-symmetric fiber architecture, curing temperature, curing time, stitching effect and resin matrix.

Specifically, for pultrusion process effect of fabric architecture, strength in different directions, effect of addition of CSM layer is verified by testing coupon and sandwich panels. In case of compression molding, coupon specimens were tested with different curing temperature, resin matrix, stitched fabrics and a layer of CSM. In addition, resin infusion specimens subjected for coupon testing differed in resin matrix and curing time. 
Table 4.3 Summary of specimen tested for mechanical testing

\begin{tabular}{|c|c|c|c|c|c|c|c|c|c|c|c|c|c|}
\hline \multirow[b]{2}{*}{$\begin{array}{l}\text { Manufacturing } \\
\text { Method }\end{array}$} & \multirow[b]{2}{*}{ ID } & \multirow[b]{2}{*}{ Description } & \multicolumn{4}{|c|}{$\begin{array}{c}\text { Fiber } \\
\text { Configuration } \\
\end{array}$} & \multicolumn{2}{|c|}{ Resin } & \multicolumn{3}{|c|}{$\begin{array}{c}\text { No. of Sample } \\
\text { Tested }\end{array}$} & \multirow[b]{2}{*}{ Thickness } & \multirow[b]{2}{*}{$\begin{array}{c}\text { Fiber } \\
\text { Content } \\
(w t \%)\end{array}$} \\
\hline & & & 元 & 竞 & 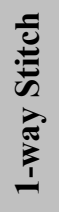 & 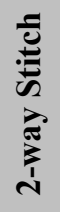 & 충 & $>$ & 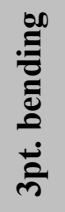 & 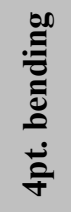 & 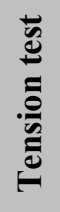 & & \\
\hline \multirow{12}{*}{ Pultrusion } & $\mathrm{C} 1+\mathrm{L}+\mathrm{T}$ & Run1+Long. ${ }^{*+T o p}$ & $x$ & $\checkmark$ & $x$ & $x$ & $x$ & $\checkmark$ & 4 & \multirow{4}{*}{8} & 4 & \multirow{12}{*}{$0.22 "-0.27 "$} & \multirow{12}{*}{$55-65 \%$} \\
\hline & $\mathrm{C} 1+\mathrm{L}+\mathrm{B}$ & Run1+Long.+Bottom & $x$ & $\checkmark$ & $x$ & $x$ & $x$ & $\checkmark$ & 4 & & 4 & & \\
\hline & $\mathrm{C} 1+\mathrm{T}+\mathrm{T}$ & Run1+Trans.*+Top & $x$ & $\checkmark$ & $x$ & $x$ & $x$ & $\checkmark$ & 4 & & 0 & & \\
\hline & $\mathrm{C} 1+\mathrm{T}+\mathrm{B}$ & Run1+Trans.+Bottom & $x$ & $\checkmark$ & $x$ & $x$ & $x$ & $\checkmark$ & 4 & & 0 & & \\
\hline & $\mathrm{C} 2+\mathrm{L}+\mathrm{T}$ & Run2+Long.+Top+CSM & $\checkmark$ & $x$ & $x$ & $x$ & $x$ & $\checkmark$ & 5 & \multirow{8}{*}{8} & 4 & & \\
\hline & $\mathrm{C} 2+\mathrm{L}+\mathrm{B}$ & Run2+Long.+Bottom+CSM & $\checkmark$ & $x$ & $x$ & $x$ & $x$ & $\checkmark$ & 5 & & 4 & & \\
\hline & $\mathrm{C} 2+\mathrm{T}+\mathrm{T}$ & Run2+Trans. ${ }^{*+T o p+C S M}$ & $\checkmark$ & $x$ & $x$ & $x$ & $x$ & $\checkmark$ & 6 & & 4 & & \\
\hline & $\mathrm{C} 2+\mathrm{T}+\mathrm{B}$ & Run2+Trans.+Bottom+CSM & $\checkmark$ & $x$ & $x$ & $x$ & $x$ & $\checkmark$ & 6 & & 4 & & \\
\hline & $\mathrm{C} 5+\mathrm{L}+\mathrm{T}$ & Run2+Long.+Top+ no CSM & $\checkmark$ & $x$ & $x$ & $x$ & $x$ & $\checkmark$ & 10 & & 3 & & \\
\hline & $\mathrm{C} 5+\mathrm{L}+\mathrm{B}$ & Run2+Long.+Bottom+ no CSM & $\checkmark$ & $x$ & $x$ & $x$ & $x$ & $\checkmark$ & 8 & & 3 & & \\
\hline & $\mathrm{C} 5+\mathrm{T}+\mathrm{T}$ & Run2+Trans.*+Top+ no CSM & $\checkmark$ & $x$ & $x$ & $x$ & $x$ & $\checkmark$ & 6 & & 5 & & \\
\hline & $\mathrm{C} 5+\mathrm{T}+\mathrm{B}$ & Run2+Trans.+Bottom+ no CSM & $\checkmark$ & $x$ & $x$ & $x$ & $x$ & $\checkmark$ & 6 & & 5 & & \\
\hline \multirow{8}{*}{$\begin{array}{l}\text { Compression } \\
\text { Molding }\end{array}$} & 5 & $\mathrm{CT}^{*} 190 \mathrm{~F}$ & $\checkmark$ & $x$ & $x$ & $x$ & $x$ & $\checkmark$ & 8 & \multirow{12}{*}{ NA } & 6 & \multirow{8}{*}{$0.16 "-0.19 ”$} & \multirow{8}{*}{$60-70 \%$} \\
\hline & 6 & CT RT* & $\checkmark$ & $x$ & $x$ & $x$ & $x$ & $\checkmark$ & 8 & & 5 & & \\
\hline & 7 & CT RT +CSM* & $\checkmark$ & $x$ & $x$ & $x$ & $x$ & $\checkmark$ & 4 & & 4 & & \\
\hline & 8 & $\mathrm{CT} 190 \mathrm{~F}$ & $\checkmark$ & $x$ & $x$ & $x$ & $x$ & $\checkmark$ & 4 & & 4 & & \\
\hline & 9 & CT 190F & $\checkmark$ & $x$ & $\checkmark$ & $x$ & $\checkmark$ & $x$ & 7 & & 4 & & \\
\hline & 10 & CT 190F & $\checkmark$ & $x$ & $x$ & $\checkmark$ & $\checkmark$ & $x$ & 4 & & 4 & & \\
\hline & 11 & CT 190F & $x$ & $\checkmark$ & $x$ & $x$ & $\checkmark$ & $x$ & 3 & & 0 & & \\
\hline & 12 & CT 190F & $\checkmark$ & $x$ & $x$ & $x$ & $\checkmark$ & $x$ & 9 & & 0 & & \\
\hline \multirow{4}{*}{ Resin Infusion } & 1 & CT $140 \mathrm{~F}$ & $\checkmark$ & $x$ & $x$ & $x$ & $\checkmark$ & $x$ & 8 & & 6 & \multirow{4}{*}{$0.25 "-0.30 "$} & \multirow{4}{*}{$50-65 \%$} \\
\hline & 2 & CT 140F & $\checkmark$ & $x$ & $x$ & $x$ & $\checkmark$ & $x$ & 8 & & 6 & & \\
\hline & 3 & CT RT & $\checkmark$ & $x$ & $x$ & $x$ & $x$ & $\checkmark$ & 8 & & 5 & & \\
\hline & 4 & CT RT & $\checkmark$ & $x$ & $x$ & $x$ & $x$ & $\checkmark$ & 9 & & 6 & & \\
\hline
\end{tabular}




\section{DATA ANALYSIS ANI RESULTS}

\subsection{Introduction}

In this chapter, a detailed analysis of experimental data is presented. As described earlier, specimens were subjected to tension test and bending as per ASTM D3039, D790 and D6272 standards. In addition, a summary of stress-strain behavior and load-deflection behavior is presented and tabulated. Test results of coupon laminate and sandwich panel are shown in subsequent sections. Moreover, physical property characterization of composites such as voids, fiber-matrix adhesion by scanning electron microscopy discussed in last section.

\subsection{Coupon Level Testing}

Composite laminates were tested for their mechanical properties. Coupon specimens with desired dimensions were prepared for testing under bending and tension. Stress-strain curves are then plotted to obtain tensile stress and tensile modulus. Similarly, loaddeflection behavior was plotted for the bending response. General trends for stress-strain and load-deflection behavior are presented in Chapter 4 in addition providing deterministic relations through mathematical equations.

\subsection{Tension Test}

Composites specimens prepared for this study differed in their matrix and manufacturing method. Objective of this test was to compare the effect of various parameters on tensile properties of composite materials manufactured by different methods. Stress-strain behavior is shown for each set of specimen. Tensile stress and tensile modulus are then calculated and tabulated for each of test.

\subsubsection{Compression Molding}

Compression molding was used as one of the choices for fabricating composite plate, wherein resin enriched fabric was pressurized between two heated plates. Test specimens 
in here differed in resin matrix, curing temperature and stitching effect. Details for each set of specimen including sample dimension and test results are listed below.

\subsubsection{Symmetric Fiber Architecture with 510A VE Cured at 190F}

Test specimens for this set of specimens were manufactured with VE resin cured at $190 \mathrm{~F}$ having symmetric fabric configuration. Table 5.1 shows results of tension test for six specimens tested. The average maximum stress for this set of specimen was found to be $78.23 \mathrm{ksi}$ and tensile modulus $5.35 \mathrm{msi}$.

Table 5.1 Tension test results for carbon/VE composites cured at high temperature

\begin{tabular}{|c|c|c|c|c|c|c|c|c|c|}
\hline $\begin{array}{c}\text { Sample } \\
\text { ID }\end{array}$ & $\begin{array}{c}\text { Avg. } \\
\text { Width }\end{array}$ & $\begin{array}{l}\text { Avg. } \\
\text { Thick }\end{array}$ & $\left(i^{2}\right)$ & $\begin{array}{c}\text { Slope } \\
\text { stress } \\
\text { vs. } \\
\text { Strain } \\
(p s i / \mu \varepsilon)\end{array}$ & $\begin{array}{l}\text { Max. } \\
\text { Load } \\
\text { P } \\
\text { (lbs) }\end{array}$ & $\begin{array}{c}\text { Max. } \\
\text { Stress }\end{array}$ & (msi) & $\begin{array}{c}\text { Strain } \\
\text { at } \\
\text { max. } \\
\text { Load } \\
(\mu \varepsilon)\end{array}$ & $\begin{array}{c}\begin{array}{c}\text { Fiber } \\
\text { Content }\end{array} \\
(\mathrm{wt} \%)\end{array}$ \\
\hline $5.1 \mathrm{D}$ & 1.0086 & 0.2336 & 0.2357 & 1.2874 & 18245 & 77.41 & 5.46 & 14824 & \multirow{8}{*}{64.68} \\
\hline $5.2 \mathrm{D}$ & 0.986 & 0.2303 & 0.2297 & 1.2073 & 16674 & 72.58 & 5.25 & 14669 & \\
\hline $5.3 \mathrm{D}$ & 1.0213 & 0.2290 & 0.2339 & 1.2315 & 18799 & 80.37 & 5.26 & 15814 & \\
\hline $5.1 \mathrm{~W}$ & 1.0233 & 0.2416 & 0.2473 & 1.2553 & 19831 & 80.18 & 5.07 & 15812 & \\
\hline $5.2 \mathrm{~W}$ & 0.9626 & 0.2376 & 0.2288 & 1.2120 & 18368 & 80.28 & 5.29 & 15256 & \\
\hline $5.3 \mathrm{~W}$ & 1.0303 & 0.2320 & 0.239 & 1.3761 & 18768 & 78.51 & 5.75 & 15102 & \\
\hline \multicolumn{6}{|r|}{ AVG } & 78.23 & 5.35 & 15246 & \\
\hline \multicolumn{6}{|c|}{$\%$ STD } & 3.83 & 4.35 & 3.17 & \\
\hline
\end{tabular}

Sample ID followed by D and W indicates dry cutting and wet cutting method used for sample preparation respectively. It appears from the results above and many others that, the cutting method (dry or wet) does not affect the material response to any considerable extent and henceforth it has been considered indifferently. Stress-strain response for the above set of specimen is shown in Figure 5.1 below.

\subsubsection{Symmetric Fiber Architecture with 510A VE Cured at RT}

In this set of experiment, curing of composite plate was carried out at room temperature with a symmetric fabric architecture and vinyl ester resin. Tension test results are listed in Table 5.2. The average maximum stress for this set of experiments was found to be 76.50 ksi and average tensile modulus was $6.69 \mathrm{msi}$. Stress-strain behavior of specimen is shown in Figure 5.2. 


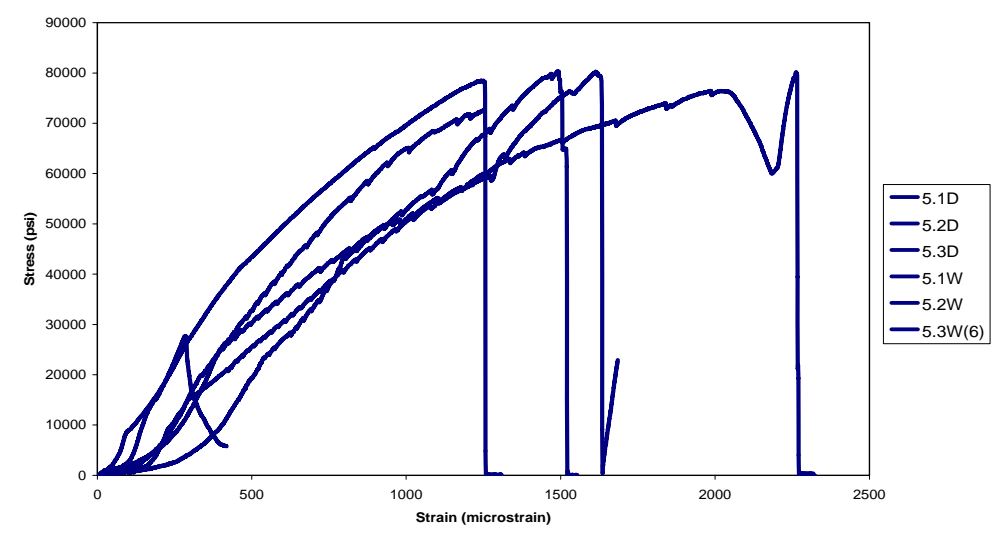

Figure 5.1 Stress-strain behavior of carbon/VE composites cured at high temperature

Table 5.2 Tension test results for carbon/VE composites cured at room temperature

\begin{tabular}{|c|c|c|c|c|c|c|c|c|c|}
\hline $\begin{array}{c}\text { Sample } \\
\text { ID }\end{array}$ & $\begin{array}{c}\text { Avg. } \\
\text { Width } \\
\text { (in.) }\end{array}$ & $\begin{array}{l}\text { Avg. } \\
\text { Thick } \\
\text { (in.) }\end{array}$ & $\left(\mathrm{in}^{2}\right)$ & $\begin{array}{c}\text { Slope } \\
\text { Stress } \\
\text { vs. } \\
\text { Strain } \\
(\text { psi } / \mu \varepsilon)\end{array}$ & $\begin{array}{l}\text { Max. } \\
\text { Load } \\
\quad P \\
\text { (lbs) }\end{array}$ & $\begin{array}{c}\text { Max. } \\
\text { Stress } \\
\text { (ksi) }\end{array}$ & (msi) & $\begin{array}{l}\text { Strain } \\
\text { at } \\
\text { Max. } \\
\text { load } \\
(\mu \varepsilon)\end{array}$ & $\begin{array}{c}\text { Fiber } \\
\text { Content } \\
\text { (wt } \%)\end{array}$ \\
\hline $6.1 \mathrm{D}$ & 0.969 & 0.186 & 0.18 & 1.254 & 14442 & 80.1 & 6.95 & 15827 & \multirow{7}{*}{65.25} \\
\hline $6.2 \mathrm{D}$ & 0.961 & 0.1873 & 0.18 & 1.127 & 13857 & 76.97 & 6.26 & 14702 & \\
\hline $6.3 \mathrm{D}$ & 1.002 & 0.1904 & 0.191 & 1.25 & 12332 & 64.61 & 6.54 & 14323 & \\
\hline $6.1 \mathrm{~W}$ & 0.996 & 0.1866 & 0.186 & 1.263 & 15104 & 81.24 & 6.79 & 15811 & \\
\hline $6.2 \mathrm{~W}$ & 1.01 & 0.186 & 0.188 & 1.303 & 14950 & 79.58 & 6.93 & 15172 & \\
\hline \multicolumn{6}{|r|}{ AVG } & 76.5 & 6.69 & 15167 & \\
\hline \multicolumn{6}{|c|}{$\%$ STD } & 8.91 & 4.33 & 4.39 & \\
\hline
\end{tabular}

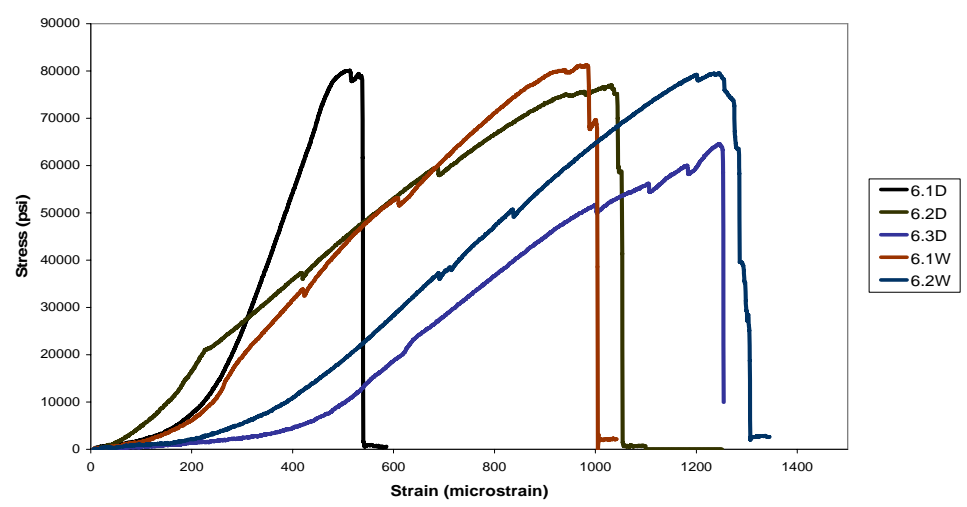

Figure 5.2 Stress-strain behavior of room temperature cured carbon/VE composites 


\subsubsection{Symmetric Fiber Architecture with CSM and 510A VE Cured at RT}

Pultruded CFRP sandwich panels produced in second manufacturing run contained a layer of CSM on top and bottom face sheet. The FRP composite with CSM was expected to provide better resin enrichment on outer fabric layers during pultrusion process. In this case, same arrangement of carbon fabric as in section 5.3.1.2 was compression molded together with a layer of CSM on one side for the purpose of comparison. The curing of resin was carried out at room temperature. Sample dimension and results of tension tests are listed in Table 5.3 below. Stress-strain behavior is shown in Figure 5.3. Average maximum stress for this set of specimen was found to be $70.56 \mathrm{ksi}$ and tensile modulus of 5.99 msi.

Table 5.3 Tension test results for carbon/VE composites cured at room temperature with CSM layer

\begin{tabular}{|c|c|c|c|c|c|c|c|c|c|}
\hline $\begin{array}{c}\text { Sample } \\
\text { ID }\end{array}$ & $\begin{array}{l}\text { Avg. } \\
\text { Width }\end{array}$ & $\begin{array}{l}\text { Avg. } \\
\text { Thick }\end{array}$ & $\left(\mathrm{in}^{2}\right)$ & $\begin{array}{c}\text { Slope } \\
\text { Stress } \\
\text { vs. } \\
\text { Strain } \\
(\mathrm{psi} / \mu \varepsilon)\end{array}$ & $\begin{array}{c}\text { Max. } \\
\text { Load } \\
\text { P } \\
\text { (lbs) }\end{array}$ & $\begin{array}{l}\text { Max. } \\
\text { Stress }\end{array}$ & (msi) & $\begin{array}{c}\text { Strain } \\
\text { at } \\
\text { Max. } \\
\text { load } \\
(\mu \varepsilon)\end{array}$ & $\begin{array}{c}\text { Fiber } \\
\text { Content }\end{array}$ \\
\hline 7.3D & 1.02 & 0.2166 & 0.221 & 1.4024 & 15535 & 70.29 & 6.34 & 15232 & \multirow{6}{*}{65.21} \\
\hline $7.4 \mathrm{D}$ & 1.0196 & 0.2183 & 0.2226 & 1.2885 & 15812 & 71.02 & 5.78 & 15797 & \\
\hline $7.5 \mathrm{D}$ & 1.0153 & 0.215 & 0.2183 & 1.2663 & 15335 & 70.24 & 5.8 & 15825 & \\
\hline $7.6 \mathrm{D}$ & 0.992 & 0.2166 & 0.2149 & 1.2984 & 15196 & 70.7 & 6.04 & 15009 & \\
\hline \multicolumn{6}{|r|}{ AVG } & 70.56 & 5.99 & 15465 & \\
\hline \multicolumn{6}{|c|}{$\%$ STD } & 0.51 & 4.34 & 2.64 & \\
\hline
\end{tabular}

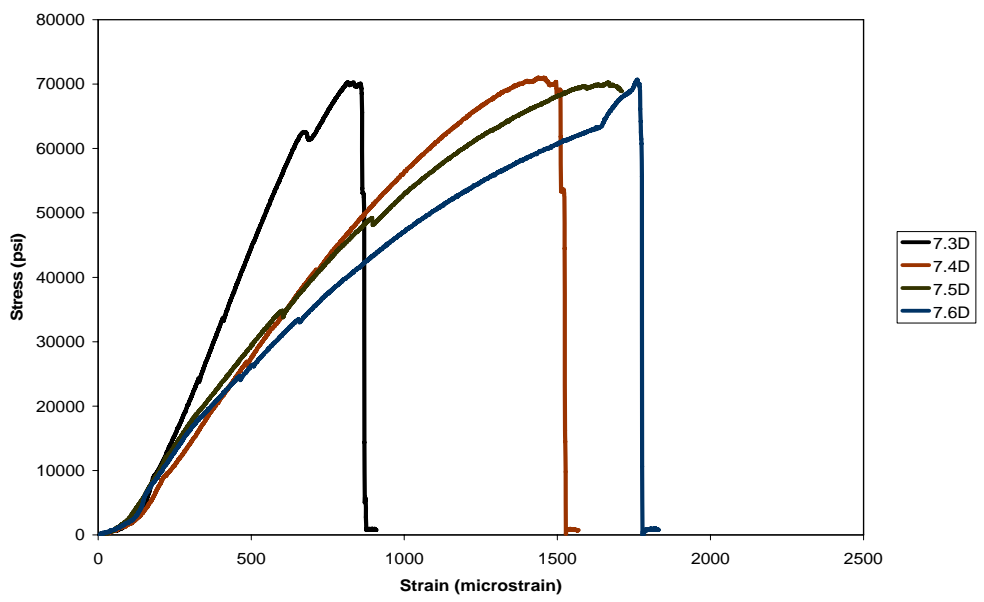

Figure 5.3 Stress-strain behavior of room temperature cured carbon/VE composites with CSM 


\subsubsection{Symmetric Fiber Architecture with Epoxy Cured At 190F}

Epoxies are expected to show excellent degree of adhesion, high strength and good reproducibility for FRP composites. In this study halogen (BR) free toughened epoxy was used as a matrix. For this set of specimen composite plate was manufactured with epoxy matrix and curing temperature of $190 \mathrm{~F}$. Average maximum stress for the test specimen was found to be $101.90 \mathrm{ksi}$ and tensile modulus of $6.88 \mathrm{msi}$. Average thickness of the composite plate manufactured was around 0.19 ". Results of the experiment are tabulated in Table 5.4 with stress-strain behavior shown in Figure 5.4.

Table 5.4 Tension test results for carbon/epoxy composites cured at $\mathbf{1 9 0 F}$

\begin{tabular}{|c|c|c|c|c|c|c|c|c|c|}
\hline $\begin{array}{c}\text { Sample } \\
\text { ID }\end{array}$ & $\begin{array}{l}\text { Avg. } \\
\text { width } \\
\text { (in.) }\end{array}$ & $\begin{array}{l}\text { Avg. } \\
\text { Thick } \\
\text { (in.) }\end{array}$ & $\left(\mathrm{in}^{2}\right)$ & $\begin{array}{l}\text { Slope } \\
\text { Stress } \\
\text { vs. } \\
\text { Strain } \\
(p s i / \mu \varepsilon)\end{array}$ & $\begin{array}{c}\text { Max. } \\
\text { Load P } \\
\text { (lbs) }\end{array}$ & $\begin{array}{c}\text { Max. } \\
\text { Stress } \\
\text { (ksi) }\end{array}$ & (msi) & $\begin{array}{r}\text { Strain } \\
\text { at Max. } \\
\text { load } \\
(\mu \varepsilon)\end{array}$ & $\begin{array}{c}\begin{array}{c}\text { Fiber } \\
\text { Content }\end{array} \\
(\mathrm{wt} \%) \\
\end{array}$ \\
\hline $8.1 \mathrm{~W}$ & 1.02 & 0.191 & 0.1948 & 1.339 & 17506 & 89.85 & 6.87 & 14696 & \multirow{6}{*}{76.38} \\
\hline $8.2 \mathrm{~W}$ & 1.04 & 0.188 & 0.1963 & 1.417 & 21001 & 106.96 & 7.22 & 14128 & \\
\hline $8.3 \mathrm{~W}$ & 1.05 & 0.189 & 0.1997 & 1.386 & 21247 & 106.42 & 6.94 & 15857 & \\
\hline $8.4 \mathrm{~W}$ & 1.02 & 0.192 & 0.1977 & 1.289 & 20631 & 104.37 & 6.52 & 15852 & \\
\hline \multicolumn{6}{|r|}{ AVG } & 101.9 & 6.88 & 15133 & \\
\hline \multicolumn{6}{|c|}{$\%$ STD } & 7.95 & 4.06 & 5.71 & \\
\hline
\end{tabular}

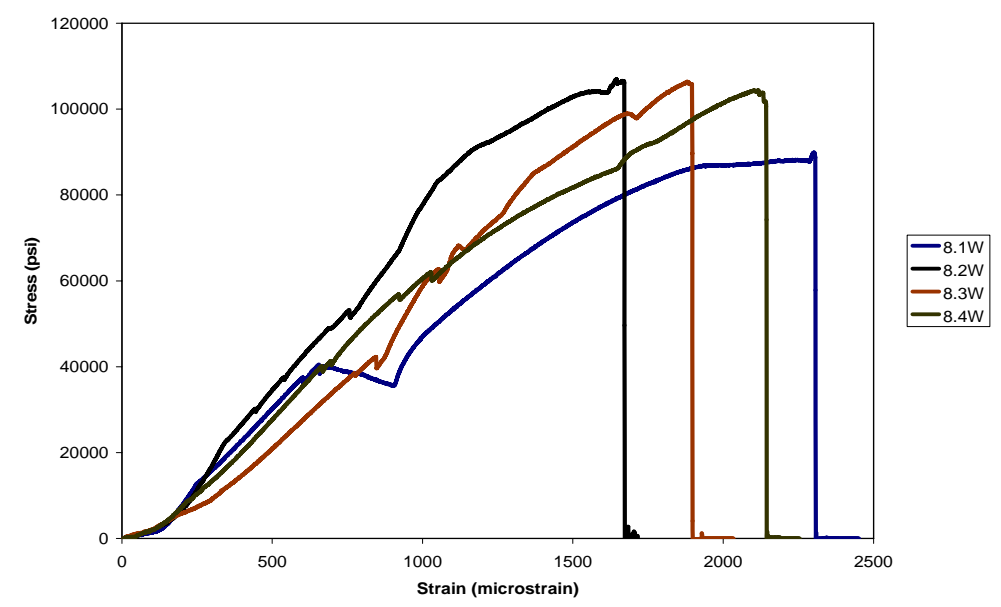

Figure 5.4 Stress-strain behavior of $190 \mathrm{~F}$ cured carbon/epoxy composites 


\subsubsection{Symmetric Fiber Architecture with Stitched Layers and Epoxy Cured at $190 \mathrm{~F}$}

For the FRP composites, fiber arrangement ensures good strength behavior in a 2D material plane. In contrast, the third plane remains the weakest of all. The strength in later direction can be improved by providing reinforcement like stitching the layers fabric, also called as $3 \mathrm{D}$ stitching.

Two sets of composite plates were manufactured with six layers of symmetric fabric stitched in one direction (sample ID 9) as well as two directions (sample ID 10) in order to study the stitching effect. Test results are listed in Table 5.5. Average maximum stress observed for 1-way stitched composites was $93.97 \mathrm{ksi}$ and average tensile modulus of $6.58 \mathrm{msi}$. For two way stitched fabric, the average maximum stress was $95.27 \mathrm{ksi}$ and $6.48 \mathrm{msi}$ of average maximum tensile modulus. Table 5.5 shows the tension test results of stitched CFRP composites. Stress-strain behavior for the same is shown in Figures 5.5 and 5.6.

Table 5.5 Tension test results for stitched carbon/epoxy composites cured at 190F

\begin{tabular}{|c|c|c|c|c|c|c|c|c|c|}
\hline $\begin{array}{c}\text { Sample } \\
\text { ID }\end{array}$ & $\begin{array}{c}\text { Avg. } \\
\text { Width } \\
\text { (in.) }\end{array}$ & $\begin{array}{l}\text { Avg. } \\
\text { Thick } \\
\text { (in.) }\end{array}$ & $\begin{array}{l}\text { Area } \\
\left(\text { in }^{2}\right)\end{array}$ & $\begin{array}{l}\text { Slope } \\
\text { Stress } \\
\text { vs. } \\
\text { Strain } \\
(\mathrm{psi} / \mu \varepsilon)\end{array}$ & $\begin{array}{l}\text { Max. } \\
\text { Load } \\
\text { P } \\
\text { (lbs) }\end{array}$ & $\begin{array}{c}\text { Max. } \\
\text { Stress } \\
\\
\text { (ksi) }\end{array}$ & (msi) & $\begin{array}{l}\text { Strain } \\
\text { at } \\
\text { Max. } \\
\text { load } \\
(\mu \varepsilon)\end{array}$ & $\begin{array}{c}\text { Fiber } \\
\text { Content }\end{array}$ \\
\hline $9.1 \mathrm{~W}$ & 0.962 & 0.194 & 0.1866 & 1.2311 & 17075 & 91.49 & 6.59 & 15848 & \multirow{6}{*}{76.28} \\
\hline $9.2 \mathrm{~W}$ & 0.931 & 0.1926 & 0.1794 & 1.1743 & 17105 & 95.36 & 6.54 & 15301 & \\
\hline $9.3 \mathrm{~W}$ & 0.872 & 0.1923 & 0.1677 & 1.115 & 16351 & 97.49 & 6.64 & 15827 & \\
\hline $9.4 \mathrm{~W}$ & 0.8706 & 0.1966 & 0.1712 & 1.1225 & 15673 & 91.53 & 6.55 & 15825 & \\
\hline \multicolumn{6}{|r|}{ AVG } & 93.97 & 6.58 & 15700 & \\
\hline \multicolumn{6}{|r|}{$\%$ STD } & 3.14 & 0.75 & 1.69 & \\
\hline $10.1 \mathrm{~W}$ & 0.92 & 0.1986 & 0.1828 & 1.1698 & 17275 & 94.51 & 6.4 & 15875 & \multirow{5}{*}{75.9} \\
\hline $10.2 \mathrm{~W}$ & 0.8553 & 0.2 & 0.1711 & 1.1298 & 16305 & 95.31 & 6.6 & 15828 & \\
\hline $10.3 \mathrm{~W}$ & 0.9006 & 0.1973 & 0.1777 & 1.1481 & 17059 & 95.98 & 6.45 & 15838 & \\
\hline \multicolumn{6}{|r|}{ AVG } & 95.27 & 6.48 & 15847 & \\
\hline \multicolumn{6}{|r|}{$\%$ STD } & 0.76 & 1.54 & 0.15 & \\
\hline
\end{tabular}




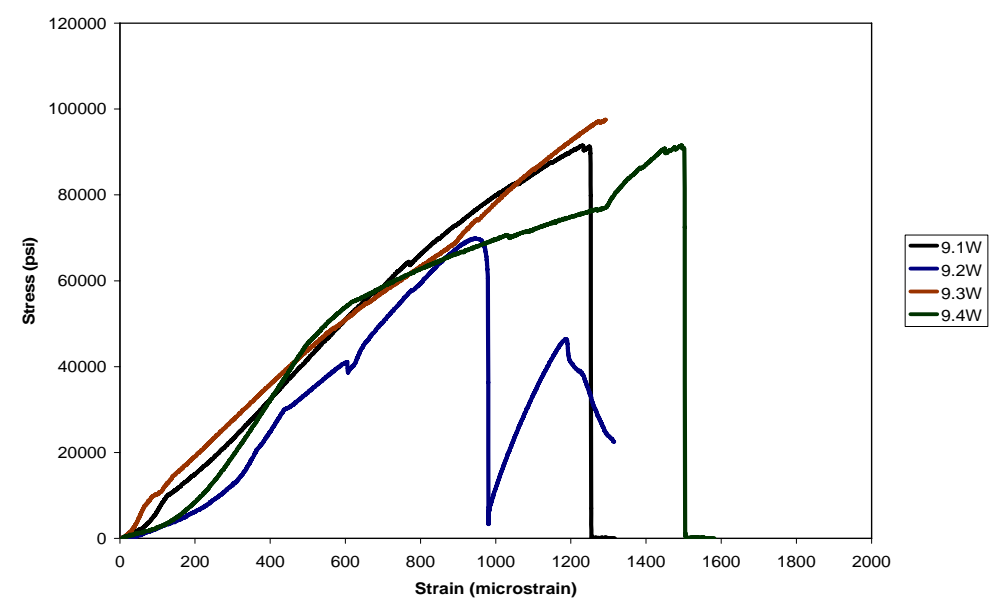

Figure 5.5 Stress-strain behavior of 190F cured one way stitched carbon/Epoxy composites

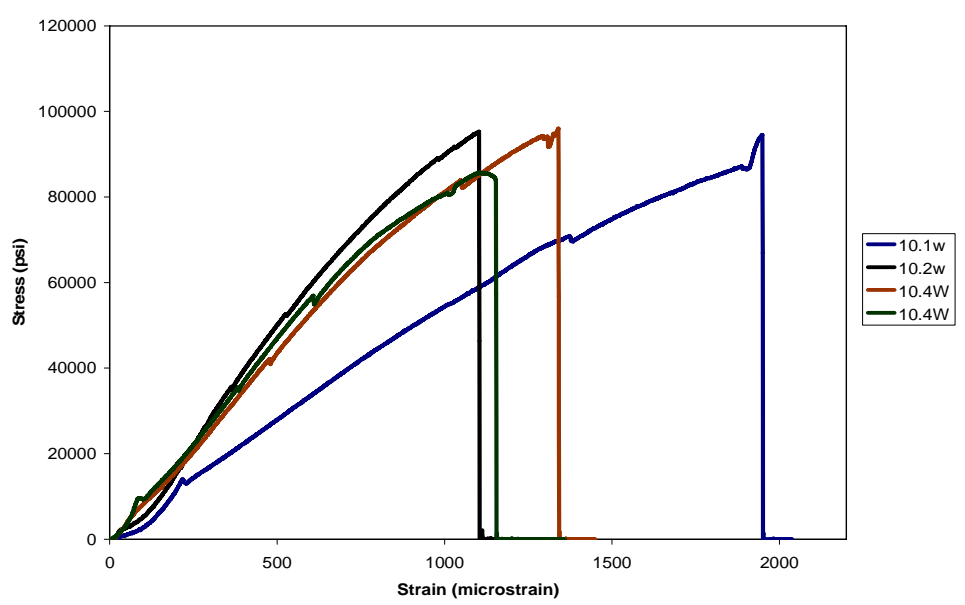

Figure 5.6 Stress-strain behavior of 190F cured two way stitched carbon/Epoxy composites

\subsubsection{Conclusions}

Figures 5.7 and 5.8 show the average maximum stress and average tensile modulus plotted for the entire set of specimens made from compression molding process respectively. Theoretical prediction for the same is done by laminate theory. It is clear from the results that, curing of $\mathrm{VE}$ at room temperature results in about $25 \%$ increase in tensile modulus with about $2.2 \%$ drop in maximum stress for similar fabric configuration. Addition of CSM layer significantly reduces the tensile modulus by about $10.5 \%$ and maximum stress reduces by about $7.8 \%$. Reduction in mechanical strength due to additional layer of CSM is attributed to the fact that CSM does not provide strength to the FRP laminate in direction of loading although it increasing the cross sectional area. 
In case of epoxy matrix, it appears that one way stitching on fabric drops down tensile modulus by about $4.5 \%$ and maximum stress by about $7.8 \%$. In addition, two ways stitching also results in poor response with drop of $6 \%$ in tensile modulus and $6.5 \%$ in maximum stress. The reason for the drop in mechanical strength after stitching is due to the fact that large area of the fabric gets damaged during the stitching process. Moreover, size of the needle and motion of the stitching needle damages good proportion of the fibers in layers of fabrics. Such damaged region could be responsible for a drop in strength of composites.

Comparison of mechanical properties in Figures 5.7 and 5.8 further confirms the fact that carbon/epoxy composites have better strength than carbon/VE composites. The reason behind better performance of epoxy as compared to vinyl ester lies in their chemical composition. In case of epoxies, presence of polar hydroxyl and ether group helps in low shrinkage curing. The phenomenon of shrinkage during curing occurs due to molecule rearranging and re-orientating themselves in the liquid and semi-gelled phase. Low shrinkage results in less molecular rearrangements. On the other hand, vinyl esters require considerable molecular rearrangements to reach their cured state and show shrinkage up to $8 \%$. Such molecular rearrangements for epoxies are very small and hence they show shrinkage of up to $2 \%$ only. The absence of shrinkage is in part responsible for improved mechanical properties of epoxies over vinyl esters. Another reason for superior performance of epoxies over vinyl ester is that adhesive properties of resin with fiber helps composite laminate to achieve higher micro cracking strain and hence causing failure at higher load magnitude.

In conclusion, room temperature curing of VE results in better mechanical properties of composites. Addition of CSM layer is expected to enrich the fabric with resin and improve properties of the composites. In contrast, it shows reduction in mechanical strength of a composite caused due to its failure in providing appropriate strength. Also 3D stitched fabric does not show any improvement with the material strength which can be attributed to the fact of fabric damage during stitching results in poor performance of 
composite. Carbon/epoxy composites have better strength than those of carbon/VE composites due to less shrinkage during curing.

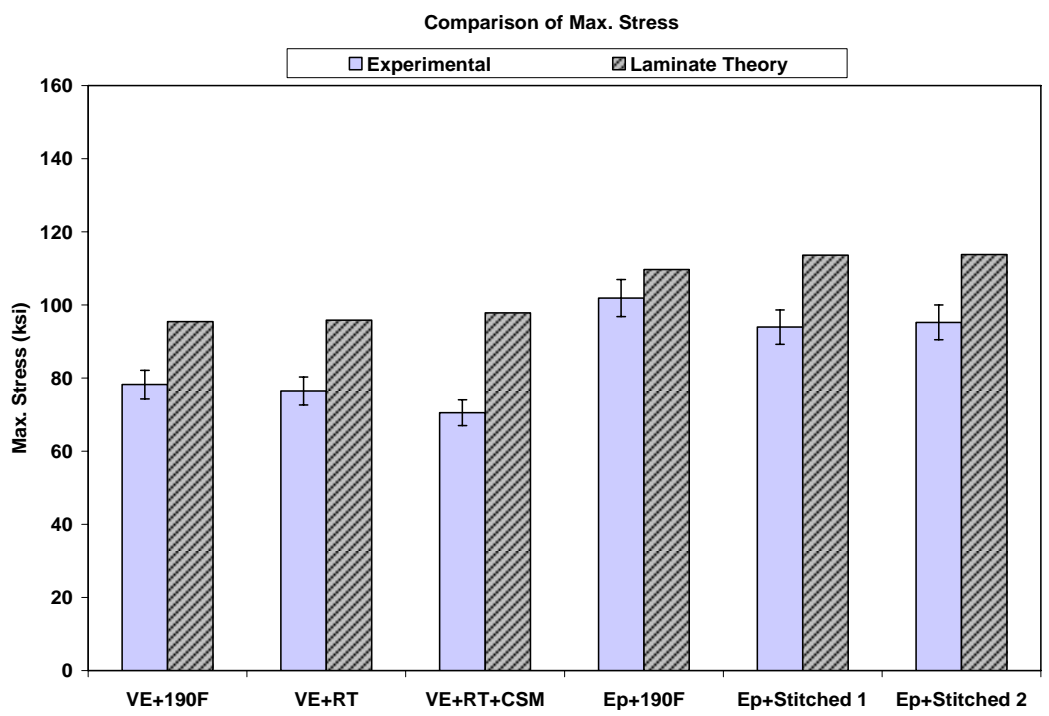

Figure 5.7 Chart comparison of tensile strength for carbon/VE or epoxy composites by compression molding

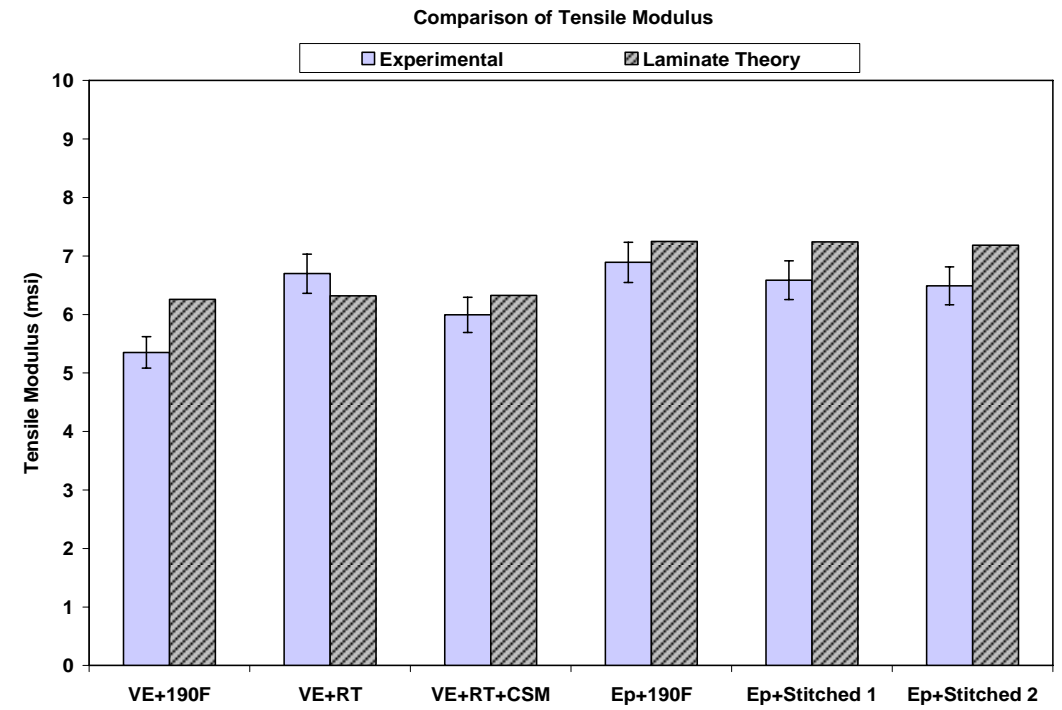

Figure 5.8 Chart comparison of tensile modulus for carbon/VE or epoxy composites by compression molding 


\subsubsection{Pultrusion Process}

CFRP composite sandwich panels were produced by pultrusion process with symmetric and non-symmetric fabric configuration. For both types of panels, end grain balsa was used as core material. In case of symmetric fabric architecture, top face sheet was layered with CSM. The effect of adding CSM layer has been further quantified with mechanical testing in subsequent sections. For non-symmetric architecture the width of pultruded sandwich panel was 12 " and for symmetric it was 40 ". Tension test samples were prepared both in longitudinal and transverse direction for 40" wide panel. On the other hand, 12" panel was tested by tension test only in longitudinal direction. Longitudinal direction here refers to direction of $0^{0}$ fibers and transverse refers to $90^{\circ}$ fibers. Top and bottom face sheets were tested respectively in order to verify their uniformity in mechanical response due to potential wet-out effect. Mechanical responses for tension test and stress-strain behavior are discussed in detail in the following section.

\subsubsection{Non-symmetric Fiber Architecture with 510A VE: Long. Direction (Run1)}

Top (T) and bottom (B) face sheets of 12" wide panel were tested under tension for mechanical response. The entire set of test specimens contained non-symmetrical fabric architecture with VE matrix. Sample ID followed with T and B represents the top and bottom face-sheet of panels respectively in corresponds to production set up. Average maximum stress for top test specimen was found to be $65.91 \mathrm{ksi}$ and tensile modulus of $5.24 \mathrm{msi}$. In addition, bottom test specimen showed average value of maximum stress around $52.94 \mathrm{ksi}$ and tensile modulus of $5.05 \mathrm{msi}$. Tension test results for this set of experiment are summarized in Table 5.6 below. Figure 5.9 shows the stress-strain behavior for test specimens.

\subsubsection{Symmetric Fiber Architecture with CSM and 510A VE: Long. Direction (Run2)}

Test specimens were prepared from top and bottom face sheet of 48 " wide CFRP sandwich panels. These face sheet contained a layer of CSM with carbon fabric. Samples were cut in direction of $0^{0}$ fibers and hence referred as longitudinal. Each sample consisted of symmetric fiber architecture and VE matrix. Results of tension test are 
summarized in Table 5.7. Figure 5.10 represents the stress-strain behavior. Average maximum stress was observed to be $50.69 \mathrm{ksi}$ and tensile modulus of $3.41 \mathrm{msi}$ for top specimen. For bottom test specimen average maximum stress was evaluated as $60.56 \mathrm{ksi}$ and tensile modulus of $4.46 \mathrm{msi}$.

Table 5.6 Tension test results for carbon/VE composites in longitudinal direction

\begin{tabular}{|c|c|c|c|c|c|c|c|c|c|}
\hline $\begin{array}{c}\text { Sample } \\
\text { ID }\end{array}$ & $\begin{array}{c}\text { Avg. } \\
\text { Width }\end{array}$ & $\begin{array}{l}\text { Avg. } \\
\text { Thick }\end{array}$ & $\left(\mathbf{i n}^{2}\right)$ & $\begin{array}{c}\text { Slope } \\
\text { Stress } \\
\text { vs. } \\
\text { Strain } \\
\text { (psi/ } / \mu \varepsilon)\end{array}$ & $\begin{array}{l}\text { Max. } \\
\text { Load } \\
\text { P } \\
\text { (lbs) }\end{array}$ & $\begin{array}{c}\text { Max. } \\
\text { Stress }\end{array}$ & (msi) & $\begin{array}{c}\text { Strain } \\
\text { at } \\
\text { Max. } \\
\text { load } \\
(\mu \varepsilon)\end{array}$ & $\begin{array}{c}\begin{array}{c}\text { Fiber } \\
\text { Content }\end{array} \\
(\mathrm{wt} \%)\end{array}$ \\
\hline $\mathrm{C} 1 / \mathrm{T} 1$ & 1.038 & 0.2373 & 0.2464 & 1.4335 & 16166 & 65.62 & 5.81 & 11420 & \multirow{6}{*}{65.1} \\
\hline $\mathrm{C} 1 / \mathrm{T} 2$ & 1.024 & 0.2366 & 0.2423 & 1.2416 & 16459 & 67.91 & 5.12 & 15795 & \\
\hline $\mathrm{C} 1 / \mathrm{T} 5$ & 0.9886 & 0.232 & 0.2294 & 1.1572 & 15489 & 67.52 & 5.04 & 13609 & \\
\hline $\mathrm{C} 1 / \mathrm{T} 6$ & 1.006 & 0.2356 & 0.2371 & 1.1862 & 14842 & 62.6 & 5 & 12281 & \\
\hline \multicolumn{6}{|c|}{ AVG } & 65.91 & 5.24 & 13276 & \\
\hline \multicolumn{6}{|c|}{$\%$ STD } & 3.67 & 7.25 & 14.34 & \\
\hline $\mathrm{C} 1 / \mathrm{B} 1$ & 1.0333 & 0.2643 & 0.2731 & 1.6015 & 13934 & 51.01 & 5.86 & 12262 & \multirow{6}{*}{65.1} \\
\hline $\mathrm{C} 1 / \mathrm{B} 2$ & 1.0216 & 0.2753 & 0.2813 & 1.3827 & 12255 & 43.56 & 4.91 & 11058 & \\
\hline $\mathrm{C} 1 / \mathrm{B} 3$ & 1.0333 & 0.2663 & 0.2752 & 1.3889 & 16951 & 61.59 & 5.04 & 15835 & \\
\hline $\mathrm{C} 1 / \mathrm{B} 4$ & 1.001 & 0.2826 & 0.2829 & 1.2431 & 15735 & 55.61 & 4.39 & 15661 & \\
\hline \multicolumn{6}{|r|}{ AVG } & 52.94 & 5.05 & 13704 & \\
\hline \multicolumn{6}{|c|}{$\%$ STD } & 14.35 & 11.8 & 17.5 & \\
\hline
\end{tabular}

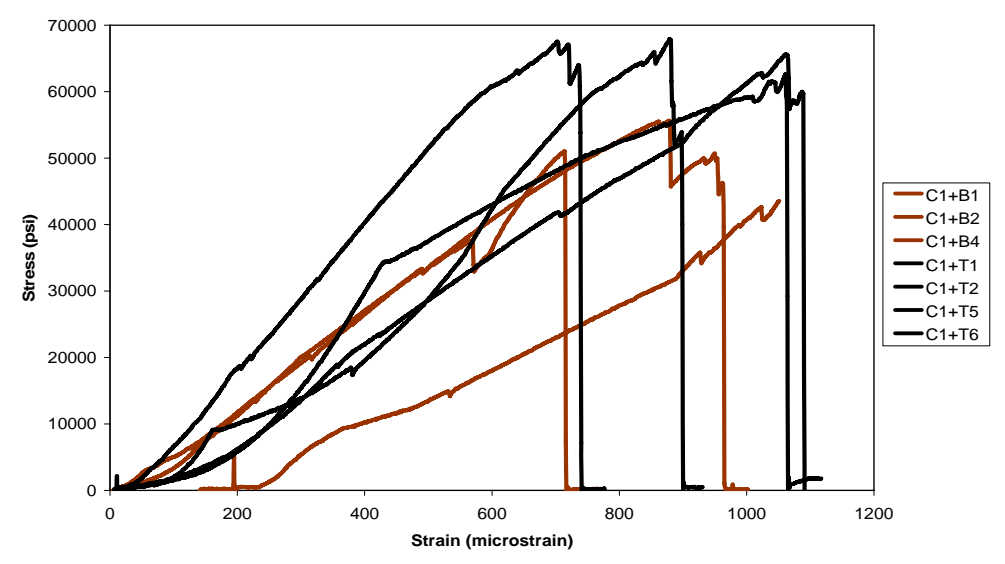

Figure 5.9 Stress-strain behavior of pultruded carbon/VE composites in longitudinal direction (Run1) 
Table 5.7 Tension test results for pultruded carbon/VE composites in longitudinal direction (with CSM, Run2)

\begin{tabular}{|c|c|c|c|c|c|c|c|c|c|}
\hline $\begin{array}{c}\text { Sample } \\
\text { ID }\end{array}$ & $\begin{array}{c}\text { Avg. } \\
\text { Width } \\
\text { (in.) }\end{array}$ & $\begin{array}{l}\text { Avg. } \\
\text { Thick }\end{array}$ & Area & $\begin{array}{c}\text { Slope } \\
\text { Stress } \\
\text { vs. } \\
\text { Strain } \\
(p s i / \mu \varepsilon)\end{array}$ & $\begin{array}{c}\text { Max. } \\
\text { Load } \\
\text { P } \\
\text { (lbs) }\end{array}$ & $\begin{array}{l}\text { Max. } \\
\text { Stress }\end{array}$ & (msi) & $\begin{array}{c}\text { Strain } \\
\text { at } \\
\text { Max. } \\
\text { Load } \\
(\mu \varepsilon)\end{array}$ & $\begin{array}{c}\begin{array}{c}\text { Fiber } \\
\text { Content }\end{array} \\
(\mathrm{wt} \%)\end{array}$ \\
\hline $\mathrm{C} 2 / \mathrm{L} / \mathrm{T} 2$ & 1.0266 & 0.300 & 0.308 & 0.7605 & 16859 & 54.73 & 2.46 & 15819 & \multirow{6}{*}{58.3} \\
\hline $\mathrm{C} 2 / \mathrm{L} / \mathrm{T} 3$ & 1.0120 & 0.292 & 0.2955 & 1.1834 & 16859 & 57.05 & 4.00 & 14358 & \\
\hline $\mathrm{C} 2 / \mathrm{L} / \mathrm{T} 6$ & 0.9883 & 0.2996 & 0.2962 & 0.9444 & 13195 & 44.55 & 3.18 & 14463 & \\
\hline $\mathrm{C} 2 / \mathrm{L} / \mathrm{T} 7$ & 1.0376 & 0.3006 & 0.312 & 1.2431 & 14488 & 46.43 & 3.98 & 11633 & \\
\hline \multicolumn{6}{|r|}{ AVG } & 50.69 & 3.41 & 14068 & \\
\hline \multicolumn{6}{|r|}{$\%$ STD } & 12.07 & 21.4 & 12.46 & \\
\hline $\mathrm{C} 2 / \mathrm{L} / \mathrm{B} 2$ & 1.0570 & 0.2866 & 0.303 & 1.2945 & 19215 & 63.41 & 4.27 & 15895 & \multirow{6}{*}{58.3} \\
\hline $\mathrm{C} 2 / \mathrm{L} / \mathrm{B} 4$ & 1.0446 & 0.2473 & 0.2584 & 1.2742 & 13980 & 54.1 & 4.93 & 12988 & \\
\hline C2/L/B5 & 1.0350 & 0.295 & 0.306 & 1.3160 & 18814 & 61.48 & 4.30 & 14379 & \\
\hline C2/L/B6 & 1.0280 & 0.2943 & 0.3026 & 1.3124 & 19138 & 63.25 & 4.33 & 13890 & \\
\hline \multicolumn{6}{|r|}{ AVG } & 60.56 & 4.46 & 14288 & \\
\hline \multicolumn{6}{|c|}{$\%$ STD } & 7.24 & 6.95 & 8.51 & \\
\hline
\end{tabular}

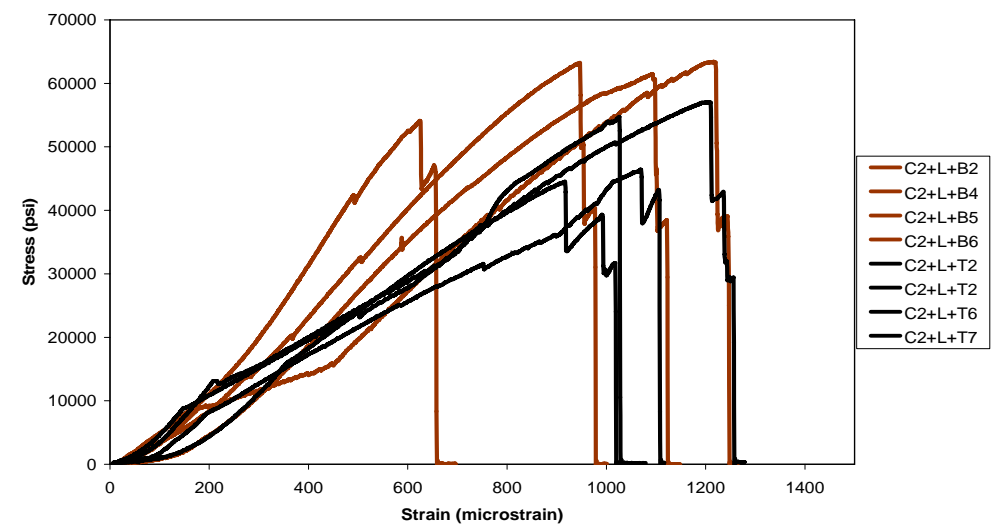

Figure 5.10 Stress-strain behavior of pultruded carbon/VE composites in longitudinal direction (with CSM, Run2)

\subsubsection{Symmetrical Fiber Architecture with CSM and 510A VE: Trans. direction} (Run2)

For this set of experiment, specimens were cut in direction of $90^{\circ}$ fibers and hence were referred as transverse direction. Each sample consisted of symmetric fiber architecture and VE matrix. Results of tension test are summarized in Table 5.8. Figure 5.11 represents the stress-strain behavior. Average maximum stress was observed to be 47.20 
ksi and tensile modulus of $4.26 \mathrm{msi}$ for top specimen. For bottom test specimen average maximum stress was evaluated as $35.50 \mathrm{ksi}$ and tensile modulus of $4.60 \mathrm{msi}$.

Table 5.8 Tension test results for pultruded carbon/VE composites in transverse direction (with CSM)

\begin{tabular}{|c|c|c|c|c|c|c|c|c|c|}
\hline $\begin{array}{c}\text { Sample } \\
\text { ID }\end{array}$ & $\begin{array}{c}\text { Avg. } \\
\text { Width } \\
\text { (in.) }\end{array}$ & $\begin{array}{l}\text { Avg. } \\
\text { Thick }\end{array}$ & $\left(\right.$ in $\left.^{2}\right)$ & $\begin{array}{l}\text { Slope } \\
\text { Stress } \\
\text { vs. } \\
\text { Strain } \\
(p s i / \mu \varepsilon)\end{array}$ & $\begin{array}{l}\text { Max. } \\
\text { Load } \\
\text { P } \\
\text { (lbs) }\end{array}$ & $\begin{array}{l}\text { Max. } \\
\text { Stress } \\
\\
\text { (ksi) }\end{array}$ & (msi) & $\begin{array}{c}\text { Strain } \\
\text { at } \\
\text { Max. } \\
\text { Load } \\
(\mu \varepsilon)\end{array}$ & $\begin{array}{c}\text { Fiber } \\
\text { Content }\end{array}$ \\
\hline $\mathrm{C} 2 / \mathrm{T} / \mathrm{T} 1$ & 1.0301 & 0.279 & 0.2874 & 1.1403 & 14580 & 50.73 & 3.96 & 12708 & \multirow{6}{*}{58.3} \\
\hline $\mathrm{C} 2 / \mathrm{T} / \mathrm{T} 2$ & 1.036 & 0.275 & 0.2849 & 1.2528 & 14165 & 49.71 & 4.39 & 11208 & \\
\hline $\mathrm{C} 2 / \mathrm{T} / \mathrm{T} 3$ & 1.0406 & 0.294 & 0.306 & 1.4026 & 12548 & 41.01 & 4.58 & 8943 & \\
\hline $\mathrm{C} 2 / \mathrm{T} / \mathrm{T} 5$ & 1.0346 & 0.2913 & 0.3014 & 1.2445 & 14272 & 47.34 & 4.12 & 12284 & \\
\hline \multicolumn{6}{|r|}{ AVG } & 47.2 & 4.26 & 11285 & \\
\hline \multicolumn{6}{|c|}{$\%$ STD } & 9.23 & 6.33 & 14.92 & \\
\hline $\mathrm{C} 2 / \mathrm{T} / \mathrm{B} 1$ & 1.0173 & 0.2883 & 0.2933 & 1.5375 & 8806 & 30.02 & 5.24 & 7432 & \multirow{6}{*}{58.3} \\
\hline $\mathrm{C} 2 / \mathrm{T} / \mathrm{B} 2$ & 1.052 & 0.283 & 0.2977 & 1.2832 & 9438 & 31.7 & 4.31 & 8513 & \\
\hline $\mathrm{C} 2 / \mathrm{T} / \mathrm{B} 4$ & 1.0456 & 0.281 & 0.2938 & 1.3075 & 13302 & 45.27 & 4.44 & 12027 & \\
\hline $\mathrm{C} 2 / \mathrm{T} / \mathrm{B} 5$ & 1.0736 & 0.281 & 0.3017 & 1.3329 & 10562 & 35 & 4.41 & 7935 & \\
\hline \multicolumn{6}{|r|}{ AVG } & 35.5 & 4.6 & 8976.7 & \\
\hline \multicolumn{6}{|c|}{$\%$ STD } & 19.23 & 9.34 & 23.13 & \\
\hline
\end{tabular}

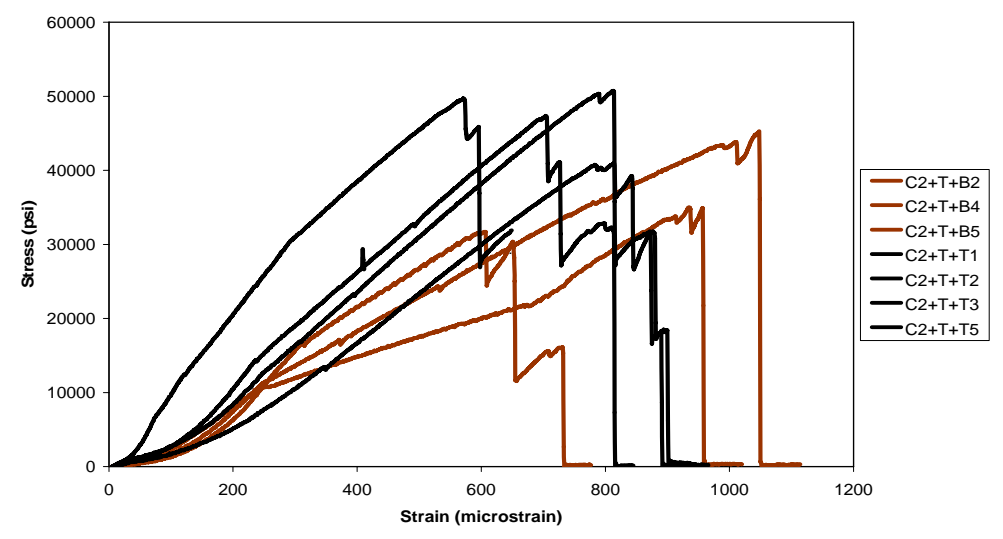

Figure 5.11 Stress-strain behavior of pultruded carbon/VE composites in transverse direction (with CSM) 


\subsubsection{Symmetrical Fiber Architecture after Removing CSM and 510A VE: Long. direction (Run2)}

Specimen tested in set 2 and 3 contained a layer of CSM. For this set of samples, CSM layer was removed from the sample without damaging the underneath layer of carbon. Significant change in mechanical properties was observed by removal of CSM from original specimens. Results for this experimental set are listed in Table 5.9 and stress strain behavior is shown in Figure 5.12. Average maximum stress for top layer was observed to be $43.22 \mathrm{ksi}$ and tensile modulus of $4.72 \mathrm{msi}$. Bottom layer showed average maximum stress of $53.66 \mathrm{ksi}$ and tensile modulus of $4.33 \mathrm{msi}$.

Table 5.9 Tension test results for pultruded carbon/VE composites in longitudinal direction (w/o CSM)

\begin{tabular}{|c|c|c|c|c|c|c|c|c|c|}
\hline $\begin{array}{c}\text { Sample } \\
\text { ID }\end{array}$ & $\begin{array}{l}\text { Avg. } \\
\text { Width } \\
\text { (in.) }\end{array}$ & $\begin{array}{l}\text { Avg. } \\
\text { Thick } \\
\text { (in.) }\end{array}$ & $\left(\right.$ in $\left.^{2}\right)$ & $\begin{array}{c}\text { Slope } \\
\text { Stress } \\
\text { vs. } \\
\text { Strain } \\
(\mathrm{psi} / \mu \varepsilon) \\
\end{array}$ & $\begin{array}{l}\text { Max. } \\
\text { Load } \\
\text { P } \\
\text { (lbs) } \\
\end{array}$ & $\begin{array}{l}\text { Max. } \\
\text { Stress } \\
\text { (ksi) }\end{array}$ & (msi) & $\begin{array}{c}\text { Strain } \\
\text { at } \\
\text { Max. } \\
\text { Load } \\
(\mu \varepsilon)\end{array}$ & $\begin{array}{c}\begin{array}{c}\text { Fiber } \\
\text { Content }\end{array} \\
(\mathrm{wt} \%)\end{array}$ \\
\hline $\mathrm{C} 2 / \mathrm{L} / \mathrm{T} 1$ & 1.055 & 0.251 & 0.2648 & 1.2642 & 13872 & 52.38 & 4.77 & 15047 & \multirow{5}{*}{58.3} \\
\hline $\mathrm{C} 2 / \mathrm{L} / \mathrm{T} 2$ & 1.045 & 0.263 & 0.2748 & 1.2021 & 10023 & 36.47 & 4.37 & 13114 & \\
\hline $\mathrm{C} 2 / \mathrm{L} / \mathrm{T} 3$ & 1.046 & 0.251 & 0.2625 & 1.324 & 10716 & 40.81 & 5.04 & 10342 & \\
\hline \multicolumn{6}{|r|}{ AVG } & 43.22 & 4.72 & 12834 & \\
\hline \multicolumn{6}{|c|}{$\%$ STD } & 19.01 & 7.0 & 18.49 & \\
\hline $\mathrm{C} 2 / \mathrm{L} / \mathrm{B} 1$ & 1.0433 & 0.2243 & 0.2341 & 1.0099 & 11625 & 49.66 & 4.31 & 14959 & \multirow{5}{*}{58.3} \\
\hline $\mathrm{C} 2 / \mathrm{L} / \mathrm{B} 7$ & 1.0393 & 0.222 & 0.2307 & 0.9448 & 13749 & 59.58 & 4.09 & 14785 & \\
\hline $\mathrm{C} 2 / \mathrm{L} / \mathrm{B} 8$ & 1.0673 & 0.2093 & 0.2234 & 1.0297 & 11562 & 51.75 & 4.6 & 11681 & \\
\hline \multicolumn{6}{|c|}{ AVG } & 53.66 & 4.33 & 13808 & \\
\hline \multicolumn{6}{|c|}{$\%$ STD } & 9.72 & 5.77 & 13.35 & \\
\hline
\end{tabular}

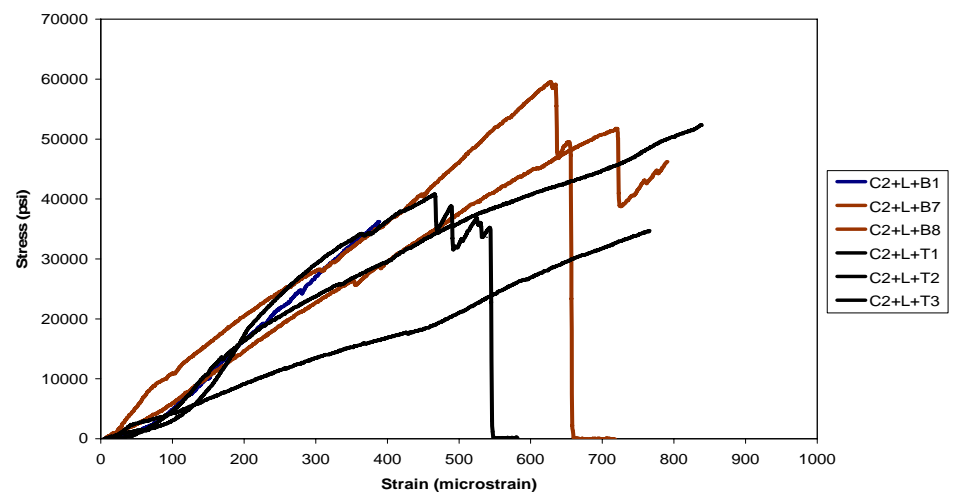

Figure 5.12 Stress-strain behavior of pultruded carbon/VE composites in longitudinal direction (w/o CSM) 


\subsubsection{Symmetrical Fiber Architecture after Removing CSM and 510A VE: Trans. direction (Run2)}

Similar to specimen in set 5, CFRP laminates were tested for transverse properties after removing CSM layer. Results for this experimental set are listed in Table 5.10 and stress strain behavior is shown in Figure 5.13. Average maximum stress for top layer was observed to be $44.11 \mathrm{ksi}$ and tensile modulus of $5.25 \mathrm{msi}$. Bottom layer showed average maximum stress of $43.82 \mathrm{ksi}$ and tensile modulus of $5.27 \mathrm{msi}$.

Table 5.10 Tension test results for pultruded carbon/VE composites in transverse direction (w/o CSM)

\begin{tabular}{|c|c|c|c|c|c|c|c|c|c|}
\hline $\begin{array}{c}\text { Sample } \\
\text { ID }\end{array}$ & $\begin{array}{c}\text { Avg. } \\
\text { Width } \\
\text { (in.) }\end{array}$ & $\begin{array}{l}\text { Avg. } \\
\text { Thick }\end{array}$ & Area & $\begin{array}{c}\text { Slope } \\
\text { Stress } \\
\text { vs. } \\
\text { Strain } \\
(\mathrm{psi} / \mu \varepsilon)\end{array}$ & $\begin{array}{l}\text { Max. } \\
\text { Load P }\end{array}$ & $\begin{array}{l}\text { Max. } \\
\text { Stress }\end{array}$ & (msi) & $\begin{array}{c}\text { Strain } \\
\text { at } \\
\text { Max. } \\
\text { Load } \\
(\mu \varepsilon)\end{array}$ & $\begin{array}{c}\text { Fiber } \\
\text { Content } \\
(\mathbf{w t} \%)\end{array}$ \\
\hline $\mathrm{C} 2 / \mathrm{T} / \mathrm{T} 1$ & 1.044 & 0.246 & 0.2568 & 1.3767 & 14334 & 55.81 & 5.36 & 11343 & \multirow{7}{*}{58.3} \\
\hline $\mathrm{C} 2 / \mathrm{T} / \mathrm{T} 2$ & 1.006 & 0.218 & 0.2195 & 1.0035 & 8776 & 39.99 & 4.57 & 10113 & \\
\hline $\mathrm{C} 2 / \mathrm{T} / \mathrm{T} 3$ & 1.039 & 0.2176 & 0.2263 & 1.0839 & 10655 & 47.08 & 4.78 & 12425 & \\
\hline $\mathrm{C} 2 / \mathrm{T} / \mathrm{T} 4$ & 1.031 & 0.2163 & 0.2232 & 1.4528 & 8807 & 39.46 & 6.5 & 5704 & \\
\hline $\mathrm{C} 2 / \mathrm{T} / \mathrm{T} 5$ & 1.038 & 0.2246 & 0.2333 & 1.1716 & 8914 & 38.21 & 5.02 & 8869 & \\
\hline \multicolumn{6}{|r|}{ AVG } & 44.11 & 5.25 & 9690 & \\
\hline \multicolumn{6}{|r|}{$\%$ STD } & 16.77 & 14.47 & 26.78 & \\
\hline $\mathrm{C} 2 / \mathrm{T} / \mathrm{B} 1$ & 1.025 & 0.2536 & 0.26 & 1.3717 & 11732 & 45.12 & 5.27 & 9443 & \multirow{7}{*}{58.3} \\
\hline $\mathrm{C} 2 / \mathrm{T} / \mathrm{B} 2$ & 1.0343 & 0.2363 & 0.2444 & 1.4332 & 9823 & 40.18 & 5.86 & 6930 & \\
\hline $\mathrm{C} 2 / \mathrm{T} / \mathrm{B} 3$ & 1.0583 & 0.2356 & 0.2494 & 1.384 & 11624 & 46.6 & 5.54 & 8874 & \\
\hline $\mathrm{C} 2 / \mathrm{T} / \mathrm{B} 4$ & 1.0556 & 0.2393 & 0.2527 & 1.2079 & 9407 & 37.23 & 4.78 & 7682 & \\
\hline $\mathrm{C} 2 / \mathrm{T} / \mathrm{B} 5$ & 1.03 & 0.257 & 0.2647 & 1.3011 & 13225 & 49.96 & 4.91 & 10721 & \\
\hline \multicolumn{6}{|r|}{ AVG } & 43.82 & 5.27 & 8730 & \\
\hline \multicolumn{6}{|r|}{$\%$ STD } & 11.62 & 8.34 & 17.01 & \\
\hline
\end{tabular}

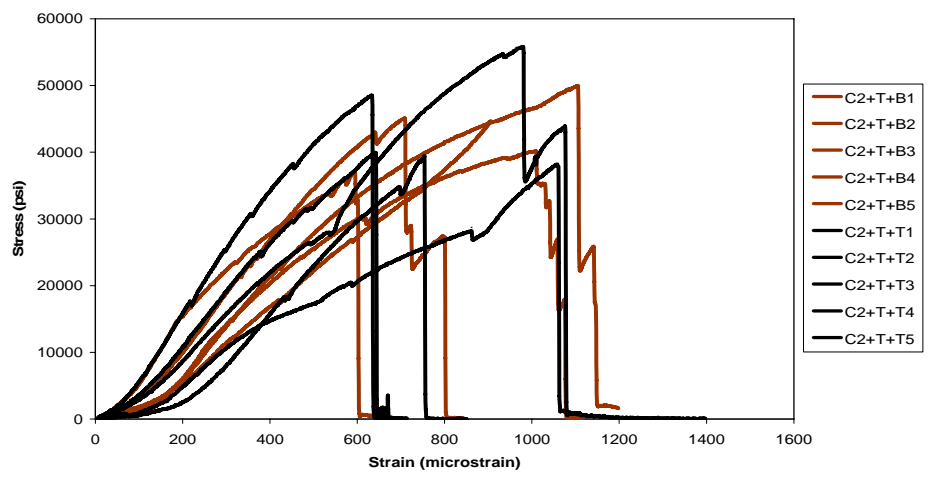

Figure 5.13 Stress-strain behavior of pultruded carbon/VE composites in transverse direction (w/o CSM) 


\subsubsection{Conclusions}

Figures 5.14 and 5.15 show the average maximum stress and average tensile modulus plotted for the entire set of experiments as well as theoretical predictions in pultrusion process respectively.

\section{i. Top vs. Bottom Face-sheet}

In case of Run1 specimens, top face sheet shows better strength with $25 \%$ high tensile stress and 4\% higher tensile modulus. In contrast for Run 2 in longitudinal direction, bottom face sheet shows better properties with $20 \%$ higher tensile strength and 30\% higher tensile modulus than that of top face sheets.

The observed deviation in properties between top and bottom face sheets of panels is attributed to the fact of improper resin enrichment. During pultrusion process, layers of fabric pass through the resin bath before entering the heating die. At this stage, resin from the resin bath is pumped and sprayed on both the surface of the fabric. This resin spraying may no ensure uniform resin spread all over the fabric which may result in either top or bottom surface with improper enrichment.

\section{ii. Longitudinal vs. Transverse Direction Specimens}

For Run 2 specimens with CSM, top face sheet in longitudinal direction showed 7\% better tensile strength with $25 \%$ smaller tensile modulus compared to specimens in transverse direction. In addition, bottom face-sheets in longitudinal direction behaved with $41 \%$ higher tensile strength and nearly equal tensile modulus as compared to specimens in transverse direction.

Moreover for Run 2 specimens after removal of CSM, top face sheet in longitudinal direction showed nearly equal tensile strength and drop of $11 \%$ in tensile modulus as against bottom specimens. Furthermore, bottom face sheet in longitudinal direction behaved with $18 \%$ better tensile strength and $21 \%$ less tensile modulus as compared to transverse specimens. 


\section{iii. Specimens with CSM vs. without CSM}

In case of top face-sheet longitudinal specimen of Run 2, on removal of CSM tensile strength of specimen reduced by about $15 \%$ whereas tensile modulus increased by $38 \%$. In addition, for bottom face sheet longitudinal specimen of Run 2, CSM removal resulted in drop of tensile strength $11 \%$ and only $3 \%$ reduction or no significant change in tensile modulus was observed.

On the same line for transverse specimens in longitudinal direction, for the top face-sheet drop of $7 \%$ in tensile strength and $23 \%$ rise in tensile modulus was observed after removal of CSM. In addition, bottom face-sheet showed $23 \%$ improvement in tensile strength and $14 \%$ higher tensile modulus on removal of CSM.

CSM contains randomly oriented continuous glass fiber strands. It has been reported that in-homogeneity due to non-uniform distribution of fibers in CSM causes a large scatter in the mechanical properties of the composites (Mallick, 1997). Furthermore, E-glass being weaker as compared strength of carbon fibers, CSM layer was found to be inefficient to provide any strength in loading direction. In addition, Vadlamani D. (2006) and Shekhar V. (2007) have reported similar trends in the results for E-glass and epoxy/vinyl ester/ urethane.

\section{iv. Symmetric vs. Non-symmetric Fabric Architecture}

For the specimens in longitudinal direction, top face sheet of Run 1 with symmetric fiber architecture possessed 35\% higher tensile strength and 10\% higher tensile modulus to those of top face sheet of Run 2 with non-symmetric fiber architecture. Bottom face sheet of Run 1 showed nearly equal tensile strength and 14\% tensile modulus as compared to bottom face sheet of Run 2 .

On comparison between compression molding and pultrusion, results show a close resemblance of experimental stress and modulus for compression molding as compared to pultrusion. It leads to a conclusion that compression molding is more efficient to produce a better performance composite as compared to pultrusion. It must be also noted 
that pultrusion was used for mass scale production whereas other one was used for lab scale manufacturing. For large scale production, it is more challenging to produce composites with uniform properties.

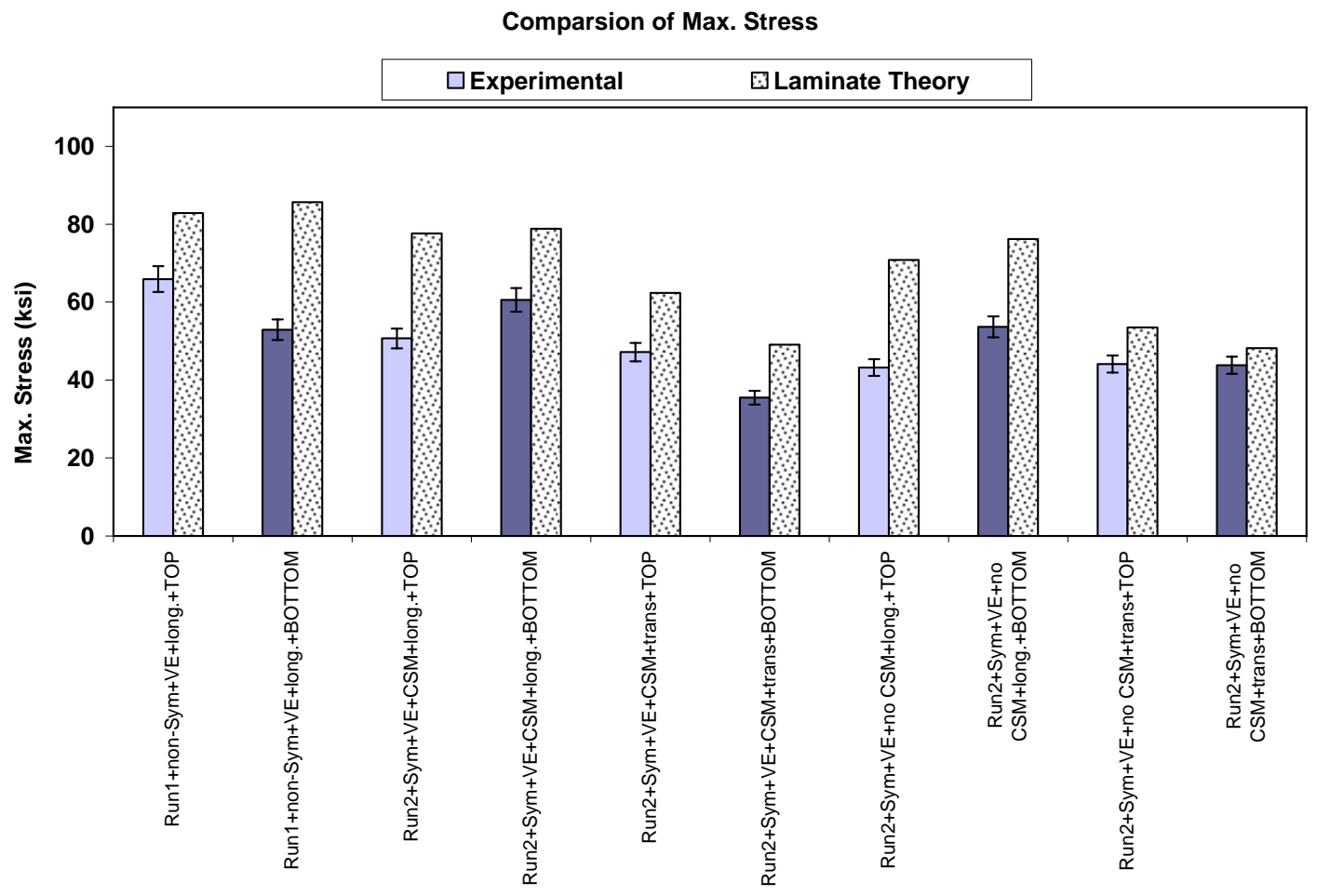

Figure 5.14 Chart comparison of maximum stress for carbon/VE composites by pultrusion 


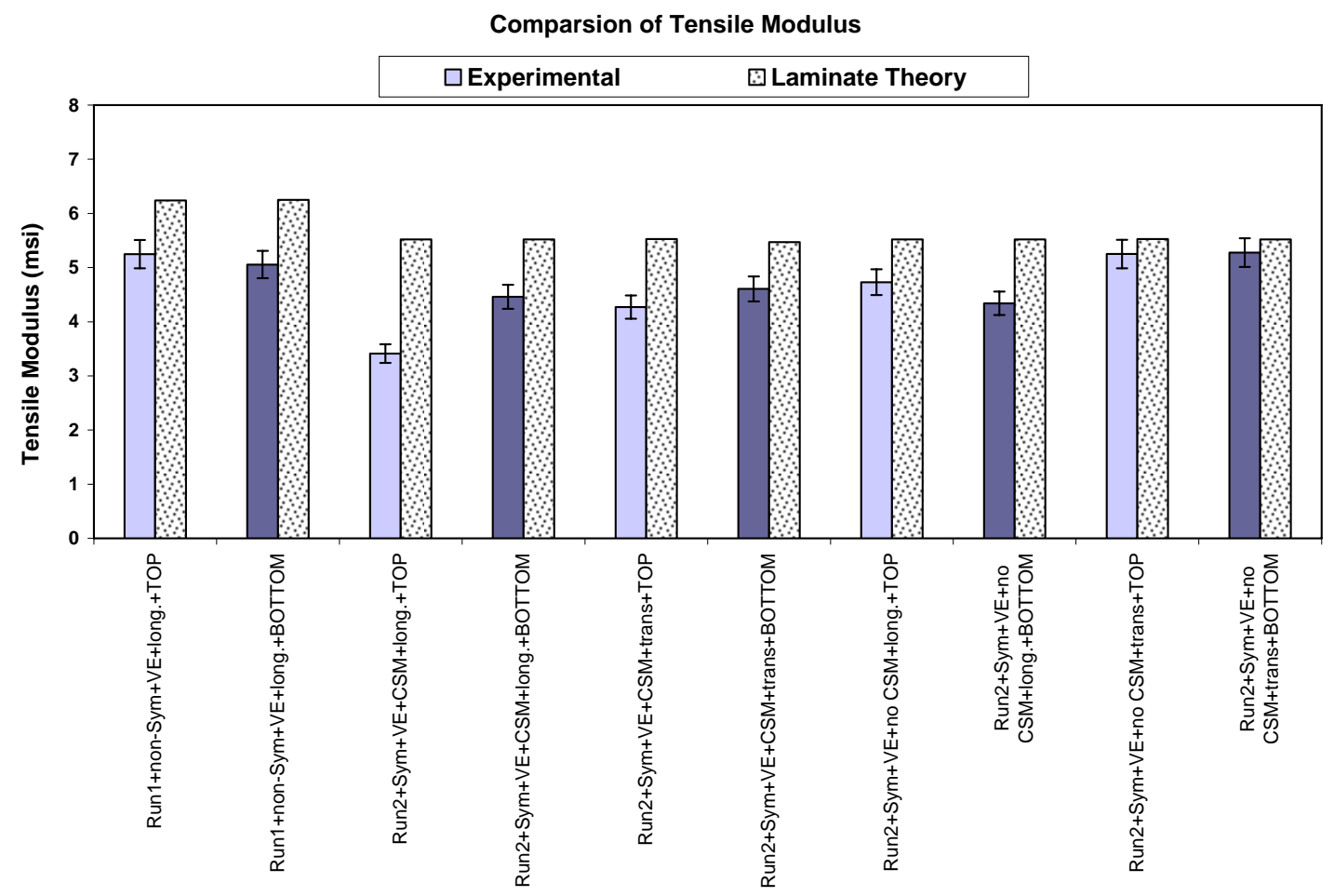

Figure 5.15 Chart comparison of tensile modulus for carbon/VE composites by pultrusion

\subsubsection{Resin Infusion}

CFRP composite plates with 6 layers of carbon fabric were prepared with epoxy and Vinyl Ester resin by resin infusion process. Epoxy was cured at a high temperature and VE at room temperature. Samples were tested for tensile properties by tension test. Summary of the tension test is tabulated below.

\subsubsection{Symmetric Fiber Architecture with Epoxy Cured at 140 F for 105 min}

For this set of specimens curing was carried out at $140 \mathrm{~F}$ for curing time of $105 \mathrm{~min}$. Average thickness of composites plate was around 0.23 " slightly higher than those compression molded samples. Average maximum stress for this set of sample was found to be $81.74 \mathrm{ksi}$ and tensile modulus of $5.52 \mathrm{msi}$. Table 5.11 summarizes the data for tension test. Stress-strain behavior for the above test specimen is shown in Figure. 5.16. 
Table 5.11 Tension test results for carbon/epoxy composite by resin infusion

\begin{tabular}{|c|c|c|c|c|c|c|c|c|c|}
\hline $\begin{array}{c}\text { Sample } \\
\text { ID }\end{array}$ & $\begin{array}{c}\text { Avg. } \\
\text { Width } \\
\text { (in.) }\end{array}$ & $\begin{array}{l}\text { Avg. } \\
\text { Thick }\end{array}$ & $\left(\mathrm{in}^{2}\right)$ & $\begin{array}{c}\text { Slope } \\
\text { Stress } \\
\text { vs. } \\
\text { Strain } \\
(\mathrm{psi} / \mu \varepsilon)\end{array}$ & $\begin{array}{l}\text { Max. } \\
\text { Load } \\
\quad P \\
\text { (lbs) }\end{array}$ & $\begin{array}{l}\text { Max. } \\
\text { Stress }\end{array}$ & (msi) & $\begin{array}{c}\text { Strain } \\
\text { at Max. } \\
\text { Load } \\
(\mu \varepsilon)\end{array}$ & $\begin{array}{c}\text { Fiber } \\
\text { Content }\end{array}$ \\
\hline $1.1 \mathrm{D}$ & 0.9933 & 0.254 & 0.2523 & 1.3085 & 19384 & 76.88 & 5.18 & 15265 & \multirow{8}{*}{66.13} \\
\hline $1.2 \mathrm{D}$ & 0.9816 & 0.2396 & 0.2353 & 1.2869 & 20339 & 86.44 & 5.46 & 15862 & \\
\hline $1.3 \mathrm{D}$ & 0.9906 & 0.2323 & 0.2302 & 1.3764 & 15843 & 68.83 & 5.98 & 15156 & \\
\hline $1.1 \mathrm{~W}$ & 1.013 & 0.254 & 0.2573 & 1.3373 & 21278 & 82.69 & 5.19 & 15812 & \\
\hline $1.2 \mathrm{~W}$ & 1.0317 & 0.2203 & 0.2273 & 1.339 & 21001 & 92.38 & 5.89 & 15810 & \\
\hline $1.3 \mathrm{~W}$ & 1.0017 & 0.2476 & 0.2481 & 1.3512 & 20662 & 83.29 & 5.44 & 15841 & \\
\hline \multicolumn{6}{|r|}{ AVG } & 81.74 & 5.52 & 15624.3 & \\
\hline \multicolumn{6}{|c|}{$\%$ STD } & 9.92 & 6.15 & 2.06 & \\
\hline
\end{tabular}

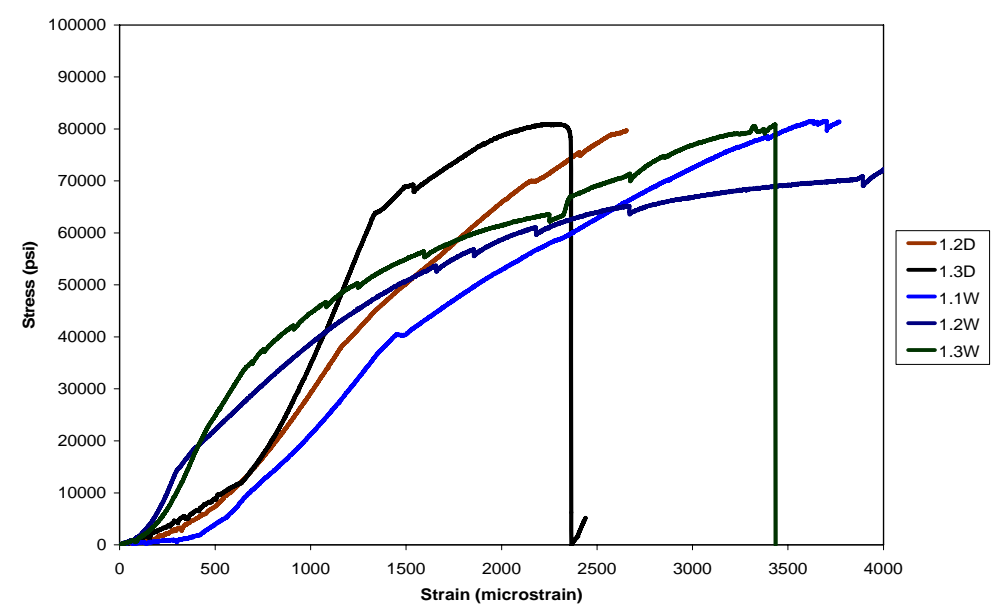

Figure 5.16 Stress-strain behavior of carbon/epoxy composites by resin infusion

\subsubsection{Symmetric Fiber Architecture with Epoxy Cured at 140 F for 145 min}

For this set of specimen curing was carried out at $140 \mathrm{~F}$ for curing time of $145 \mathrm{~min}$. with slightly extended curing time Average thickness of composites plate was around 0.24". Average maximum stress for this set of sample was found to be $79.6 \mathrm{ksi}$ and tensile modulus of $5.31 \mathrm{msi}$. Table 5.12 summarizes the data for tension test. Stress-strain behavior is shown in Figure. 5.17. 
Table 5.12 Tension test results for carbon/epoxy composite by resin infusion

\begin{tabular}{|c|c|c|c|c|c|c|c|c|c|}
\hline $\begin{array}{c}\text { Sample } \\
\text { ID }\end{array}$ & $\begin{array}{c}\text { Avg. } \\
\text { Width } \\
\text { (in.) }\end{array}$ & $\begin{array}{l}\text { Avg. } \\
\text { Thick } \\
\text { (in.) }\end{array}$ & $\left(\mathrm{in}^{2}\right)$ & $\begin{array}{c}\text { Slope } \\
\text { Stress } \\
\text { vs. } \\
\text { Strain } \\
(p s i / \mu \varepsilon)\end{array}$ & $\begin{array}{l}\text { Max. } \\
\text { Load } \\
\quad P \\
\text { (lbs) }\end{array}$ & $\begin{array}{l}\text { Max. } \\
\text { Stress }\end{array}$ & (msi) & $\begin{array}{c}\text { Strain } \\
\text { at } \\
\text { Max. } \\
\text { Load } \\
(\mu \varepsilon)\end{array}$ & $\begin{array}{c}\text { Fiber } \\
\text { Content }\end{array}$ \\
\hline $2.1 \mathrm{D}$ & 1.039 & 0.2526 & 0.2625 & 1.3302 & 20354 & 77.53 & 5.06 & 15865 & \multirow{8}{*}{78.64} \\
\hline $2.2 \mathrm{D}$ & 1.0376 & 0.2383 & 0.2473 & 1.3464 & 19446 & 78.63 & 5.44 & 15320 & \\
\hline $2.3 \mathrm{D}$ & 1.0396 & 0.2453 & 0.2551 & 1.3489 & 21124 & 82.81 & 5.28 & 15855 & \\
\hline $2.1 \mathrm{~W}$ & 0.9816 & 0.2493 & 0.2448 & 1.2995 & 17321 & 70.76 & 5.3 & 14297 & \\
\hline $2.2 \mathrm{~W}$ & 0.9193 & 0.24 & 0.2206 & 1.2083 & 17922 & 81.22 & 5.47 & 15816 & \\
\hline $2.3 \mathrm{~W}$ & 0.9686 & 0.245 & 0.2373 & 1.2641 & 20570 & 86.67 & 5.32 & 14996 & \\
\hline \multicolumn{6}{|r|}{ AVG } & 79.61 & 5.31 & 15358 & \\
\hline \multicolumn{6}{|r|}{$\%$ STD } & 6.78 & 2.63 & 4.08 & \\
\hline
\end{tabular}

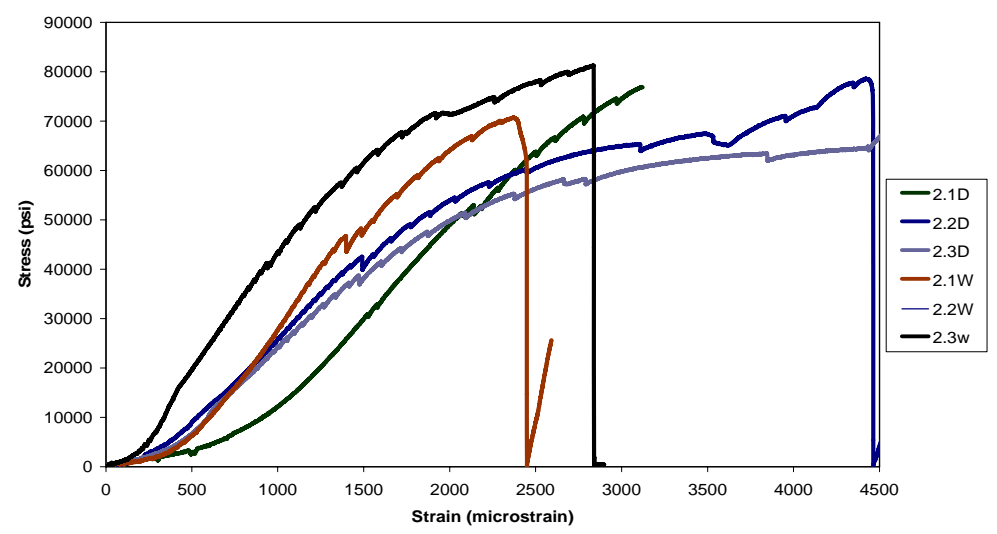

Figure 5.17 Stress-strain behavior of carbon/epoxy composites by resin infusion

\subsubsection{Symmetric Fiber Architecture with 510A VE Cured at RT}

Two sets of specimens here were prepared with VE resin and cured at room temperature. Average thickness of composite plate was found to be around 0.26 " -0.28 ". Sample set 3 and 4 only differed in fiber content else remaining the same. Tension test data are reported in Tables 5.13 and 5.14 with stress-strain behavior in Figures 5.18 and 5.19 respectively. Average maximum stress for set 3 was observed to be $58.49 \mathrm{ksi}$ and for set $464.33 \mathrm{ksi}$. Average value of tensile modulus was found to be $4.56 \mathrm{msi}$ and $4.48 \mathrm{msi}$ for set 3 and set 4 respectively. 
Table 5.13 Tension test results for carbon/VE composite by resin infusion

\begin{tabular}{|c|c|c|c|c|c|c|c|c|c|}
\hline $\begin{array}{c}\text { Sample } \\
\text { ID }\end{array}$ & $\begin{array}{c}\text { Avg. } \\
\text { Width } \\
\text { (in.) }\end{array}$ & $\begin{array}{l}\text { Avg. } \\
\text { Thick } \\
\text { (in.) }\end{array}$ & $\left(\mathrm{in}^{2}\right)$ & $\begin{array}{c}\text { Slope } \\
\text { Stress } \\
\text { vs. } \\
\text { Strain } \\
(\mathrm{psi} / \mu \varepsilon)\end{array}$ & $\begin{array}{l}\text { Max. } \\
\text { Load } \\
\quad \mathbf{P} \\
\text { (lbs) }\end{array}$ & $\begin{array}{l}\text { Max. } \\
\text { Stress }\end{array}$ & (msi) & $\begin{array}{c}\text { Strain } \\
\text { at } \\
\text { Max. } \\
\text { Load } \\
(\mu \varepsilon)\end{array}$ & $\begin{array}{c}\text { Fiber } \\
\text { Content } \\
(w t \%)\end{array}$ \\
\hline $3.1 \mathrm{D}$ & 1.0053 & 0.2766 & 0.2781 & 1.2211 & 16397 & 58.95 & 4.39 & 15811 & \multirow{7}{*}{55.66} \\
\hline $3.2 \mathrm{D}$ & 0.9526 & 0.2466 & 0.235 & 1.0998 & 14750 & 62.76 & 4.68 & 14728 & \\
\hline $3.3 \mathrm{D}$ & 1.0066 & 0.2603 & 0.2621 & 1.1507 & 15951 & 60.86 & 4.3 & 15741 & \\
\hline $3.1 \mathrm{~W}$ & 0.988 & 0.2813 & 0.278 & 1.3157 & 16105 & 57.94 & 4.73 & 14150 & \\
\hline $3.2 \mathrm{~W}$ & 0.9847 & 0.2676 & 0.2636 & 1.2157 & 13687 & 51.95 & 4.61 & 11111 & \\
\hline \multicolumn{6}{|r|}{ AVG } & 58.49 & 4.56 & 14308 & \\
\hline \multicolumn{6}{|c|}{$\%$ STD } & 6.99 & 3.94 & 13.41 & \\
\hline
\end{tabular}

Table 5.14 Tension test results for carbon/VE composite by resin infusion

\begin{tabular}{|c|c|c|c|c|c|c|c|c|c|}
\hline $\begin{array}{c}\text { Sample } \\
\text { ID }\end{array}$ & $\begin{array}{l}\text { Avg. } \\
\text { Width }\end{array}$ & $\begin{array}{l}\text { Avg. } \\
\text { Thick }\end{array}$ & Area & $\begin{array}{c}\text { Slope } \\
\text { Stress } \\
\text { vs. } \\
\text { Strain } \\
(\mathrm{psi} / \mu \varepsilon)\end{array}$ & $\begin{array}{l}\text { Max. } \\
\text { Load } \\
\quad \text { P } \\
\text { (lbs) }\end{array}$ & $\begin{array}{l}\text { Max. } \\
\text { Stress }\end{array}$ & (msi) & $\begin{array}{c}\text { Strain } \\
\text { at } \\
\text { Max. } \\
\text { Load } \\
(\mu \varepsilon)\end{array}$ & $\begin{array}{c}\text { Fiber } \\
\text { Content }\end{array}$ \\
\hline 4.1D & 1.017 & 0.3126 & 0.318 & 1.3652 & 21001 & 66.05 & 4.29 & 15806 & \multirow{8}{*}{49.76} \\
\hline $4.2 \mathrm{D}$ & 1.0286 & 0.2976 & 0.3062 & 1.2912 & 18553 & 60.59 & 4.21 & 14859 & \\
\hline $4.3 \mathrm{D}$ & 1.0373 & 0.285 & 0.2956 & 1.3387 & 21155 & 71.55 & 4.52 & 15833 & \\
\hline $4.1 \mathrm{~W}$ & 0.998 & 0.2383 & 0.2379 & 1.1839 & 14550 & 61.08 & 4.97 & 13854 & \\
\hline $4.2 \mathrm{~W}$ & 0.9753 & 0.2973 & 0.29 & 1.2663 & 18245 & 62.91 & 4.36 & 15825 & \\
\hline $4.3 \mathrm{~W}$ & 0.9793 & 0.267 & 0.2615 & 1.1835 & 16659 & 63.71 & 4.52 & 14231 & \\
\hline \multicolumn{6}{|r|}{ AVG } & 64.33 & 4.48 & 15068 & \\
\hline \multicolumn{6}{|r|}{$\%$ STD } & 6.29 & 6.06 & 5.87 & \\
\hline
\end{tabular}

\subsubsection{Conclusions}

Figures 5.20 and 5.21 show the average maximum stress and average tensile modulus plotted for all the set of experiments in resin infusion process respectively.

Figures 5.20 and 5.21 indicate that higher curing time results in deterioration of mechanical properties. Average maximum stress dropped by $2.5 \%$ and tensile stress dropped by $3.8 \%$ for extended curing times. Maximum stress value for epoxy composites observed to be $24 \%$ higher than those VE composites for same fabric type. Moreover, 
tensile modulus for epoxy specimens was found to be about $20 \%$ higher than those VE specimens.

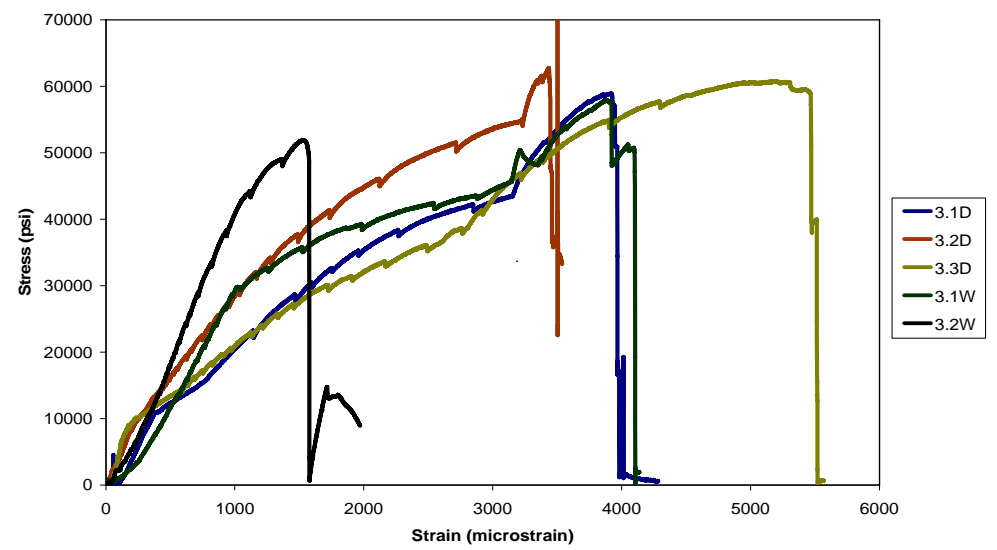

Figure 5.18 Stress-strain behavior of carbon/VE composites by resin infusion (fiber content $55.66 \%$ )

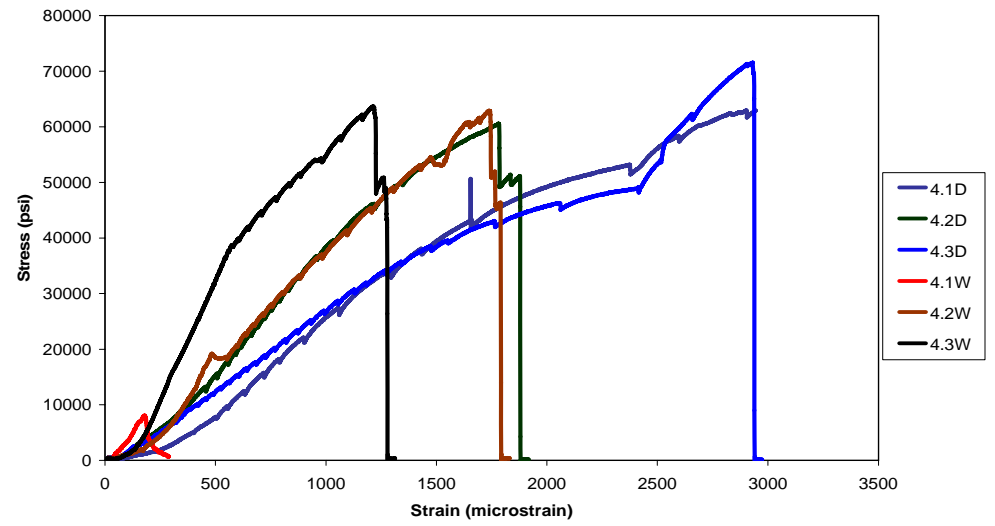

Figure 5.19 Stress-strain behavior of carbon/VE composites by resin infusion (fiber content $49.76 \%$ ) 


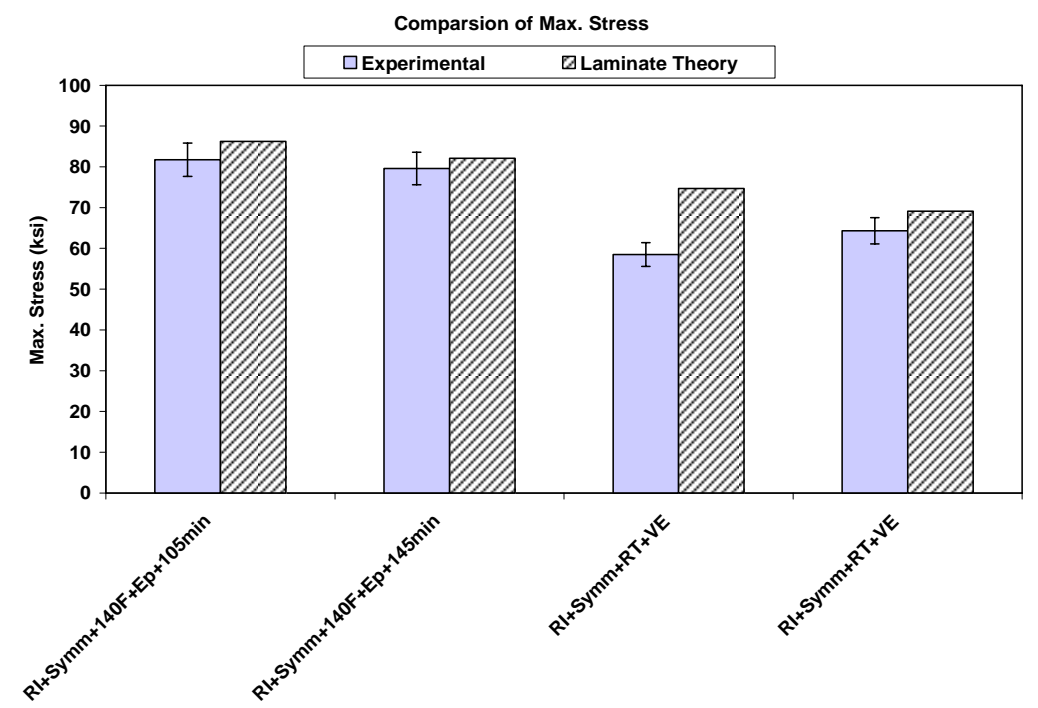

Figure 5.20 Chart comparison of maximum stress for carbon/VE or epoxy composites by resin infusion

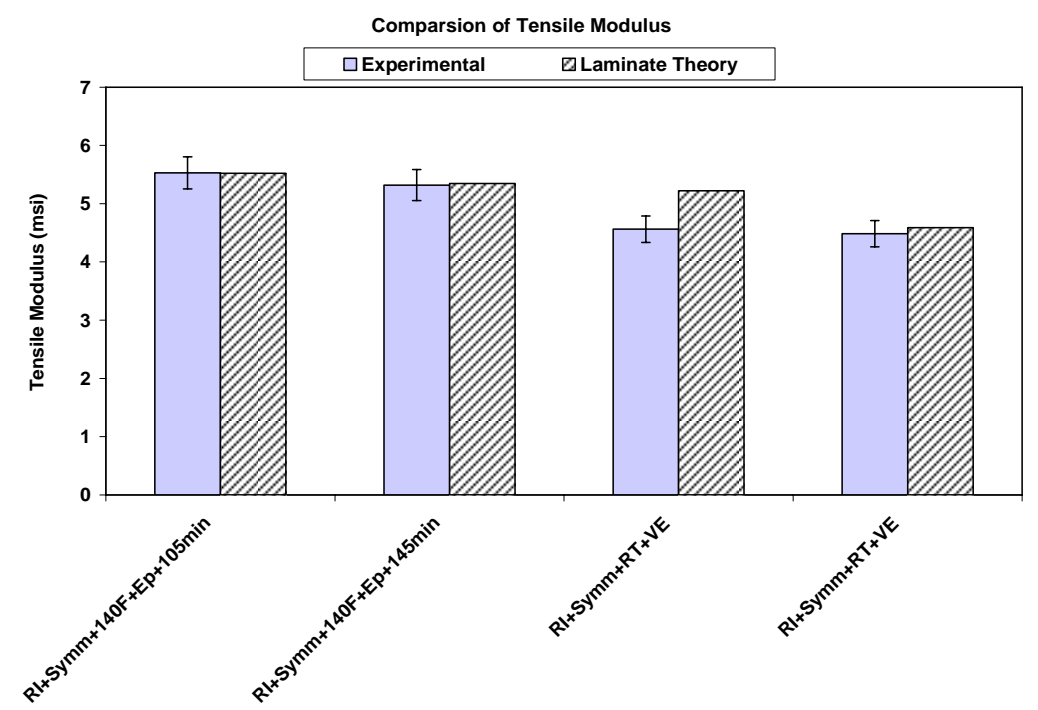

Figure 5.21 Chart comparison of tensile modulus for carbon/VE or epoxy composites by resin infusion

\subsection{Bending Test}

Composite laminates were also tested under flexural in addition to tension. Objective under bending is to compare the effects of various parameters on flexural properties of composite materials. Load-deflection behavior is shown for each set of specimens. Bending stress and modulus are then calculated and tabulated for each set of tests. 


\subsubsection{Compression Molding}

Upon fabricating the composite laminates through compression molding, composite plates were cut into dimensions specified by ASTM for mechanical characterization under bending. All specimens were tested under three point loading. Step by step procedure and experimental set up are described in detail in Chapter 3. Results and findings of coupon bending test are summarized in subsequent sections.

\subsubsection{Symmetric Fiber Architecture with 510A VE Cured at 190F}

Carbon composite specimens were prepared with VE resin cured at $190 \mathrm{~F}$ having symmetric fabric configuration. Table 5.15 shows results of bending test for eight specimens tested. Figure 5.22 shows the load-deflection curves. Average bending stress was found to be $77.92 \mathrm{ksi}$ and flexural modulus of $5.34 \mathrm{msi}$.

Table 5.15 Bending test results for carbon /VE composite by compression molding

\begin{tabular}{|c|c|c|c|c|c|c|c|}
\hline Sample & $\begin{array}{c}\text { Avg. } \\
\text { Width } \\
\text { (in.) }\end{array}$ & $\begin{array}{c}\text { Avg. } \\
\text { Thickness } \\
\text { (in.) }\end{array}$ & $\begin{array}{l}\text { Slope } \\
\text { P vs. } \\
\text { defl. } \\
\text { (lb/in.) }\end{array}$ & $\begin{array}{l}\text { Max. } \\
\text { Load } \\
(\text { lbs })\end{array}$ & $\begin{array}{c}\text { Bending } \\
\text { Stress } \\
\text { (ksi) }\end{array}$ & $\begin{array}{c}\mathbf{E}_{\mathrm{b}} \\
(\mathbf{m s i})\end{array}$ & $\begin{array}{c}\begin{array}{c}\text { Fiber } \\
\text { Content }\end{array} \\
(\mathbf{w t} \%) \\
\end{array}$ \\
\hline $5.1 \mathrm{D}$ & 0.541 & 0.237 & 2359.5 & 397 & 78.4 & 5.23 & \multirow{10}{*}{64.68} \\
\hline $5.2 \mathrm{D}$ & 0.529 & 0.235 & 2174.1 & 353 & 72.46 & 5.06 & \\
\hline 5.3D & 0.539 & 0.236 & 2339.9 & 385 & 76.76 & 5.25 & \\
\hline $5.4 \mathrm{D}$ & 0.49 & 0.238 & 2236.3 & 392 & 85.0 & 5.43 & \\
\hline $5.1 \mathrm{~W}$ & 0.501 & 0.241 & 2418.1 & 384 & 78.93 & 5.49 & \\
\hline $5.2 \mathrm{~W}$ & 0.533 & 0.232 & 2338.2 & 383 & 80.09 & 5.6 & \\
\hline $5.3 \mathrm{~W}$ & 0.525 & 0.244 & 2546.8 & 422 & 81.36 & 5.36 & \\
\hline $5.4 \mathrm{~W}$ & 0.51 & 0.238 & 2281.3 & 338 & 70.36 & 5.32 & \\
\hline \multicolumn{5}{|c|}{ AVG } & 77.92 & 5.34 & \\
\hline \multicolumn{5}{|c|}{$\%$ STD } & 6.05 & 3.0 & \\
\hline
\end{tabular}




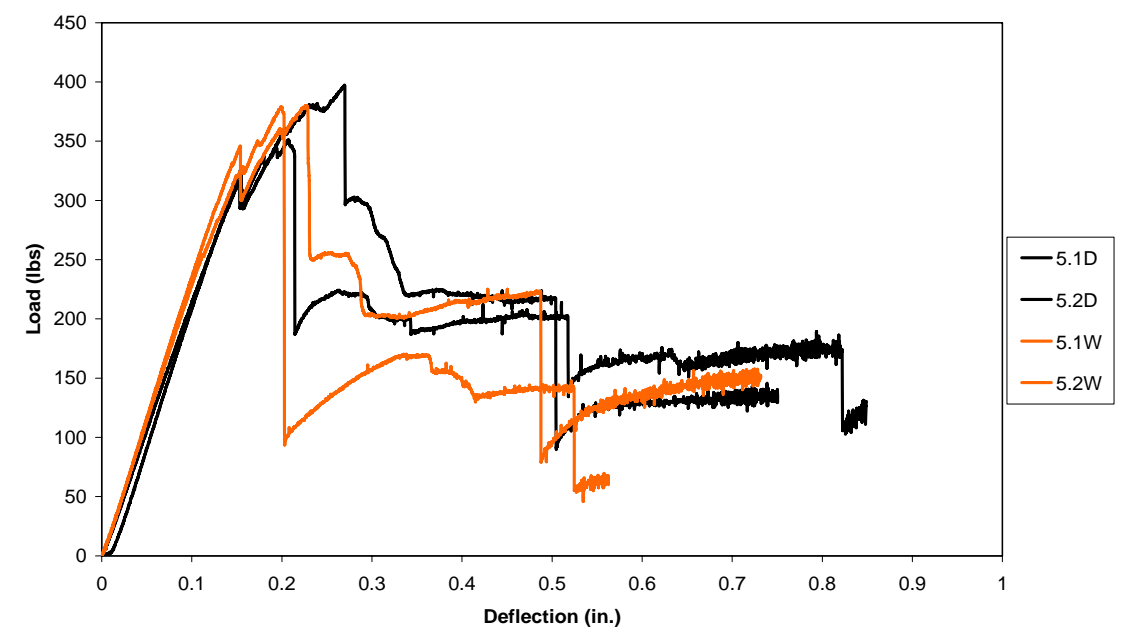

Figure 5.22 Load-deflection behavior of carbon/VE (190F) composites by compression molding

\subsubsection{Symmetric fiber architecture with $510 \mathrm{~A}$ VE cured at RT}

In this set of experiments, curing of composite plates was carried out at room temperature with symmetric fabric configuration and vinyl ester resin. Bending test results are listed in Table 5.16. Average bending stress for this set of experiment was found to be $86.43 \mathrm{ksi}$ and average flexural modulus is $6.82 \mathrm{msi}$. Load-deflection behavior of test specimens is shown in Figure 5.23.

Table 5.16 Bending test results for carbon /VE (RT) composite by compression molding

\begin{tabular}{|c|c|c|c|c|c|c|c|}
\hline Sample & $\begin{array}{c}\text { Avg. } \\
\text { Width } \\
\text { (in.) }\end{array}$ & $\begin{array}{l}\text { Avg. } \\
\text { Thickness } \\
\text { (in.) }\end{array}$ & $\begin{array}{l}\text { Slope } \\
\text { P vs. } \\
\text { defl. } \\
\text { (lb/in.) }\end{array}$ & $\begin{array}{l}\text { Max. } \\
\text { Load } \\
\text { (lbs) }\end{array}$ & $\begin{array}{c}\text { Bending } \\
\text { Stress } \\
\text { (ksi) }\end{array}$ & (msi) & $\begin{array}{c}\text { Fiber } \\
\text { Content } \\
(w t \%)\end{array}$ \\
\hline $6.1 \mathrm{D}$ & 0.5430 & 0.1900 & 1553.6 & 283 & 86.74 & 6.67 & \multirow{10}{*}{65.25} \\
\hline $6.2 \mathrm{D}$ & 0.5410 & 0.1940 & 1517.1 & 282 & 83.38 & 6.17 & \\
\hline $6.3 \mathrm{D}$ & 0.5320 & 0.1910 & 1455.7 & 259 & 80.15 & 6.28 & \\
\hline $6.4 \mathrm{D}$ & 0.5420 & 0.1910 & 1571.9 & 289 & 88.06 & 6.69 & \\
\hline $6.1 \mathrm{~W}$ & 0.5110 & 0.1880 & 1536.5 & 279 & 93.14 & 7.27 & \\
\hline $6.2 \mathrm{~W}$ & 0.4900 & 0.1880 & 1435.3 & 270 & 93.60 & 7.05 & \\
\hline $6.3 \mathrm{~W}$ & 0.4880 & 0.1850 & 1408.5 & 240 & 86.16 & 7.28 & \\
\hline $6.4 \mathrm{~W}$ & 0.5050 & 0.1880 & 1490.8 & 238 & 80.23 & 7.11 & \\
\hline \multicolumn{5}{|c|}{ AVG } & 86.43 & 6.82 & \\
\hline \multicolumn{5}{|c|}{ \% STD } & 5.97 & 6.30 & \\
\hline
\end{tabular}




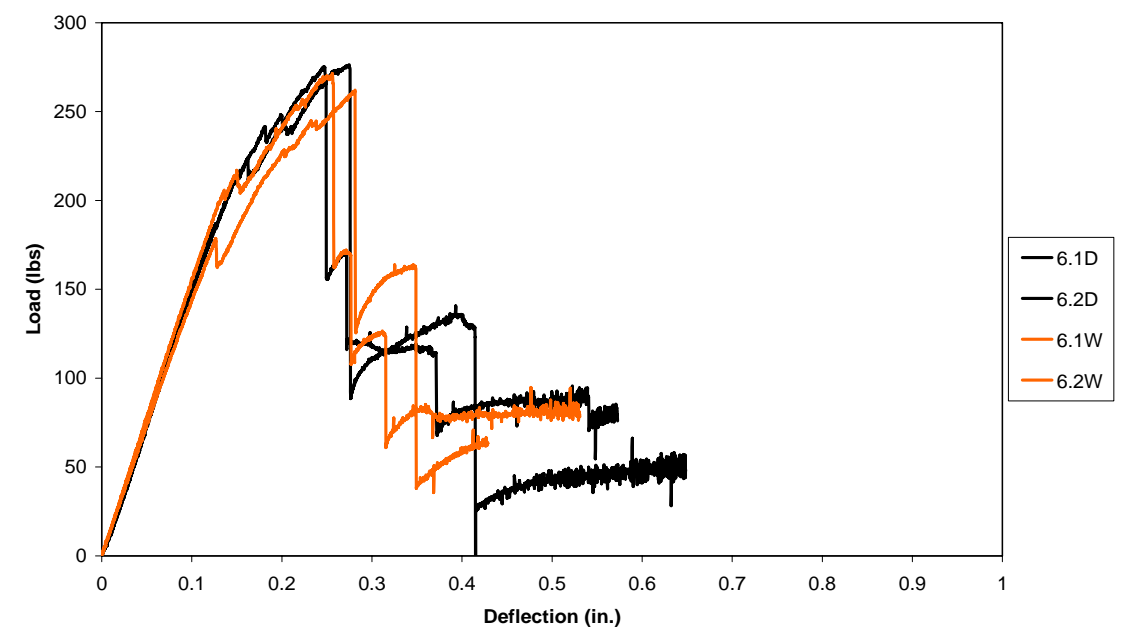

Figure 5.23 Load-deflection behavior of carbon/VE (RT) composites by compression molding

\subsubsection{Symmetric Fiber Architecture with CSM and 510A VE Cured at RT}

Layers of carbon fabric were compression molded with a layer of CSM. Curing of resin was carried out at room temperature. Composite plate was cut into desired dimension for bending tests. Average bending stress of $58.45 \mathrm{ksi}$ and flexural modulus of $4.81 \mathrm{msi}$ was observed for the listed set of specimen in Table 5.17. Behavior of load-deflection curve is shown in Figure 5.24.

Table 5.17 Bending test results for carbon /VE composite by compression molding (with CSM)

\begin{tabular}{|c|c|c|c|c|c|c|c|}
\hline Sample & $\begin{array}{l}\text { Avg. } \\
\text { Width } \\
\text { (in.) }\end{array}$ & $\begin{array}{l}\text { Avg. } \\
\text { Thickness } \\
\text { (in.) }\end{array}$ & $\begin{array}{l}\text { Slope } \\
\text { P vs. } \\
\text { defl. } \\
\text { (lb/in.) }\end{array}$ & $\begin{array}{l}\text { Max. } \\
\text { Load } \\
\text { (lbs) }\end{array}$ & $\begin{array}{c}\text { Bending } \\
\text { Stress } \\
\text { (ksi) }\end{array}$ & (msi) & $\begin{array}{c}\text { Fiber } \\
\text { Content } \\
(\mathbf{w t} \%)\end{array}$ \\
\hline $7.1 \mathrm{D}$ & 0.4820 & 0.2250 & 1645.4 & 234 & 57.51 & 4.77 & \multirow{6}{*}{65.21} \\
\hline $7.2 \mathrm{D}$ & 0.5170 & 0.2170 & 1721.0 & 276 & 68.00 & 5.20 & \\
\hline 7.3D & 0.4940 & 0.2230 & 1540.5 & 221 & 54.00 & 4.47 & \\
\hline 7.4D & 0.5070 & 0.2250 & 1716.1 & 231 & 54.28 & 4.77 & \\
\hline \multicolumn{5}{|c|}{$A V G$} & 58.45 & 4.80 & \\
\hline \multicolumn{5}{|c|}{ \% STD } & 11.22 & 6.25 & \\
\hline
\end{tabular}




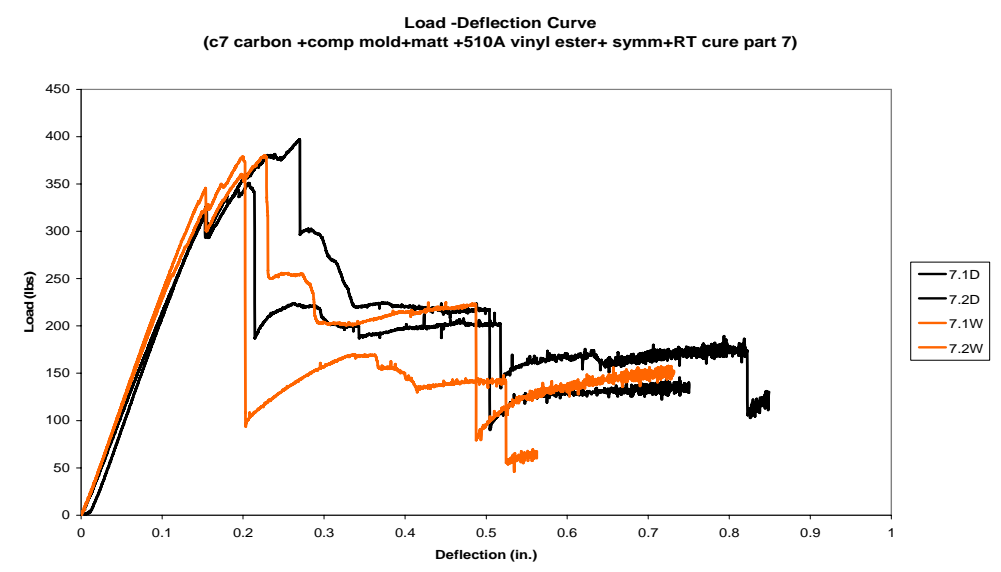

Figure 5.24 Load-deflection behavior of carbon/VE composites by compression molding (with CSM)

\subsubsection{Symmetric Fiber Architecture with Epoxy Cured at 190F}

Composite plate with symmetric fabric architecture was prepared with epoxy matrix cured at 190F. Average width of each sample was around 0.5 " and span of 4 " with 1" overhang on each side. Test results are summarized in Table 5.18. Load-deflection behavior is plotted in Figure 5.25. Average bending stress was around $93.39 \mathrm{ksi}$ and flexural modulus is $6.80 \mathrm{msi}$.

Table 5.18 Bending test results for carbon/epoxy composite by compression molding

\begin{tabular}{|c|c|c|c|c|c|c|c|}
\hline Sample & $\begin{array}{c}\text { Avg. } \\
\text { Width } \\
\text { (in.) }\end{array}$ & $\begin{array}{l}\text { Avg. } \\
\text { Thickness } \\
\text { (in.) }\end{array}$ & $\begin{array}{c}\text { Slope } \\
\text { P vs. } \\
\text { defl. } \\
\text { (lb/in.) }\end{array}$ & $\begin{array}{l}\text { Max. } \\
\text { Load } \\
\text { (lbs) }\end{array}$ & $\begin{array}{c}\text { Bending } \\
\text { Stress } \\
\text { (ksi) }\end{array}$ & (msi) & $\begin{array}{c}\text { Fiber } \\
\text { Content } \\
(\mathbf{w t} \%)\end{array}$ \\
\hline 1 & 0.4840 & 0.1860 & 1359.7 & 272 & 97.80 & 6.98 & \multirow{15}{*}{76.38} \\
\hline 2 & 0.5220 & 0.1860 & 1480.2 & 282 & 93.79 & 7.05 & \\
\hline 3 & 0.4890 & 0.1900 & 1336.1 & 242 & 82.58 & 6.37 & \\
\hline 4 & 0.5010 & 0.1890 & 1431.3 & 247 & 83.07 & 6.77 & \\
\hline 5 & 0.5180 & 0.1840 & 1448.3 & 293 & 100.47 & 7.18 & \\
\hline 6 & 0.4840 & 0.1900 & 1272.9 & 257 & 88.38 & 6.13 & \\
\hline 7 & 0.4860 & 0.1880 & 1391.8 & 270 & 94.56 & 6.89 & \\
\hline 8 & 0.4820 & 0.1900 & 1417.0 & 278 & 95.93 & 6.85 & \\
\hline 9 & 0.4970 & 0.1890 & 1462.1 & 307 & 103.95 & 6.97 & \\
\hline $8.1 \mathrm{~W}$ & 0.5510 & 0.1860 & 1643.5 & 312 & 98.28 & 7.42 & \\
\hline $8.2 \mathrm{~W}$ & 0.5420 & 0.1890 & 1655.1 & 304 & 94.36 & 7.23 & \\
\hline $8.3 \mathrm{~W}$ & 0.4630 & 0.1880 & 1394.4 & 286 & 105.30 & 7.29 & \\
\hline $8.4 \mathrm{~W}$ & 0.4690 & 0.1860 & 1370.1 & 255 & 94.44 & 7.25 & \\
\hline \multicolumn{5}{|r|}{ AVG } & 76.38 & 6.80 & \\
\hline \multicolumn{5}{|c|}{ \% STD } & 9.08 & 5.29 & \\
\hline
\end{tabular}




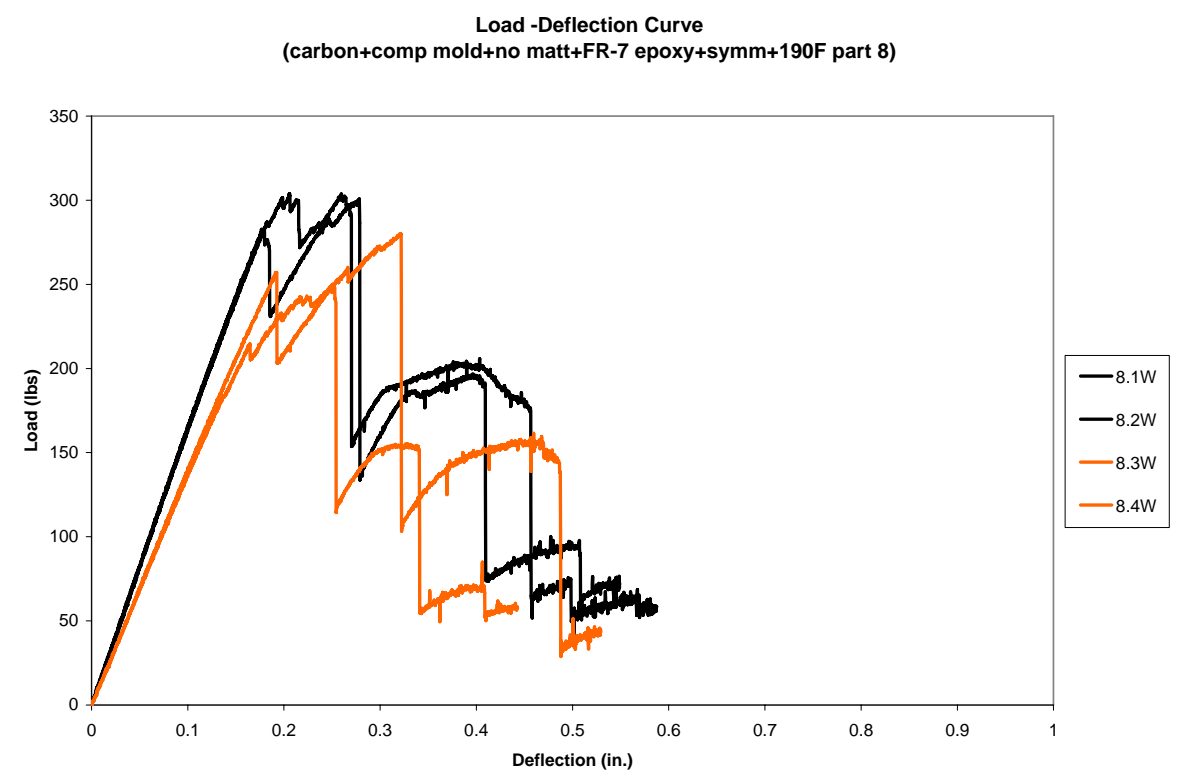

Figure 5.25 load-deflection behavior of carbon/epoxy composites by compression molding

\subsubsection{Symmetric Fiber Architecture with Stitched Layers and Epoxy Cured at $190 \mathrm{~F}$}

The effect of 3D stitching was quantified by stitching layers of carbon fabric stacked together. Direction of stitching for one way and two way stitch remains the same as described in tension test specimens. Summary of bending tests is presented in Table 5.19 where last two sample ID indicates the two way stitched (") test specimen. Loaddeflection behavior is plotted in Figure 5.26 and Figure 5.27. Average bending stress for one way stitched specimen was found to be around $90.88 \mathrm{ksi}$ with flexural modulus of $6.56 \mathrm{msi}$. In addition, two way stitched specimen showed average bending stress value of $92 \mathrm{ksi}$ and $6.86 \mathrm{msi}$ as flexural modulus. 
Table 5.19 Bending test results for carbon (stitched fabric)/epoxy composite by compression molding

\begin{tabular}{|c|c|c|c|c|c|c|c|}
\hline Sample & $\begin{array}{c}\text { Avg. } \\
\text { Width } \\
\text { (in.) }\end{array}$ & $\begin{array}{c}\text { Avg. } \\
\text { Thickness } \\
\text { (in.) }\end{array}$ & $\begin{array}{l}\text { Slope } \\
\text { P vs. } \\
\text { defl. } \\
\text { (lb/in.) }\end{array}$ & $\begin{array}{l}\text { Max. } \\
\text { Load } \\
(\text { lbs }) \\
\end{array}$ & $\begin{array}{c}\begin{array}{c}\text { Bending } \\
\text { Stress }\end{array} \\
\text { (ksi) } \\
\end{array}$ & (msi) & $\begin{array}{c}\begin{array}{c}\text { Fiber } \\
\text { Content }\end{array} \\
(w t \%)\end{array}$ \\
\hline \multicolumn{8}{|c|}{ ONE WAY STITCHED } \\
\hline 1 & 0.5030 & 0.1900 & 1398.4 & 279 & 92.42 & 6.48 & \multirow{18}{*}{76.28} \\
\hline 2 & 0.5260 & 0.1940 & 1414.1 & 288 & 87.54 & 5.89 & \\
\hline 3 & 0.5360 & 0.1930 & 1598.7 & 296 & 89.12 & 6.63 & \\
\hline 4 & 0.4640 & 0.1930 & 1329.8 & 254 & 88.28 & 6.37 & \\
\hline 5 & 0.5060 & 0.1900 & 1533.6 & 282 & 92.64 & 7.07 & \\
\hline 1 & 0.5480 & 0.1960 & 1643.0 & 319 & 91.04 & 6.37 & \\
\hline 2 & 0.5450 & 0.1950 & 1662.4 & 318 & 92.10 & 6.58 & \\
\hline 4 & 0.5460 & 0.1960 & 1739.7 & 313 & 89.63 & 6.77 & \\
\hline 5 & 0.5480 & 0.1950 & 1759.8 & 330 & 95.14 & 6.92 & \\
\hline $9.1 \mathrm{~W}$ & 0.8540 & 0.1960 & 2787.9 & 586 & 107.71 & 6.97 & \\
\hline $9.2 \mathrm{~W}$ & 0.8130 & 0.1900 & 2498.0 & 480 & 98.22 & 7.16 & \\
\hline $9.3 \mathrm{~W}$ & 0.8190 & 0.1940 & 2649.4 & 536 & 104.69 & 7.12 & \\
\hline $9.4 \mathrm{~W}$ & 0.7700 & 0.1920 & 2404.4 & 475 & 100.59 & 7.05 & \\
\hline $9.5 \mathrm{~W}$ & 0.6450 & 0.1910 & 1934.6 & 395 & 101.44 & 6.94 & \\
\hline $9.6 \mathrm{~W}$ & 0.5910 & 0.1920 & 1807.6 & 328 & 90.51 & 6.91 & \\
\hline $9.7 \mathrm{~W}$ & 0.5330 & 0.1920 & 1637.5 & 341 & 104.33 & 6.94 & \\
\hline \multicolumn{5}{|c|}{ AVG } & 95.33 & 6.76 & \\
\hline \multicolumn{5}{|c|}{$\%$ STD } & 6.87 & 5.03 & \\
\hline \multicolumn{8}{|c|}{ TWO WAY STITCHED } \\
\hline 3" & 0.5400 & 0.1970 & 1749.1 & 325 & 93.26 & 6.77 & \multirow{8}{*}{75.90} \\
\hline 6" & 0.5440 & 0.1970 & 1808.0 & 324 & 92.17 & 6.95 & \\
\hline $10.1 \mathrm{~W}$ & 0.5170 & 0.1980 & 1743.2 & 341 & 101.07 & 6.95 & \\
\hline $10.2 \mathrm{~W}$ & 0.5870 & 0.1980 & 1927.6 & 360 & 94.09 & 6.76 & \\
\hline $10.3 \mathrm{~W}$ & 0.5760 & 0.1970 & 1783.1 & 342 & 91.62 & 6.44 & \\
\hline $10.4 \mathrm{~W}$ & 0.5810 & 0.1970 & 1821.4 & 360 & 95.85 & 6.55 & \\
\hline \multirow{2}{*}{\multicolumn{5}{|c|}{$\begin{array}{r}\text { AVG } \\
\% \text { STD }\end{array}$}} & 94.68 & 6.73 & \\
\hline & & & & & 3.66 & 3.21 & \\
\hline
\end{tabular}


Load -Deflection Curve

(carbon+comp mold+no matt+FR-7 epoxy+stitched1 Alder machine+symm part 9)

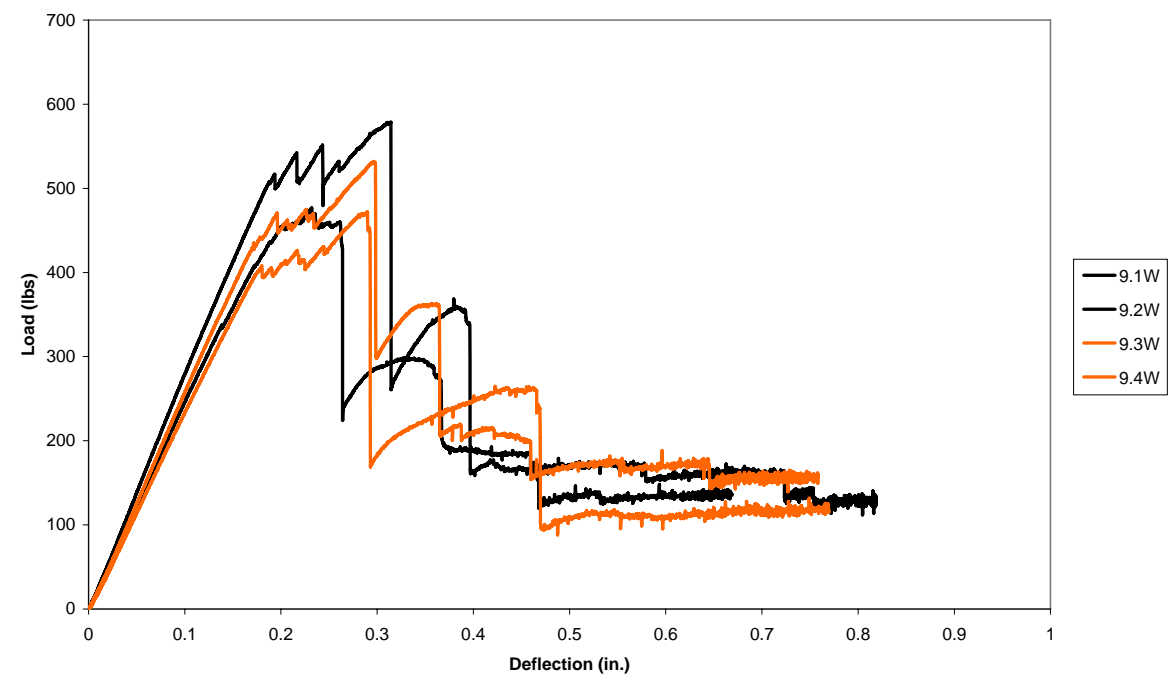

Figure 5.26 Load-deflection behavior of carbon (stitched-1 fabric)/epoxy composites by compression molding

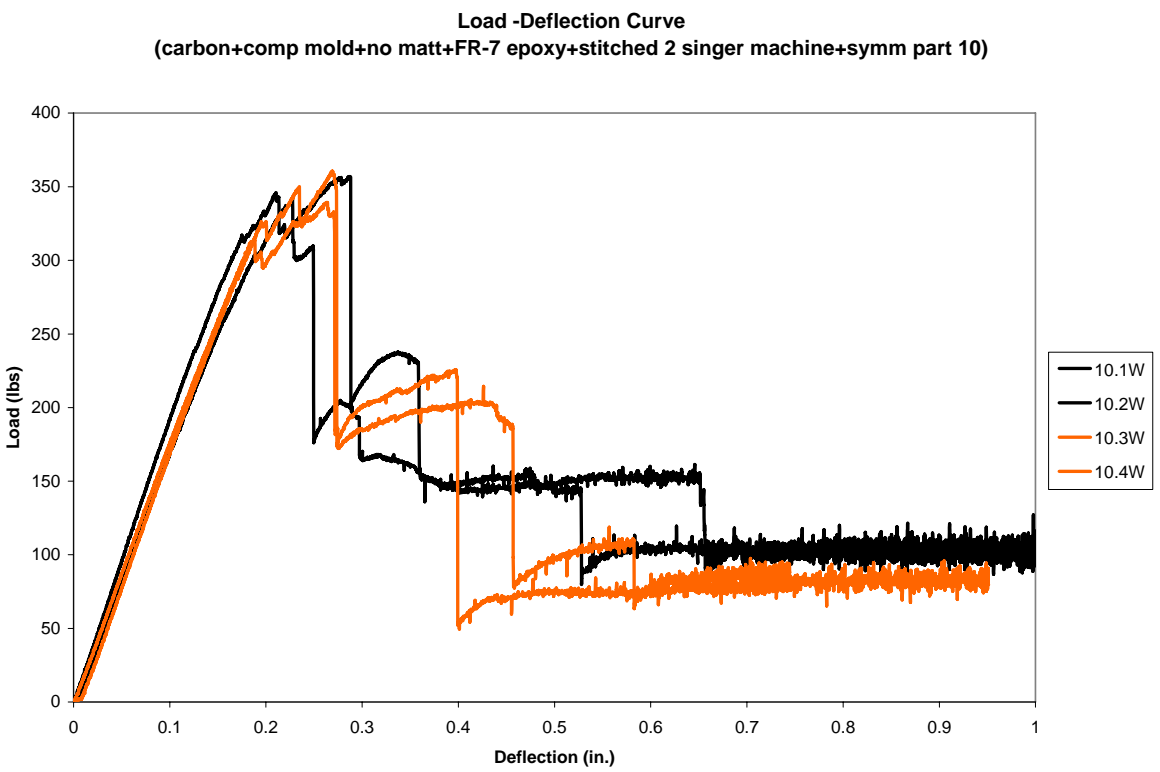

Figure 5.27 Load-deflection behavior of carbon (stitched-2 fabric)/epoxy composites by compression molding

\subsubsection{Conclusions}

Figures 5.28 and 5.29 show the average bending stress and modulus data plotted for all the set of specimens made by compression molding process. 


\section{i. High Temperature vs. Room Temperature Curing}

Figure 5.28 indicates, $11 \%$ increase in value of bending stress for room temperature cure compared to $190 \mathrm{~F}$ for epoxy resin while $27 \%$ increase is noted for flexural modulus. Data indicate that curing of VE must be carried out at room temperature instead of high temperatures since the specified VE 510 resin is specially formulated for room temperature curing resulting in better performance.

Vinyl Ester 510A type of resins are specially formulated to cure at room temperature in combination with a initiator such as methyl ethyl ketone peroxide (MEKP). Higher temperature used for curing results in high reaction rate and causes gel time drift increasing resin viscosity before it could impregnates layers of fabric. Due to this reason, high temperatures curing of VE showed poor performance in mechanical properties.

\section{ii. CSM layer vs. no CSM layer}

Addition of CSM layer with carbon fabric layers is observed to degrade the mechanical properties of FRP composites. With addition of CSM layer, bending stress was observed to drop down by about $33 \%$ and flexural modulus by about $30 \%$. It shows that addition of CSM does not help in strengthening mechanical properties of FRP composites.

\section{iii. Non-stitched vs. Stitched Fabric}

No significant change in bending stress was noted for stitched fabric composites as compared to non-stitched fabric composites. One can observe a drop in value of $\mathrm{E}_{\mathrm{b}}$ for one way stitched fabric by about $4 \%$ and by about $8.5 \%$ for that of two way stitched fabrics over non-stitched fabrics. It suggests that the implemented 3D reinforcement by way of stitching failed to improve bending as well as tensile properties of FRP composites.

Although, 3D stitching showed poor performance in tension and bending, it is expected to improve the shear strength of composites. Shear strength of such specimens can be evaluated by shear test. It must be noted that before commenting on stitching effect, one needs to fully understand the performance of test specimens under shear. 
Comparison of Bending Stress

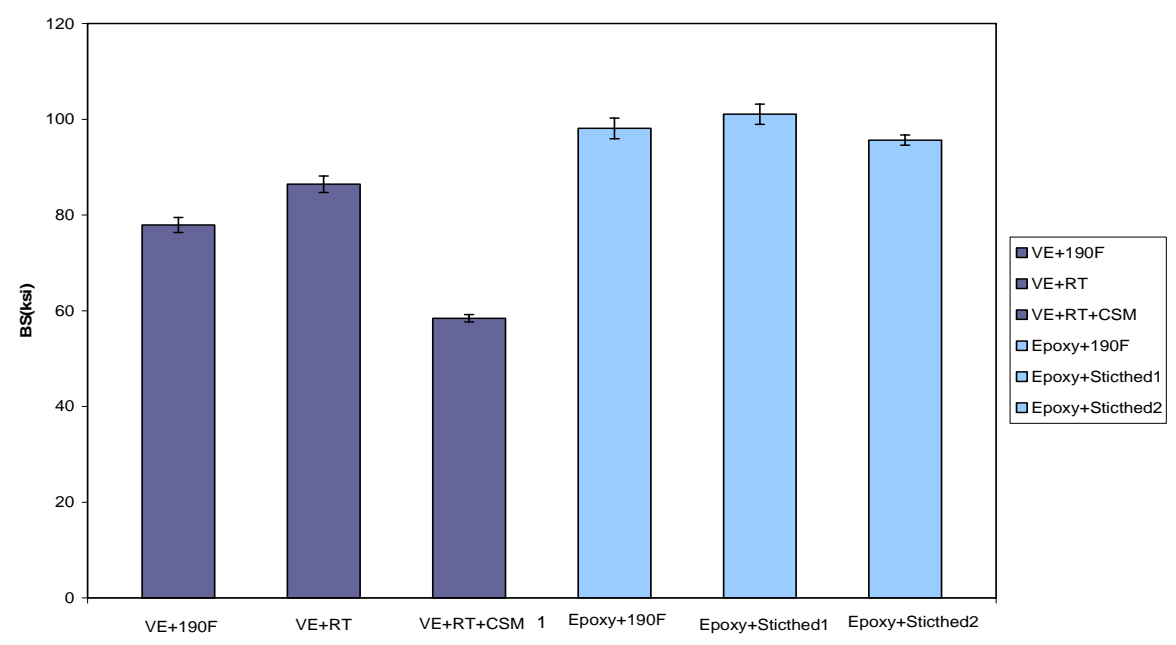

Figure 5.28 Chart comparison of bending stress for compression molding

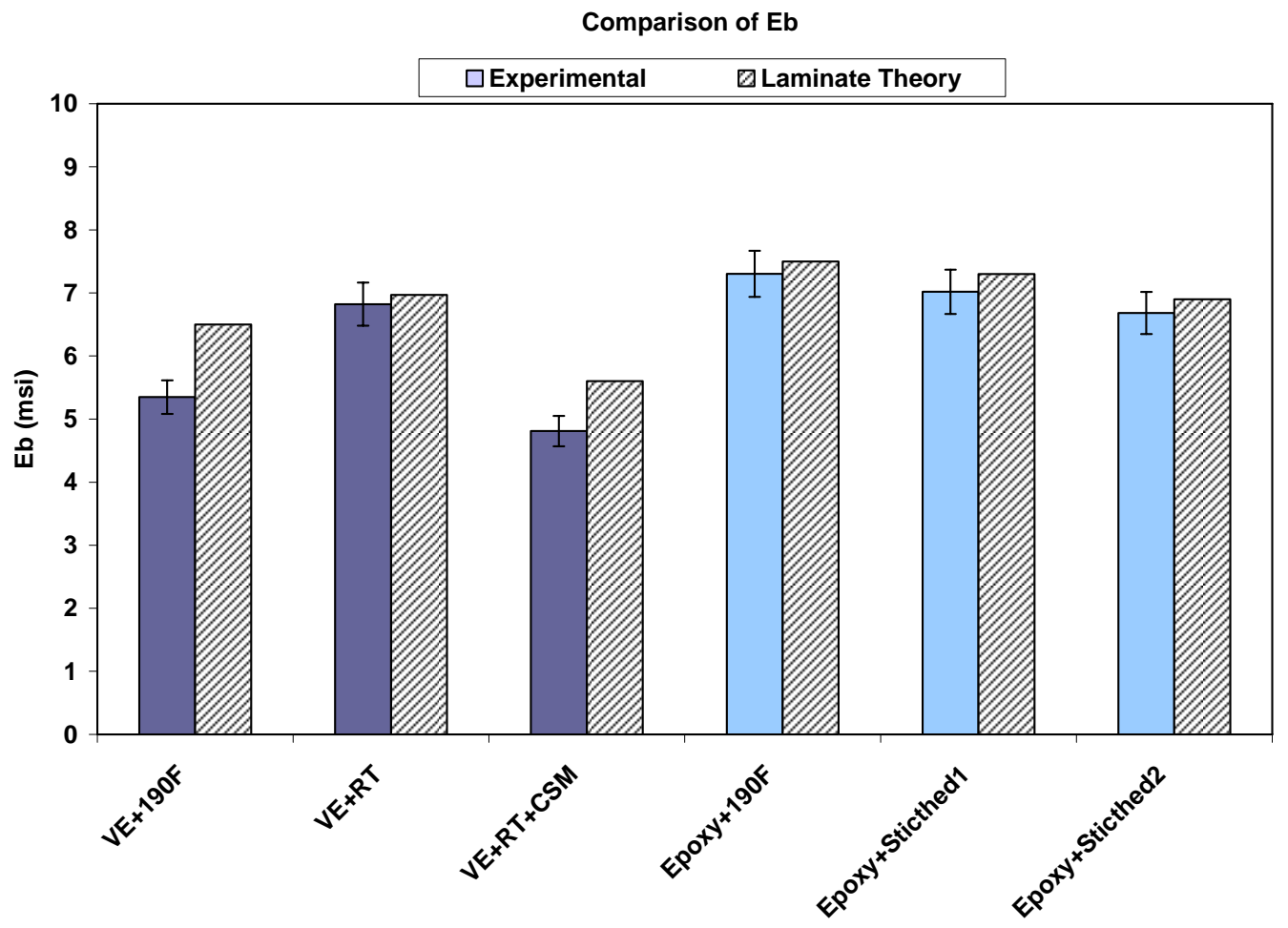

Figure 5.29 Chart comparison of $E_{b}$ for compression molding

\subsubsection{Pultrusion Process}


CFRP face sheets were tested for flexural properties. Top and bottom face sheets were tested in order to verify their uniformity in mechanical response. Mechanical response under bending is discussed in detail in section 5.4.2.

\subsubsection{Non-symmetrical Fiber Architecture with 510A VE: Long. Direction (Run1)}

Sample IDs followed with $\mathrm{T}$ and $\mathrm{B}$ represents the top and bottom face-sheet of panels respectively. Average bending stress for top test specimen was found to be $67.08 \mathrm{ksi}$ and flexural modulus is $5.21 \mathrm{msi}$. In addition, bottom test specimen showed average value of bending stress around $50.84 \mathrm{ksi}$ and flexural modulus of $3.95 \mathrm{msi}$. Bending results for this set of experiment are summarized in Table 5.20. Figure 5.30 shows the loaddeflection behavior for test specimens.

\subsubsection{Non-symmetrical Fiber Architecture with 510A VE: Trans. direction (Run1)}

Test specimens were prepared from top and bottom face sheets of 12" wide CFRP sandwich panels. Specimens were cut in transverse direction which is the direction of $90^{\circ}$ fibers. This set of specimen was not subjected to tension test due to limitation in sample dimensions (length). Average bending stress for top test specimen was found to be 49.03 ksi and flexural modulus of $4.44 \mathrm{msi}$. In addition, bottom test specimen showed average value of bending stress around $41.12 \mathrm{ksi}$ and flexural modulus of $3.29 \mathrm{msi}$. Results of bending tests are summarized in Table 5.21. Figure 5.31 represents the load-deflection behavior.

Table 5.20 Bending test results for carbon /VE composite by pultrusion (longitudinal)

\begin{tabular}{|c|c|c|c|c|c|c|c|}
\hline Sample & $\begin{array}{c}\text { Avg. } \\
\text { Width } \\
\text { (in.) }\end{array}$ & $\begin{array}{c}\text { Avg. } \\
\text { Thickness } \\
\text { (in.) }\end{array}$ & $\begin{array}{l}\text { Slope } \\
\text { P vs. } \\
\text { defl. } \\
\text { (lb/in.) }\end{array}$ & $\begin{array}{l}\text { Max. } \\
\text { Load } \\
\text { (lbs) }\end{array}$ & $\begin{array}{c}\text { Bending } \\
\text { Stress } \\
\text { (ksi) }\end{array}$ & (msi) & $\begin{array}{c}\text { Fiber } \\
\text { Content } \\
(\mathbf{w t} \%) \\
\end{array}$ \\
\hline $\mathrm{C} 1 / \mathrm{L} / \mathrm{T} 1$ & 0.5370 & 0.2350 & 2333.3 & 357 & 72.28 & 5.35 & \multirow{6}{*}{65.1} \\
\hline $\mathrm{C} 1 / \mathrm{L} / \mathrm{T} 2$ & 0.5080 & 0.2340 & 2172.6 & 348 & 74.92 & 5.32 & \\
\hline $\mathrm{C} 1 / \mathrm{L} / \mathrm{T} 3$ & 0.5200 & 0.2320 & 2023.0 & 258 & 55.28 & 4.96 & \\
\hline $\mathrm{C} 1 / \mathrm{L} / \mathrm{T} 4$ & 0.5220 & 0.2300 & 2073.8 & 304 & 65.82 & 5.19 & \\
\hline \multicolumn{5}{|r|}{ AVG } & 67.08 & 5.21 & \\
\hline \multicolumn{5}{|c|}{$\%$ STD } & 13.03 & 3.26 & \\
\hline
\end{tabular}




\begin{tabular}{|c|c|c|c|c|c|c|c|}
\hline $\mathrm{C} 1 / \mathrm{L} / \mathrm{B} 1$ & 0.5470 & 0.2820 & 2832.0 & 315 & 43.40 & 3.68 & \multirow{7}{*}{65.1} \\
\hline $\mathrm{C} 1 / \mathrm{L} / \mathrm{B} 2$ & 0.5220 & 0.2770 & 3046.3 & 451 & 67.79 & 4.40 & \\
\hline $\mathrm{C} 1 / \mathrm{L} / \mathrm{B} 3$ & 0.5310 & 0.2650 & 2556.4 & 287 & 46.21 & 4.13 & \\
\hline $\mathrm{C} 1 / \mathrm{L} / \mathrm{B} 4$ & 0.5210 & 0.2820 & 2703.4 & 315 & 45.80 & 3.71 & \\
\hline C1/L/B5 & 0.5380 & 0.2860 & 3016.8 & 374 & 51.01 & 3.83 & \\
\hline \multicolumn{5}{|c|}{$\mathrm{AVG}$} & 50.84 & 3.95 & \\
\hline \multicolumn{5}{|c|}{$\%$ STD } & 19.40 & 7.85 & \\
\hline
\end{tabular}

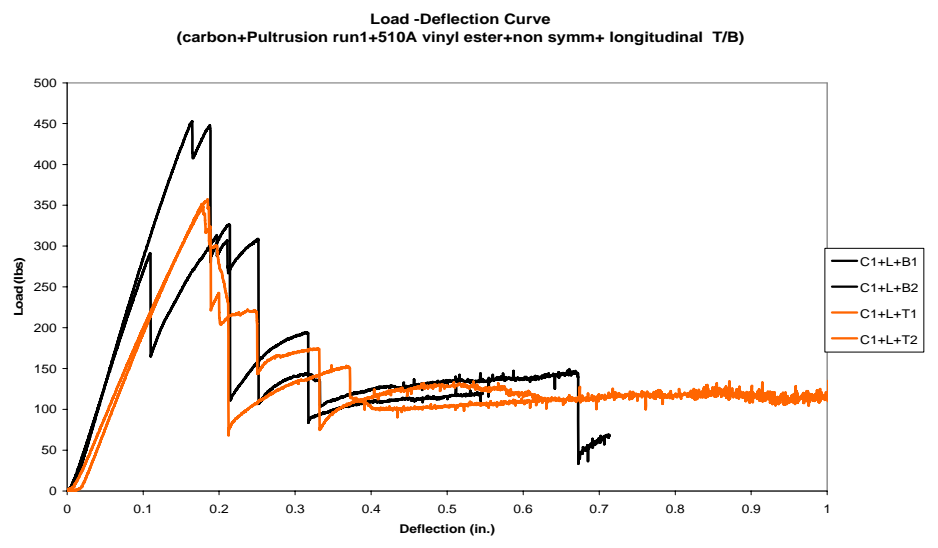

Figure 5.30 Load-deflection behavior of carbon/VE composites by pultrusion (longitudinal)

Table 5.21 Bending test results for carbon /VE composite by pultrusion (transverse)

\begin{tabular}{|c|c|c|c|c|c|c|c|}
\hline Sample & $\begin{array}{l}\text { Avg. } \\
\text { Width } \\
\text { (in.) }\end{array}$ & $\begin{array}{l}\text { Avg. } \\
\text { Thickness } \\
\text { (in.) }\end{array}$ & $\begin{array}{l}\text { Slope } \\
\text { P vs. } \\
\text { defl. } \\
\text { (lb/in.) }\end{array}$ & $\begin{array}{l}\text { Max. } \\
\text { Load } \\
\text { (lbs) }\end{array}$ & $\begin{array}{c}\text { Bending } \\
\text { Stress } \\
(\mathrm{ksi})\end{array}$ & (msi) & $\begin{array}{c}\text { Fiber } \\
\text { Content } \\
(\mathbf{w t} \%)\end{array}$ \\
\hline $\mathrm{C} 1 / \mathrm{T} / \mathrm{T} 1$ & 0.5220 & 0.2270 & 1670.1 & 237 & 52.99 & 4.37 & \multirow{6}{*}{65.1} \\
\hline $\mathrm{C} 1 / \mathrm{T} / \mathrm{T} 2$ & 0.5240 & 0.2260 & 1564.8 & 215 & 48.17 & 4.12 & \\
\hline $\mathrm{C} 1 / \mathrm{T} / \mathrm{T} 3$ & 0.5440 & 0.2230 & 1754.4 & 225 & 49.90 & 4.63 & \\
\hline $\mathrm{C} 1 / \mathrm{T} / \mathrm{T} 4$ & 0.5370 & 0.2250 & 1782.6 & 204 & 45.07 & 4.66 & \\
\hline \multicolumn{5}{|r|}{ AVG } & 49.03 & 4.44 & \\
\hline \multicolumn{5}{|c|}{ \% STD } & 5.833 & 4.72 & \\
\hline $\mathrm{C} 1 / \mathrm{T} / \mathrm{B} 1$ & 0.5460 & 0.2930 & 2784.8 & 308 & 39.56 & 3.25 & \multirow{5}{*}{65.1} \\
\hline $\mathrm{C} 1 / \mathrm{T} / \mathrm{B} 2$ & 0.5640 & 0.2890 & 2904.5 & 327 & 41.64 & 3.40 & \\
\hline $\mathrm{C} 1 / \mathrm{T} / \mathrm{B} 4$ & 0.5390 & 0.2910 & 2673.2 & 320 & 42.18 & 3.22 & \\
\hline \multicolumn{5}{|r|}{ AVG } & 41.12 & 3.29 & \\
\hline \multicolumn{5}{|c|}{$\%$ STD } & 3.35 & 2.73 & \\
\hline
\end{tabular}




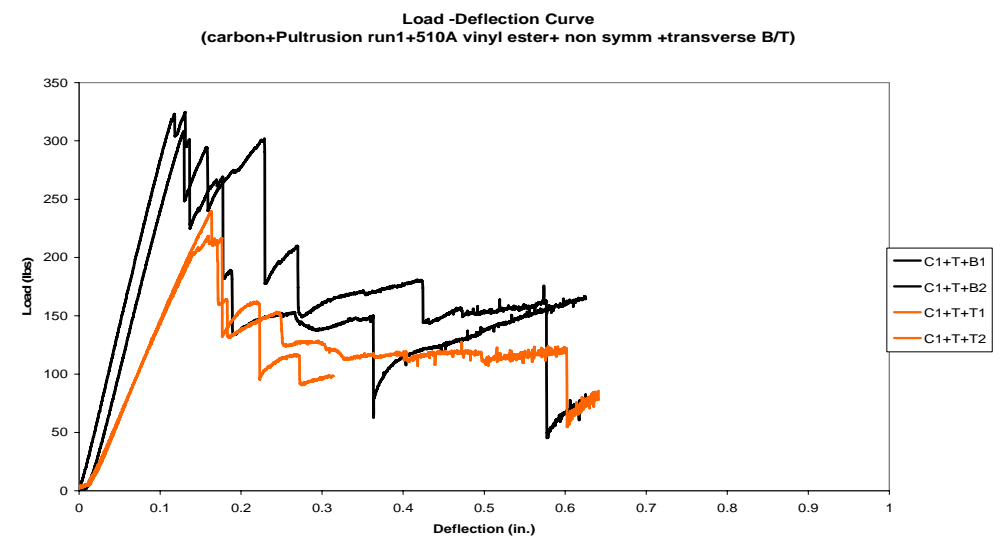

Figure 5.31 Load-deflection behavior of carbon/VE composites by pultrusion (transverse)

5.4.2.3 Symmetrical Fiber Architecture with CSM and 510A VE: Long. direction (Run2)

Test specimens were prepared from top and bottom face sheets of 48 " wide CFRP sandwich panels. Both top and bottom face-sheets contained a layer of CSM with carbon fabric. Samples were cut in direction of $0^{0}$ fibers and hence referred as longitudinal. Each sample consists of symmetric fiber architecture and VE matrix. Results of bending tests are summarized in Table 5.22. Figure 5.32 represents the load-deflection behavior. Average bending stress for top test specimen was found to be $51.93 \mathrm{ksi}$ and flexural modulus of $2.90 \mathrm{msi}$. In addition, bottom test specimen showed average value of bending stress around $55.53 \mathrm{ksi}$ and flexural modulus of $3.68 \mathrm{msi}$.

Table 5.22 Bending test results for carbon /VE composite by pultrusion (CSM+Longitudinal)

\begin{tabular}{|c|c|c|c|c|c|c|c|}
\hline Sample & $\begin{array}{c}\text { Avg. } \\
\text { Width } \\
\text { (in.) }\end{array}$ & $\begin{array}{c}\text { Avg. } \\
\text { Thickness } \\
\text { (in.) }\end{array}$ & $\begin{array}{c}\text { Slope } \\
\text { P vs. } \\
\text { defl. } \\
\text { (lb/in.) }\end{array}$ & $\begin{array}{l}\text { Max. } \\
\text { Load } \\
\text { (lbs) }\end{array}$ & $\begin{array}{c}\text { Bending } \\
\text { Stress } \\
\text { (ksi) }\end{array}$ & (msi) & $\begin{array}{c}\text { Fiber } \\
\text { Content } \\
(w t \%) \\
\end{array}$ \\
\hline $\mathrm{C} 2 / \mathrm{L} / \mathrm{T} 1$ & 0.5100 & 0.3130 & 2876.7 & 481 & 57.72 & 2.94 & \multirow{7}{*}{58.3} \\
\hline $\mathrm{C} 2 / \mathrm{L} / \mathrm{T} 2$ & 0.5190 & 0.3050 & 2730.6 & 437 & 54.47 & 2.97 & \\
\hline C2/L/T3 & 0.5180 & 0.3280 & 3149.6 & 447 & 48.27 & 2.76 & \\
\hline $\mathrm{C} 2 / \mathrm{L} / \mathrm{T} 4$ & 0.5030 & 0.3210 & 2992.7 & 402 & 46.50 & 2.87 & \\
\hline C2/L/T5 & 0.4910 & 0.3190 & 2925.5 & 438 & 52.71 & 2.93 & \\
\hline \multirow{2}{*}{\multicolumn{5}{|c|}{$\begin{array}{r}\text { AVG } \\
\% \text { STD }\end{array}$}} & 51.93 & 2.89 & \\
\hline & & & & & 8.78 & 2.76 & \\
\hline $\mathrm{C} 2 / \mathrm{L} / \mathrm{B} 1$ & 0.4920 & 0.2640 & 2092.0 & 313 & 54.87 & 3.70 & \multirow[b]{4}{*}{58.3} \\
\hline $\mathrm{C} 2 / \mathrm{L} / \mathrm{B} 3$ & 0.5200 & 0.2560 & 2149.7 & 317 & 55.84 & 3.94 & \\
\hline $\mathrm{C} 2 / \mathrm{L} / \mathrm{B} 4$ & 0.4940 & 0.2830 & 2149.8 & 344 & 52.27 & 3.07 & \\
\hline $\mathrm{C} 2 / \mathrm{L} / \mathrm{B} 5$ & 0.4350 & 0.2630 & 1988.9 & 296 & 59.17 & 4.02 & \\
\hline
\end{tabular}




\begin{tabular}{|r|c|c|c|}
\hline AVG & 55.53 & 3.68 & \\
\cline { 1 - 2 } \% STD & 5.13 & 11.68 & \\
\hline
\end{tabular}

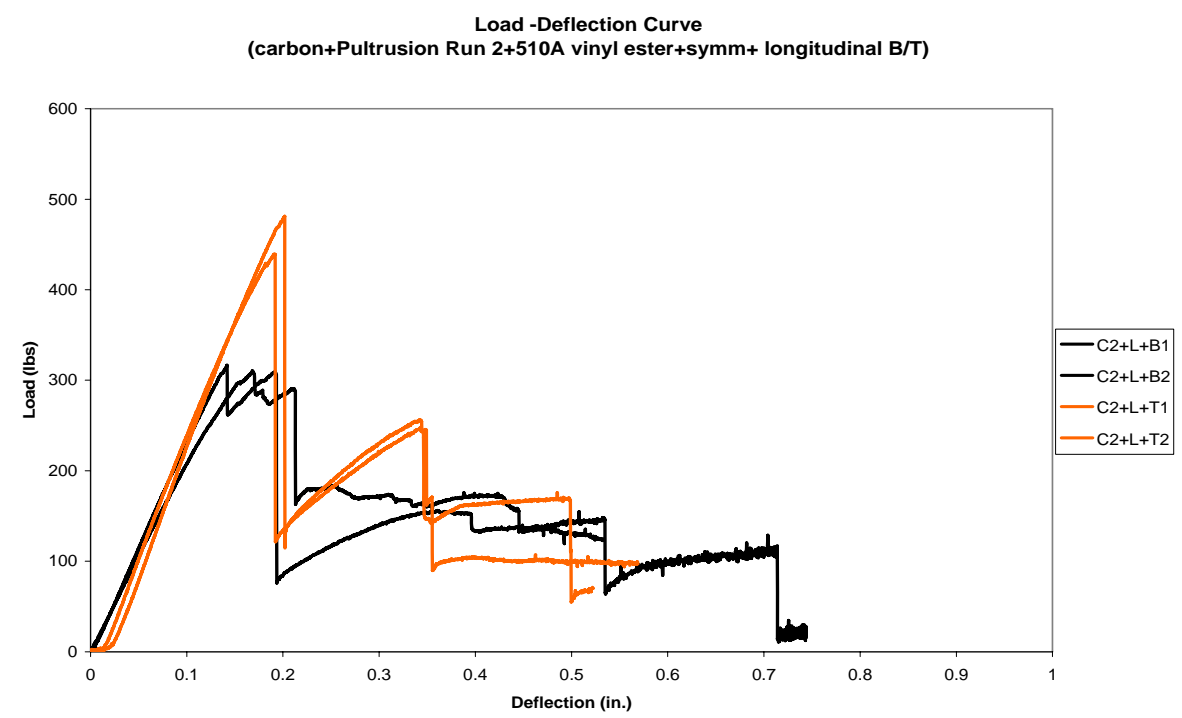

Figure 5.32 Load-deflection behavior of carbon/VE composites by pultrusion (CSM+Longitudinal)

\subsubsection{Symmetrical Fiber Architecture with CSM and 510A VE: Trans. direction (Run2)}

Results of bending tests are summarized in Table 5.23. Figure 5.33 represents the loaddeflection behavior. Average bending stress for top test specimen was found to be 46.51 ksi and flexural modulus of $3.27 \mathrm{msi}$. In addition, bottom test specimen showed average value of bending stress around $45.10 \mathrm{ksi}$ and flexural modulus of $3.03 \mathrm{msi}$.

\subsubsection{Symmetrical Fiber Architecture after Removing CSM and 510A VE: Long. direction (Run2)}

For this set of samples, CSM layer was removed from the sample without damaging the underneath layer of carbon. Significant change in mechanical properties was observed after removal of CSM from original specimens. Results for this experimental set are listed in Table 5.24 and load-deflection behavior is shown in Figure 5.34. Average bending stress for top test specimen was found to be $50.50 \mathrm{ksi}$ and flexural modulus of 
$3.99 \mathrm{msi}$. In addition, bottom test specimen showed average value of bending stress around $59.37 \mathrm{ksi}$ and flexural modulus of $4.67 \mathrm{msi}$.

Table 5.23 Bending test results for carbon /VE composite by pultrusion (CSM+Transverse)

\begin{tabular}{|c|c|c|c|c|c|c|c|}
\hline Sample & $\begin{array}{l}\text { Avg. } \\
\text { Width } \\
\text { (in.) }\end{array}$ & $\begin{array}{l}\text { Avg. } \\
\text { Thickness } \\
\text { (in.) }\end{array}$ & $\begin{array}{l}\text { Slope } \\
\text { P vs. } \\
\text { defl. } \\
\text { (lb/in.) }\end{array}$ & $\begin{array}{l}\text { Max. } \\
\text { Load } \\
\text { (lbs) }\end{array}$ & $\begin{array}{c}\text { Bending } \\
\text { Stress } \\
\text { (ksi) }\end{array}$ & (msi) & $\begin{array}{c}\text { Fiber } \\
\text { Content } \\
(\mathbf{w t} \%)\end{array}$ \\
\hline $\mathrm{C} 2 / \mathrm{T} / \mathrm{T} 1$ & 0.5480 & 0.2870 & 2542.7 & 444 & 59.24 & 3.15 & \multirow{8}{*}{58.3} \\
\hline $\mathrm{C} 2 / \mathrm{T} / \mathrm{T} 2$ & 0.5330 & 0.2770 & 2416.9 & 331 & 48.55 & 3.39 & \\
\hline $\mathrm{C} 2 / \mathrm{T} / \mathrm{T} 3$ & 0.5350 & 0.2790 & 2340.2 & 281 & 40.63 & 3.23 & \\
\hline $\mathrm{C} 2 / \mathrm{T} / \mathrm{T} 4$ & 0.5350 & 0.2820 & 2432.7 & 310 & 43.77 & 3.24 & \\
\hline $\mathrm{C} 2 / \mathrm{T} / \mathrm{T} 5$ & 0.5310 & 0.27600 & 2230.4 & 318 & 47.18 & 3.19 & \\
\hline C2/T/T6 & 0.5480 & 0.2740 & 2416.3 & 272 & 39.70 & 3.43 & \\
\hline \multicolumn{5}{|c|}{ AVG } & 46.51 & 3.27 & \\
\hline \multicolumn{5}{|c|}{$\%$ STD } & 15.35 & 3.36 & \\
\hline $\mathrm{C} 2 / \mathrm{T} / \mathrm{B} 1$ & 0.5310 & 0.2820 & 2452.0 & 385 & 54.90 & 3.30 & \multirow{8}{*}{58.3} \\
\hline $\mathrm{C} 2 / \mathrm{T} / \mathrm{B} 2$ & 0.5280 & 0.2880 & 2376.9 & 331 & 45.41 & 3.01 & \\
\hline $\mathrm{C} 2 / \mathrm{T} / \mathrm{B} 3$ & 0.5310 & 0.29300 & 2492.9 & 274 & 36.17 & 2.98 & \\
\hline $\mathrm{C} 2 / \mathrm{T} / \mathrm{B} 4$ & 0.5370 & 0.2950 & 2622.1 & 317 & 40.83 & 3.04 & \\
\hline $\mathrm{C} 2 / \mathrm{T} / \mathrm{B} 5$ & 0.5320 & 0.3060 & 2920.0 & 426 & 51.31 & 3.06 & \\
\hline C2/T/B6 & 0.5320 & 0.3060 & 2669.5 & 348 & 42.00 & 2.80 & \\
\hline \multicolumn{5}{|c|}{ AVG } & 45.01 & 3.03 & \\
\hline \multicolumn{5}{|c|}{$\%$ STD } & 15.46 & 5.28 & \\
\hline
\end{tabular}

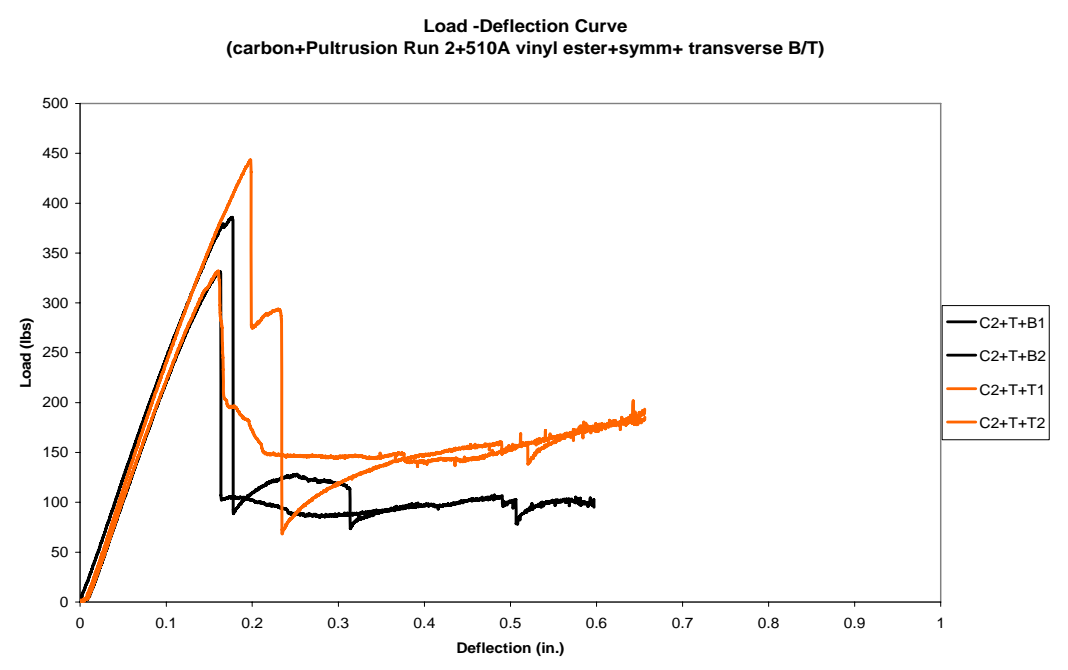

Figure 5.33 Load-deflection behavior of carbon/VE composites by pultrusion (CSM+Transverse) 
Table 5.24 Bending test results for carbon /VE composite by pultrusion (No CSM+Longitudinal)

\begin{tabular}{|c|c|c|c|c|c|c|c|}
\hline Sample & $\begin{array}{c}\text { Avg. } \\
\text { Width } \\
\text { (in.) }\end{array}$ & $\begin{array}{c}\text { Avg. } \\
\text { Thickness } \\
\text { (in.) }\end{array}$ & $\begin{array}{l}\text { Slope } \\
\text { P vs. } \\
\text { defl. } \\
\text { (lb/in.) }\end{array}$ & $\begin{array}{l}\text { Max. } \\
\text { Load } \\
\text { (lbs) }\end{array}$ & $\begin{array}{c}\text { Bending } \\
\text { Stress } \\
\text { (ksi) }\end{array}$ & (msi) & $\begin{array}{c}\begin{array}{c}\text { Fiber } \\
\text { Content }\end{array} \\
(\mathbf{w t} \%)\end{array}$ \\
\hline C2/L/T1 & 0.5400 & 0.2670 & 2624.6 & 331 & 51.84 & 4.10 & \multirow{12}{*}{58.3} \\
\hline $\mathrm{C} 2 / \mathrm{L} / \mathrm{T} 2$ & 0.5320 & 0.2670 & 2552.4 & 325 & 51.38 & 4.02 & \\
\hline C2/L/T3 & 0.5250 & 0.2750 & 2285.6 & 261 & 39.64 & 3.35 & \\
\hline $\mathrm{C} 2 / \mathrm{L} / \mathrm{T} 4$ & 0.5280 & 0.2690 & 2222.2 & 244 & 38.38 & 3.46 & \\
\hline $\mathrm{C} 2 / \mathrm{L} / \mathrm{T} 5$ & 0.5470 & 0.2700 & 2804.6 & 398 & 59.91 & 4.15 & \\
\hline C2/L/T6 & 0.5420 & 0.2660 & 2817.0 & 385 & 60.53 & 4.43 & \\
\hline $\mathrm{C} 2 / \mathrm{L} / \mathrm{T} 7$ & 0.5380 & 0.2380 & 1457.1 & 186 & 36.72 & 3.22 & \\
\hline $\mathrm{C} 2 / \mathrm{L} / \mathrm{T} 8$ & 0.5420 & 0.2710 & 2944.9 & 389 & 58.68 & 4.36 & \\
\hline C2/L/T9 & 0.5260 & 0.2710 & 2938.8 & 377 & 58.52 & 4.48 & \\
\hline C2/L/T10 & 0.5350 & 0.2660 & 2727.8 & 312 & 49.42 & 4.31 & \\
\hline \multicolumn{5}{|c|}{ AVG } & 46.51 & 3.27 & \\
\hline \multicolumn{5}{|c|}{$\%$ STD } & 19.99 & 14.37 & \\
\hline $\mathrm{C} 2 / \mathrm{L} / \mathrm{B} 1$ & 0.4780 & 0.2460 & 2029.4 & 297 & 61.79 & 4.56 & \multirow{10}{*}{58.3} \\
\hline $\mathrm{C} 2 / \mathrm{L} / \mathrm{B} 2$ & 0.5170 & 0.2440 & 2084.9 & 297 & 58.02 & 4.44 & \\
\hline $\mathrm{C} 2 / \mathrm{L} / \mathrm{B} 3$ & 0.5120 & 0.2380 & 2164.0 & 328 & 68.02 & 5.01 & \\
\hline $\mathrm{C} 2 / \mathrm{L} / \mathrm{B} 5$ & 0.4930 & 0.2420 & 1879.9 & 267 & 55.63 & 4.30 & \\
\hline $\mathrm{C} 2 / \mathrm{L} / \mathrm{B} 7$ & 0.5240 & 0.2270 & 1942.2 & 285 & 63.46 & 5.07 & \\
\hline $\mathrm{C} 2 / \mathrm{L} / \mathrm{B} 8$ & 0.5220 & 0.2240 & 1709.5 & 286 & 65.64 & 4.66 & \\
\hline $\mathrm{C} 2 / \mathrm{L} / \mathrm{B} 9$ & 0.5480 & 0.2290 & 2084.9 & 296 & 62.00 & 5.06 & \\
\hline $\mathrm{C} 2 / \mathrm{L} / \mathrm{B} 10$ & 0.5310 & 0.2370 & 1886.1 & 200 & 40.42 & 4.26 & \\
\hline \multicolumn{5}{|r|}{ AVG } & 45.01 & 3.03 & \\
\hline \multicolumn{5}{|c|}{$\%$ STD } & 19.24 & 10.89 & \\
\hline
\end{tabular}

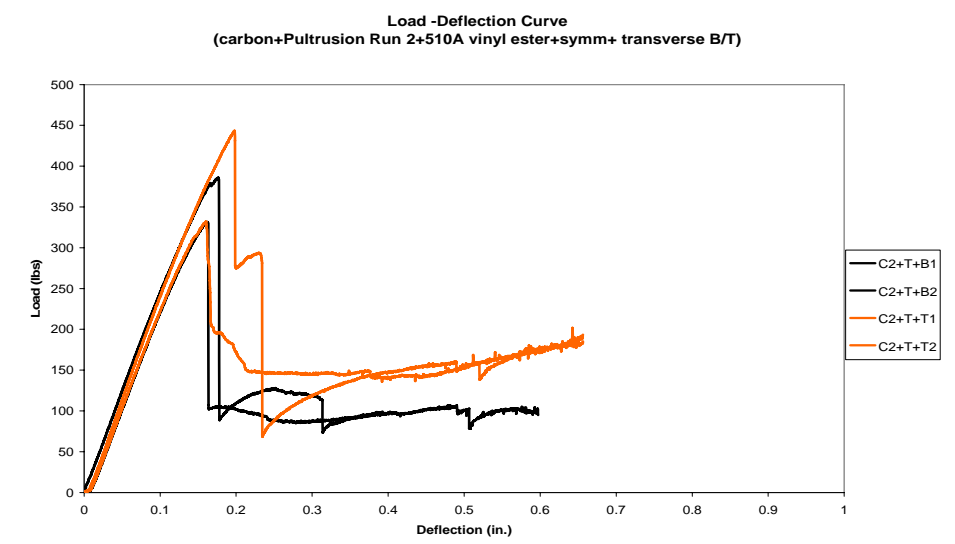

Figure 5.34 Load-deflection behavior of carbon/VE composites by pultrusion (No CSM + Long.) 


\subsubsection{Symmetrical Fiber Architecture after Removing CSM and 510A VE: Trans.}

\section{direction (Run2)}

Average bending stress for top composite layer specimen was found to be $44.90 \mathrm{ksi}$ with elasticity modulus of $4.50 \mathrm{msi}$. In addition, bottom composite layer specimen showed average value of bending stress around $44.80 \mathrm{ksi}$ and flexural modulus of $4.14 \mathrm{msi}$. Summary of bending test results is shown in Table 5.25 and load-deflection behavior is shown in Figure 5.35.

Table 5.25 Bending test results for carbon /VE composite by pultrusion (No CSM+Transverse)

\begin{tabular}{|c|c|c|c|c|c|c|c|}
\hline Sample & $\begin{array}{l}\text { Avg. } \\
\text { Width } \\
\text { (in.) }\end{array}$ & $\begin{array}{l}\text { Avg. } \\
\text { Thickness } \\
\text { (in.) }\end{array}$ & $\begin{array}{l}\text { Slope } \\
\text { P vs. } \\
\text { defl. } \\
\text { (lb/in.) }\end{array}$ & $\begin{array}{l}\text { Max. } \\
\text { Load } \\
\text { (lbs) }\end{array}$ & $\begin{array}{c}\text { Bending } \\
\text { Stress } \\
\text { (ksi) }\end{array}$ & (msi) & $\begin{array}{c}\text { Fiber } \\
\text { Content } \\
(w t \%)\end{array}$ \\
\hline $\mathrm{C} 2 / \mathrm{T} / \mathrm{T} 1$ & 0.5640 & 0.2460 & 2360.1 & 261 & 45.91 & 4.50 & \multirow{8}{*}{58.3} \\
\hline $\mathrm{C} 2 / \mathrm{T} / \mathrm{T} 2$ & 0.5360 & 0.2460 & 2108.6 & 212 & 39.38 & 4.22 & \\
\hline $\mathrm{C} 2 / \mathrm{T} / \mathrm{T} 3$ & 0.5180 & 0.2330 & 2004.6 & 215 & 46.02 & 4.91 & \\
\hline $\mathrm{C} 2 / \mathrm{T} / \mathrm{T} 4$ & 0.5190 & 0.2420 & 2093.4 & 234 & 46.07 & 4.53 & \\
\hline $\mathrm{C} 2 / \mathrm{T} / \mathrm{T} 5$ & 0.5480 & 0.2440 & 2333.3 & 270 & 49.71 & 4.69 & \\
\hline C2/T/T6 & 0.5570 & 0.2460 & 2140.2 & 237 & 42.34 & 4.14 & \\
\hline \multicolumn{5}{|r|}{ AVG } & 44.90 & 4.50 & \\
\hline \multicolumn{5}{|c|}{$\%$ STD } & 7.95 & 6.22 & \\
\hline $\mathrm{C} 2 / \mathrm{T} / \mathrm{B} 1$ & 0.5370 & 0.2400 & 1963.5 & 251 & 48.63 & 4.21 & \multirow{8}{*}{58.3} \\
\hline $\mathrm{C} 2 / \mathrm{T} / \mathrm{B} 2$ & 0.5400 & 0.2470 & 2011.9 & 233 & 42.70 & 3.96 & \\
\hline $\mathrm{C} 2 / \mathrm{T} / \mathrm{B} 3$ & 0.5390 & 0.2430 & 1986.2 & 245 & 46.07 & 4.09 & \\
\hline $\mathrm{C} 2 / \mathrm{T} / \mathrm{B} 4$ & 0.5500 & 0.2540 & 2524.5 & 251 & 42.33 & 4.46 & \\
\hline $\mathrm{C} 2 / \mathrm{T} / \mathrm{B} 5$ & 0.5380 & 0.2690 & 2657.7 & 275 & 42.47 & 4.05 & \\
\hline $\mathrm{C} 2 / \mathrm{T} / \mathrm{B} 6$ & 0.5460 & 0.2500 & 2174.1 & 265 & 46.61 & 4.07 & \\
\hline \multicolumn{5}{|r|}{ AVG } & 44.80 & 4.14 & \\
\hline \multicolumn{5}{|c|}{$\%$ STD } & 5.94 & 18.60 & \\
\hline
\end{tabular}

Load -Deflection Curve

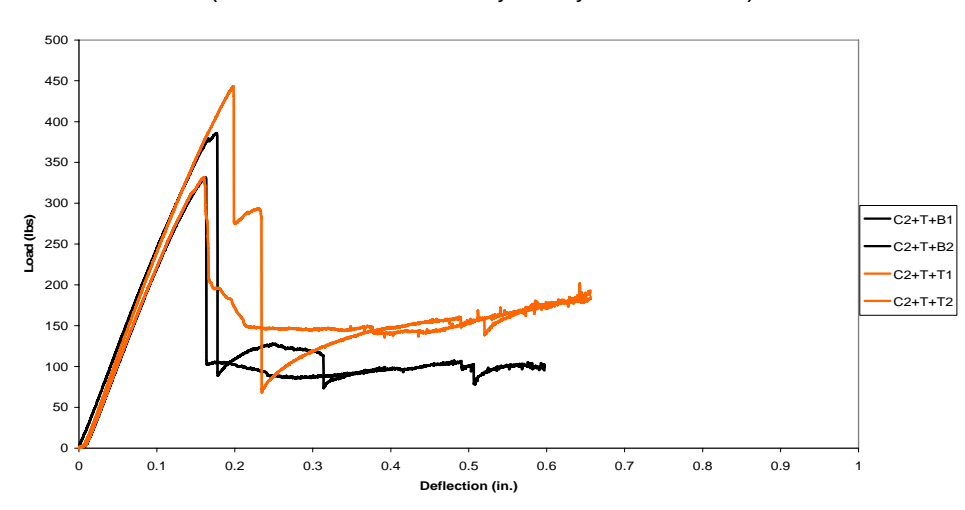

Figure 5.35 Load-deflection behavior of carbon/VE composites by pultrusion (No CSM + Trans.) 


\subsubsection{Conclusions}

Figures 5.36 and 5.37 show the average bending stress and modulus plotted for the entire set of experiments in the pultrusion process.

Figure 5.36 indicates that for longitudinal as well transverse specimen, there is no significant change in bending stress before and after removal of CSM. On the other hand, it is also observed that removal of CSM layer significantly increases the tensile modulus by around $38 \%$ in longitudinal direction and by around $37.5 \%$ in transverse direction. The higher strength in bending than in tension has been explained in literature in terms of Weibull statistical strength theory (Wisnom, 1992). The presence of a stress gradient in the flexural test results in an apparent increase in strength compared to tensile test under uniform stress.

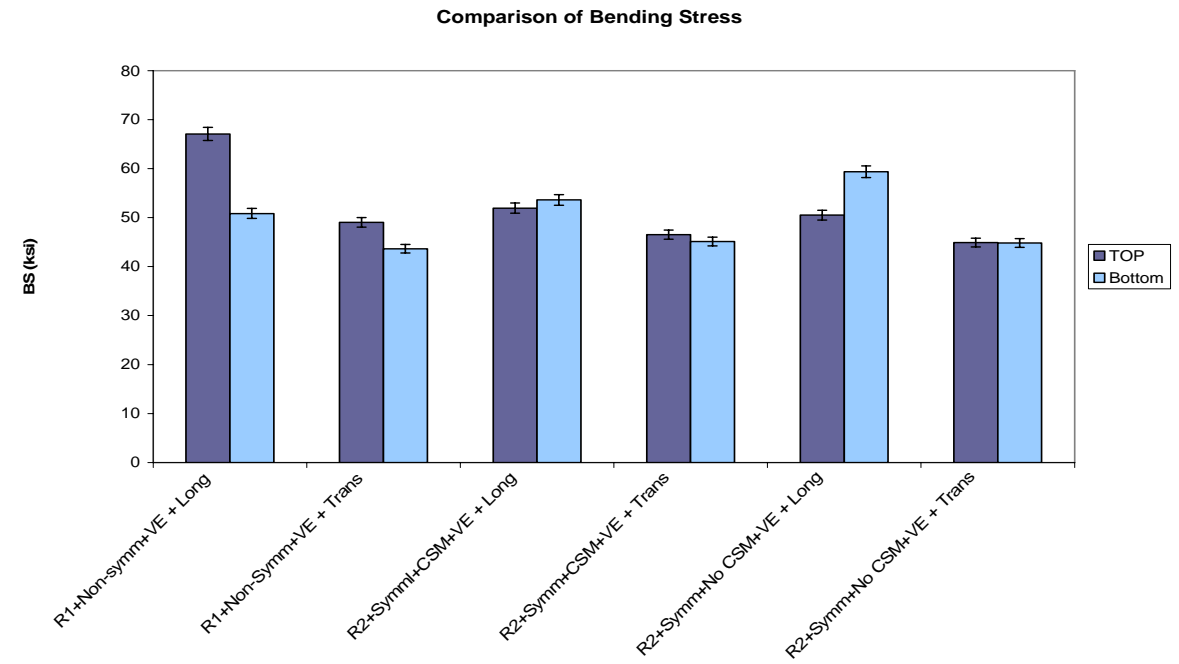

Figure 5.36 Chart comparison of bending stress for carbon/VE composites by pultrusion 


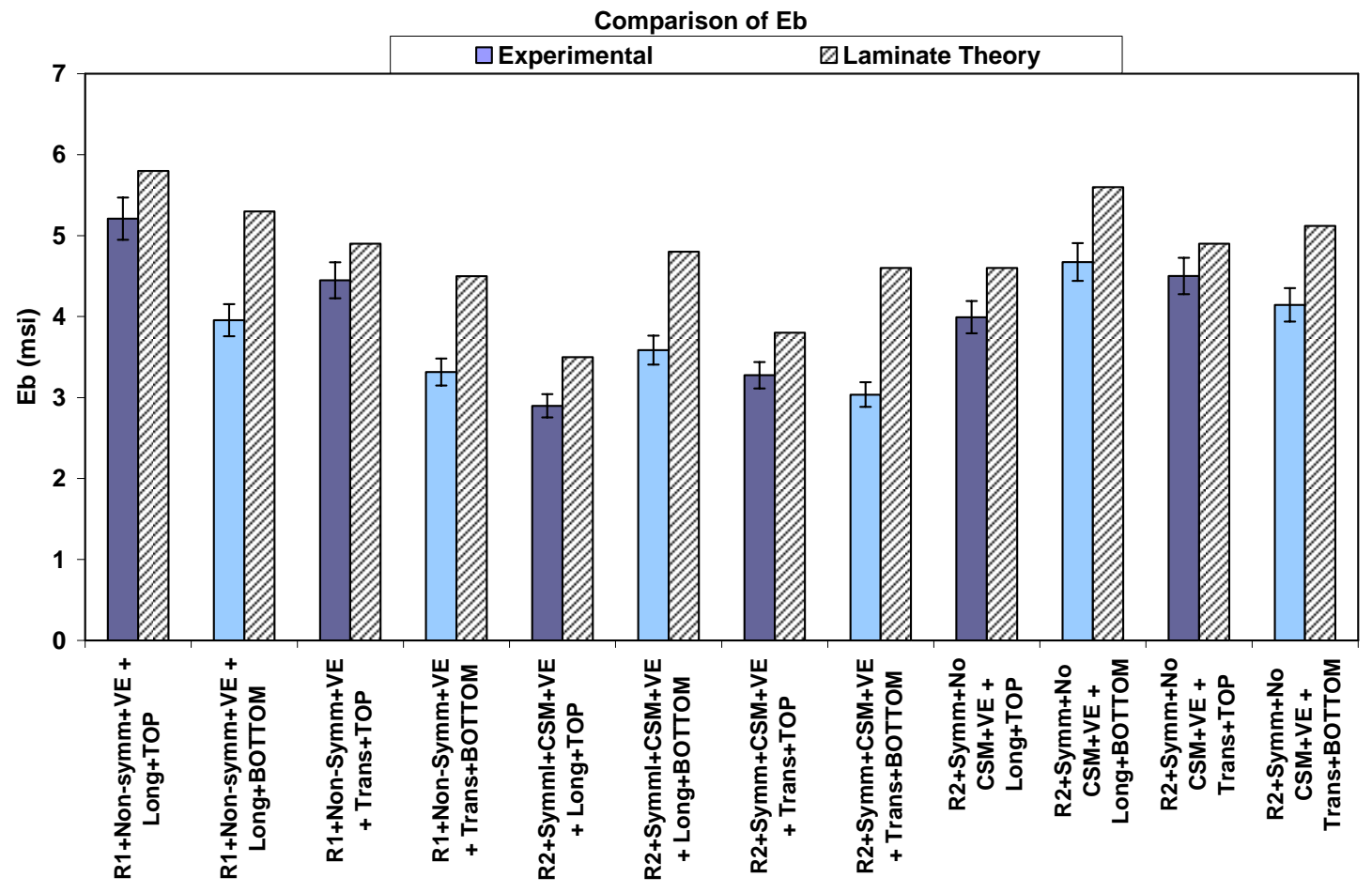

Figure 5.37 Chart comparison of flexural modulus for carbon/VE composites by pultrusion

\section{i. Top vs. Bottom Face-sheet}

In case of Run1 specimens, longitudinal top face sheet shows better strength with $32 \%$ higher bending stress as well as flexural modulus. For transverse direction specimens, top face-sheet shows 12\% higher bending stress and 34\% higher flexural modulus.

For Run 2 in longitudinal direction specimens, bottom face-sheet shows nearly equal bending stress as that of top face-sheet and bottom specimen shows $24 \%$ higher flexural modulus. As similar to tension test results, deviation in mechanical strength of top and bottom face sheet is attributed to improper resin enrichment.

\section{ii. Longitudinal vs. Transverse Direction Specimens}

In case of Run 1, top specimens in longitudinal direction show 37\% higher bending stress and $17 \%$ higher flexural modulus. Furthermore, bottom specimen behaves with 16\% higher bending stress and 20\% higher flexural modulus. For Run 2, both top and bottom showed same trend with better strength in top specimens. 


\section{iii. Specimens with CSM vs. without CSM}

For longitudinal direction, both top and bottom specimens showed slight drop in properties after removal of CSM layer. On the other hand, both top and bottom transverse specimens indicated small increase in bending stress but significant reduction in flexural modulus after removal of CSM.

\section{iv. Symmetric vs. Non-symmetric Fabric Architecture}

Top longitudinal specimen of Run 1 with symmetric architecture showed 29\% higher bending strength and nearly $80 \%$ higher flexural modulus than those of top longitudinal specimens of Run 2. Similar trend was also observed for the bottom longitudinal specimens.A parallel conclusion to the above can also be drawn for the case of transverse top as well as bottom specimens.

\subsubsection{Resin Infusion}

CFRP composite plates with 6 layers of carbon fabric were prepared with epoxy and Vinyl Ester resin by resin infusion. Epoxy was cured at high at temperature and VE at room temperature. Samples were tested for flexural properties by bending test. Summary of the bending test is presented below.

\subsubsection{Symmetric Fiber Architecture with Epoxy cured at $140 \mathrm{~F}$ for $105 \mathrm{~min}$}

For this set of specimens curing was carried out at $140 \mathrm{~F}$ for a curing time of $105 \mathrm{~min}$. Average thickness of composite plates was around 0.26 " slightly higher than those made from compression molding. Average bending stress for test specimens was found to be $77.60 \mathrm{ksi}$ and flexural modulus of $4.65 \mathrm{msi}$. Test results are tabulated in Table 5.26 and load-deflection behavior is shown in Figure 5.38. 
Table 5.26 Bending test results for carbon /epoxy composite by resin infusion

\begin{tabular}{|c|c|c|c|c|c|c|c|}
\hline Sample & $\begin{array}{c}\text { Avg. } \\
\text { Width } \\
\text { (in.) }\end{array}$ & $\begin{array}{c}\text { Avg. } \\
\text { Thickness } \\
\text { (in.) }\end{array}$ & $\begin{array}{l}\text { Slope } \\
\text { P vs. } \\
\text { defl. } \\
\text { (lb/in.) }\end{array}$ & $\begin{array}{l}\text { Max. } \\
\text { Load } \\
\text { (lbs) }\end{array}$ & $\begin{array}{c}\text { Bending } \\
\text { Stress } \\
\text { (ksi) } \\
\end{array}$ & (msi) & $\begin{array}{c}\text { Fiber } \\
\text { Content } \\
(w t \%) \\
\end{array}$ \\
\hline $1.1 \mathrm{D}$ & 0.5460 & 0.2600 & 2826.7 & 497 & 80.72 & 4.69 & \multirow{10}{*}{66.13} \\
\hline $1.2 \mathrm{D}$ & 0.5530 & 0.2670 & 3058.8 & 538 & 82.03 & 4.66 & \\
\hline $1.3 \mathrm{D}$ & 0.5360 & 0.2670 & 2952.2 & 491 & 77.44 & 4.65 & \\
\hline $1.4 \mathrm{D}$ & 0.5470 & 0.2590 & 2915.6 & 459 & 74.88 & 4.88 & \\
\hline $1.1 \mathrm{~W}$ & 0.5340 & 0.2710 & 3184.5 & 507 & 77.50 & 4.77 & \\
\hline $1.2 \mathrm{~W}$ & 0.5040 & 0.2650 & 2661.0 & 451 & 76.47 & 4.53 & \\
\hline $1.3 \mathrm{~W}$ & 0.5300 & 0.2700 & 2898.4 & 469 & 72.69 & 4.42 & \\
\hline $1.4 \mathrm{~W}$ & 0.5310 & 0.2620 & 2753.1 & 478 & 79.03 & 4.63 & \\
\hline \multicolumn{5}{|r|}{ AVG } & 77.60 & 4.65 & \\
\hline \multicolumn{5}{|c|}{ \% STD } & 6.89 & 7.52 & \\
\hline
\end{tabular}

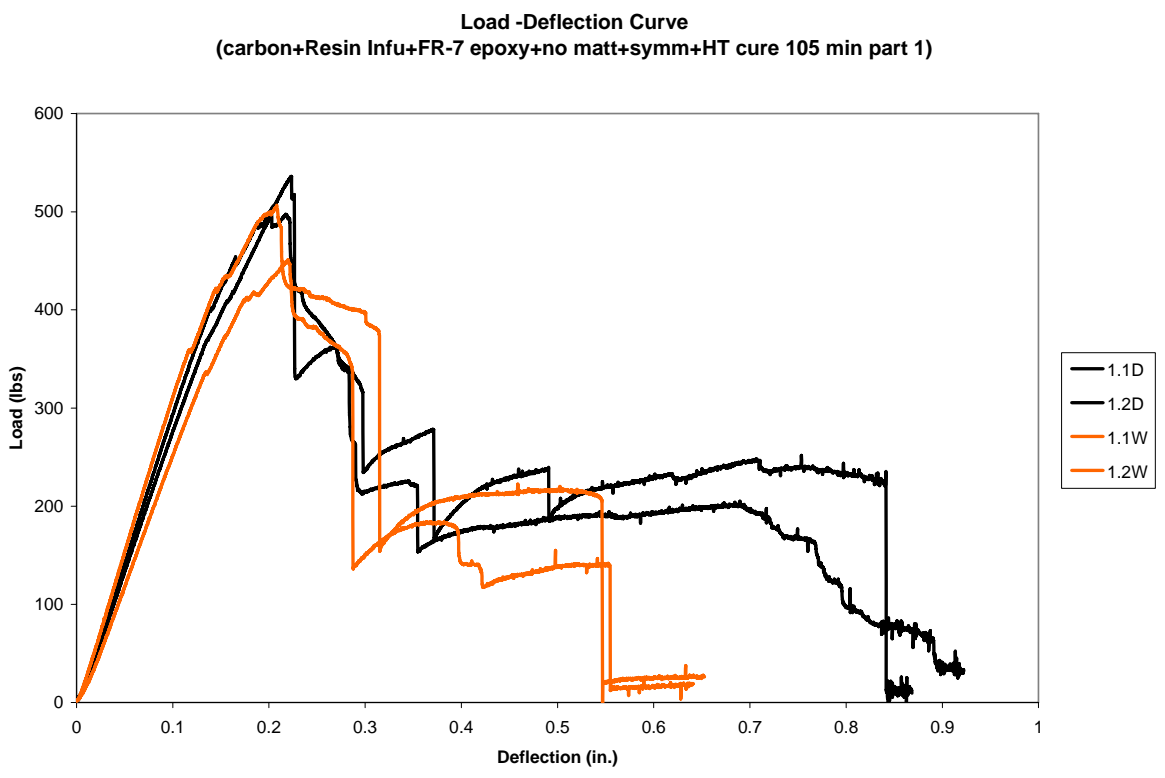

Figure 5.38 Load-deflection of carbon/epoxy composites by resin infusion

\subsubsection{Symmetric Fiber Architecture with Epoxy Cured at $140 \mathrm{~F}$ for $145 \mathrm{~min}$}

For this set of specimens curing was carried out at $140 \mathrm{~F}$ for a curing time of $145 \mathrm{~min}$. with extended curing time. Average thickness of composites plate was around 0.26 ". Average bending stress for test specimens was found to be $81.61 \mathrm{ksi}$ and flexural modulus of $5.07 \mathrm{msi}$. Table 5.27 shows the data from experiment and load-deflection are plotted in Figure 5.39. 
Table 5.27 Bending test results for carbon /epoxy composite by resin infusion (extended curing)

\begin{tabular}{|c|c|c|c|c|c|c|c|}
\hline Sample & $\begin{array}{c}\text { Avg. } \\
\text { Width } \\
\text { (in.) }\end{array}$ & $\begin{array}{c}\text { Avg. } \\
\text { Thickness } \\
\text { (in.) }\end{array}$ & $\begin{array}{l}\text { Slope } \\
\text { P vs. } \\
\text { defl. } \\
\text { (lb/in.) }\end{array}$ & $\begin{array}{l}\text { Max. } \\
\text { Load } \\
\text { (lbs) }\end{array}$ & $\begin{array}{c}\text { Bending } \\
\text { Stress } \\
(\mathrm{ksi})\end{array}$ & (msi) & $\begin{array}{c}\text { Fiber } \\
\text { Content } \\
(\mathbf{w t} \%) \\
\end{array}$ \\
\hline $2.1 \mathrm{D}$ & 0.5550 & 0.2530 & 2919.5 & 458 & 77.23 & 5.17 & \multirow{10}{*}{78.64} \\
\hline $2.2 \mathrm{D}$ & 0.5570 & 0.2640 & 3173.0 & 537 & 82.87 & 4.93 & \\
\hline $2.3 \mathrm{D}$ & 0.5510 & 0.2530 & 2810.9 & 462 & 78.95 & 5.06 & \\
\hline $2.4 \mathrm{D}$ & 0.5530 & 0.2500 & 2781.8 & 470 & 81.49 & 5.13 & \\
\hline $2.1 \mathrm{~W}$ & 0.4840 & 0.2560 & 2637.5 & 455 & 86.27 & 5.20 & \\
\hline $2.2 \mathrm{~W}$ & 0.4860 & 0.2560 & 2587.2 & 456 & 86.05 & 5.07 & \\
\hline $2.3 \mathrm{~W}$ & 0.4660 & 0.2610 & 2548.5 & 431 & 81.72 & 4.93 & \\
\hline $2.4 \mathrm{~W}$ & 0.5100 & 0.2590 & 2836.0 & 447 & 78.31 & 5.09 & \\
\hline \multicolumn{5}{|c|}{ AVG } & 81.61 & 5.07 & \\
\hline \multicolumn{5}{|c|}{ \% STD } & 3.87 & 1.77 & \\
\hline
\end{tabular}

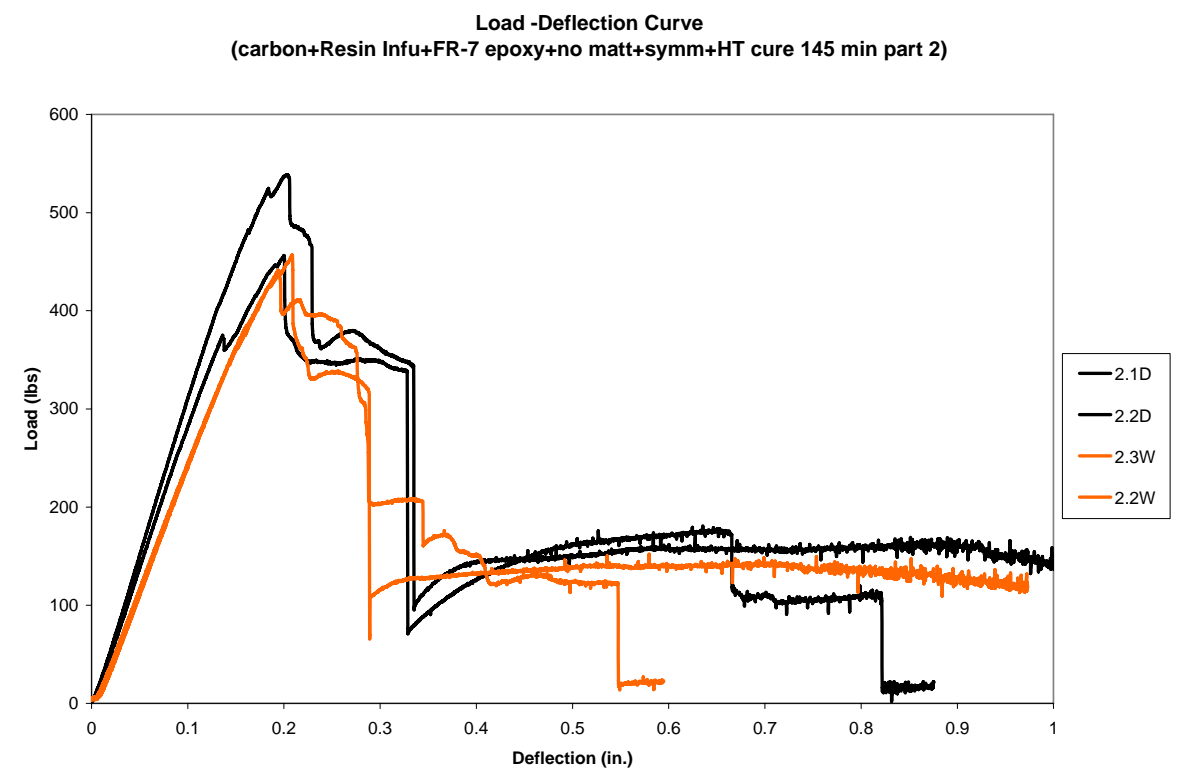

Figure 5.39 Load-deflection behavior of carbon/epoxy composites by resin infusion (extended curing)

\subsubsection{Symmetric Fiber Architecture with 510A VE Cured at RT}

Specimens were prepared with VE resin cured at room temperature. Average thickness of composite plate was found to be around 0.28 ". Sample sets 3 and 4 only differed in fiber content else remaining the same. Bending test data are reported in Tables 5.28 and 5.29 with stress-strain behavior in Figures 5.40 and 5.41 respectively. Average bending stress 
was found to be $52.71 \mathrm{ksi}$ and $54.38 \mathrm{ksi}$ with flexural modulus of $4.24 \mathrm{msi}$ and $3.67 \mathrm{msi}$ respectively.

Table 5.28 Bending test results for carbon /VE composite by resin infusion

\begin{tabular}{|c|c|c|c|c|c|c|c|}
\hline Sample & $\begin{array}{c}\text { Avg. } \\
\text { Width } \\
\text { (in.) }\end{array}$ & $\begin{array}{c}\text { Avg. } \\
\text { Thickness } \\
\text { (in.) }\end{array}$ & $\begin{array}{l}\text { Slope } \\
\text { P vs. } \\
\text { defl. } \\
\text { (lb/in.) }\end{array}$ & $\begin{array}{l}\text { Max. } \\
\text { Load } \\
\text { (lbs) }\end{array}$ & $\begin{array}{c}\text { Bending } \\
\text { Stress } \\
\text { (ksi) }\end{array}$ & (msi) & $\begin{array}{c}\text { Fiber } \\
\text { Content }\end{array}$ \\
\hline $3.1 \mathrm{D}$ & 0.5160 & 0.3070 & 3239.9 & 398 & 49.07 & 3.46 & \multirow{10}{*}{55.66} \\
\hline $3.2 \mathrm{D}$ & 0.4600 & 0.3040 & 2941.2 & 352 & 49.85 & 3.64 & \\
\hline $3.3 \mathrm{D}$ & 0.4630 & 0.3020 & 3026.8 & 338 & 48.10 & 3.79 & \\
\hline $3.4 \mathrm{D}$ & 0.4420 & 0.3050 & 2793.3 & 344 & 50.27 & 3.56 & \\
\hline $3.1 \mathrm{~W}$ & 0.5220 & 0.2610 & 2836.3 & 319 & 54.00 & 4.90 & \\
\hline $3.2 \mathrm{~W}$ & 0.4740 & 0.2530 & 2063.1 & 265 & 52.40 & 4.29 & \\
\hline $3.3 \mathrm{~W}$ & 0.5410 & 0.2650 & 2753.6 & 333 & 52.77 & 4.39 & \\
\hline $3.4 \mathrm{~W}$ & 0.4990 & 0.2480 & 2796.8 & 335 & 65.50 & 5.87 & \\
\hline \multicolumn{5}{|r|}{ AVG } & 52.71 & 4.24 & \\
\hline \multicolumn{5}{|c|}{$\%$ STD } & 10.47 & 19.33 & \\
\hline
\end{tabular}

Table 5.29 Bending test results for carbon /VE composite by resin infusion

\begin{tabular}{|c|c|c|c|c|c|c|c|}
\hline Sample & $\begin{array}{l}\text { Avg. } \\
\text { Width } \\
\text { (in.) }\end{array}$ & $\begin{array}{l}\text { Avg. } \\
\text { Thickness } \\
\text { (in.) }\end{array}$ & $\begin{array}{l}\text { Slope } \\
\text { P vs. } \\
\text { defl. } \\
\text { (lb/in.) }\end{array}$ & $\begin{array}{l}\text { Max. } \\
\text { Load } \\
\text { (lbs) }\end{array}$ & $\begin{array}{c}\text { Bending } \\
\text { Stress } \\
\text { (ksi) }\end{array}$ & (msi) & $\begin{array}{c}\begin{array}{c}\text { Fiber } \\
\text { Content }\end{array} \\
(\mathbf{w t} \%)\end{array}$ \\
\hline $4.1 \mathrm{D}$ & 0.5210 & 0.3140 & 3820.0 & 464 & 54.23 & 3.78 & \multirow{11}{*}{49.76} \\
\hline $4.2 \mathrm{D}$ & 0.5410 & 0.3240 & 4185.0 & 531 & 56.32 & 3.65 & \\
\hline $4.3 \mathrm{D}$ & 0.5400 & 0.3240 & 4137.1 & 527 & 55.70 & 3.59 & \\
\hline $4.4 \mathrm{D}$ & 0.5320 & 0.3110 & 3754.0 & 453 & 52.68 & 3.73 & \\
\hline $4.1 \mathrm{~W}$ & 0.5200 & 0.2950 & 3370.4 & 437 & 58.12 & 4.05 & \\
\hline $4.2 \mathrm{~W}$ & 0.5250 & 0.3240 & 3607.0 & 506 & 55.16 & 3.23 & \\
\hline $4.3 \mathrm{~W}$ & 0.5000 & 0.3210 & 3651.3 & 437 & 50.82 & 3.52 & \\
\hline $4.4 \mathrm{~W}$ & 0.4840 & 0.3320 & 3999.3 & 482 & 54.21 & 3.61 & \\
\hline $4.5 \mathrm{~W}$ & 0.5020 & 0.3080 & 3597.6 & 414 & 52.16 & 3.91 & \\
\hline \multicolumn{5}{|r|}{ AVG } & 54.38 & 3.67 & \\
\hline \multicolumn{5}{|c|}{$\frac{\text { AVG }}{\% \text { STD }}$} & 4.13 & 6.26 & \\
\hline
\end{tabular}




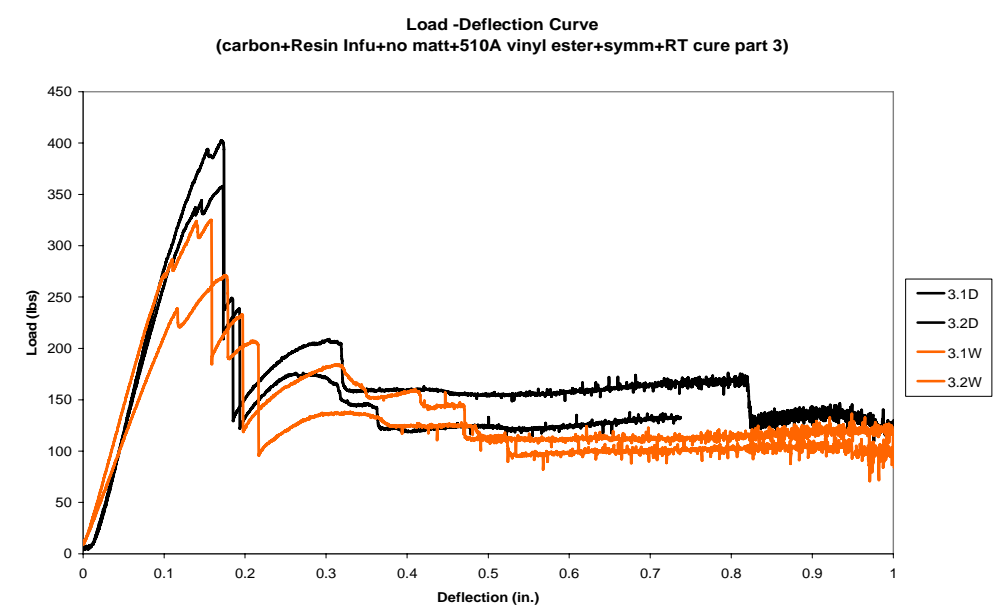

Figure 5.40 Load-deflection of carbon/VE composites by resin infusion

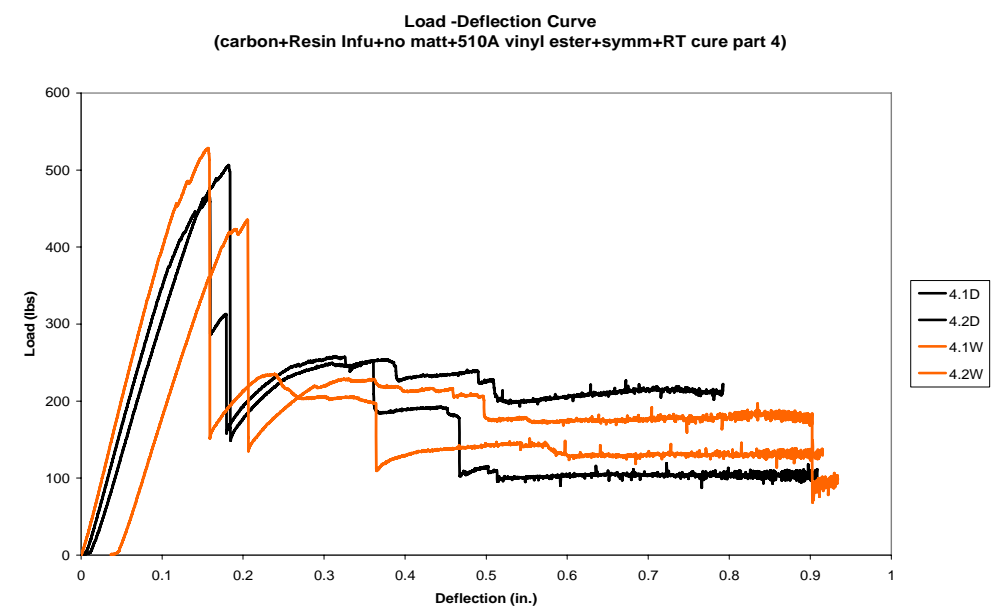

Figure 5.41 Load-deflection of carbon/VE composites by resin infusion

\subsubsection{Conclusions}

Figures 5.42 and 5.43 shows the average bending stress and average flexural modulus plotted for all the set of experiments in resin infusion process respectively. 
Comparison of Bending Stress

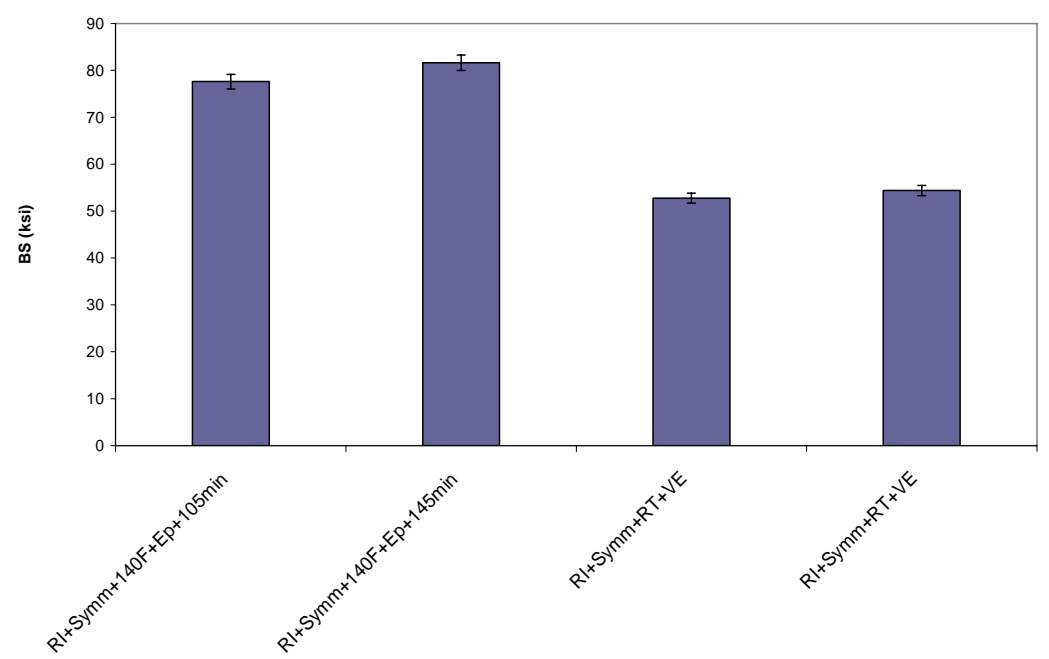

Figure 5.42 Chart comparison of bending stress for carbon/VE/epoxy composites by resin infusion

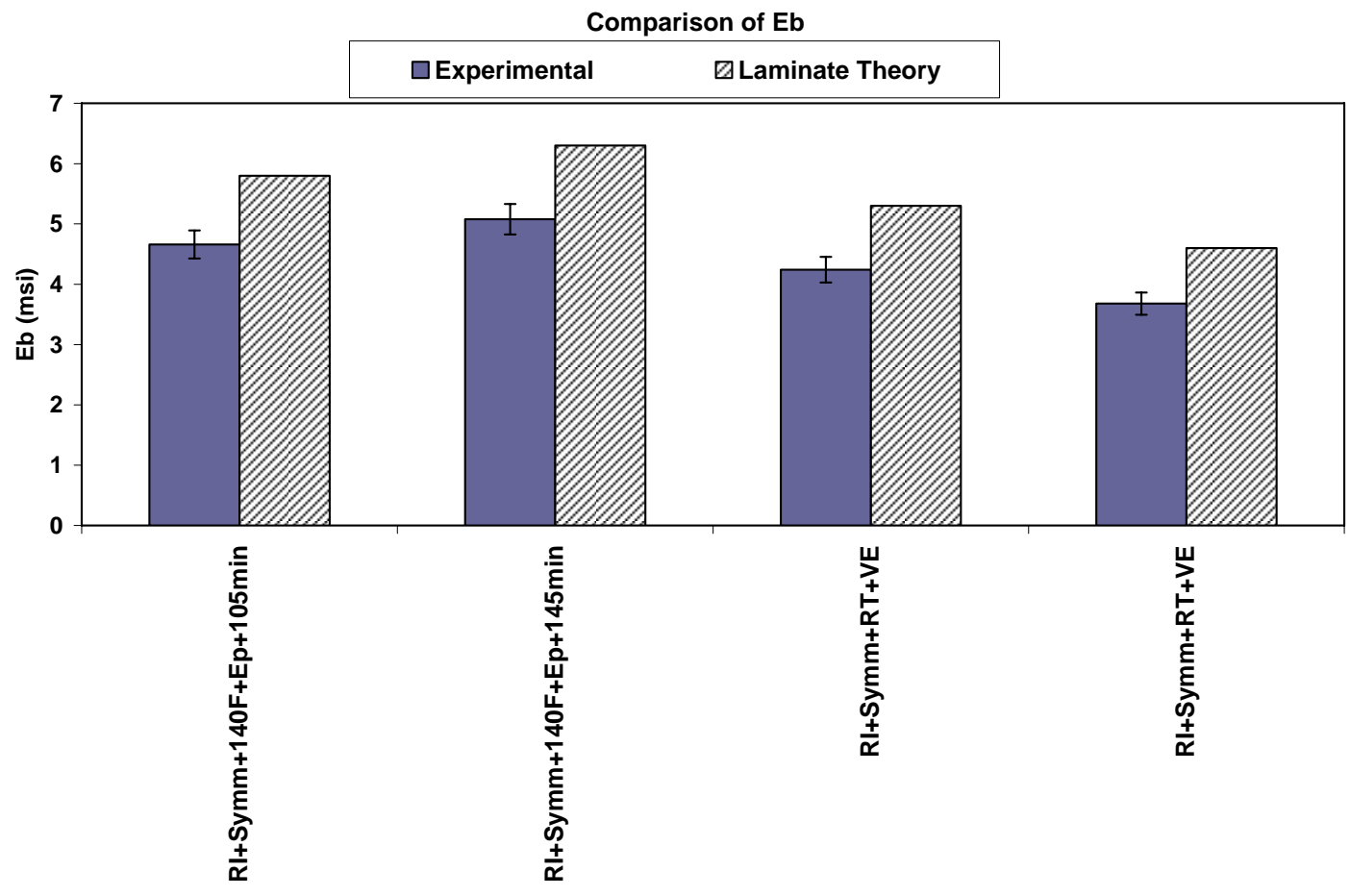

Figure 5.43 Chart comparison of $E_{b}$ for carbon/VE/epoxy composites by resin infusion 
Figures 5.42 and 5.43 indicate that with increased curing time increases in bending stress and flexural modulus is small. Moreover, carbon/epoxy composites show better strength in terms of bending stress and flexural modulus as compared to carbon/VE composites.

\subsection{Sandwich Panel Testing}

Fabrication of CFRP sandwich panels was accomplished in collaboration with Bedford reinforced Plastics (BRP) Inc. As described in Chapter 3, two production runs were carried out for CFRP panel manufacturing. Further details of panel dimensions, fabric architecture, resin etc. can be referred in Table 3.3.

After manufacturing, sandwich panels were subjected to mechanical testing under four point bending. Composite panels were tested at different scales for static bending properties. Smaller panels (12"x27") were evaluated for longitudinal and transverse properties whereas larger panel (40"x100") evaluation represents structural properties for bulkhead construction. Experimental results for the same are provided in subsequent sections.

\subsubsection{2"x27"x3.5" CFRP Panels}

Sandwich panels with short span of 27" were tested for shear response of a shear beam. Table 5.30 shows the results of this set of testing. Samples 9, 10 and 11 were made from the first manufacturing run. On the other hand, samples 2 and 4 represents panels from second manufacturing run. Entire set of panels were tested with strain gages mounted on top (T) and bottom (B) surface of panels. For the second manufacturing run, test panels were prepared in both longitudinal (L) and transverse direction (T).

Panels 9 and 10 were tested without removing side caps on the side whereas panel 11 contained side caps. Average core shear stress of panels without side caps was found to be about $208 \mathrm{ksi}$ and for those with side caps was nearly $542 \mathrm{ksi}$. In addition, average bending stress for side cap panel was $15.75 \mathrm{ksi}$ and for other case it was $6.06 \mathrm{ksi}$. Also, significant increase in overall panel stiffness was observed for panels with side caps. Similar trend in shear stress, bending stress and elasticity modulus was also observed for 
sample number 4 panel from second run (with and without caps). Results of panel 2 indicate superior property in longitudinal direction than in transverse direction which is attributed to the fiber orientation in that direction.

\subsubsection{2"x80"x3.5" CFRP Panels}

Pultruded CFRP panels were further evaluated under four point bending at a span of 80 ". The experimental data and calculated mechanical properties are summarized in Table 5.31. Panel ID from 1 to 5 indicates test panels from manufacturing run 1 whereas panel ID 6 represents second manufacturing run. Panels 3 and 4 were tested with end caps and remaining without any end caps. End capped panel showed the average core shear stress of 440 psi, average FRP bending stress of $38 \mathrm{ksi}$ and elasticity modulus of $6.16 \mathrm{msi}$. Panels without any end caps responded with average core shear stress of 183 psi, average FRP bending stress of $16 \mathrm{ksi}$ and elasticity modulus of $5.22 \mathrm{msi}$. All the panels were tested for failure load.

\subsubsection{0"x100"x3.5" CFRP Panels}

Out of the two manufacturing runs, only second run produced 48 " wide panels. Two panels were selected for bending tests. Strains on both the top and bottom face-sheet were measured with three strain gages each on top and bottom. Out of these three gages, two were mounted in the longitudinal and one in transverse direction. Experimental results show close resemblance in response for both the panel with an average core shear stress of 223 psi, average FRP bending stress of $24 \mathrm{ksi}$ and elastic modulus of $6.33 \mathrm{msi}$. 
Table 5.30 12"x27" Sandwich Panels Bending Properties

\begin{tabular}{|c|c|c|c|c|c|c|c|c|c|c|c|c|c|c|}
\hline $\begin{array}{c}\text { Sample } \\
\text { No. }\end{array}$ & $\begin{array}{c}\text { Width } \\
\text { b, } \\
\text { ( in.) }\end{array}$ & $\begin{array}{l}\text { Depth } \\
\text { d, } \\
\text { (in.) }\end{array}$ & $\begin{array}{c}\text { Span } \\
\text { Length, } \\
\text { (in.) }\end{array}$ & $\begin{array}{c}\text { Load } \\
\text { P, } \\
(\mathrm{lbs})\end{array}$ & $\begin{array}{c}\mathrm{P} / \varepsilon \\
\times 10^{\wedge} 6 \\
(\mathrm{lbs})\end{array}$ & $\begin{array}{c}\text { Failure } \\
\text { load } \\
\text { per unit } \\
\text { width } \\
\text { (lbs/in.) }\end{array}$ & $\begin{array}{c}\text { Failure } \\
\text { strain, } \\
(\mu \varepsilon)\end{array}$ & $\begin{array}{c}\text { FRP } \\
\text { strain } \\
(\mu \varepsilon)\end{array}$ & $\begin{array}{c}\text { Core } \\
\text { strain } \\
(\mu \varepsilon)\end{array}$ & $\begin{array}{c}\text { Avg. } \\
\text { Core } \\
\text { Shear } \\
\text { Stress } \\
\text { psi } \\
\end{array}$ & $\begin{array}{c}\text { Avg. } \\
\text { FRP } \\
\text { E } \\
\text { msi. }\end{array}$ & $\begin{array}{c}\text { Avg } \\
\text { FRP } \\
\text { S, } \\
\text { Ksi }\end{array}$ & $\begin{array}{c}\text { Load vs } \\
\text { defl } \\
\text {.slope }\end{array}$ & $\begin{array}{c}\text { FRP E } \\
\text { def, } \\
\text { msi }\end{array}$ \\
\hline $9 \mathrm{~T}$ & 10.90 & 3.5 & 27 & 16470 & 11.870 & 1,510 & 1,362 & 1,388 & 10,177 & \multirow[t]{2}{*}{232.3} & \multirow[t]{2}{*}{5.02} & \multirow[t]{2}{*}{6.76} & \multirow[t]{2}{*}{123746} & \multirow[t]{2}{*}{2.422} \\
\hline $9 \mathrm{~B}$ & 10.90 & 3.5 & 27 & 16470 & 12.598 & 1,510 & 1,289 & 1,307 & 10,177 & & & & & \\
\hline & & & & & & & & & & & & & & \\
\hline $10 \mathrm{~T}$ & 11.06 & 3.5 & 27 & 13283 & 12.009 & 1,201 & 1,107 & 1,106 & 8,092 & \multirow{2}{*}{184.7} & \multirow[t]{2}{*}{4.83} & \multirow{2}{*}{5.37} & \multirow{2}{*}{114053} & \multirow[t]{2}{*}{2.201} \\
\hline $10 \mathrm{~B}$ & 11.06 & 3.5 & 27 & 13283 & 11.870 & 1,201 & 1,123 & 1,119 & 8,092 & & & & & \\
\hline & & & & & & & & & & & & & & \\
\hline $11 \mathrm{~T}$ & 12.00 & 3.5 & 27 & 42258 & 16.014 & 3,522 & 1,943 & 2,639 & 23,732 & \multirow{2}{*}{541.8} & \multirow{2}{*}{6.07} & \multirow{2}{*}{15.75} & \multirow{2}{*}{195537} & \multirow[t]{2}{*}{3.479} \\
\hline $11 \mathrm{~B}$ & 12.00 & 3.5 & 27 & 42258 & 16.544 & 3,522 & 1,896 & 2,554 & 23,732 & & & & & \\
\hline & & & & & & & & & & & & & & \\
\hline $2 \mathrm{~L} 1 \mathrm{~T}$ & 11.96 & 3.5 & 27 & 17158 & 12.800 & 1,434 & 1,329 & 1,340 & 9,661 & \multirow{2}{*}{220.5} & \multirow{2}{*}{5.43} & \multirow{2}{*}{6.41} & \multirow{2}{*}{138520} & \multirow[t]{2}{*}{2.471} \\
\hline 2L1 B & 11.96 & 3.5 & 27 & 17158 & 16.270 & 1,434 & 1,045 & 1,055 & 9,661 & & & & & \\
\hline & & & & & & & & & & & & & & \\
\hline $2 \mathrm{~T} 2 \mathrm{~T}$ & 11.96 & 3.5 & 27 & 16296 & 11.425 & 1,418 & 7,526 & 1,426 & 9,176 & \multirow{2}{*}{209.5} & \multirow{2}{*}{4.69} & \multirow{2}{*}{6.09} & \multirow{2}{*}{117864} & \multirow{2}{*}{2.102} \\
\hline $2 \mathrm{~T} 2 \mathrm{~B}$ & 11.96 & 3.5 & 27 & 16296 & 13.697 & 1,189 & 7,826 & 1,190 & 9,176 & & & & & \\
\hline & & & & & & & & & & & & & & \\
\hline $4 \mathrm{~L} 1 \mathrm{~T}$ & 12.00 & 3.5 & 27 & 16070 & 27.588 & 1,339 & 578 & 583 & 9,025 & \multirow{2}{*}{206.0} & \multirow[t]{2}{*}{7.71} & \multirow[t]{2}{*}{5.99} & \multirow{2}{*}{123593} & \multirow[t]{2}{*}{2.199} \\
\hline 4L1 B & 12.00 & 3.5 & 27 & 16070 & 13.790 & 1,339 & 1,142 & 1,165 & 9,025 & & & & & \\
\hline & & & & & & & & & & & & & & \\
\hline $4 \mathrm{~L} 2 \mathrm{~T}$ & 12.00 & 3.5 & 27 & 15583 & 13.488 & 1,299 & 1,148 & 1,155 & 8,751 & 199.8 & 5.18 & 5.81 & 129126 & 2.297 \\
\hline 4L2 B & 12.00 & 3.5 & 27 & 15583 & 14.277 & 1,299 & 1,092 & 1,091 & 8,751 & & & & & \\
\hline & & & & & & & & & & & & & & \\
\hline $4 \mathrm{~T} 1 \mathrm{~T}$ & 11.87 & 3.5 & 27 & 19783 & 12.691 & 1,558 & 3,203 & 1,559 & 11,227 & 256.3 & 5.01 & 7.45 & 140861 & 2.532 \\
\hline $4 \mathrm{~T} 1 \mathrm{~B}$ & 11.87 & 3.5 & 27 & 19783 & 13.914 & 1,418 & 2,866 & 1,422 & 11,227 & & & & & \\
\hline
\end{tabular}


Table 5.31 12"x80" Sandwich Panels Bending Properties

\begin{tabular}{|c|c|c|c|c|c|c|c|c|c|c|c|c|c|c|}
\hline $\begin{array}{c}\text { Sample } \\
\text { No. }\end{array}$ & $\begin{array}{c}\text { Width } \\
\text { b, } \\
\text { ( in.) }\end{array}$ & $\begin{array}{l}\text { Depth } \\
\text { d, } \\
\text { (in.) }\end{array}$ & $\begin{array}{c}\text { Span } \\
\text { Length, } \\
\text { (in.) }\end{array}$ & $\begin{array}{c}\text { Load } \\
\text { P, } \\
(\mathrm{lbs})\end{array}$ & $\begin{array}{c}P / \varepsilon \\
\times 10^{\wedge} 6 \\
(\mathrm{lbs})\end{array}$ & $\begin{array}{c}\text { Failure } \\
\text { load } \\
\text { per } \\
\text { unit } \\
\text { width } \\
\text { lbs/in. } \\
\end{array}$ & $\begin{array}{c}\text { Failure } \\
\text { strain, } \\
(\mu \varepsilon)\end{array}$ & $\begin{array}{c}\text { FRP } \\
\text { strain } \\
(\mu \varepsilon)\end{array}$ & $\begin{array}{c}\text { Core } \\
\text { strain } \\
(\mu \varepsilon)\end{array}$ & $\begin{array}{l}\text { Avg. } \\
\text { Core } \\
\text { Shear } \\
\text { Stress } \\
\text { Psi } \\
\end{array}$ & $\begin{array}{c}\text { Avg. } \\
\text { FRP } \\
\text { E } \\
\text { msi. }\end{array}$ & $\begin{array}{c}\text { Avg } \\
\text { FRP } \\
\text { S, } \\
\text { Ksi }\end{array}$ & $\begin{array}{c}\text { Load vs } \\
\text { defl } \\
\text {.slope }\end{array}$ & $\begin{array}{c}\text { FRP E } \\
\text { def, } \\
\text { msi }\end{array}$ \\
\hline $5 \mathrm{~T}$ & 10.93 & 3.5 & 80 & 10753 & 19.908 & 983 & 568 & 540 & 6,626 & \multirow{2}{*}{151.3} & \multirow{2}{*}{14.62} & \multirow{2}{*}{13.03} & \multirow{2}{*}{8163.2} & \multirow{2}{*}{4.145} \\
\hline $5 \mathrm{~B}$ & 10.93 & 3.5 & 80 & 10753 & 4.2183 & 983 & 2,548 & 2,549 & 6,626 & & & & & \\
\hline & & & & & & & & & & & & & & \\
\hline $4 \mathrm{~T}$ & 12.00 & 3.5 & 80 & 31375 & 6.099 & 2,615 & 5,853 & 5,144 & 17,620 & \multirow{2}{*}{402.2} & \multirow{2}{*}{6.95} & \multirow{2}{*}{34.65} & \multirow{2}{*}{11785} & \multirow{2}{*}{5.454} \\
\hline $4 \mathrm{~B}$ & 12.00 & 3.5 & 80 & 31375 & 6.4914 & 2,615 & 5,276 & 4,833 & 17,620 & & & & & \\
\hline & & & & & & & & & & & & & & \\
\hline $3 \mathrm{~T}$ & 12.00 & 3.5 & 80 & 37258 & 4.9634 & 3,105 & 7,526 & 7,507 & 20,924 & \multirow{2}{*}{477.7} & \multirow{2}{*}{5.37} & \multirow{2}{*}{41.15} & \multirow{2}{*}{10685} & \multirow{2}{*}{4.945} \\
\hline $3 \mathrm{~B}$ & 12.00 & 3.5 & 80 & 37258 & 4.7681 & 3,105 & 7,826 & 7,814 & 20,924 & & & & & \\
\hline & & & & & & & & & & & & & & \\
\hline $1 \mathrm{~T}$ & 10.62 & 3.5 & 80 & 12474 & 3.8199 & 1,174 & 3,203 & 3,265 & 7,912 & \multirow{2}{*}{180.6} & \multirow{2}{*}{5.05} & \multirow{2}{*}{15.56} & \multirow{2}{*}{8980.1} & \multirow[t]{2}{*}{4.694} \\
\hline $1 \mathrm{~B}$ & 10.62 & 3.5 & 80 & 12474 & 4.2693 & 1,174 & 2,866 & 2,922 & 7,912 & & & & & \\
\hline & & & & & & & & & & & & & & \\
\hline $2 \mathrm{~T}$ & 10.62 & 3.5 & 80 & 15024 & 4.3828 & 1,414 & 3,348 & 3,428 & 9,529 & \multirow{2}{*}{217.5} & \multirow{2}{*}{5.40} & \multirow{2}{*}{18.74} & \multirow{2}{*}{10032} & \multirow{2}{*}{5.244} \\
\hline $2 \mathrm{~B}$ & 10.62 & 3.5 & 80 & 15024 & 4.2722 & 1,414 & 3,448 & 3,517 & 9,529 & & & & & \\
\hline & & & & & & & & & & & & & & \\
\hline $6.1 \mathrm{~T}$ & 11.93 & 3.5 & 80 & 13774 & 4.7156 & 1,154 & 2,908 & 2,921 & 7,776 & \multirow{2}{*}{177.5} & \multirow{2}{*}{4.93} & \multirow{2}{*}{15.29} & \multirow{2}{*}{9846} & \multirow{2}{*}{4.581} \\
\hline $6.1 \mathrm{~B}$ & 11.93 & 3.5 & 80 & 13774 & 4.157 & 1,154 & 3,290 & 3,313 & 7,776 & & & & & \\
\hline & & & & & & & & & & & & & & \\
\hline $6.2 \mathrm{~B}$ & 11.87 & 3.5 & 80 & 11611 & 4.6814 & 978 & 2,415 & 2,480 & 6,589 & \multirow[t]{2}{*}{150.4} & 5.22 & 12.96 & 10958 & 5.125 \\
\hline $6.2 \mathrm{~B}$ & 11.87 & 3.5 & 80 & 11611 & 4.6776 & 978 & 2,414 & 2,482 & 6,589 & & & & & \\
\hline
\end{tabular}


Table 5.32 40"x100" Sandwich Panels Bending Properties

\begin{tabular}{|c|c|c|c|c|c|c|c|c|c|c|c|c|c|c|}
\hline $\begin{array}{c}\text { Sample } \\
\text { No. }\end{array}$ & $\begin{array}{c}\text { Width } \\
\text { b, } \\
\text { ( in.) }\end{array}$ & $\begin{array}{c}\text { Depth } \\
\text { d, } \\
\text { (in.) }\end{array}$ & $\begin{array}{c}\text { Span } \\
\text { Length, } \\
\text { (in.) }\end{array}$ & $\begin{array}{c}\text { Load } \\
\text { P, } \\
\text { Lbs }\end{array}$ & $\begin{array}{c}\mathrm{P} / \varepsilon \\
\mathbf{x 1 0 ^ { \wedge } 6} \\
(\mathrm{lbs})\end{array}$ & $\begin{array}{c}\text { Failure } \\
\text { load } \\
\text { per } \\
\text { unit } \\
\text { width } \\
\end{array}$ & $\begin{array}{c}\text { Failure } \\
\text { strain, } \\
(\mu \varepsilon)\end{array}$ & $\begin{array}{c}\text { FRP } \\
\text { strain } \\
(\mu \varepsilon)\end{array}$ & $\begin{array}{c}\text { Core } \\
\text { strain } \\
(\mu \varepsilon)\end{array}$ & $\begin{array}{c}\text { Avg. } \\
\text { Core } \\
\text { Shear } \\
\text { Stress } \\
\text { Psi } \\
\end{array}$ & $\begin{array}{c}\text { Avg. } \\
\text { FRP } \\
\text { E } \\
\text { msi. }\end{array}$ & $\begin{array}{c}\text { Avg } \\
\text { FRP } \\
\text { S, } \\
\text { Ksi }\end{array}$ & $\begin{array}{c}\text { Load vs } \\
\text { defl } \\
\text {.slope }\end{array}$ & $\begin{array}{c}\text { FRP E } \\
\text { def, } \\
\text { msi }\end{array}$ \\
\hline $3 \mathrm{~T}(\mathrm{~T})$ & 40.00 & 3.5 & 100 & 55745 & 70.542 & 1,394 & 783 & 790 & 9,392 & \multirow{3}{*}{214.4} & \multirow{3}{*}{6.35} & \multirow{3}{*}{23.09} & \multirow{6}{*}{23512} & \multirow{6}{*}{6.376} \\
\hline $3 \mathrm{~T}(\mathrm{~L})$ & 40.00 & 3.5 & 100 & 55745 & 15.543 & 1,394 & $-3,512$ & 3,587 & 9,392 & & & & & \\
\hline $3 \mathrm{~T}(\mathrm{~L})$ & 40.00 & 3.5 & 100 & 55745 & 15.124 & 1,394 & $-3,606$ & 3,686 & 9,392 & & & & & \\
\hline 3B (L) & 40.00 & 3.5 & 100 & 55745 & 15.523 & 1,394 & 3,523 & 3,591 & 9,392 & \multirow{3}{*}{214.4} & \multirow{3}{*}{6.26} & \multirow{3}{*}{23.09} & & \\
\hline 3B (T) & 40.00 & 3.5 & 100 & 55745 & -74.086 & 1,394 & -760 & -752 & 9,392 & & & & & \\
\hline 3B (L) & 40.00 & 3.5 & 100 & 55745 & 14.700 & 1,394 & 3,711 & 3,792 & 9,392 & & & & & \\
\hline & & & & & & & & & & & & & & \\
\hline $5 \mathrm{~T}(\mathrm{~T})$ & 40.00 & 3.5 & 100 & 60458 & 62.399 & 1,511 & 973 & 969 & 10,186 & \multirow{3}{*}{232.5} & \multirow{3}{*}{6.47} & \multirow{3}{*}{25.04} & \multirow{6}{*}{23113} & \multirow{6}{*}{6.268} \\
\hline $5 \mathrm{~T}(\mathrm{~L})$ & 40.00 & 3.5 & 100 & 60458 & 16.181 & 1,511 & $-3,713$ & 3,736 & 10,186 & & & & & \\
\hline $5 \mathrm{~T}(\mathrm{~L})$ & 40.00 & 3.5 & 100 & 60458 & 15.037 & 1,511 & $-3,990$ & 4,021 & 10,186 & & & & & \\
\hline $5 B(L)$ & 40.00 & 3.5 & 100 & 60458 & 15.634 & 1,511 & 3,845 & 3,867 & 10,186 & \multirow{3}{*}{232.5} & \multirow{3}{*}{6.26} & \multirow{3}{*}{25.04} & & \\
\hline $5 \mathrm{~B}(\mathrm{~T})$ & 40.00 & 3.5 & 100 & 60458 & 74.147 & 1,511 & -822 & 815 & 10,186 & & & & & \\
\hline $5 B(\mathrm{~L})$ & 40.00 & 3.5 & 100 & 60458 & 14.586 & 1,511 & 4,119 & 4,145 & 10,186 & & & & & \\
\hline
\end{tabular}




\subsection{Physical Characterization}

Physical characterization of FRP composites includes study of physical properties such as fiber content, void content and fiber-matrix adhesion. Results from scanning electron microscopy (SEM) measurement are discussed in following section.

\subsubsection{Void Analysis of FRP Composites by Scanning Electron Microscopy}

The properties of a composite are governed by the nature of interfacial bonding between fiber and matrix. The quality of this bonding must be as high as possible so as to achieve strong adhesion. In order to obtain an optimized stress transfer from the matrix to the fiber, good adhesion between the fiber and the sizing is needed in addition to good adhesion between sizing and matrix and correct intrinsic physiochemical and mechanical characteristics. Such microstructure insight offers a good understanding of composite properties. Scanning electron microscopy which is an imaging technique can be utilized as an effective tool for such analysis. Sample preparations including dimensions for SEM images are described in Chapter 3.

Objective of SEM study includes;

1. examination of fiber-matrix adhesion

2. analysis of void and void contents

3. confirmation of fiber orientation

With the aid of SEM images, fiber orientations were confirmed within a composite specimen. Electron beam was aligned in the direction of a plane perpendicular to the plane of $0^{0}$ fibers. It resulted in circular shape dots on SEM images for $0^{0}$ fiber and remaining fiber orientations were oval shape as shown in Figure 5.44.
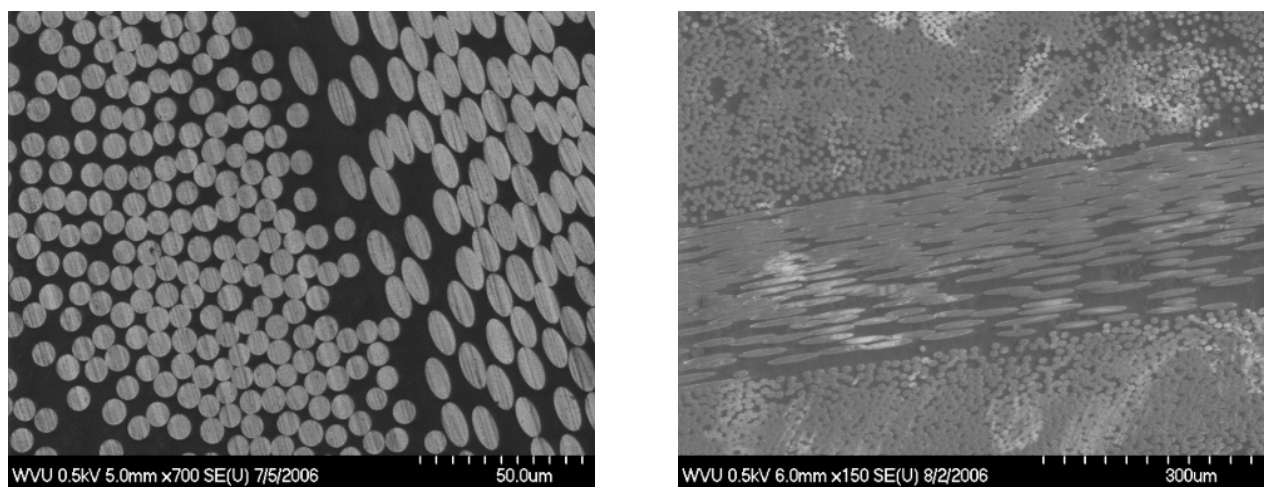

Figure 5.44 Different fiber orientations of carbon/VE composites produced by pultrusion method 
Strength of fiber reinforced polymer composites is governed by the degree of compatibility between fiber and matrix. Good interface bonding results in high performance composites. SEM images in Figure 5.45 shows the effective bonding between fiber and matrix. It reveals the continuous matrix region between two fibers and good interface contact.
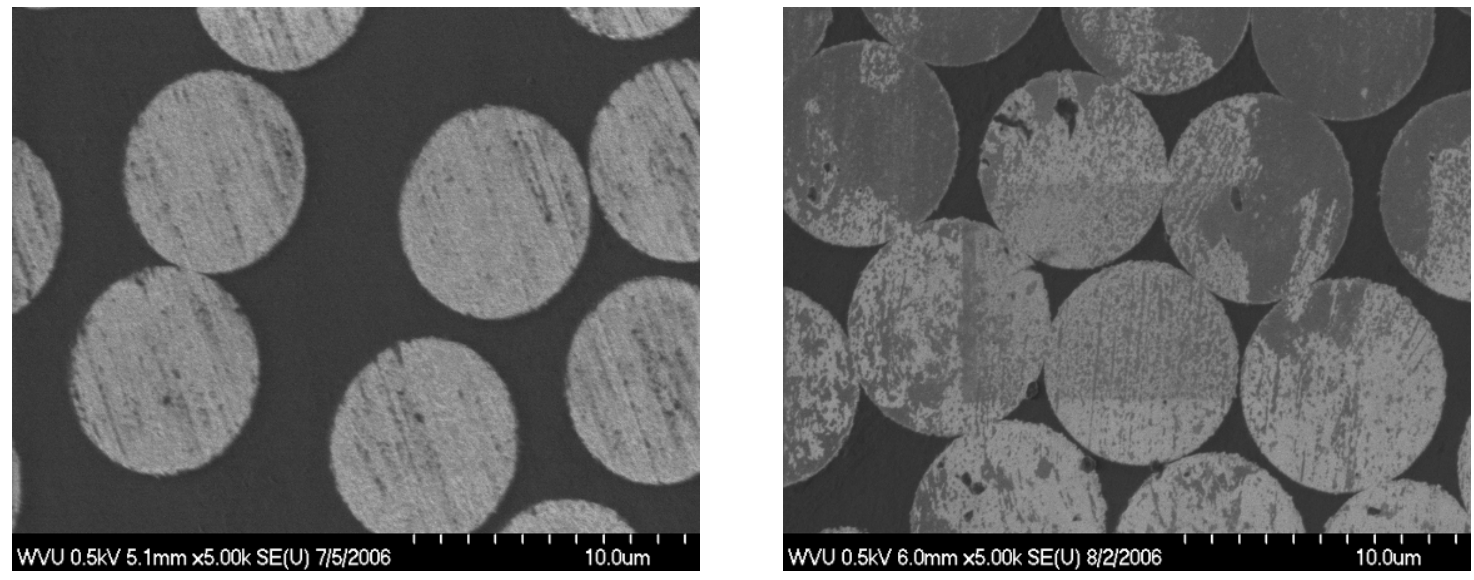

Figure 5.45 SEM images showing good fiber-matrix adhesions for carbon/VE composites

Presence of voids in composites significantly drops mechanical strength of material. The region with high void content is often responsible for crack propagation during loading. Voids are created due to entrapment of air inside the material during manufacturing operation or poor wet out without adequate resin. Although, voids can not be completely removed from the material, void density can be effectively reduced by proper selection of curing or reaction rate, applied pressure and pull rate. Figure 5.46 shows the region of voids and Figure 5.47 indicates void density over the sample surface.
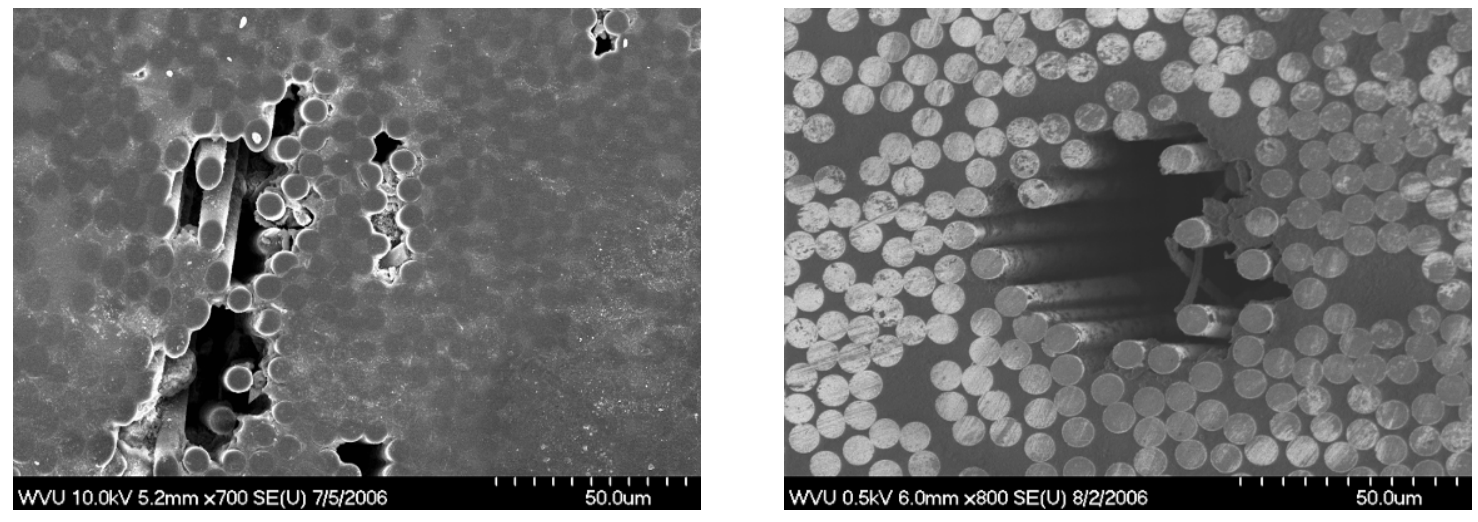

Figure 5.46 Pultrusion sample showing high void surface for carbon/VE composites 

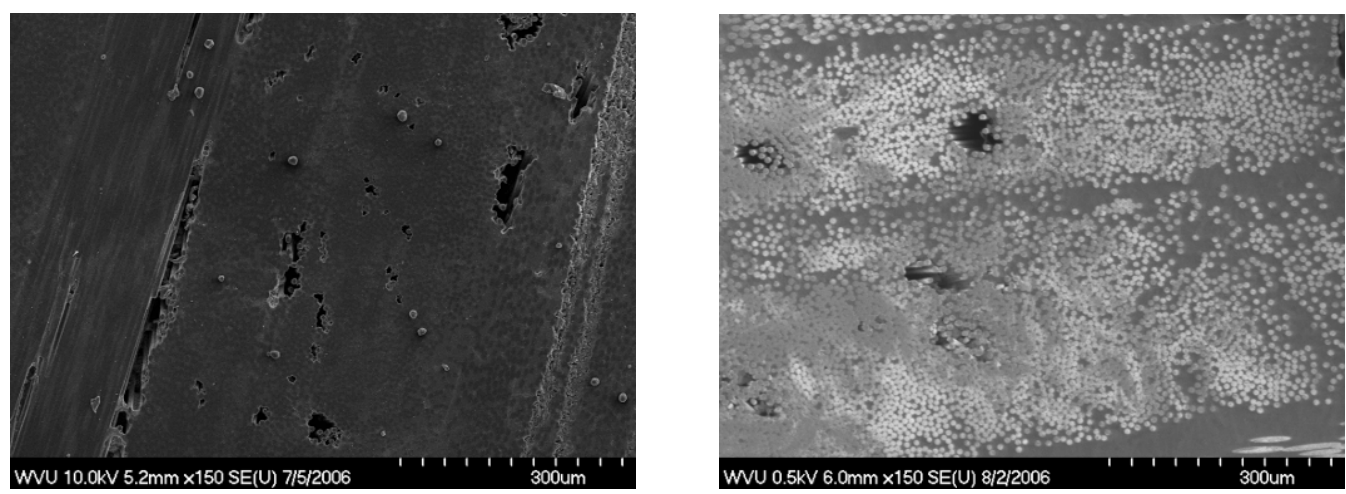

Figure 5.47 Pultrusion sample with regions of high/low void density for carbon/VE composites

Of particular importance is an understanding and optimization of the chemical composition and morphology of the fiber surface, given the nature of the matrix that the fiber is used to reinforce and the conditions for incorporating the fiber into that matrix. The type of bonding required at the fiber-matrix interface often dictates the characteristics that must be designed into the fiber surface. In addition, surface coating may be required to enhance the fiber strength, to act as a diffusion barrier preventing chemical attack by the matrix, or to accommodate any thermal expansion coefficient mismatch between fiber and matrix. Process parameters such as temperature, pressure, curing time and pulling rate dictate the resin enrichment over fibers. Even with compatible resin-matrix system, FRP composites can show poor properties if the resin wet out over fiber layers is improper. Figures 5.48 and 5.49 below shows the typical poor resin wet out observed in resin infusion specimens. In addition, Figure 5.49 shows the case of better wet out specimen of compression molding.
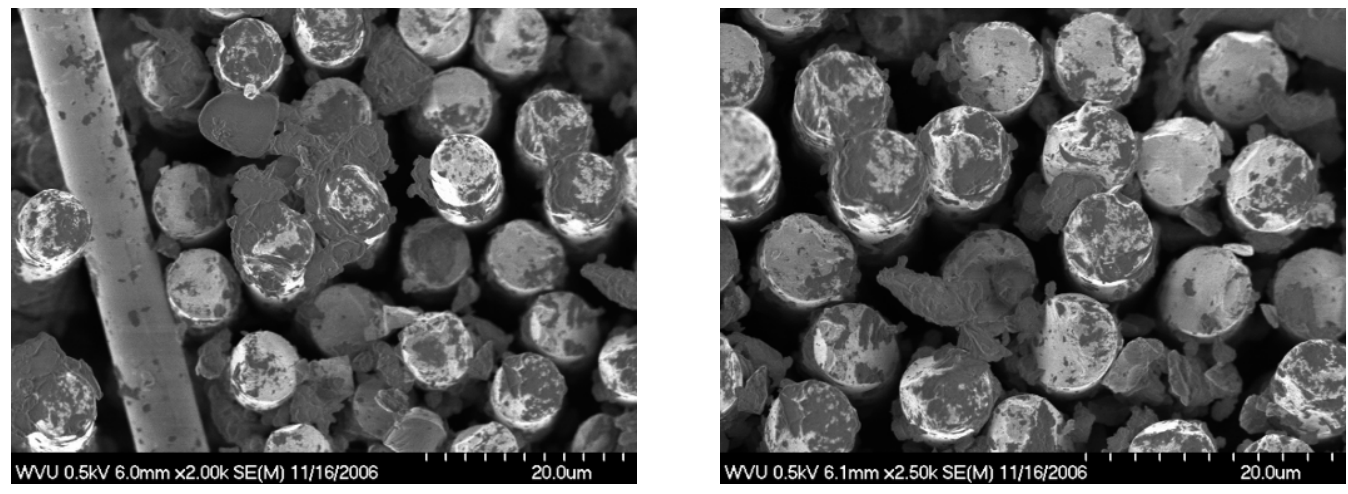

Figure 5.48 Resin infusion showing improper wet out for carbon/VE composites 

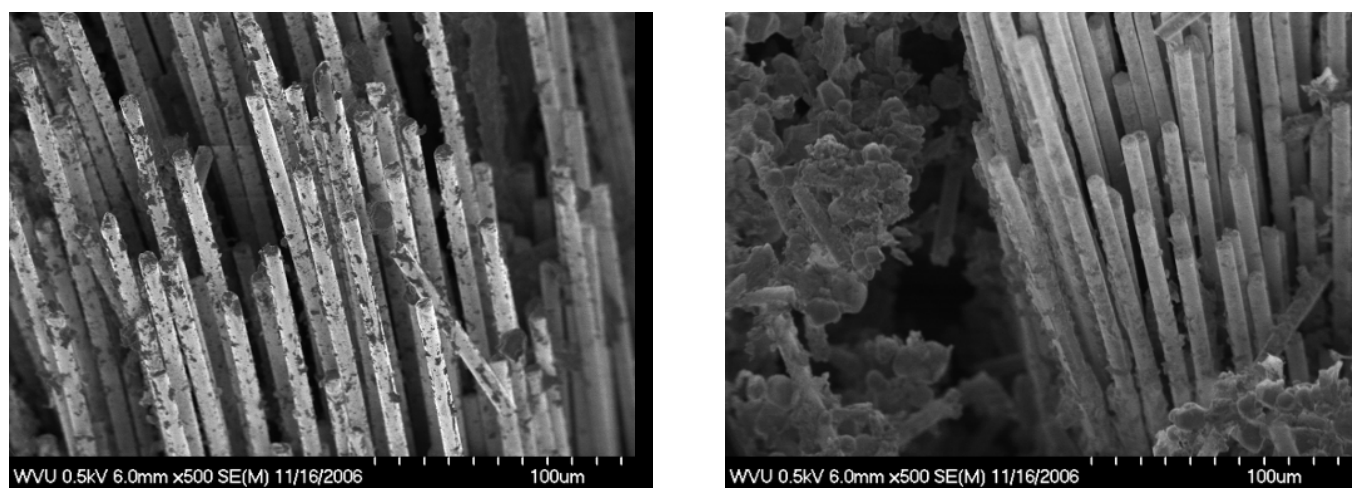

Figure 5.49 Resin infusion showing improper wet out for carbon/VE composites

Load transfer is accomplished from the generally lower-stiffness matrix to the highmodulus fibers through the interphase. Mechanical fiber-matrix bonding is sufficient to accomplish this transfer for axial composite properties, but highly bonded regions are necessary to achieve high levels of off-axis and shear properties.
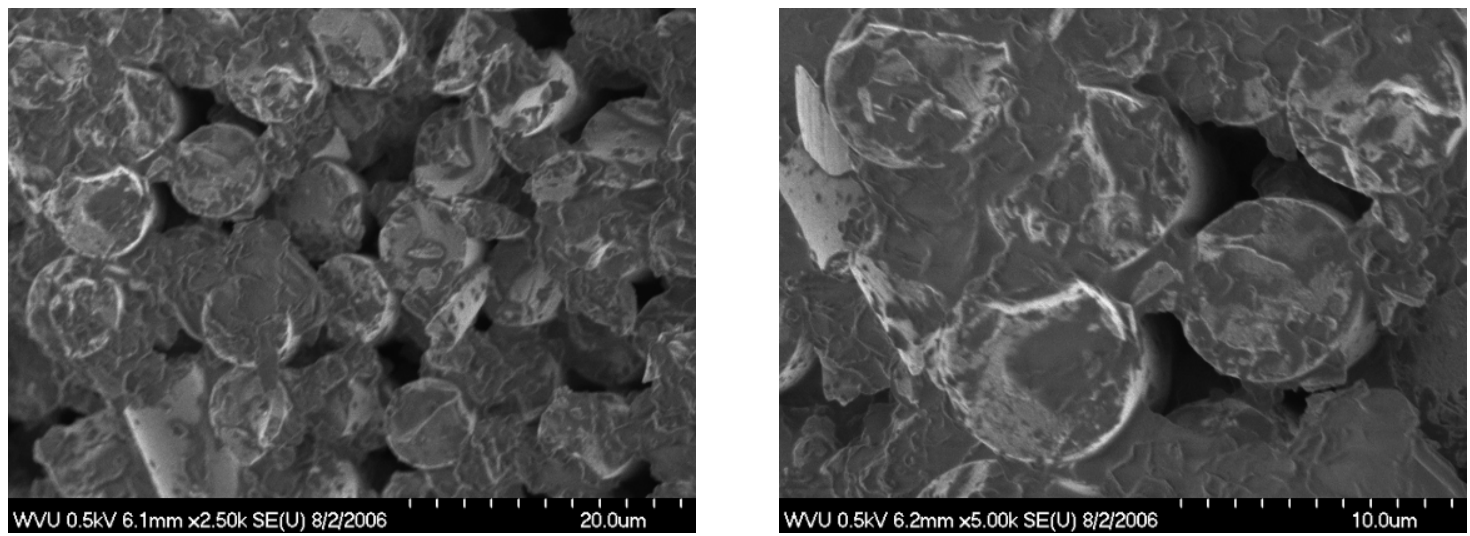

Figure 5.50 Compression molding sample showing better wet out for carbon/epoxy composites

\subsubsection{Conclusions}

SEM image study was found to be helpful in order examine fiber-matrix adhesion, void and void contents, and confirm different fiber orientation present in FRP composites. This analysis in turn was used to derive proper conclusion and making some process modification to improve strength. It must be also noted that sample dimension for SEM is only a very small part entire laminate. So, a good number of specimens from different part of mother specimen must be analyzed in order to derive a conclusion. 


\section{MOIDLING DF FRP SANIDWICH PANELS}

Extensive experimental data have demonstrated that pultruded composite sandwich panels present significant advantages in mechanical and cost performance over the sandwich panels manufactured using other production processes. An effort is being made to predict the response of composite sandwich panel with finite element analysis. This chapter provides an overview of different modeling approaches tested for accuracy of prediction, prediction of CFRP panels on different scales and jointed panel response using FE.

\subsection{Objectives}

The objective of FEA is to model and predict sandwich panel response under static loads. In the first step, small scale (12"x80") GFRP panels were modeled using MSC.NASTRAN with different modeling approaches. On the basis of accuracy, one of the modeling approaches was confirmed to represent composite sandwich panel response. This model was further explored to analyze response of the panel with different geometry and material properties. Comparison of FE results with experimental data helped in fine tuning the accurate modeling approach. In addition, response of jointed sandwich panel was predicted by exploiting the same modeling technique.

\subsection{Finite Element Analysis Software - MSC.Nastran}

MSC.Nastran program is a finite element analysis software that is based on NASTRAN and marketed by MSC Software Corporation. NASTRAN, originally developed by NASA, is a general purpose FEA computer program that addresses a wide range of engineering problem solving requirements (i.e. beam versus plate structures and various types of responses such as static or dynamics) as compared to specialty programs that concentrate on particular types of analysis. It contains significant enhancements in analysis capability and numerical performance. The software includes the following features: User friendly graphic interface; Powerful 3D display; Visualizing analysis/design model; Fast input/output data interfaces to major CAD programs; Fast 
and efficient handling of large FE-models; Visualizing pre-/post processing; Data of structure optimization; and Updating of analysis structure with optimized parameters.

Nastran FEA is widely used to analyze the aerospace, automotive, maritime industries and civil structures. Some of its typical applications include automotive crash, static and transient structural analysis, crash/crush simulations, ship collision, and projectile penetration. The results reported herein are generated by using MSC.Nastran for Windows version 2004r2. Recently, MSC Software has introduced MSC.Patran as a preprocessor for many products including Nastran. The newest version MSC.Patran 2005 r2 (available to CFC-WVU researchers) offers an expansive portfolio of significant improvements, including: rapid creation of analysis models; vastly improved CAD access speed, accuracy, and integration power; improved large model handling performance; and expanded surface meshing capabilities.

\subsection{Experimental Set-up and Loading Conditions}

GFRP composite sandwich panels were tested at different scales for static bending properties as per ASTM C393. Larger panels (40”x100”x3.5”, full scale panel) would lead to representative structural properties for bulkhead construction while smaller panels along pull direction (12"x96"x3.5") would allow a direct comparison with results obtained from the joined panels for joint strength and joint efficiency. Typical test set up and loading diagram for four point bending test are shown in Chapter 4.

\subsection{Evaluation of FE Models for Sandwich Panels}

Earlier analytical work on sandwich structures treated the three dimensional sandwich structures as a pair of membrane face sheets held apart by core material with relatively large transverse shear stiffness. Noor et al. (1996) presented an exhaustive reference list (over 1300 citations) of analytical and computational procedure for sandwich structures. Dave and Yuan (2001-9) developed finite strip formulation using B-splines for sandwich panels with anisotropic face sheets. A simple approach for predicting overall panel buckling of sandwich panels with homogeneous, isotropic face sheet and core materials loaded by in plane compression and with simply supported conditions on all edges was 
presented by Brush and Almorth (1975). Vinson (1986) developed an analytical model that includes the shear deformation for predicting overall panel buckling of composite sandwich panels with orthotropic face sheets.

The finite element analysis of composite sandwich panel using MSC.Nastran was initiated with evaluations of several models under loading conditions. The FEA models studied include: 1. Sandwich Beam Model; 2. Isotropic Solid Model; and 3. Orthotropic Beam Model. In addition, Laminate Model was also examined for its applicability. This model describes the composite material in different layers. Each layer is a well defined laminate. Each layer may contain multiple sub-layers stacked together. For adjacent laminate, the element reference surface is defined to coincide with bounding surface of adjacent laminate.

The FEA result indicates that this model gives similar results to sandwich beam model. In accordance with experimental set up, all models are constructed to have two line loads and simple-supports on the edges. Failure loads are typically applied except cases where model predictions are a function of loads. Degrees of freedom and translational boundary conditions are kept exactly same for all the models studied. Material properties required to conduct FEA include tensile modulus, Poisson ratio, and shears modulus. For orthotropic materials these properties vary along the directions. Hence, subscripts 1, 2 and 3 are used to represent directions $\mathrm{x}, \mathrm{y}$ and $\mathrm{z}$. Material properties, loading condition and degrees of freedom (DOF) are described for all the FE models in the following sections.

\subsubsection{Sandwich Beam Model}

A sandwich panel is modeled as two dimensional elements with at least three different layers. The first layer corresponds to the top face sheet or laminate. The next layer corresponds to core material, and the last layer represents the bottom face sheet or laminate. Above approach corresponds to an equivalent single-layer classical lamination theory for sandwich structures to study their deformations. 
Load, boundary conditions $(\mathrm{BC})$, and material properties used for sandwich beam model are listed in Table 6.1 for 12" x 96" panel and 40"x100" panel. For 40"x100" panel, the predicted deflection contours are shown in Figure 6.1. The deflection data across the span under failure load are plotted in Figure 6.2. The model-predicted maximum deflection is in good agreement with experimentally projected value. Similar observations are made between model predicted deflection data and experimental values under different loads as shown in Figure 6.3 showing deflection profile over full scale panel.

Table 6.1 Load/BC and material properties for sandwich beam model

\begin{tabular}{|c|c|}
\hline Property & Details \\
\hline Geometry & $\begin{array}{l}\text { 2-D, } 3 \text { layers } \\
12^{\prime \prime} \times 80^{\prime \prime} \times 3.5^{\prime \prime}\left(12^{\prime \prime} \times 96^{\prime \prime} \text { panel }\right) \\
40^{\prime \prime} \times 100^{\prime \prime} \times 3.5^{\prime \prime}\left(4^{\prime} \times 10^{\prime} \text { panel }\right)\end{array}$ \\
\hline $\begin{array}{r}\text { Material Property } \\
\text { FRP } \\
\text { Balsa }\end{array}$ & $\begin{array}{l}\text { Isotropic } \\
E=3.24 \mathrm{msi} ; \mu=0.25 \\
E=0.51 \mathrm{msi} ; \mu=0.3\end{array}$ \\
\hline $\begin{array}{r}\text { Load/BC } \\
P \\
P \\
\text { DOF at } x=0 \\
\text { DOF at } x=L \\
\text { DOF at all nodes }\end{array}$ & $\begin{array}{l}17062 \text { lbs }\left(12^{\prime \prime} \times 96^{\prime \prime} \text { panel }\right) \\
53225 \text { lbs }\left(4^{\prime} \times 10^{\prime} \text { panel }\right) \\
\text { Tx }=0 ; \text { Ty }=0 \\
\text { Tx } \neq 0 ; \text { Ty }=0 \\
\text { Tz }=0\end{array}$ \\
\hline
\end{tabular}

In addition, the predicted bending stress across the span close to failure load is shown in Figure 6.4. Quantitatively, the predicted deflection and bending stress from the above model under two different loads are shown in Table 6.2. It concludes that for a capped sandwich beam, sandwich beam model is able to accurately predict deflection but underpredicts bending stress by about $21 \%$.

Table 6.2 Sandwich beam model predictions in comparison with experimental values for 40"x100" GFRP panel

\begin{tabular}{|r|c|c|}
\hline & $\begin{array}{c}\text { Experimental } \\
\text { Data }\end{array}$ & $\begin{array}{c}\text { Sandwich Beam } \\
\text { Model }\end{array}$ \\
\hline Load lbs. & 20300 & $\mathrm{P} / 2=10150$ \\
\hline Deflection, in & 1.30 & 1.34 \\
\hline Bending Stress, ksi & 8.41 & 6.62 \\
\hline At failure load lbs & 53225 & $\mathrm{P} / 2=26612$ \\
\hline Deflection, in & 3.37 (projected) & 3.53 \\
\hline Bending Stress, ksi & 22.05 & 17.36 \\
\hline
\end{tabular}




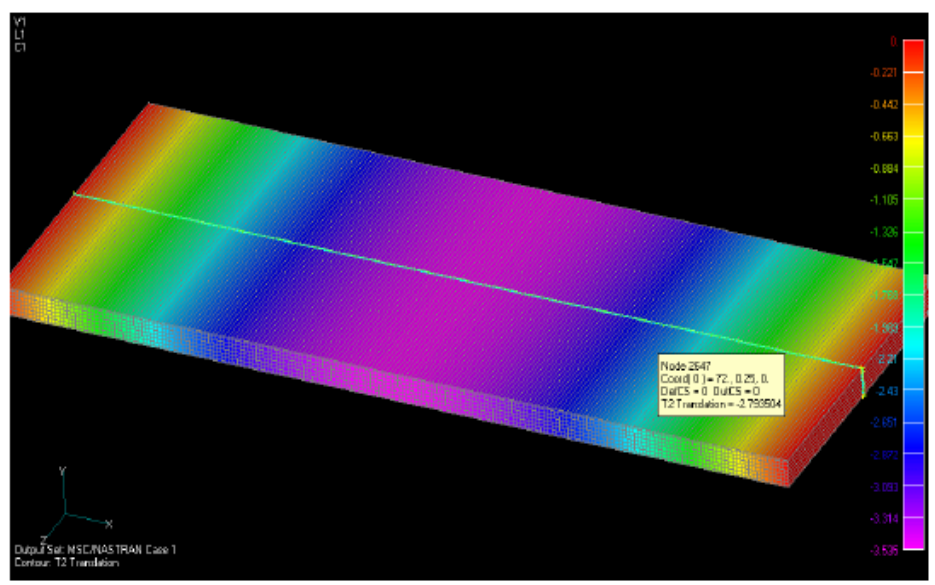

Figure 6.1 Predicted deflection contours by sandwich beam model for 40 "x100" GFRP panel

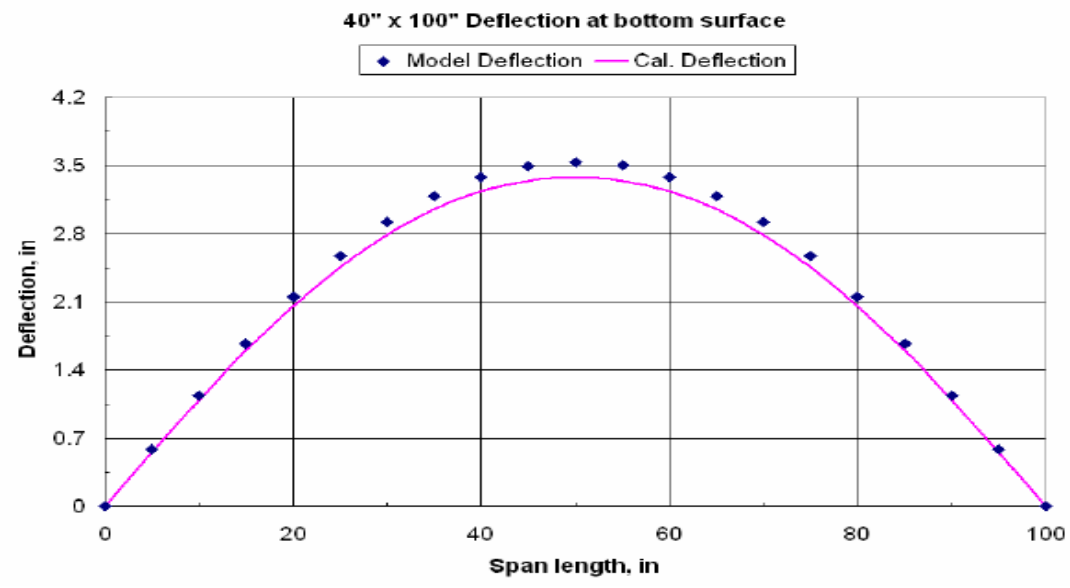

Figure 6.2 Predicted and experimental deflection data across the span under failure load for 40"x100" GFRP panel

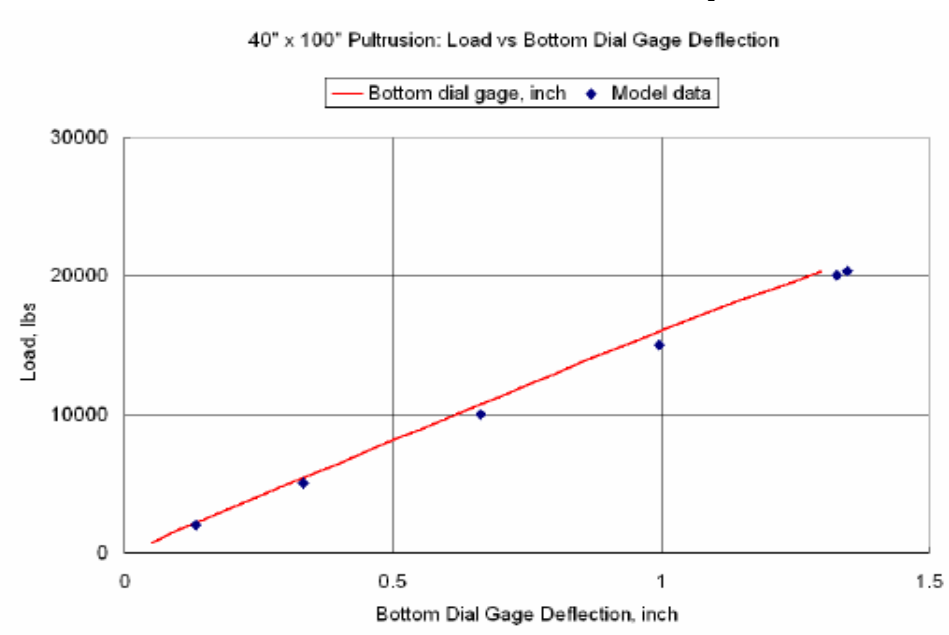

Figure 6.3 Predicted and experimental deflection as a function of loads for 40"x100" GFRP panel 


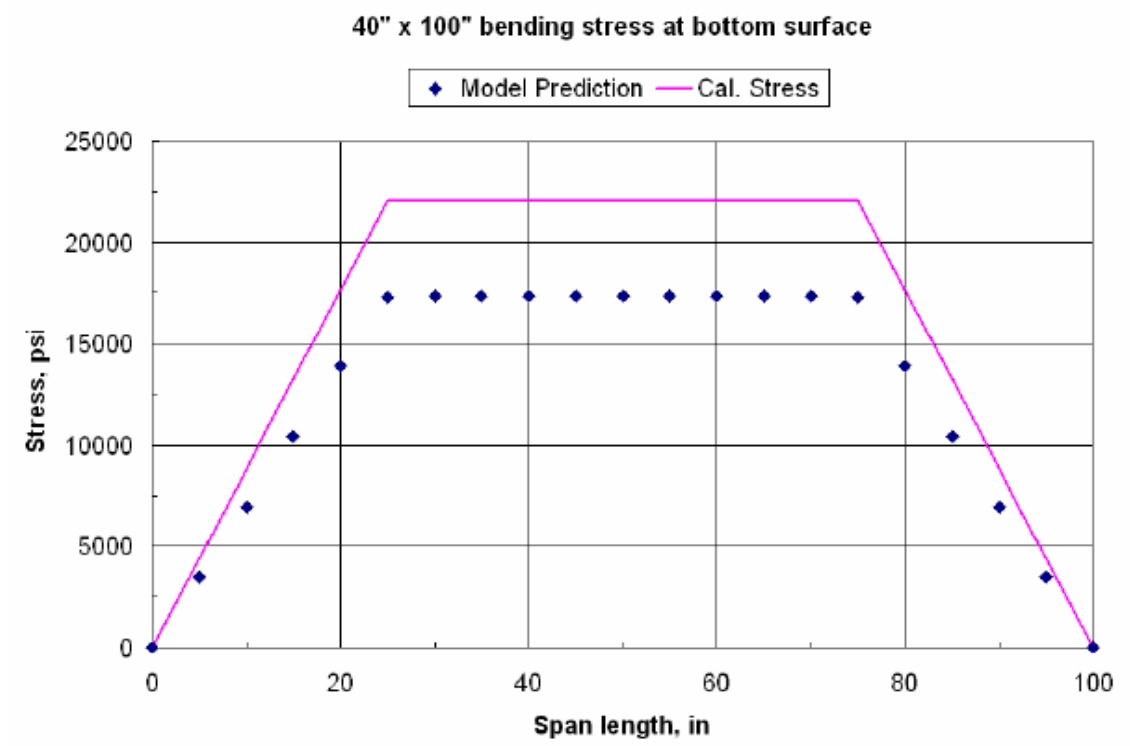

Figure 6.4 Predicted and experimental bending stress across the span under failure load for 40"x100' GFRP panel

The sandwich beam model has also been applied for modeling 12"x96" panel without end caps. The same boundary conditions and material properties as shown in Table 6.1 were used except that a failure load of $17062 \mathrm{lbs}$ was applied on composite plate of 12"x 80"x3.5". The predicted deflection and bending stress from the above model are shown in Figures 6.5 and 6.6. Table 6.4 shows deflection and stress in comparison with other model predictions.

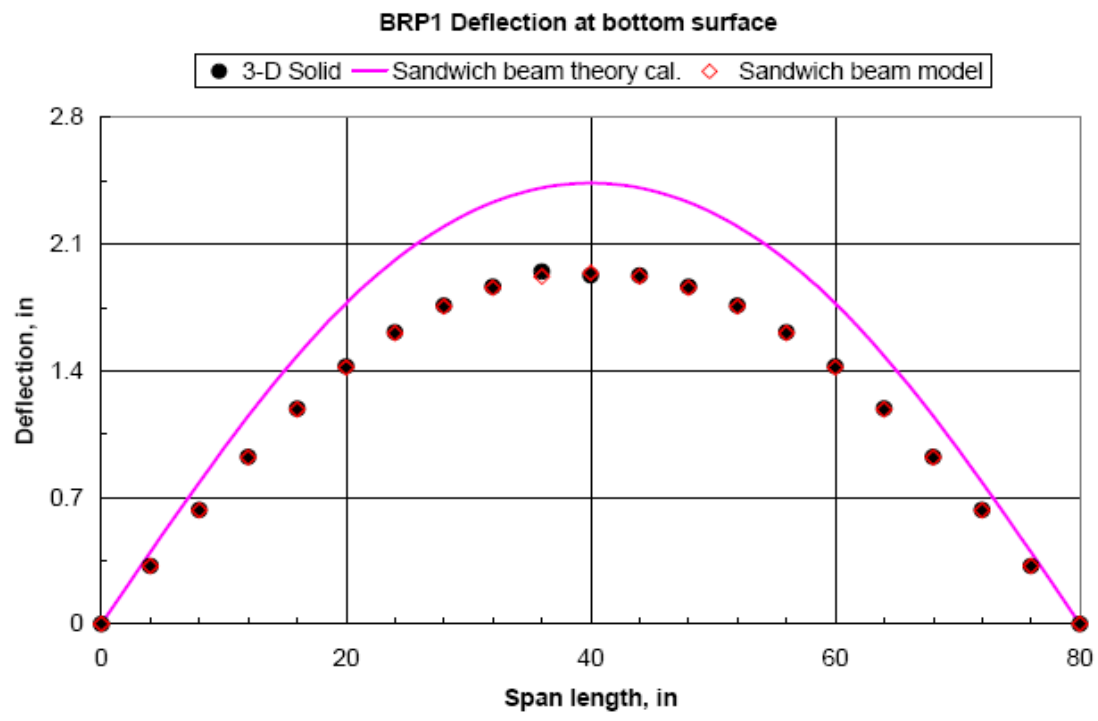

Figure 6.5 Predicted and experimental deflection data across the span under failure load for 12"x96" GFRP panel 


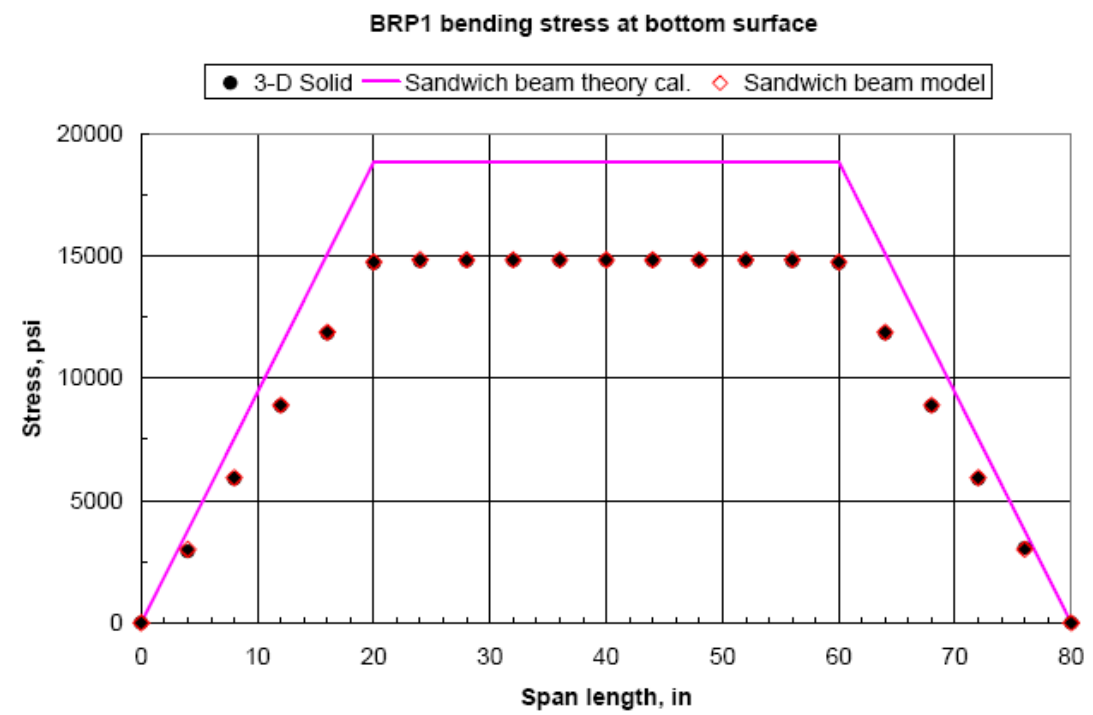

Figure 6.6 Predicted and experimental bending stress across the span under failure load for 12" x 96" GFRP panel

Interestingly, for 12"x96" panel, sandwich beam model under-predicts both deflection and bending stress by about $21 \%$. Also, the model gives erroneous prediction in shear stress. For 40"x100" panels, the sandwich beam model under predicts bending stress by about $21 \%$. However, it accurately predicts deflection for 40 "x 100 " panel, and underpredicts deflection for 12"x96" panel. Apparently, the discrepancy in predicted deflection between two types of panels is attributed to the fact that the full scale panel has end caps which makes the panel stiffer, leading to lower deformation. The reduced deflection coincidently makes up the under-predicted deflection. Therefore, search for a good model has been continued by first focusing on modeling and predicting 12"x96" panel response with high accuracy.

\subsubsection{D Solid Model}

Solid model accounts for a three dimensional nature of the test sample and uses solid shell elements to model the two face sheets and core material. This model was able to accommodate both isotropic and orthotropic material properties, but isotropic material properties were initially applied to the model as reported in the present section. Furthermore, one can also build a model with core as solid shell and face sheets with two dimensional beams, but a model with all the solid elements offers better compatibility 
among the nodes and elements. The load, boundary conditions (BC), and material properties used for 3D solid model are listed in Table 6.3 for 12"x96" panel.

Table 6.3 Load, BC and material properties for isotropic 3D solid model

\begin{tabular}{|c|c|c|}
\hline Property & \multicolumn{2}{|c|}{ Details } \\
\hline Geometry & $3-\mathrm{D}, 3$ layers, $12^{\prime \prime} \times 80^{\prime \prime} \times 3.5^{\prime \prime}$ & \\
\hline $\begin{array}{r}\text { Material Property } \\
\text { FRP } \\
\text { Balsa }\end{array}$ & $\begin{array}{l}\text { Isotropic } \\
E=3.24 \mathrm{msi} ; \mu=0.25 \\
E=0.51 \mathrm{msi} ; \mu=0.3\end{array}$ & \\
\hline $\begin{array}{r}\text { Mesh and Elements } \\
\text { FRP } \\
\text { Balsa } \\
\text { Total }\end{array}$ & $\begin{array}{ll}\text { Lengthwise } & \text { Widthwise } \\
\text { 1element } / 1^{\prime \prime}=8 & \text { 1element } / 1^{\prime \prime}=1 \\
0 & 2 \\
\text { 1element } / 1^{\prime \prime}=8 & 1 \text { element } / 1^{\prime \prime}=1 \\
0 & 2 \\
& 17901 \text { Nodes }\end{array}$ & $\begin{array}{l}\text { Thickness } \\
\text { 1element } / 0.125^{\prime \prime}=2(\times 2=4 \\
\text { 1element } / 0.25^{\prime \prime}=12 \\
15360 \text { Elements }\end{array}$ \\
\hline $\begin{array}{r}\text { Load/BC } \\
\text { DOF at } x=0 \\
\text { DOF at } x=L \\
\text { DOF at all nodes }\end{array}$ & $\begin{array}{l}17062 \mathrm{lbs} \\
\mathrm{Tx}=0 ; \mathrm{Ty}=0 \\
\mathrm{Tx} \neq 0 ; \mathrm{Ty}=0 \\
\mathrm{Tz}=0\end{array}$ & \\
\hline
\end{tabular}

The predicted deflection, bending stress and shear stress from 3D solid model are shown in Table 6.4. The predicted deflection data across the span under failure load are plotted in Figure 6.5 while the predicted bending stress across the span is plotted in Figure 6.6. The model-predicted maximum deflection and bending stress are almost the same as for sandwich beam model. Both the models under-predict deflection and bending stress by about $21 \%$.

Table 6.4 Model predictions in comparison with experimental values for 12"x96" panel@failure load 17062 lbs

\begin{tabular}{|l|c|c|c|}
\hline & $\begin{array}{c}\text { Center } \\
\text { deflection, in }\end{array}$ & $\begin{array}{c}\text { Bending } \\
\text { stress, ksi }\end{array}$ & $\begin{array}{c}\text { Core shear } \\
\text { stress, psi }\end{array}$ \\
\hline Experimental & 2.49 & 18.63 & 218.7 \\
\hline $\begin{array}{l}\text { Sandwich Beam Theory } \\
\text { Cal. }\end{array}$ & 2.44 & 18.85 & 218.7 \\
\hline Sandwich Beam Model & $\begin{array}{c}1.94 \\
(-21 \%)\end{array}$ & $\begin{array}{c}14.84 \\
(-21 \%)\end{array}$ & - \\
\hline Orthotropic Model & $\begin{array}{c}2.38 \\
(-2 \%)\end{array}$ & $\begin{array}{c}18.50 \\
(-1 \%)\end{array}$ & $?$ \\
\hline 3D Solid Model & $\begin{array}{c}1.95 \\
(-21 \%)\end{array}$ & $\begin{array}{c}14.82 \\
(-21 \%)\end{array}$ & $\begin{array}{c}350.0 \\
(+160 \%)\end{array}$ \\
\hline
\end{tabular}


However, 3D solid model is able to predict meaningful shear stress in spite of overpredicting its value as compared to experimental data. Most importantly, as seen later in Figures $6.10,6.14$ and 6.17, 3D solid model is able to yield correct profiles along the length, width and thickness directions for bending stress, shear stress and deflection.

\subsubsection{Orthotropic Beam Model}

Orthotropic model is a sandwich beam model with introduction of orthotropic nature of both face sheets and core properties. The load, boundary conditions (BC), and material properties used for the orthotropic model are listed in Table 6.5 for 12"x 80 " panel.

Table 6.5 Load/BC and material properties for orthotropic beam model

\begin{tabular}{|c|c|c|c|}
\hline Property & & & \\
\hline Geometry & 2-D, 3 layers; $12^{\prime \prime} \mathrm{x}$ & ") $\times 3.5^{\prime \prime}$ & \\
\hline Material Property & $\begin{array}{cc}\text { Orthotropic } & \\
\text { E1 } & \text { E2 } \\
3.24 \mathrm{msi} & 0.5 \mathrm{msi} \\
0.51 \mathrm{msi} & 7.65 \mathrm{ksi} \\
\end{array}$ & $\begin{array}{c}\mathbf{G} \\
1.29 \mathrm{msi} \\
22.8 \mathrm{ksi}\end{array}$ & $\begin{array}{c}\mu \\
0.25 \\
0.3\end{array}$ \\
\hline $\begin{array}{r}\text { Load/BC } \\
\text { DOF at } \mathrm{x}=0 \\
\text { DOF at } \mathrm{x}=\mathrm{L} \\
\text { DOF at all nodes }\end{array}$ & $\begin{array}{l}17062 \text { lbs } \\
T x=0 ; T y=0 \\
T x \neq 0 ; T y=0 \\
T z=0\end{array}$ & & \\
\hline
\end{tabular}

The predicted deflection and bending stress from orthotropic model are also shown in Table 6.4. The predicted deflection data across the span under failure load are plotted in Figure 6.10 while the predicted bending stress across the span under failure load is plotted in Figure 6.14. The model-predicted maximum deflection and bending stress are very closely matching with the experimental values. However, this model proved to be inefficient in predicting shear stress in spite of close predictions on deflection and bending stress. FEA results from 3D solid model and orthotropic model imply that in order to describe composite sandwich panel response under static load the proposed model has to accommodate three dimensional nature in geometry and orthotropic nature in material properties. Therefore, 3-D solid model with orthotropic material properties has been identified to be the model applicable to predict static response of sandwich panels. 


\subsubsection{D Orthotropic Solid Model}

3D orthotropic solid model exploits the advantages of isotropic solid model and orthotropic beam model. All the three layers in the model are built with solid geometry and assigned with orthotropic material properties. In the course of study, this model was first constructed in the way as shown in Figure 10 where the geometry is modeled by creating front face sheet in XY plane. In addition, the face sheet was extruded in $\mathrm{Z}$ direction with same dimensions of elements but different width for core and face sheets. Hence, $\mathrm{XY}$ becomes principle plane for material properties, instead of $\mathrm{XZ}$ as in other models discussed earlier. We designate this model as Model A for ease of discussion. Furthermore, another model was created with the face sheet in XZ plane and with the width direction of the panel being the identical direction $(Z)$, as shown in Figure 11. This model is designated as $3 \mathrm{D}$ orthotropic solid model B.
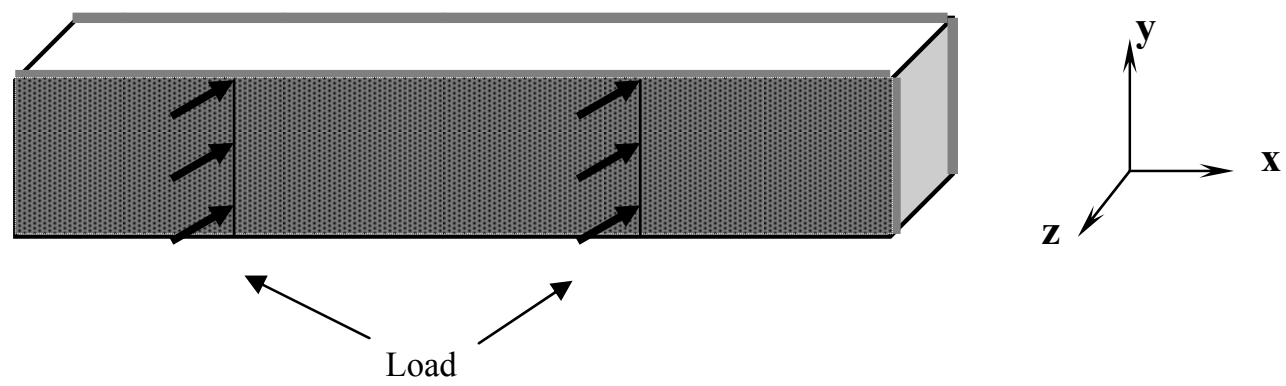

Figure 6.7 Construction of 3D Orthotropic Solid Model A
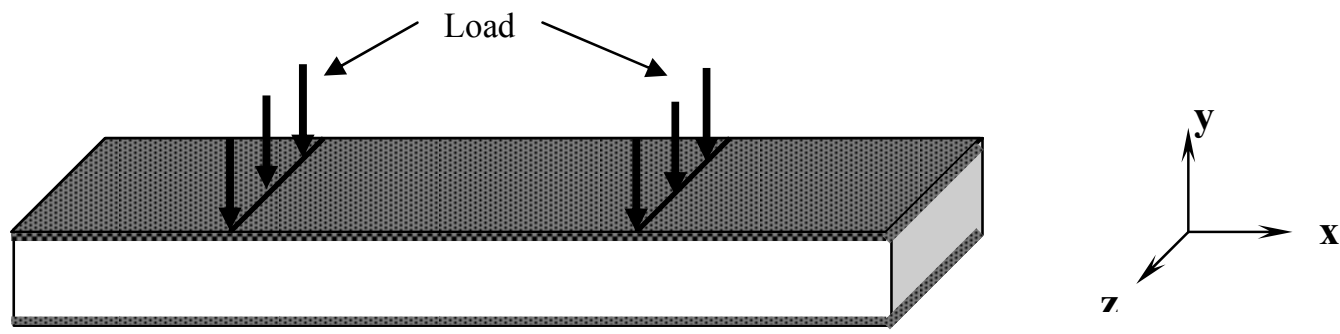

Figure 6.8 Construction of 3D Orthotropic Solid Model B

The material properties for 3D orthotropic solid models A and B are listed in Table 6.6. The orthotropic properties of balsa wood are obtained from Wood Handbook (Green et al, 1999) and Baltek balsa technical data sheet while the orthotropic properties of GFRP face sheets were experimentally determined. Model predictions from both the models A 
and $\mathrm{B}$ are summarized in Table 6.7 while comparing with experimental data. As seen from Table 6.7, Models A and B give nearly identical predictions on deflection and bending stress but model B gives better predictions on core shear stress. In particular, 3D orthotropic solid model B yields better shear stress profiles across the span and thickness as seen later. Thus emphasis was placed on improvement of 3D orthotropic solid model B.

Table 6.6 Material properties for 3D Orthotropic Solid Model A and B

\begin{tabular}{|c|c|c|}
\hline & FRP & Balsa \\
\hline $\mathrm{E} 1$ & $3.24 \mathrm{msi}$ & $7652 \mathrm{psi}$ \\
\hline $\mathrm{E} 2$ & $3.24 \mathrm{msi}$ & $7652 \mathrm{psi}$ \\
\hline $\mathrm{G} 12$ & $0.50 \mathrm{msi}$ & $2550 \mathrm{psi}$ \\
\hline $\mathrm{G} 13$ & $0.25 \mathrm{msi}$ & $22800 \mathrm{psi}$ \\
\hline $\mathrm{G} 23$ & $0.25 \mathrm{msi}$ & $22800 \mathrm{psi}$ \\
\hline$\mu$ & 0.30 & 0.30 \\
\hline
\end{tabular}

\begin{tabular}{|c|c|c|}
\hline & FRP & Balsa \\
\hline E1 & $3.24 \mathrm{msi}$ & $7652 \mathrm{psi}$ \\
\hline E2 & $0.50 \mathrm{msi}$ & $510176 \mathrm{psi}$ \\
\hline $\mathrm{G} 12$ & $0.25 \mathrm{msi}$ & $22800 \mathrm{psi}$ \\
\hline $\mathrm{G} 13$ & $0.50 \mathrm{msi}$ & $2550 \mathrm{psi}$ \\
\hline $\mathrm{G} 23$ & $0.25 \mathrm{msi}$ & $22800 \mathrm{psi}$ \\
\hline$\mu$ & 0.25 & 0.02 \\
\hline
\end{tabular}

Table 6.7 Model predictions in comparison with experimental values for 12"x96" GFRP panel

\begin{tabular}{|l|c|c|c|}
\hline failure load 17062 lbs & $\begin{array}{c}\text { Centre } \\
\text { Deflection } \\
\text { in. }\end{array}$ & $\begin{array}{c}\text { Bending } \\
\text { Stress } \\
\text { ksi. }\end{array}$ & $\begin{array}{c}\text { Core } \\
\text { Shear Stress } \\
\text { psi. }\end{array}$ \\
\hline Experimental & 2.49 & 18.63 & 215.5 \\
\hline Sandwich Beam Theory Cal. & 2.44 & 18.85 & 218.7 \\
\hline 3D orthotropic solid Model A & 2.47 & 18.73 & 222.2 \\
\hline 3D orthotropic solid Model B & 2.45 & 18.74 & 219.3 \\
\hline
\end{tabular}

\subsubsection{Deflection and strain}

Model predictions from 3D orthotropic models on deflection response are shown in Figure 6.9 (deflection contours predicted by 3D orthotropic model B), Figure 6.10 (deflection profile across the span in comparison with experimental data), Figure 6.11 (deflection as a function of loads in comparison with experimental data), and Figure 6.12 (strain as a function of loads in comparison with experimental data). As seen from those charts, nearly $100 \%$ matching is achieved in deflection and strain data between model predictions and experimental data. 


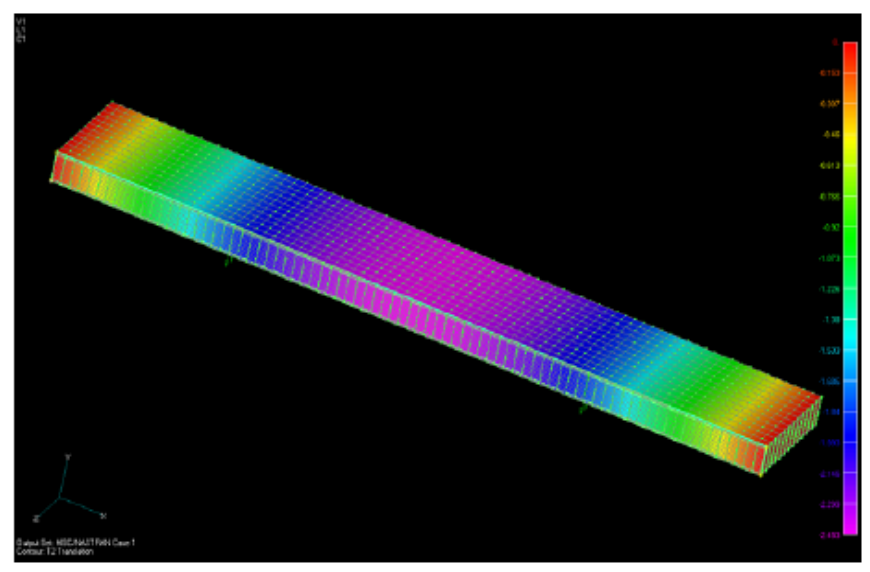

Figure 6.9 Predicted deflection contours by 3D orthotropic model B for 12"x 96" GFRP panel

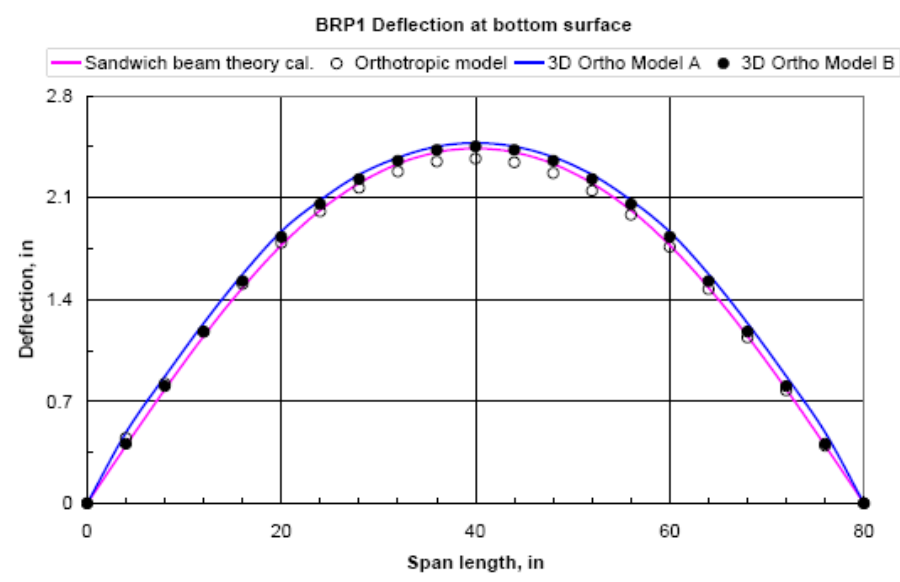

Figure 6.10 Predicted and experimental deflection data across the span under failure load for 12" x 96" GFRP panel

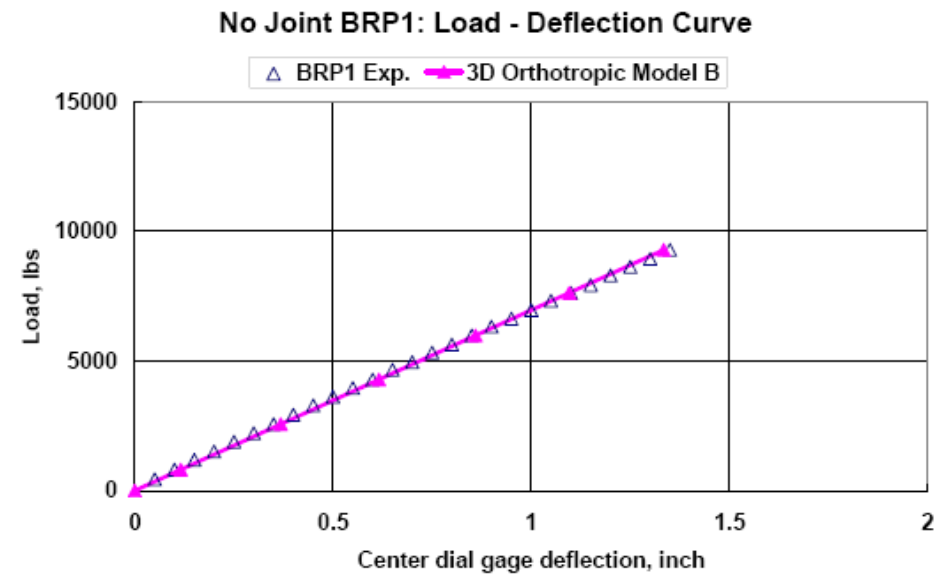

Figure 6.11 Predicted and experimental deflection data as a function of loads for 12"x96" GFRP panel 


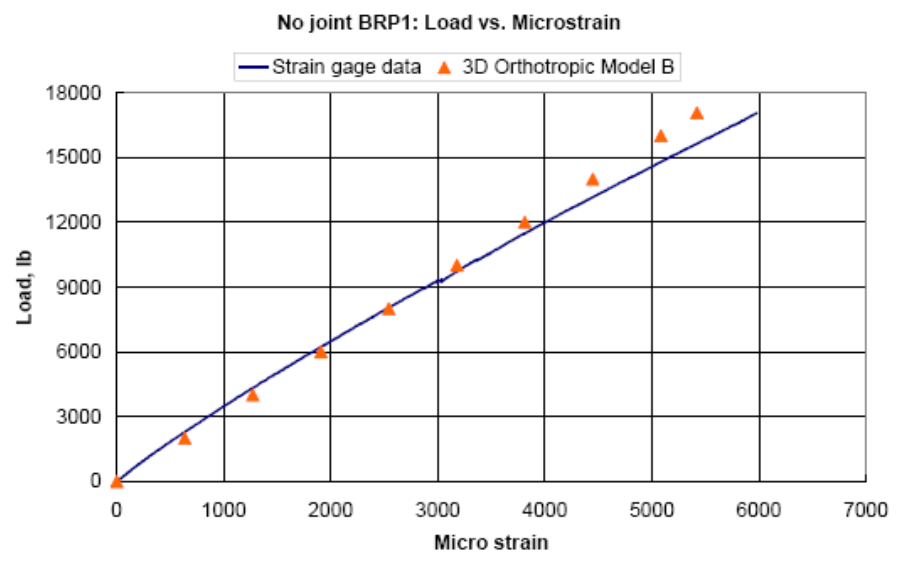

Figure 6.12 Predicted and experimental strain data as a function of loads for 12"x96" GFRP panel

\subsubsection{Bending stress}

Model predictions from 3D orthotropic models on bending stress are shown in Figure 6.13 (bending stress contours predicted by 3D orthotropic model B); Figure 6.14 (bending stress profile across the span in comparison with experimental data); and Figure 6.15 (bending stress profile across the thickness in comparison with 3D isotropic model data). Again, excellent matching in bending stress data between predictions and experiment was observed.

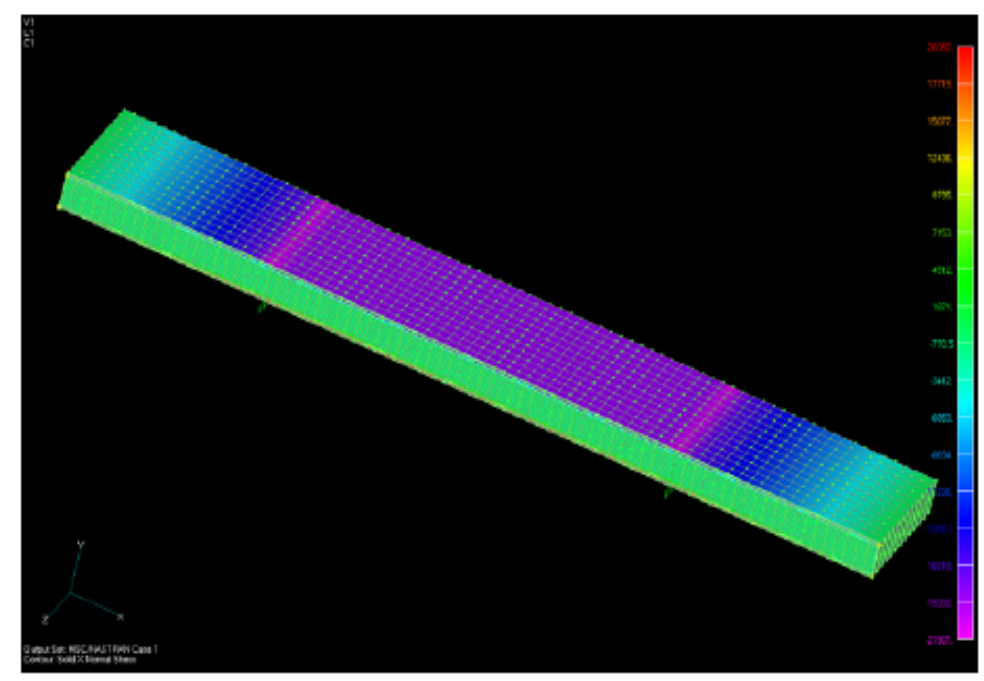

Figure 6.13 Predicted bending stress contours by 3D orthotropic model B for 12"x96" GFRP panel 


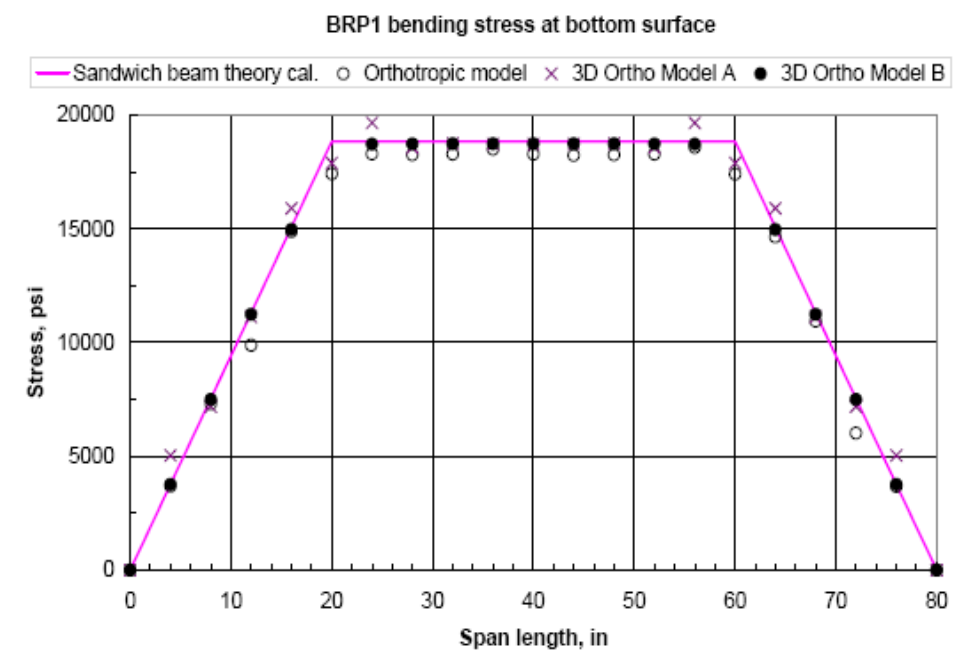

Figure 6.14 Predicted and experimental bending stress data across the span under failure load for 12" x 96" GFRP panel

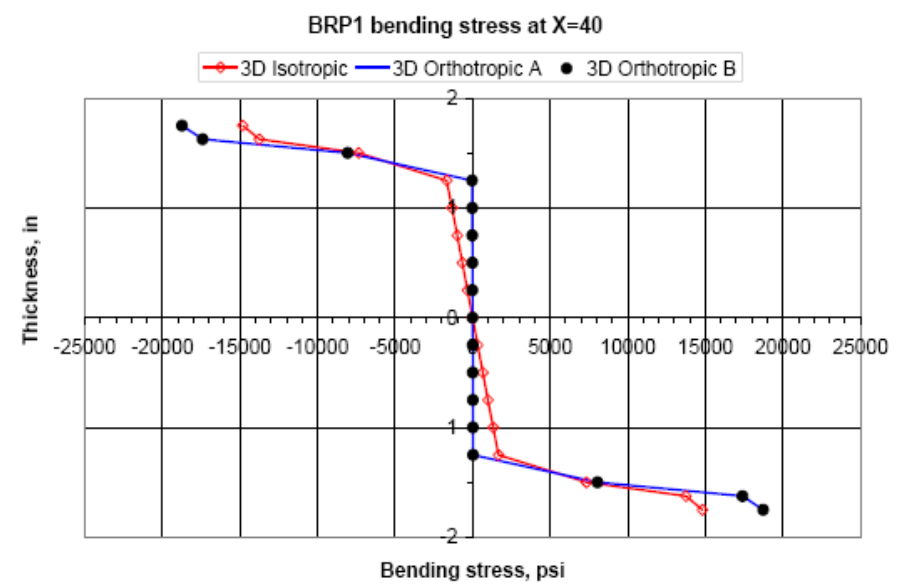

Figure 6.15 Predicted bending stress across the thickness under failure load for 12"x96" GFRP panel

\subsubsection{Shear stress}

Model predictions from 3D orthotropic models on shear stress are shown in Figure 6.16 (shear stress contours predicted by 3D orthotropic model B); Figure 6.17 (shear stress profile across the span in comparison with 3D isotropic model data); and Figure 6.18 (shear stress profile across the thickness in comparison with 3D isotropic model data). The 3D orthotropic solid model B is able to very accurately predict core shear stress across the span, thickness and width of the panel. 


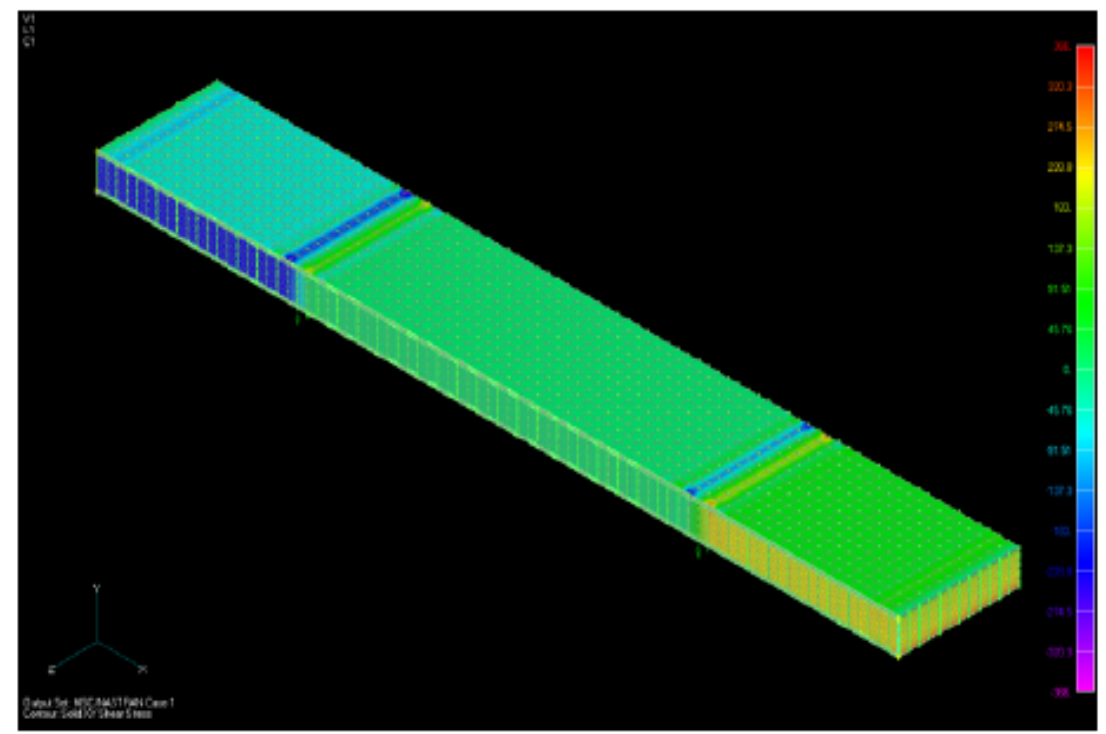

Figure 6.16 Predicted shear stress contours by 3D orthotropic model B for 12"x 96" GFRP panel

Figure 6.17 shows that model B predicts the expected behavior of shear stress between the regions of application of load.

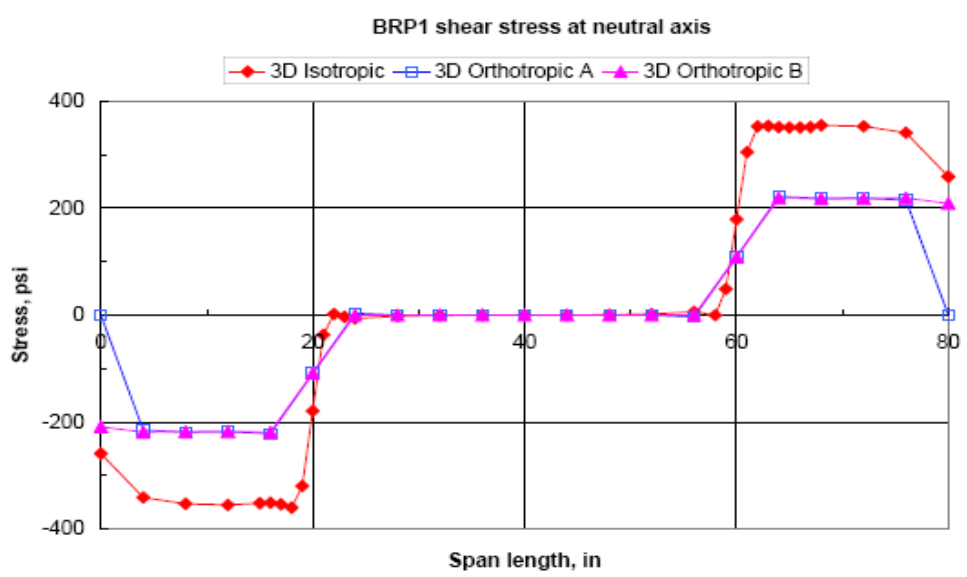

Figure 6.17 Predicted shear stress across the span under failure load for 12" x 96" GFRP panel

As seen from Figure 6.18 3D orthotropic model accurately predicts plug type behavior of shear stress across the thickness for small scale panels. 


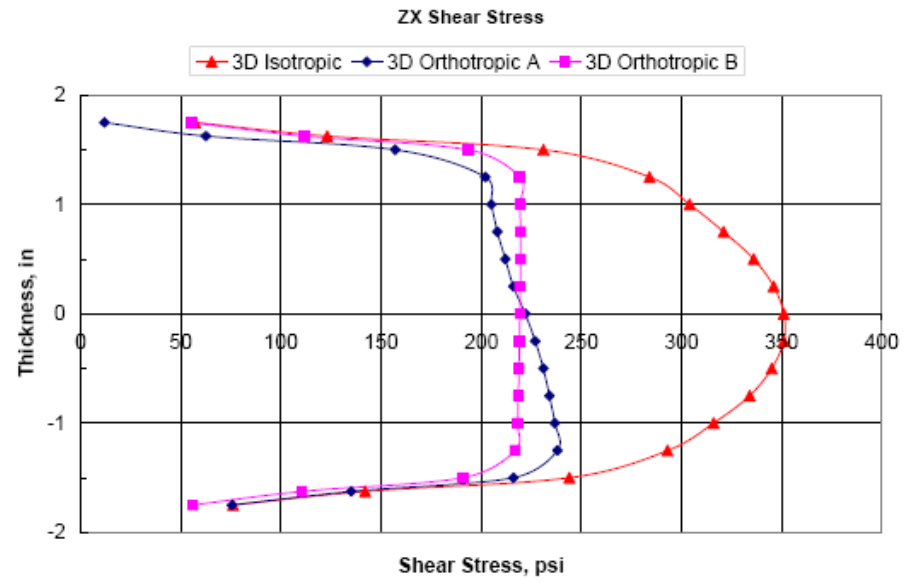

\section{Figure 6.18 Predicted shear stress across the thickness under failure load for 12"x96" GFRP panel}

\subsubsection{Conclusion}

In conclusion, different modeling approaches were evaluated for accurate prediction of composite sandwich panel response. Although, some models predicted deflection and bending stress well, they failed to accurately predict shear stress profiles. 3D orthotropic solid model was found to represent sandwich panel in best possible manner. Accuracy and dynamic applicability of this model would be further verified in subsequent section for different geometry and material properties.

\subsection{Prediction of CFRP Sandwich Panel Response}

3D orthotropic solid model was identified to be applicable to represent and model the GFRP composite sandwich panel response. This model was further implemented to predict CFRP sandwich panel response. The new user interface MSC.Patran in MSC.Nastran was used for this effort. Material properties used for CFRP composite panel are listed in Table 6.8. Note that material properties for balsa wood core were identical to the ones used in GFRP model. Tensile modulus E11 and E33 for CFRP were evaluated from tension test results of coupon specimens. On the other hand, E22 was determined from literature data and theoretical calculation. It was assumed that in absence of any fiber aligned in direction of E22, tensile modulus for the same would be less as compared to E11 and E22 which contains significantly amount of fibers aligned in that direction. 
Table 6.8 Material properties for CFRP sandwich panels

\begin{tabular}{|c|c|c|}
\hline & CFRP & Balsa \\
\hline E11 & $6.33 \mathrm{E} 6$ & 7652 \\
\hline $\mathbf{E 2 2}$ & $0.5 \mathrm{E} 6$ & 510176 \\
\hline $\mathbf{E 3 3}$ & $6.33 \mathrm{E} 6$ & 7652 \\
\hline $\boldsymbol{\mu 1 2}$ & 0.25 & 0.02 \\
\hline $\boldsymbol{\mu 2 3}$ & 0.25 & 0.02 \\
\hline $\boldsymbol{\mu 3 1}$ & 0.30 & 0.30 \\
\hline $\mathbf{G 1 2}$ & $0.25 \mathrm{E} 6$ & 22800 \\
\hline $\mathbf{G 2 3}$ & $0.25 \mathrm{E} 6$ & 22800 \\
\hline $\mathbf{G 3 1}$ & $0.5 \mathrm{E} 6$ & 2550 \\
\hline
\end{tabular}

FEA predictions are compared with experimental results in Table 6.9 for both 12"x80" and 40"x100" CFRP panels. In addition, these results in Table 6.9 are discussed in detail in subsequent sections.

Table 6.9 Model prediction in comparison with experimental values for 12"x80" and 40"x100" CFRP panels

\begin{tabular}{|c|c|c|c|c|c|}
\hline $\begin{array}{c}\text { Panel } \\
\text { Dimension }\end{array}$ & & $\begin{array}{l}\text { Failure } \\
\text { load } \\
\text { (lbs) }\end{array}$ & $\begin{array}{c}\text { Centre } \\
\text { Deflection } \\
\text { (in.) }\end{array}$ & $\begin{array}{c}\text { Bending } \\
\text { Stress } \\
\text { (ksi) }\end{array}$ & $\begin{array}{l}\text { Core Shear } \\
\text { Stress } \\
\text { (psi) }\end{array}$ \\
\hline \multirow{3}{*}{$12 " x 80 "$} & Experimental & \multirow{3}{*}{13774} & 1.39 & 15.29 & 177.50 \\
\hline & Sandwich beam theory & & 1.39 & 15.21 & 176.58 \\
\hline & $\begin{array}{l}\text { 3D Orthotropic Solid } \\
\text { Model }\end{array}$ & & 1.32 & 15.14 & 176.21 \\
\hline \multirow{5}{*}{$40 " x 100 "$} & Experimental & \multirow{5}{*}{55745} & 2.34 & 23.09 & 214.40 \\
\hline & Sandwich beam theory & & 2.38 & 23.09 & 214.40 \\
\hline & $\begin{array}{l}\text { 3D Orthotropic Solid } \\
\text { Model w/o caps }\end{array}$ & & 2.39 & 22.99 & 216.21 \\
\hline & $\begin{array}{l}\text { 3D Orthotropic Solid } \\
\text { Model with 3" caps }\end{array}$ & & 2.32 & 22.96 & $\begin{array}{l}208.14 \text { (Balsa) } \\
1738.22 \text { (FRP) } \\
\end{array}$ \\
\hline & $\begin{array}{l}\text { 3D Orthotropic Solid } \\
\text { Model with } 3.5 \text { " caps }\end{array}$ & & 2.32 & 22.96 & $\begin{array}{l}208.14 \text { (Balsa) } \\
1738.22 \text { (FRP) }\end{array}$ \\
\hline
\end{tabular}

Model predictions from 3D orthotropic models on deflection are shown in Figure 6.19 (deflection contours predicted by 3D orthotropic model); Figure 6.22 (predicted deflection across the span under failure load) Figure 6.23 (bending stress contours predicted by 3D orthotropic model); Figure 6.24 (predicted bending stress across the span under failure load); Figure 6.25 (predicted bending stress across the thickness under failure load); Figure 6.26 and 6.27 (shear stress contours predicted by 3D orthotropic model) and Figure 6.28 (predicted shear stress across the thickness under failure load) 


\subsubsection{End Caps of Pultruded Sandwich Panels}

End caps of pultruded sandwich panel are referred to edge wraps on left and right sides of the pultruded panel across the panel thickness. They are integral part of pultruded products and are usually made of same fabric configuration and resin as those of top and bottom face-sheets. Fabric for end caps is pulled over the thickness of panels such that it helps in overlapping the edges of panels by composite materials as shown in Figure 6.19. Thickness of these end caps was assumed to be same as face-sheet thickness for FEA purpose.

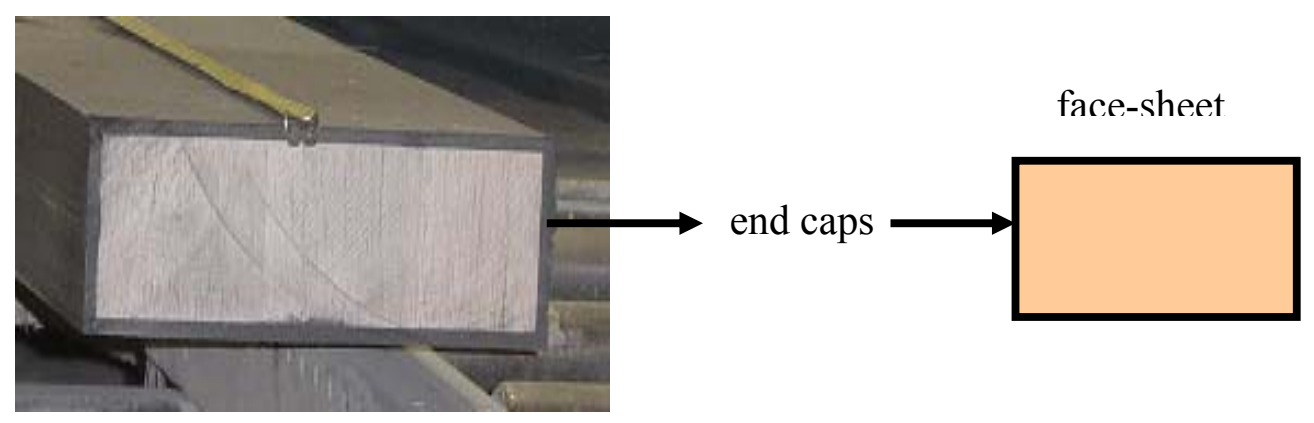

Figure 6.19 Cross sectional view of sandwich panel showing end caps

\subsubsection{Deflection}

For small scale panel, FE model predicts deflection of 1.32" in comparison to experimental value of 1.39". Model prediction for deflection with 3D orthotropic model for 40"x100" full scale CFRP panels without end caps is shown in Figure 6.20. Model prediction for deflection with 3" caps and 3.5" caps for 40"x100" CFRP panel is shown in Figure 6.21 and 6.22. For full scale panel, model with end caps predict deflection as 2.32 " and model without any end caps predicts deflection as 2.39", in comparison to experimental deflection of 2.34". From the above analysis it can be concluded that, model with end cap and without end cap closely predicts deflection from the experimental values with less than $1 \%$ deviations. Figure 6.23 shows the deflection profile across the span in comparison with experimental data. 


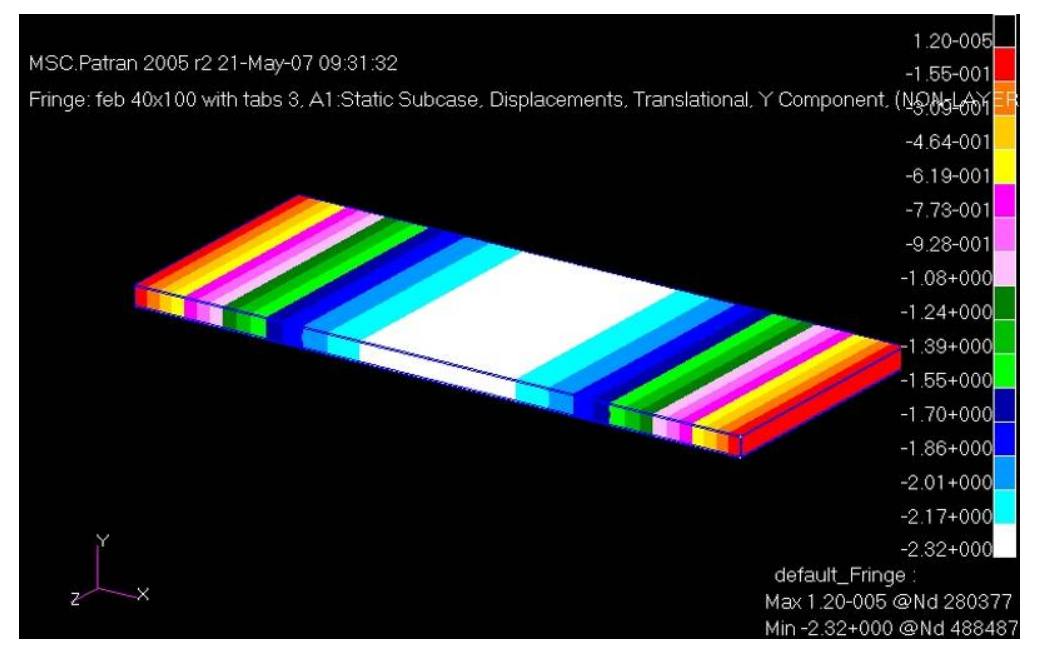

Figure 6.20 Predicted deflection contours by 3D orthotropic model for 40"x100" CFRP panel with 3" caps

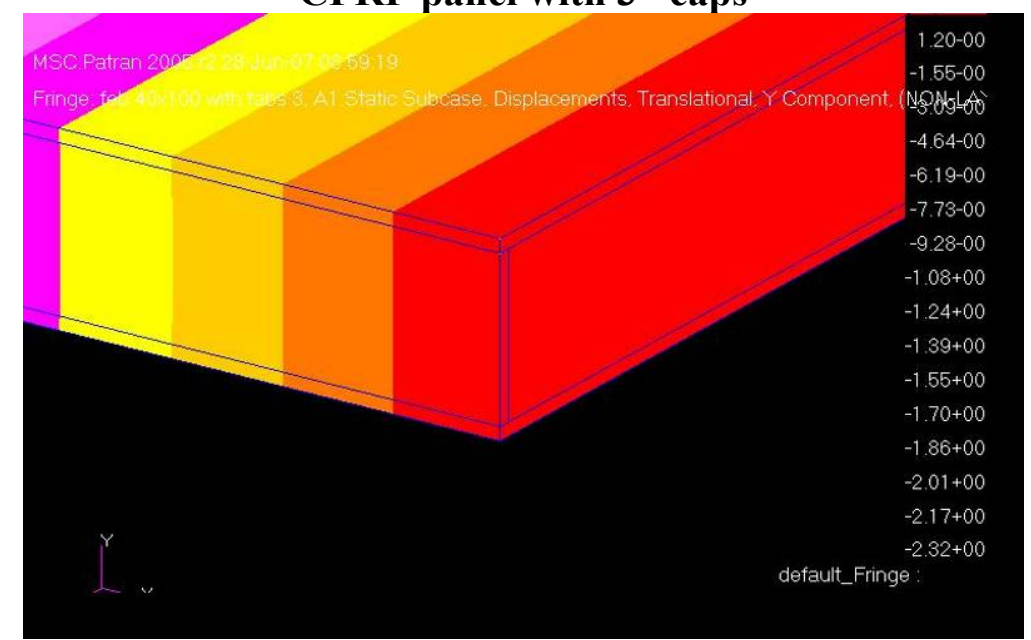

Figure 6.21 Predicted deflection contours by 3D orthotropic model for 40"x100" CFRP panel with 3" caps (close view)

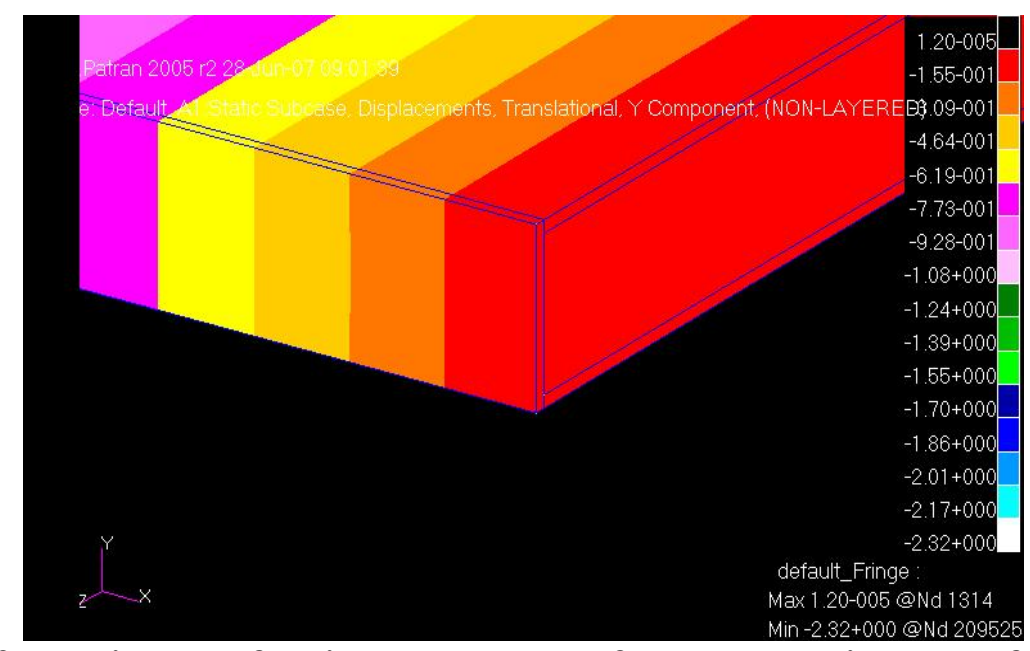

Figure 6.22 Predicted deflection contours by 3D orthotropic model for 40"x100" CFRP panel with 3.5" caps (close view) 


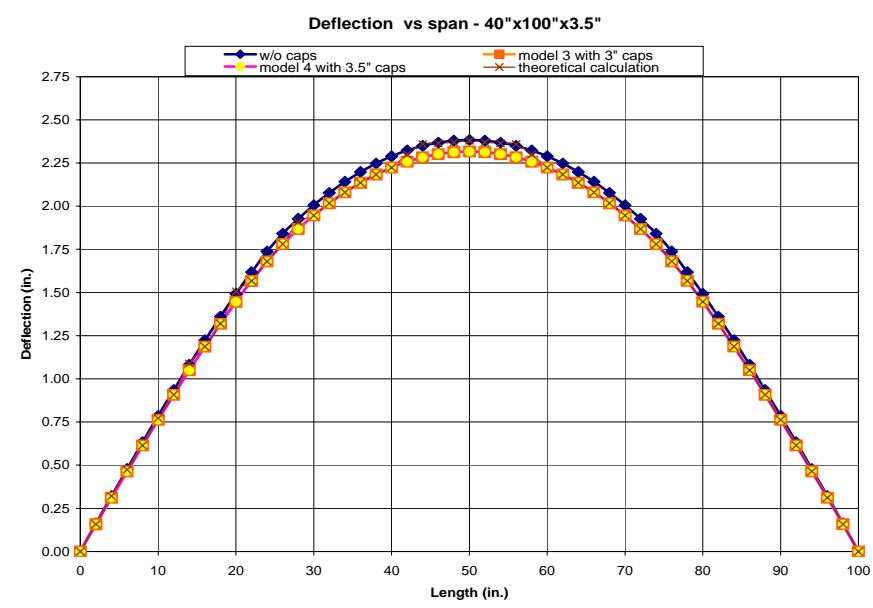

Figure 6.23 Predicted deflection data across the span under failure load for 40"x100" CFRP panel

\subsubsection{Bending Stress}

$3 \mathrm{D}$ orthotropic model gives nearly the same prediction as that of experimental bending stress. Response with and without end cap was verified with all the three models. The model with end caps predicts bending stress of $22.96 \mathrm{ksi}$ and model without end caps predicts 22.99 in comparison with experimental value of $23.09 \mathrm{ksi}$. Model prediction for bending stress for full scale panels is shown in Figure 6.24. Bending stress profile along the span is represented in Figure 6.25. Model with the end cap and without end cap yields the same bending stress profile within the region of load application as shown in Figure 6.26 .

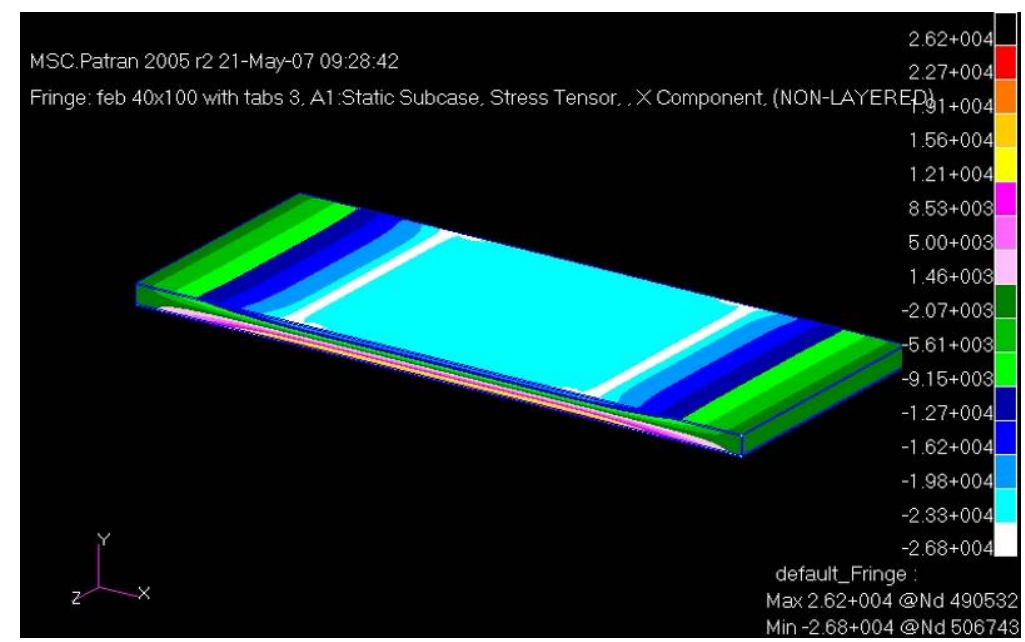

Figure 6.24 Predicted bending stress contours for 40"x100" CFRP panel with 3" caps 
Figure 6.26 shows bending stress profile across the thickness of full scale panel. All the three models give close prediction of maximum bending stress as to experimental one. Interestingly, model with end caps shows linear bending stress across the thickness over FRP surface. On the contrary, the bending stress appeared to be nearly zero in core region when plotted at the centerline of panel which was also observed in case of no end cap panels without end caps.

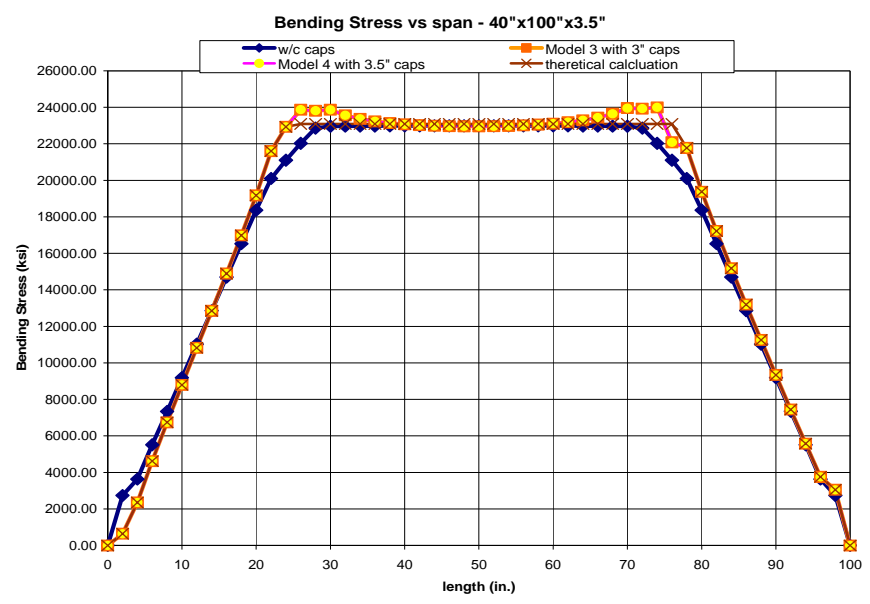

Figure 6.25 Predicted bending stress data across the span under failure load for 40"x100" CFRP panel

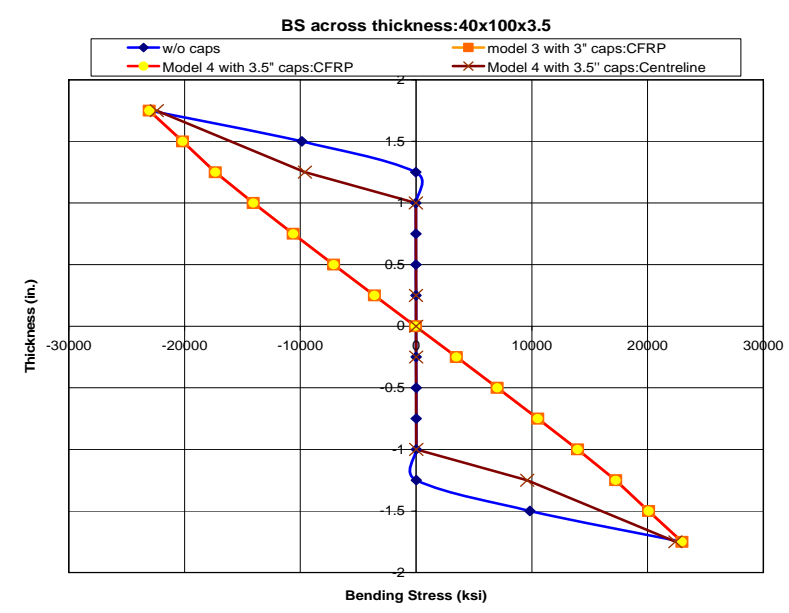

Figure 6.26 Predicted bending stress across the thickness under failure load for 40"x100" CFRP panel

\subsubsection{Shear Stress}

3D orthotropic model well predicts shear stress profile across thickness for small scale panel with deviation of less than $1 \%$. In case of full scale panel, model without end caps 
closely predicts experimental shear stress of 214.40 psi. For the model with end caps, caution should be noted that there would be two distinct profiles of shear stress, depending on how it is being tracked. Shear stress profile when plotted at the centerline of panel (across the balsa) predicts maximum shear stress value of 208.14 psi which is close to the experimental results. In contrast, shear stress on the FRP end cap surface was found to be 1738.22 psi which is nearly eight times the experimental values of 214.40. The interpretation for such a high shear stress on FRP edge is to be sought. Figure 6.27 shows shear stress contours for model without end caps. Figure 6.28 shows shear stress contours for model with end caps. Figure 6.29 represents shear stress profile across the thickness of full scale panel.

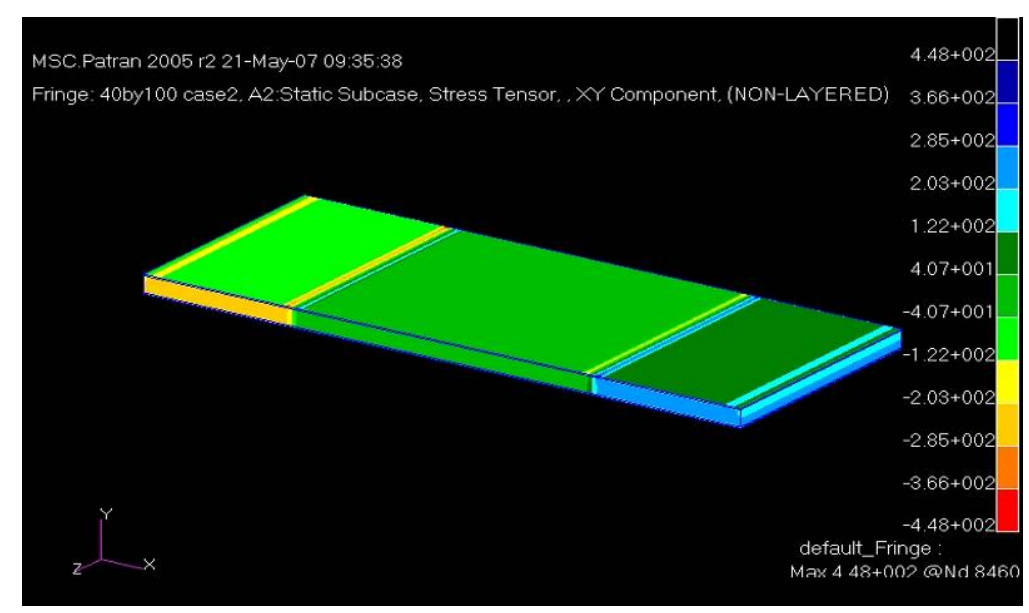

Figure 6.27 Predicted shear stress contours for model w/o end caps for 40"x100" CFRP panel

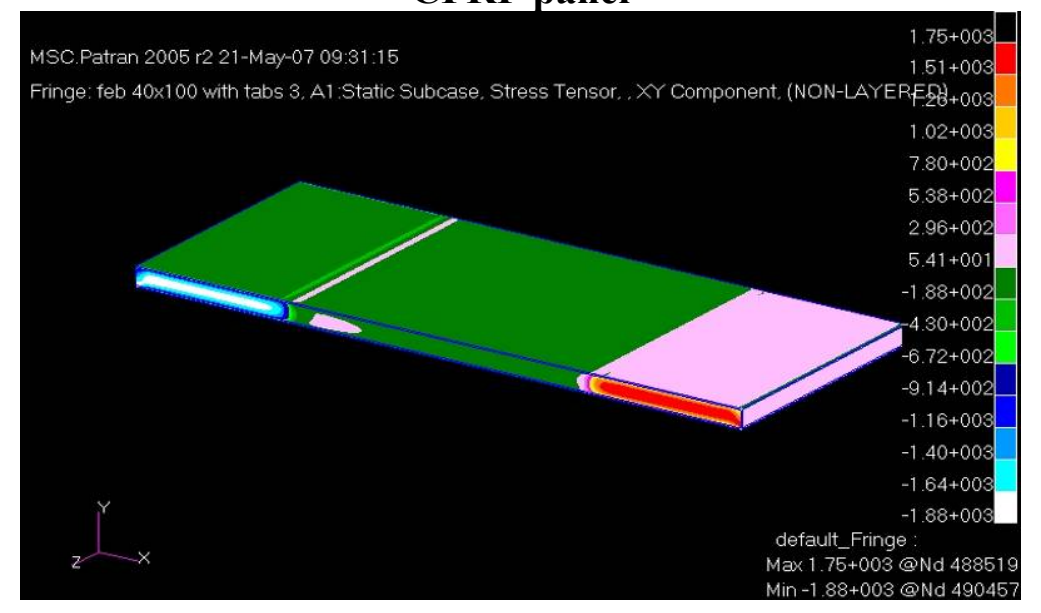

Figure 6.28 Predicted shear stress contours for model with 3" end caps for 40"x100" CFRP panel 


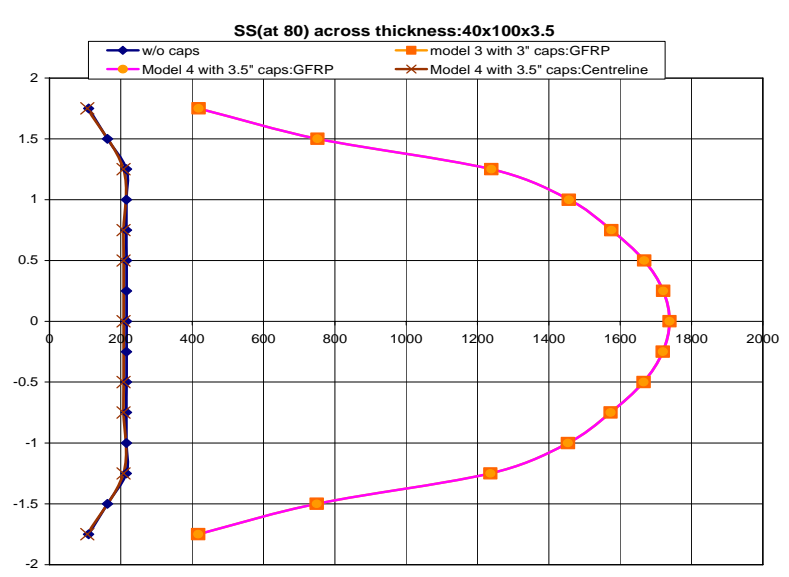

Figure 6.29 Predicted shear stress profile across the thickness under failure load for 40"x100" CFRP panel

\subsubsection{Conclusions}

In conclusion, 3D solid orthotropic model was proved to be effective approach to predict sandwich panel response. It closely predicts deflection, bending stress and shear stress data derived from experiments. However, FE model with end caps shows distinct bending stress and shear stress behavior when plotted against panel thickness. Bending stress profile over thickness was found to be linear over FRP surface. It was found to be zero in core area (non-linear) when plotted for the centre region of sandwich panel. In addition, shear stress over FRP end caps was found to be eight times higher than the experimental values. But, shear stress at centre region of panel was in good agreement of experimental values.

\subsection{Joint Analysis of Composite Sandwich Analysis}

Pultruded composite sandwich panels have tongue and grove joint profiles. Jointed sandwich panels were also tested for their mechanical response by four point bending. For testing purpose, jointed panels were prepared by joining two small 1'x4' composite panels using double sided lap joint concept. A double sided lap joint is a joint made by placing one adherend (partly above and below) into another, and bonding together the overlapping portions as shown in Figure 6.30. 


\subsubsection{Composite Panel Joints}

Two 4' wide, 3.5" thick composite sandwich panels can be adhesively joined to make 8' wide panels. CFC-WVU researchers have conducted extensive research in this aspect. The joining profiles were bonded together using structural adhesive that were comprised of two components, urethane-based adhesive system and designed to meet the FRP bonding needs. An appropriate joining surface preparation was proved to be critical to arrive at the required joint efficiency. Then three layers of 24oz/sq yd biaxial glass fabric as external reinforcement were wrapped over the joint of the joined panel at the top and bottom to achieve 100\% joint efficiency as shown in Figure 6.30.

\subsubsection{FE Analysis of Joined Sandwich Panels}

It was observed that joined panels (with tongue and groove joint profiles using three layers of $24 \mathrm{oz} / \mathrm{sq}$ yd biaxial glass fabric as an external reinforcement) resulted in 100\% joint efficiency under both shear and bending with failure in balsa core and away from the joint. Modeling approach for joined sandwich panels was developed with the assumption of $100 \%$ joint efficiency. The objective of his FE study is to model the mechanical response of joint sandwich panels using 3D orthotropic solid model. FE analysis was carried out in four steps; 1. With no external layers of reinforcement; 2. With one 24" layer, 3. With 24" and 18" layers and 4. With 24", 18" and 12" layers. Material properties used for analysis are mentioned in Table 6.10 below. Results from analysis are tabulated in Table 6.11 along with the experimental results. Thickness of each layer of external reinforcement was considered to be 0.03 " for given $24 \mathrm{oz} / \mathrm{sq}$ yd biaxial glass fabric.

Table 6.10 Material properties for GFRP sandwich panels with joints

\begin{tabular}{|c|c|c|}
\hline & GFRP & Balsa \\
\hline $\mathbf{E 1 1}$ & $3.20 \mathrm{E} 6$ & 7652 \\
\hline $\mathbf{E 2 2}$ & $0.5 \mathrm{E} 6$ & 510176 \\
\hline $\boldsymbol{E 3 3}$ & $3.20 \mathrm{E} 6$ & 7652 \\
\hline $\boldsymbol{\mu 1 2}$ & 0.25 & 0.02 \\
\hline $\boldsymbol{\mu 2 3}$ & 0.25 & 0.02 \\
\hline $\mathbf{\mu 3 1}$ & 0.30 & 0.30 \\
\hline $\mathbf{G 1 2}$ & $0.25 \mathrm{E} 6$ & 22800 \\
\hline $\mathbf{G 3 3}$ & $0.25 \mathrm{E} 6$ & 22800 \\
\hline
\end{tabular}


Deflection, bending stress and shear stress contours of FE modeling for the model with three layers of reinforcement are shown below in Figures 6.31, 6.33 and 6.34 respectively.

Table 6.11 Model prediction in comparison with experimental values for 11.5 "x80" panels with joint

\begin{tabular}{|c|c|c|c|c|}
\hline \multicolumn{1}{|c|}{} & $\begin{array}{c}\text { Max. } \\
\text { Deflection } \\
\text { in. }\end{array}$ & $\begin{array}{c}\text { Bending } \\
\text { Stress } \\
\text { ksi }\end{array}$ & $\begin{array}{c}\text { Core Shear } \\
\text { Stress } \\
\text { psi }\end{array}$ \\
\hline \multirow{3}{*}{ FE Model } & 2.32 & 18.05 & 220.4 \\
\cline { 2 - 5 } & Experimental & 2.35 & 18.87 & 220.6 \\
\cline { 2 - 5 } & Joint with no layers & 2.21 & 18.87 & 220.6 \\
\cline { 2 - 5 } & Joint with 24" layer & 2.13 & 18.87 & 220.6 \\
\cline { 2 - 5 } & Joint with 24",18"\&12" 18" layers & 2.08 & 18.87 & 220.6 \\
\hline
\end{tabular}

For the analysis purpose, experimental failure load of $16479.5 \mathrm{lbs}$ was used. FE with three layers of external reinforcement predicts deflection of 2.08" versus experimental value of 2.32". Furthermore, it is confirmed that addition of each layer of reinforcement helps in reduction of maximum deflection. It is also observed from Table 6.11 that FE model gives close prediction of bending stress and shear stress compared to experimental value. 


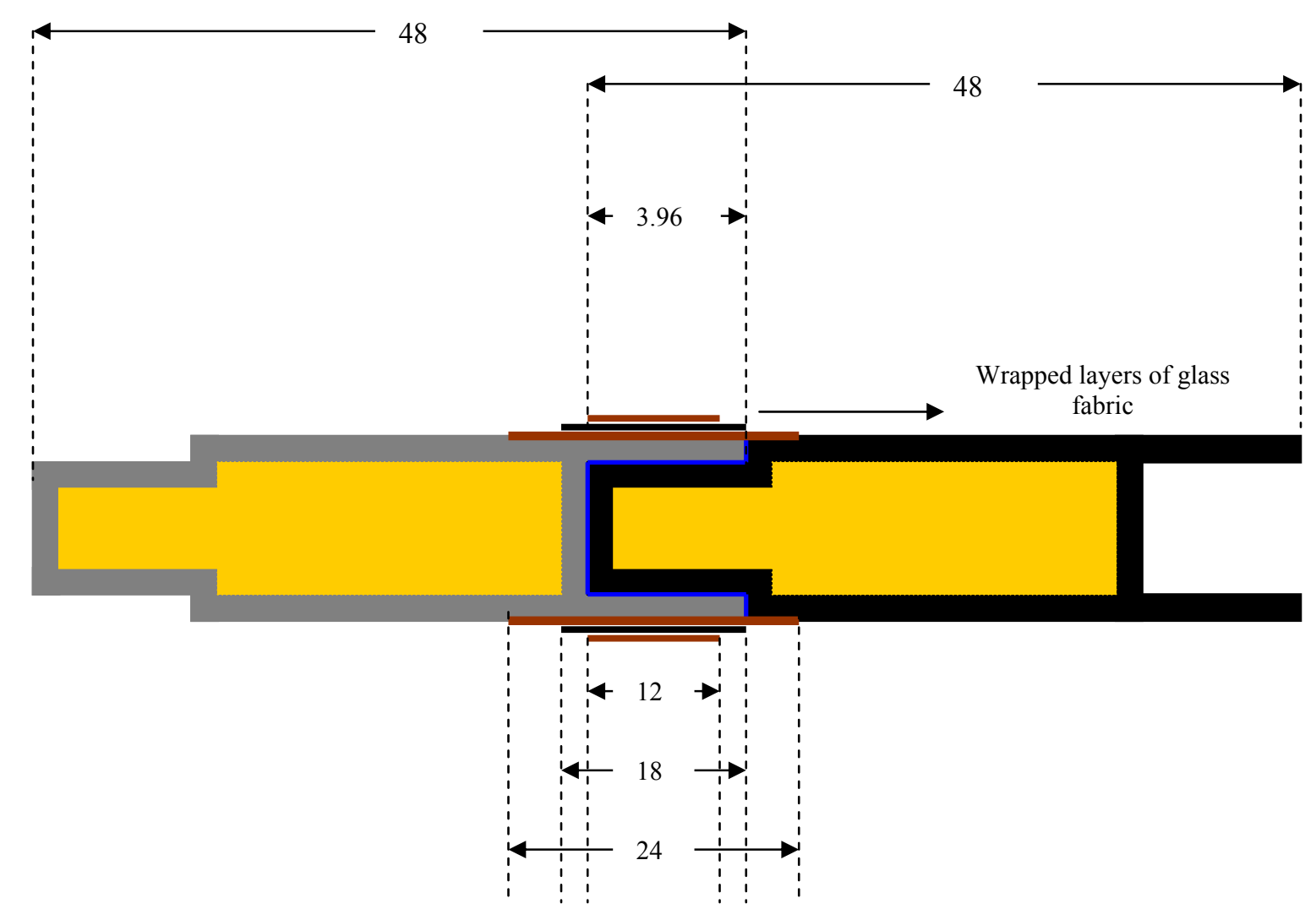

Figure 6.30 Schematic joining of two 4' wide GFRP sandwich panels by a double sided lap joint 


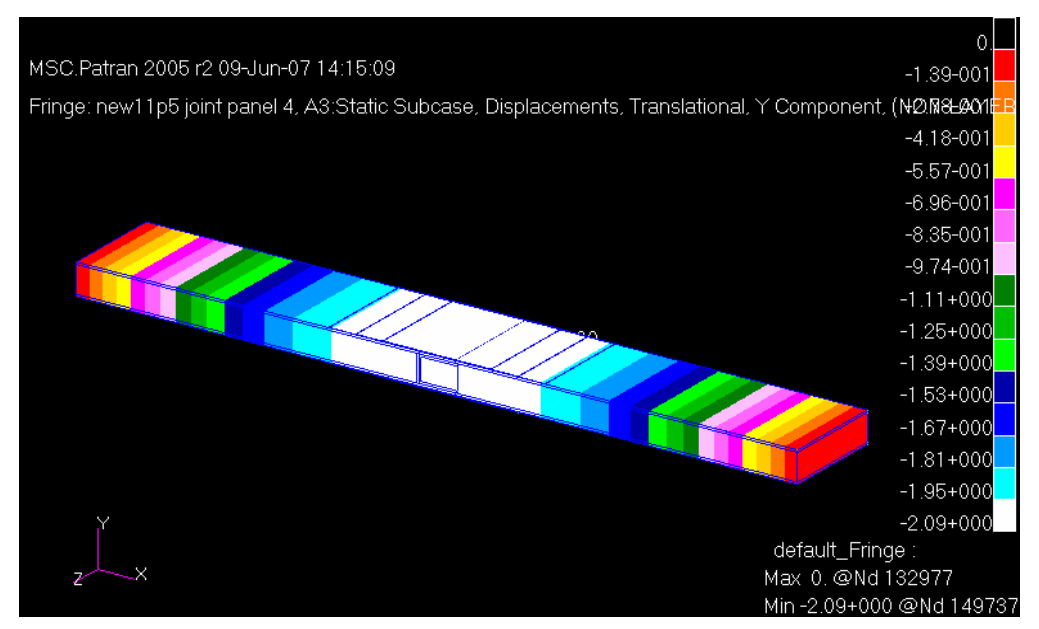

Figure 6.31 Predicted deflection contours for model with 11.5"x80" joint GFRP panel with 24", 18"and 12 " wide layers

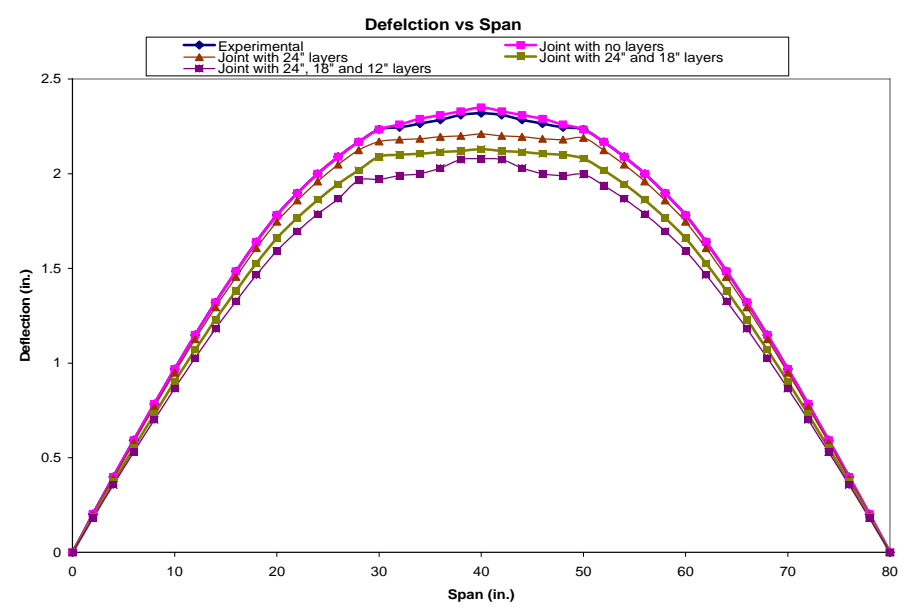

Figure 6.32 Predicted deflection contours for model with 11.5"x80" joint GFRP panel with 24", 18" and 12" wide layers

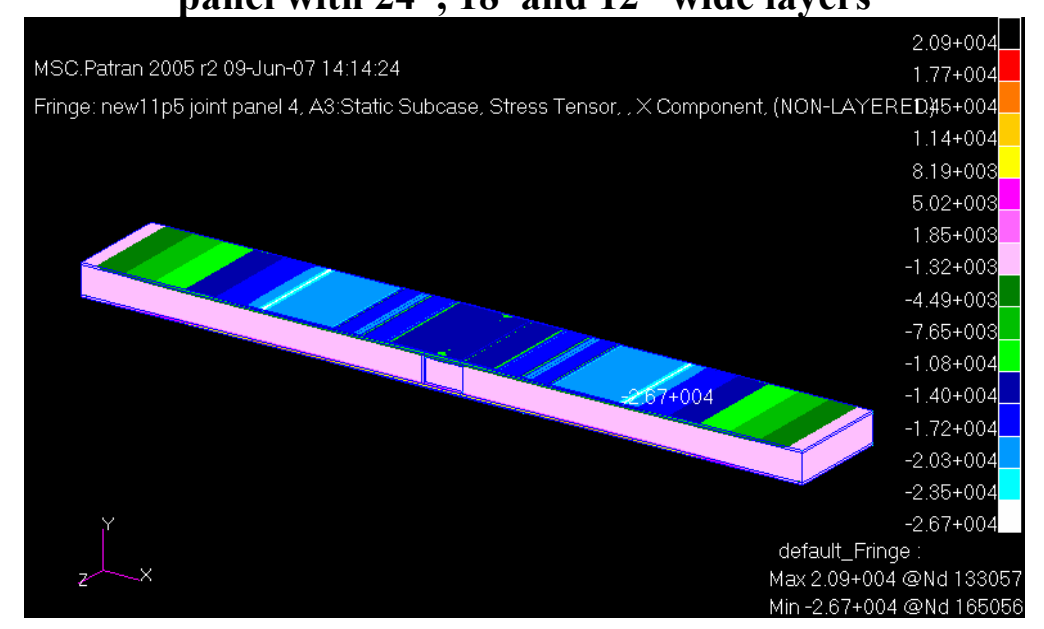

Figure 6.33 Predicted bending stress contours for model with 11.5" x80" joint GFRP panel with 24", 18" and 12" wide layers 


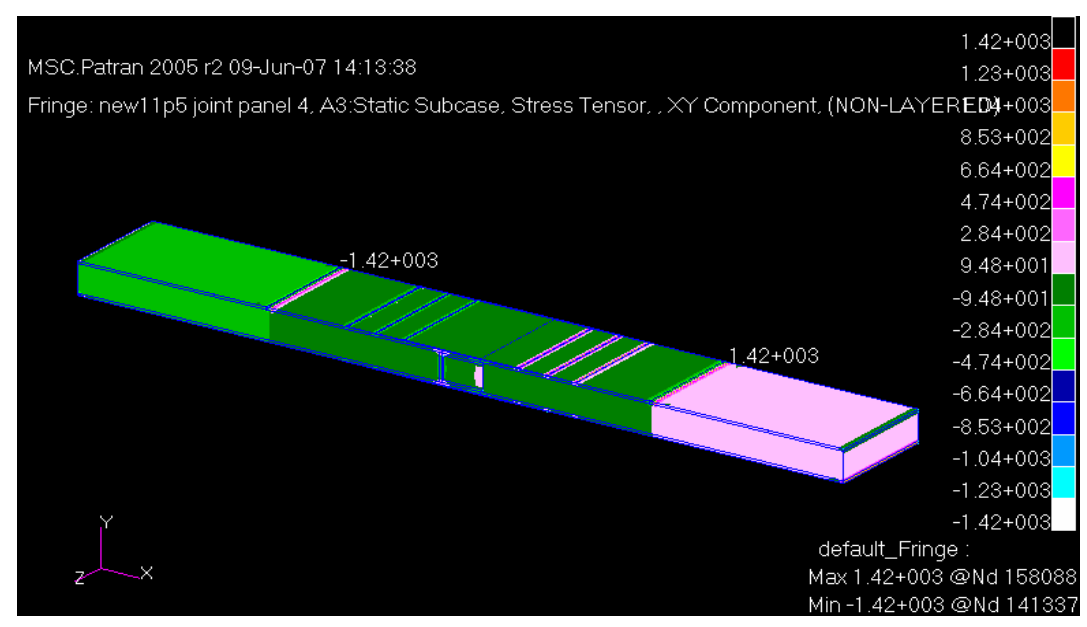

Figure 6.34 Predicted shear stress contours for model with 11.5"x80" joint GFRP panel with 24", 18"and 12" wide layers

\subsubsection{Conclusion}

In conclusion, 3D orthotropic solid model was able to predict response of joined sandwich panels under assumption of $100 \%$ joint efficiency. Results of FEA of sandwich panels with joints are closely matching to those of experimental values. In addition, effect of adding layers of external reinforcement over joint area is verified to reduce deflection in consistent with experimental observations. 
CONCLUSIONS ANID RECOMMENIDATIONS

In this study, Carbon Fiber Reinforced Polymer (CFRP) composites were tested both at coupon and panel level for their mechanical properties (stress, stiffness and modulus) under bending and tension. Properties were discussed in terms of different manufacturing process parameters and constituent material characteristics. Finite Element Modeling of composite sandwich panels was carried out using MSC.NASTRAN software. After evaluating various models, 3D orthotropic solid was identified to be successfully predicting response of FRP sandwich panels including joint panels under static conditions. The more specific conclusions as a result of present experimental and FEA studies are stated below,

\subsection{Mechanical Properties of CFRP Composites}

\subsubsection{Compression Laminates}

- Under tension and bending, CFRP composites with VE matrix cured at room temperature (RT) results in better mechanical properties with tensile modulus $25 \%$ higher and $27 \%$ higher elasticity modulus than that of high temperature (HT) cured composites.

- Addition of CSM layer significantly reduces the tensile modulus by about $10.5 \%$, maximum stress by about $7.8 \%$, flexural modulus by about $29.6 \%$ and $32.4 \%$ drop in bending stress.

- 3D stitching of fabric did not improve mechanical properties both under tension and bending.

\subsubsection{Pultrusion Laminates}

- Top CFRP face sheet from Run 1 in longitudinal direction shows better mechanical properties than that of bottom CFRP face sheets of sandwich panel.

- However, top CFRP face sheet from Run 2 in longitudinal direction with CSM shows $20 \%$ less in maximum stress than those of bottom CFRP face sheets. 
Similar trend was also observed for tensile modulus, bending stress and flexural modulus. On contrary, top face sheet in transverse direction shows better strength than that of bottom face sheet.

- After removing CSM layer, mechanical properties of top and bottom face sheet composites are nearly same.

\subsubsection{Resin Infused Laminates}

- With epoxy matrix, with a extended curing time was observed to have slightly poorer properties. e.g., reduction in average maximum stress by $2.5 \%$ and tensile stress by $3.8 \%$.

- Maximum stress for epoxy composites was $24 \%$ higher than those VE composites and tensile modulus for epoxy specimens was about $20 \%$ higher than those VE specimens.

\subsection{Sandwich Panel Properties}

\subsubsection{2"x27"x3.5" CFRP Panel}

- Average core shear stress of panels without side caps was about 208 psi while for those with side caps was nearly 542 psi.

- Average bending stress for side cap panel was $15.75 \mathrm{ksi}$ in contrast to $6.06 \mathrm{ksi}$.

- $20 \%$ higher flexural modulus indicates that the panels with side caps are much stiffer than those without any side caps.

\subsubsection{2"x80"x3.5" CFRP Panel}

- Similarly, end capped panel is much stiffer than no capped panels; For end capped panel, the average core shear stress of $440 \mathrm{psi}$, average FRP bending stress of 38 ksi and elasticity modulus of $6.16 \mathrm{msi}$. Panels without any end caps with average core shear stress of 183 psi, average FRP bending stress of 16 ksi and elasticity modulus of $5.22 \mathrm{msi}$ 


\subsubsection{0"x100"x3.5" CFRP Panel}

- Full scale panel presents a average core shear stress of 223 psi, average FRP bending stress of $24 \mathrm{ksi}$ and elasticity modulus of $6.33 \mathrm{msi}$.

\subsection{Finite Element Modeling of FRP Sandwich Panels}

- 3D Orthotropic solid model is concluded to accurately represent sandwich panel response under static loads including deflection, bending stress and shear stress.

- 3D orthotropic solid model closely predict response of small scale CFRP panels with about 5\% deviation. In particular, it very well predicts bending stress and shear stress in accordance with experimental results.

- For full scale panels with end caps, the model closely predicts shear stress of 208 psi in core region however it over predicts shear stress of 1738 psi on FRP surface. As expected, bending stress profile on FRP surface of end caps is observed to be linear over thickness whereas it is found to be zero in core region (which was the case of panel without any end caps).

- FE model is able to accurately predict shear stress and bending stress response of jointed panels but it under predicts the deflection by about $10 \%$. It is interestingly noted that, FE analysis does demonstrate that adding layers of external reinforcement would reduce deflection.

\subsection{Recommendations}

1. Mechanical properties of FRP composites greatly depend on fiber-matrix adhesion and fiber content. An attempt should always be made to manufacture composites with high fiber content, minimal void content and good fiber-matrix interaction

2. Specimens for mechanical testing should be representative, uniform and reproducible.

3. CSM layer should not be added over layers of fabric.

4. 3D stitching effect needs to $b$ quantified by analysis of large number of specimens. 
5. FE model assumes a perfect adhesion between FRP face sheet and balsa core. More precise modeling with incorporating adhesive properties should be conducted.

6. Modeling of joints need more parameters to be incorporated such as adhesive properties.

7. Effect of non-uniform meshing in region of high stress concentration should be verified. 


\section{REFERENCES}

1. Allen, H.G., 1969, Analysis and Design of Structural Sandwich Panels, Pergamon Press, New York.

2. Balsa: Baltek Product Data, Baltek Corporation. (www.baltek.com)

3. Barbero E.J., 1998, Introduction to Composite Material Design, Taylor \& Francis, Philadelphia.

4. Beach, J. and J. Cavallaro, 2002. An overview of Structures and Materials work at the Division, Carderock Division Technical Digest, NSWCCD, September 2002.

5. Brush, D. O. and Almorth, B.O., 1975, Buckling of Bars, Plates and Shells, McGrawHill, New York

6. Chung D.D.L., 1994, Carbon Fiber Composites, Butterworth-Heinemann, Massachusetts

7. Dally J.W., and Riley W.F., 1985, Experimental Stress Analysis, McGraw Hill, Singapore

8. Daniel M. and Ishai O., 2005, Engineering Mechanics of Composite Materials, Second Edition, Oxford University Press.

9. Dave, D.J and Yuan, W.X., 2001. Overall and local buckling of sandwich plates with laminated faceplates, Part I: Analysis, Computer Methods in Applied Mechanics and Engineering, Vol. 190, pp. 5197-5213.

10. Donnet J.P., and Bansal R.C., 1984, Carbon Fibers, Dekker Inc, New York, USA

11. GangaRao, H. and R. Liang, 2005. Cost analysis of fiberglass composites through pultrusion and VARTM process, Report submitted to ONR/DOD, CFC-WVU, November 1, 2005.

12. GangaRao, H. and R. Liang, 2005. Fabrication and Mechanical Characterization of Pultruded Composite Sandwich Structures, Report submitted to ONR/DOD, CFCWVU, July 15, 2006.

13. Green, D.W., Winandy J. E., and Kretschmann D.E., 1999 Mechanical properties of wood, Chapter 4, Wood Handbook, Forest Product Laboratory, USDA

14. Gill, R.M., 1973, Carbon Fibers in Composite Materials, Page Bros(Norwich) Ltd, England.

15. Kaw K.A, 1997, Mechanics of Composite Materials, CRC Press, New York, USA. 
16. Lattimer, B.Y., Ouellette, J. and Sorathia, U. 2003. Fire resistance of composite bulkheads and overheads, 2003 NFPA World Safety Conference and Exposition, May 18-21, Dallas Convention Center, TX.

17. Mallick P.K., Composite Engineering Handbook, 1997, Marcel Dekker Inc., New York, USA.

18. Noor, A. K., Burton, W. S., and Bert, C. W., 1996. Computational models for sandwich panels and shells, Applied Mechanics Reviews, Vol.49, No. 3, pp. 155-199

19. Rose, C. A., Moore D.F., Knight N. F., and Rankin C. C. 2002 Finite element modeling of the buckling response of sandwich panels, AIAA 2002, pp1-19.

20. Shekhar V., effect of Fiber Architecture on Properties of Pultruded Composites, M.S. Thesis, West Virginia University, Morgantown, WV 2007.

21. Summerscales J., 1998, Microstructural Characterization of Fiber-Reinforced Composites, Woodhead Publishing Ltd., Cambridge, England.

22. Vadlamani V., Strain Energy Density based Failure Criterion for GFRP Coupons under Tension and Bending, M.S. Thesis, West Virginia University, Morgantown, WV 2006.

23. Vinson J.R., 1999, The Behavior of Sandwich Structures of Isotropic and Composite Materials, Technomic Publishing Co.Inc, Pennsylvania USA

24. Yuan, W.X and Dave, D.J., 2001. Overall and local buckling of sandwich plates with laminated faceplates, Part II: Analysis, Computer Methods in Applied Mechanics and Engineering, Vol. 190, pp. 5215-5231.

25. Whitney J.M. and knight M., 1980, The Relationship Between Tensile Strength and Flexure Strength in Fiber-reinforced Composites, Experimental Mechanics, June, $211-216$

26. Wisnom M.R., 1992, The Relationship between Tensile and Flexural Strength of Unidirectional Composites, Journal of Composites Materials, Vol. 26, No.8, pp.11731180.

27. Wood Handbook, Forest Product Laboratory, USDA

28. Zenkert D., 1997, The Handbook of Sandwich Construction, EMAS Publishing, London UK. 